
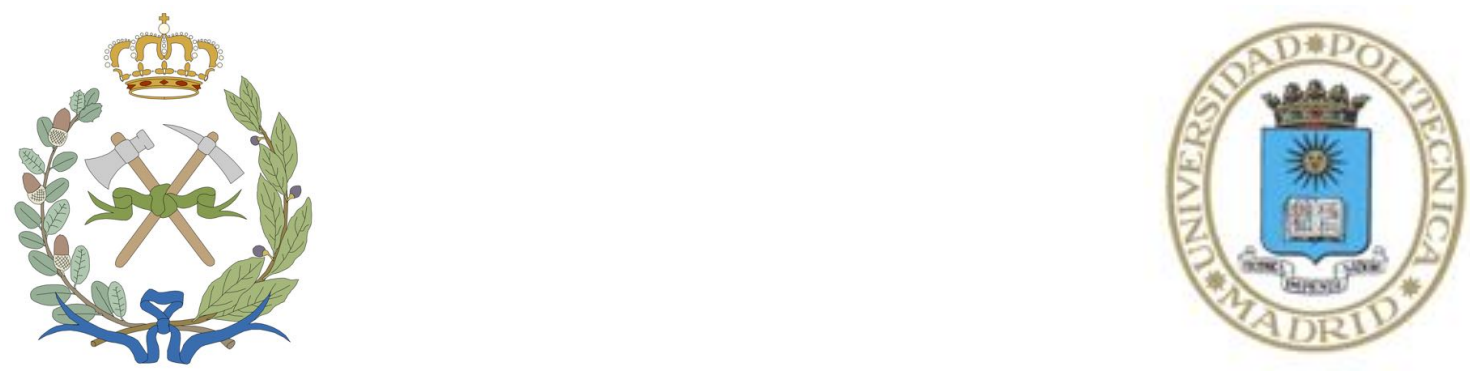

Doctoral Thesis

\title{
Xylogenesis in response to severe traumatism in the Canary Island pine (Pinus canariensis C. Sm. ex DC)
}

\author{
Víctor M. Chano González
}

PhD Program in Advanced Forestry Research

Thesis supervisors

Prof. Dr. Álvaro Soto de Viana

Prof. Dr. Carmen Collada Collada

PhD candidate

Víctor M. Chano González

This thesis is submitted in fulfilment of the requirements to obtain the doctoral degree from the Universidad Politécnica de Madrid (UPM) 

Tribunal nombrado por el Excmo. Sr. Rector de la Universidad Politécnica de Madrid, el día ....... de de 2018

Presidente D.

Vocal D.

Vocal D.

Vocal D.

Secretario D.

Realizado del acto de defensa y lectura de la Tesis el día ....... de de 2018 en Madrid.

Calificación

EL PRESIDENTE

LOS VOCALES

EL SECRETARIO 



\title{
MENCIÓN DE DOCTORADO INTERNACIONAL
}

\section{INTERNATIONAL DOCTORATE MENTION}

Esta tesis ha sido informada positivamente para su defensa en exposición pública por los siguientes investigadores:

This Ph.D. Thesis has been positively evaluated for its public defense by the following external reviewers:

\author{
Dr. Célia M. Miguel \\ Forest Biotechnology Lab \\ Instituto de Biologia Experimental e Tecnológica (iBET) \\ Oeiras, Portugal
}

Dr. David Macaya-Sanz

Departament of Biology

West Virginia University

Morgantown, WV, USA 



\section{AGRADECIMIENTOS.}

Los agradecimientos, lo primero que casi todo el mundo lee, y lo último en escribirse. Habrá quien los vaya escribiendo durante la propia escritura del documento de tesis, a ratitos, en esos momentos que la cabeza no te da para discutir resultados, o sacar conclusiones. Ese no ha sido mi caso. Estos párrafos son los últimos que escribo en este documento. Sobre todo, y como decía más arriba, porque es lo primero que muchos leen, y hay que tratar de no olvidar a nadie que haya participado o ayudado, directa o indirectamente, en la conclusión de un trabajo tan duro como es una Tesis Doctoral. Desde el mayor de los respetos, intentaré resumir en unos pocos párrafos la enorme gratitud que siento hacia todas aquellas personas presentes en mi vida personal y profesional durante estos años.

En primer lugar, y como no podría ser de otra manera, quisiera agradecer todo su esfuerzo y empeño en que esta tesis llegase a buen puerto a mis directores, los doctores Álvaro Soto y Carmen Collada. Con ambos me une una buena relación personal, y cada vez una mejor relación profesional, algo que agradezco enormemente. Junto a ellos he podido crecer científicamente, lo que me ha ayudado, y me ayudará, a ser más exigente, como Carmen, y más pragmático, como Álvaro. Ambos están muy reflejados en esta tesis doctoral.

Este trabajo ha sido financiado con una ayuda predoctoral FPI (BES-2010-037600), y apoyado por los proyectos de investigación "Adaptaciones del pino canario al vulcanismo (VULCAN; AGL2009-10606)", del Ministerio de Ciencia e Innovación, “Persistencia del pino canario tras una perturbación de gran magnitud (PersPiCan; SPIP2014-01093)", del Organismo Autónomo de PP.NN., y el proyecto "Promoting a functional and comparative understanding of the conifer genome (ProCoGen; FP7KBBE-2011-5)", financiado por el Séptimo Programa Marco de la Comunidad Europea para acciones de investigación, desarrollo tecnológico y demostración.

Muchísimas gracias también a aquellos que han sido parte activa en esta tesis. A Unai López de Heredia por sus ensamblajes, a Pilar Pita por sus pinos anillados, y a 
Rosana López por esas discusiones sobre anatomía de la madera en la pizarra de clase. Y gracias a Pedro, por su valiosísima ayuda en los análisis de los arrays, y las horas que echamos viendo cómo se iban anotando los genes (y por supuesto, gracias a ese ordenador, que ya entonces tenía sus años, y se pegó días y semanas encendido, y trabajando los fines de semana por nosotros). Quiero mostrar mi gratitud a Luís Gil, quien me acogió en el grupo cuando llegué, y me dio además la oportunidad de continuar cuando se acabó la FPI. Y del mismo modo, tengo que agradecer enormemente a Jesús Rodríguez, amigo además compañero, que contase conmigo cuando más perdido y solo me encontraba, y me invitase a aquel viaje a Córdoba a conocer a Nacho Pérez-Ramos, con la idea de que me mojase y propusiese lo que hoy día es una colaboración transformada en un proyecto de investigación. Gracias a ambos por la oportunidad que me disteis de continuar en la ciencia, porque si no posiblemente sí estaría defendiendo esta tesis, pero pidiendo el día libre en el que fuese mi trabajo.

I should like to extent my sincere thanks to Prof. Jörg Bohlmann for invite me to his lab at Michael Smith Laboratories (University of British Columbia). As well, I would like to warmly thank Karen Reid, José Celedón, Justin Whitehill, Daniel Kadow, Alfonso Lara Quesada, María Díaz, Andreas Gesell, and every lab member I met in Vancouver, not only for their help, but also for their warm hospitality. Thank you all!

Muchísimas gracias a todos los compañeros que estuvieron junto a mí desde el inicio de esta travesía. Gracias a Paula por sus abrazos, a Mati por sus asados, a Aida por sus incontables historias, a Rober por sus incontables movidas, a Elena por esas tardes y noches de cervezas, a María por las discusiones siempre acaloradas, aunque defendiésemos el mismo punto, y a Jose Carlos por hablar peor que yo pese a no ser extremeño. $Y$ también gracias a aquellos que se unieron después al grupo GENHITAL (o GFH Forestal para los remilgados), con Guille y sus locuras a la cabeza, Carlos y su incontrolable risa, y la infatigable Eva, siempre dispuesta a echar una mano. Muchísimas gracias también a Juan, por su ayuda dispuesta e incondicional, y no solo en el trabajo, sino también fuera, por sus 
palabras de ánimo cuando las he necesitado, mucho más a menudo de lo que me hubiese gustado en los últimos tiempos. ¡Muchísimas gracias a todos, sin vosotros esta tesis también habría sido posible, pero seguro que mucho más aburrida!

Gracias a las últimas incorporaciones, a Álvaro, Clara Vega y Adrián, que han ido llenando los huecos en una buhardilla que empezaba a despoblarse, a Fernando Mora y sus ganas de hacer una tesis después de firmar la jubilación, y a Clara Martínez, que se ha hecho fuerte en patología y si sigue currando tanto va a terminar antes de tiempo. ¡Gracias por estar presente este último año, y ánimo para esta etapa que habéis empezado! Y por supuesto a Natalie, que desde que ha llegado todos somos mucho más felices. Gracias a las otras personas del grupo, estén o no por aquí: a David Macaya, Juanan Martín, Victoría Fernández, Martin Venturas, David Medel, y Ramón Perea. Y gracias también a muchas otras personas, que seguramente olvido y no debería. Gracias, y que me perdonen.

Cuando vives en una ciudad como Madrid, y tienes que compartir piso porque una beca no te da para vivir solo, tienes suerte si tus compañeros se convierten en algo más que compañeros de piso. Con ellos podrás discutir, de la limpieza, de fútbol, de si el género de superhéroes es el nuevo western, o de si compensa el precio de la cerveza artesanal, aunque sea mejor..., pero sobre todo compartirás algo más que tiempo. Muchísimas gracias a Will, Tomás, Alba, Cat, Rocío y Alfon, Javi, y a todo el mundo que ha participado durante estos años en el grupo del barrio, en esas tardes de terraza y cervezas, esos pies en Lavacañas, de cine fórum, de comilonas en el salón, etc. ¡Gracias por todo este tiempo!

Gracias a mi familia, por su continuo apoyo, pero sobre todo en esos momentos más delicados en los que no era capaz de seguir por mí mismo. Gracias a mi padre, por la tranquilidad que siempre transmite y las anchas espaldas que tiene para aguantar con el peso de muchísima responsabilidad. Gracias a mi hermana, por sus ánimos y alegría. Y gracias a mi madre, por mirar siempre por mí. En este último año, que ha sido difícil para todos nosotros, y especialmente para ella, me he dado cuenta de lo vulnerable que somos todos física y emocionalmente, y que debemos 
dejar de lado el orgullo y ser valientes para pedir ayuda incluso a los más cercanos. Porque para eso están, y para eso estamos, para apoyarnos y ayudarnos entre nosotros. Este trabajo también es gracias a vosotros.

Y gracias, Tania. Gracias por todo. Gracias por apoyarme, gracias por ayudarme, gracias por aguantarme (sé lo difícil que es), y gracias por entender aquel sacrificio, cuando tomé la decisión de dejar Granada y venir a Madrid. No solo fue una decisión difícil de tomar, sino que nos llevó a una situación difícil de mantener. Conseguimos aguantar, y por eso te dedico este trabajo. Gracias por quererme. 


\section{ABBREVIATIONS}

$-{ }^{\circ} \mathrm{C} \quad$ Celsius degree

- BLAST Basic Local Alignment Search Tool

- BLASTx nucleotide (database)-nucleotide (query) BLAST

- bp base pair

- BP Biological Process

- CAZy Carbohydrate Active enZymes

- CC Cellular Component

- cDNA complementary DNA

- cm centimeter

- CT Cycle Threshold

- CTAB cetyltrimethylammonium bromide

- DEG Differentially Expressed Gene

- DNA deoxyribonucleic acid

- EC Enzyme Code

- EST Expressed Sequence Tag

- eValue significance value

- EW Earlywood

- FC Fold Change

- FDR False Discovery Rate

- GC Guanine and Cytosine content

- GEO Gene Expression Omnibus

- GO Gene Ontology

- $\mathrm{HCl}$ Hydrochloric acid

- KEGG Kyoto Encyclopedia of Genes and Genomes

- L50 Smallest number of contigs whose length sum result in $50 \%$ of transcriptome total length

- $\mathrm{LiCl} \quad$ Lithium chloride

- LW Latewood

- $\mu \mathrm{g} \quad$ microgram

- $\mu \mathrm{l} \quad$ microliter

- $\mu \mathrm{m} \quad$ micrometer

- min minute

- MF Molecular Function

- ml mililiter

- miRNA microRNA

- mRNA messenger RNA

- N50 Length of the shortest contig at 50\% of the transcriptome length distribution

- NCBI National Center of Biotechnology Information

- NGS Next Generation Sequencing

- nm nanometer

- OLC Overlap Layout Consensus

- PCR Polymerase Chain Reaction

- ph phloem 
- p-value significance value

- qRT-PCR quantitative reverse-transcriptase PCR

- r Pearson' correlation coefficient

- rd resind duct

- RefSeq Reference Sequence database

- RNA ribonucleic acid

- ROS Reactive Oxyde Specie

- SAM Shoot Apical Meristem

- SRA Sequence Read Archive

- TF Transcription Factor

- Tm Melting temperature

- UV Ultraviolet

- v/v volume/volume

- WGCNA Weight Gene Coexpression Network Analysis

- xy xylem 


\section{LIST OF FIGURES}

\section{INTRODUCTION}

Figure $1 \quad$ Natural wounding in trees. $\quad 3$

$\begin{array}{llr}\text { Figure } 2 & \text { The CODIT model explained in red maple. } & 5\end{array}$

$\begin{array}{lll}\text { Figure } 3 & \text { Watercolour of } P \text {. canariensis by G. Torner. } & 11\end{array}$

$\begin{array}{llr}\text { Figure } 4 & \text { Anatomy of } P \text {. canariensis. } & 13\end{array}$

Figure 5 A pinewood affected by the intense fires occurred in Tenerife in 2007.

\section{RESULTS}

Chapter 1. Transcriptomic analysis of juvenile Wood formation during the growing season in Pinus canariensis

$\begin{array}{lll}\text { Figure } 1 \quad \text { Transcriptome statistics. } & 30\end{array}$

Figure 2 Micrographs in bright-field microscopy of the cambial zone in Pinus 31 canariensis during the growing season

Figure $3 \quad \mathrm{~K}$-means clustering $(\mathrm{k}=6)$ of differentially expressed genes 32

Figure $4 \quad$ qRT-PCR validation of microarray transcription profiles. 33

Figure 5 Picture of a Pinus canariensis C. Sm. ex DC wood ring. 35

Chapter 2. Proliferation of axial parenchymatic xylem cells is a key step in wound closure of girdled stems in Pinus canariensis

$\begin{array}{lll}\text { Figure } 1 \quad \text { Mechanical wounds. } & 55\end{array}$

$\begin{array}{lll}\text { Figure } 2 & \text { Lignification and suberization of cortical parenchymatous cells. } & 57\end{array}$

$\begin{array}{lll}\text { Figure } 3 & \text { New traumatic periderm and initiation of healing callus. } & 58\end{array}$

$\begin{array}{llr}\text { Figure } 4 & \text { Progress of the healing callus } & 59\end{array}$

$\begin{array}{lll}\text { Figure } 5 & \text { Differentiation of vascular tissues. } & 61\end{array}$

$\begin{array}{llr}\text { Figure } 6 & \text { Wound closure. } & 62\end{array}$

Figure $7 \quad$ Macroscopic view of the healing process in girdled stems. 63

$\begin{array}{lll}\text { Figure } 8 & \text { Microscopic view of the column-like structures. } & 64\end{array}$

$\begin{array}{lll}\text { Figure } 9 & \text { Abnormal orientation in healing tissues. } & 68\end{array}$

$\begin{array}{lll}\text { Figure } 10 & \text { De-orientation of tracheids. } & 70\end{array}$ 
Chapter 3. Transcriptomic of wound xylem formation in Pinus canariensis

$\begin{array}{lll}\text { Figure } 1 & \text { MA plot of microarray normalized data during wound-response. } & 77\end{array}$

$\begin{array}{lll}\text { Figure } 2 & \text { Differentially expressed genes during first healing. } & 81\end{array}$

$\begin{array}{lll}\text { Figure } 3 & \text { Clustering of DEGs according to expression patterns. } & 82\end{array}$

Figure $4 \quad$ qRT-PCR validation of microarray transcription profiles. 84

$\begin{array}{lll}\text { Figure } 5 & \text { Expression of xylogenesis-related genes during wound response. } & 90\end{array}$

$\begin{array}{lll}\text { Figure } 6 & \text { Micrograph of wound-wood. } & 92\end{array}$

$\begin{array}{lll}\text { Figure } 7 & \text { Wounded stem of } P \text {. canariensis at the sampling dates } & 95\end{array}$

Chapter 4. Differential gene expression analysis provides new insights of the resprouting process in Pinus canariensis.

$\begin{array}{lll}\text { Figure } 1 \quad \text { Description of the resprouting process and sample collection. } & 105\end{array}$

Figure 2 MA plot of microarray normalized data during resprouting process. $\quad 106$

Figure 3 Differentially expressed genes during resprouting in response to wounding 107

$\begin{array}{llr}\text { Figure } 4 & \text { Clustering of DEGs according to expression patterns. } & 108\end{array}$

$\begin{array}{lll}\text { Figure } 5 & \text { qRT-PCR validation of microarray transcription profiles } & 109\end{array}$

$\begin{array}{llr}\text { Figure } 6 & \text { Anatomy of seasonal apical growth. } & 122\end{array}$

Figure $7 \quad$ K-means clustering $(\mathrm{k}=6)$ of Differentially Expressed Genes 123

$\begin{array}{llr}\text { Figure } 8 & \text { qRT-PCR validation of microarray expression profiles. } & 124\end{array}$

Figure 9 Expression of apical growth genes during resprouting in response to 126 wounding

\section{SUPPLEMENTARY DATA}

Chapter 1. Transcriptomic analysis of juvenile Wood formation during the growing season in Pinus canariensis

Figure S1 Pairwise correlation of microarray signals obtained for the three biological 203 replicates (BR1, BR2 and BR3) for each sampling point.

Figure S2 Two relevant co-expression networks.

Chapter 3. Transcriptomic of wound xylem formation in Pinus canariensis

Figure S1 Hierarchical clustering of samples. 
Chapter 4. Differential gene expression analysis provides new insights of the resprouting process in Pinus canariensis

Figure S1 Hierarchical clustering of samples.

Figure S2 Distribution of GO terms associated to resprouting DEGs. 


\section{LIST OF TABLES}

\section{RESULTS}

Chapter 1. Transcriptomic analysis of juvenile Wood formation during the growing season in Pinus canariensis

$\begin{array}{llr}\text { Table } 1 & \text { Primers used for qRT-PCR verification. } & 28\end{array}$

Table $2 \quad$ Summary of transcriptome quality assessment. 29

Table $3 \quad$ Most relevant differentially expressed genes (DEGs) presumably involved in 36 earlywood development.

Table $4 \quad$ Most relevant differentially expressed genes (DEGs) presumably involved in 44 latewood development.

Chapter 3. Transcriptomic of wound xylem formation in Pinus canariensis

Table 1 Selected wound-responsive DEGs, grouped according to their putative role 78 and their expression profile clustering.

Table 2 Primers used for qRT-PCR

Chapter 4. Differential gene expression analysis provides new insights of the resprouting process in Pinus canariensis

Table $1 \quad$ Selected resprouting DEGs, grouped according to their putative role and 110 their expression profile clustering

Table $2 \quad$ Selected Differentially Expressed Genes during apical growth

Table 3 Primers used for qRT-PCR.

\section{SUPPLEMENTARY DATA}

Chapter 1. Transcriptomic analysis of juvenile Wood formation during the growing season in Pinus canariensis

Table S1* Probes included in the microarray and correspondence to contigs obtained 204 after meta-assembly of libraries.

Table S2* Complete annotation of the transcriptome for xylogenesis in P. canariensis 204

Table S3* Differentially expressed genes (DEG) during wood formation in $P$. 205 canariensis

Table S4 DEGs included in co-expression networks (Figure S2)

Chapter 3. Transcriptomic of wound xylem formation in Pinus canariensis

Table S1* Wound-responsive differentially expressed genes. FC: fold change. FDR: 208 adjusted p-value by False Discovery Rate. In bold, statistically significant values 
Chapter 4. Differential gene expression analysis provides new insights of the resprouting process in Pinus canariensis

Table S1* Differentially expressed genes during resprouting. FC: fold change. FDR:

210 adjusted p-value by False Discovery Rate. In bold, statistically significant values

Table S2* Differentially expressed genes during seasonal apical growth in $P$. 210 canariensis 

INDEX

ACKNOWLEDGMENTS vii

ABBREVIATIONS $\quad$ xi

LIST OF FIGURES X Xiii

LISTO OF TABLES $\quad$ xvi

INDEX $\quad$ xix

SUMMARY $\quad$ Xxi

$\begin{array}{ll}\text { RESUMEN } & \text { xxiii }\end{array}$

I. INTRODUCTION 1

1. Effects of wounding in plants: wood decay in living trees. 3

2. Tree responses to wounding. 4

3. Role of xylem parenchyma cells in response to traumatism. 8

4. Molecular analysis of the wound response 9

5. Pinus canariensis, a model species for the study of tree responses to 12 traumatic events

$\begin{array}{lr}\text { II. OBJETIVES } & 15\end{array}$

$\begin{array}{ll}\text { III. RESULTS } & 19\end{array}$

Chapter 1. Transcriptomic analysis of juvenile wood formation during 21 the growing season in Pinus canariensis

Chapter 2. Proliferation of axial parenchymatic xylem cells is a key step 51 in wound closure of girdled stems in Pinus canariensis

Chapter 3. Transcriptomic analysis of wound xylem formation in Pinus 73 canariensis

Chapter 4. Differential gene expression analysis provides new insights of the resprouting process in Pinus canariensis 
$\begin{array}{ll}\text { ANNEX } & 201\end{array}$

$\begin{array}{ll}\text { Supplementary Data for Chapter } 1 & 203\end{array}$

$\begin{array}{ll}\text { Supplementary Data for Chapter } 3 & 208\end{array}$

$\begin{array}{ll}\text { Supplementary Data for Chapter } 4 & 209\end{array}$ 


\section{SUMMARY}

This thesis aims to increase our understanding of the xylogenesis processes in response to severe traumatism in conifers, using Canary Island pine (Pinus canariensis C. Sm. Ex DC) as model species. Our strategy involved the employment of different approaches to analyse anatomical and molecular aspects of the response to injuries, and the results are presented and discussed in four chapters in the Results section.

Chapter 1 reports the construction and analysis of two cDNA libraries from the $P$. canariensis cambial zone, in order to cover the transcriptional profiles both of earlywood and latewood differentiation. This approach allowed the detection of genes missed in previous studies performed in other species, providing a more complete picture of wood formation in conifers.

Chapter 2 examines the anatomical aspects of the reorganization of traumatic tissue, mainly when it affects the lateral meristem. Additionally, we describe for the first time the formation of column-like structures derived from axial parenchymatic cells, as essential elements of the wound closure process after girdling.

Chapter 3 focuses on the molecular basis of traumatic wood formation in $P$. canariensis. Transcriptomic profile throughout traumatic wood formation is compared to that of normal wood development, including earlywood and latewood. This analysis shows that immediately after injury, radial growth activity stops and defensive genes, mostly related to biotic stress, are induced in the wound margins. Later on, during traumatic wood development overexpression of earlywood-related genes is observed, together with repression of certain latewood-related genes.

Chapter 4 analyzes gene expression after wounding and during the very early steps of the resprouting process. Furthermore, we analyzed as well the seasonal apical growth and compare both processes, obtaining a better understanding of 
the genetic dynamics of induced resprouting in conifers, as response to mechanical wounding.

Finally, all findings are summarized and discussed in the framework of the response to wound in conifers. Future prospects for the research of this issue are also provided. 


\section{RESUMEN}

Esta tesis tiene como objetivo profundizar en el conocimiento del proceso de xilogénesis en respuesta a traumatismos en coníferas, utilizando como especie modelo el pino canario (Pinus canariensis C. Sm. ex DC). Nuestra estrategia incluyó el uso de diferentes metodologías para analizar aspectos anatómicos y moleculares de la respuesta a heridas, y los resultados son presetados y discutidos en cuatro capítulos en la sección de Resultados.

El Capítulo 1 presenta la construcción y el análisis de dos librerías de cDNA de la zona cambial de $P$. canariensis, con el fin de abarcar los perfiles transcriptómicos de los procesos de diferenciación de madera temprana y madera tardía. Este enfoque permitió la detección de genes que pudieron ser omitidos en estudios previos realizados en otras especies, proporcionando una imagen más completa del proceso de formación de madera en coníferas.

El Capítulo 2 examina aspectos anatómicos de la reorganización del tejido traumático, principalmente cuando afecta al meristemo lateral. Adicionalmente, se describen por primera vez la formación de estructuras columnares derivadas de las células de parénquima axial, elementos que serán claves durante el proceso de cicatrización y cierre de heridas después de anillado.

El Capítulo 3 se centra en las bases moleculares de la formación de madera traumática en $P$. canariensis. El perfil transcriptómico a lo largo del proceso de formación de madera traumática es comparado con el de formación de madera normal, incluyendo madera temprana y madera tardía. Este análisis muestra que inmediatamente después de producirse la herida, el crecimiento radial cesa, y se induce la expresión de genes de defensa, principalmente relacionados con estrés biótico, en los márgenes de la herida. Más adelante, durante el desarrollo de madera traumática, se observa la sobreexpresión de genes relacionados con la formación de madera temprana, al mismo tiempo que se reprimen ciertos genes relacionados con la formación de madera tardía. 
El Capítulo 4 analiza la expresión genética después de la inducción de heridas y durante las primeras fases del proceso de rebrote. Además, analizamos el crecimiento apical estacional y comparamos ambos procesos, obteniendo una mejor comprensión de las dinámicas genéticas del rebrote inducido en coníferas, como respuesta al daño mecánico.

Finalmente, se resumen y comentan los resultados obtenidos, al tiempo que se proporcionan nuevas perspectivas sobre investigaciones futuras en el marco de la respuesta a heridas en coníferas. 


\section{INTRODUCTION}





\section{INTRODUCTION}

\section{Effects of wounding in plants: wood decay in living trees.}

Wounds are injuries that usually have been suddenly produced to organisms, damaging or removing tissues and causing mechanical stress. In nature, different agents may cause wounding in tree species. For instance, birds such as sapsuckers produce holes in many woody plants, and larger animals such as bears and deer remove bark by rubbing, exposing wood to further external damage and infections by opportunistic pathogens. Additionally, insects such as bark beetles and wood borers may attack weakened trees, producing even deeper wounds. Moreover, abiotic agents can also cause wounding to tree species. Fire is considered a major cause of tree injury with great impact in forest ecosystems (Piñol et al. 1998, Dale et al. 2001, Pausas 2004, Pausas et al. 2004). As well, traumatisms can also be caused by impacts of large and heavy elements such as stones carried away by floodings and avalanches, rockfalls, or pyroclastic material propelled by volcanic eruptions (Figure 1).

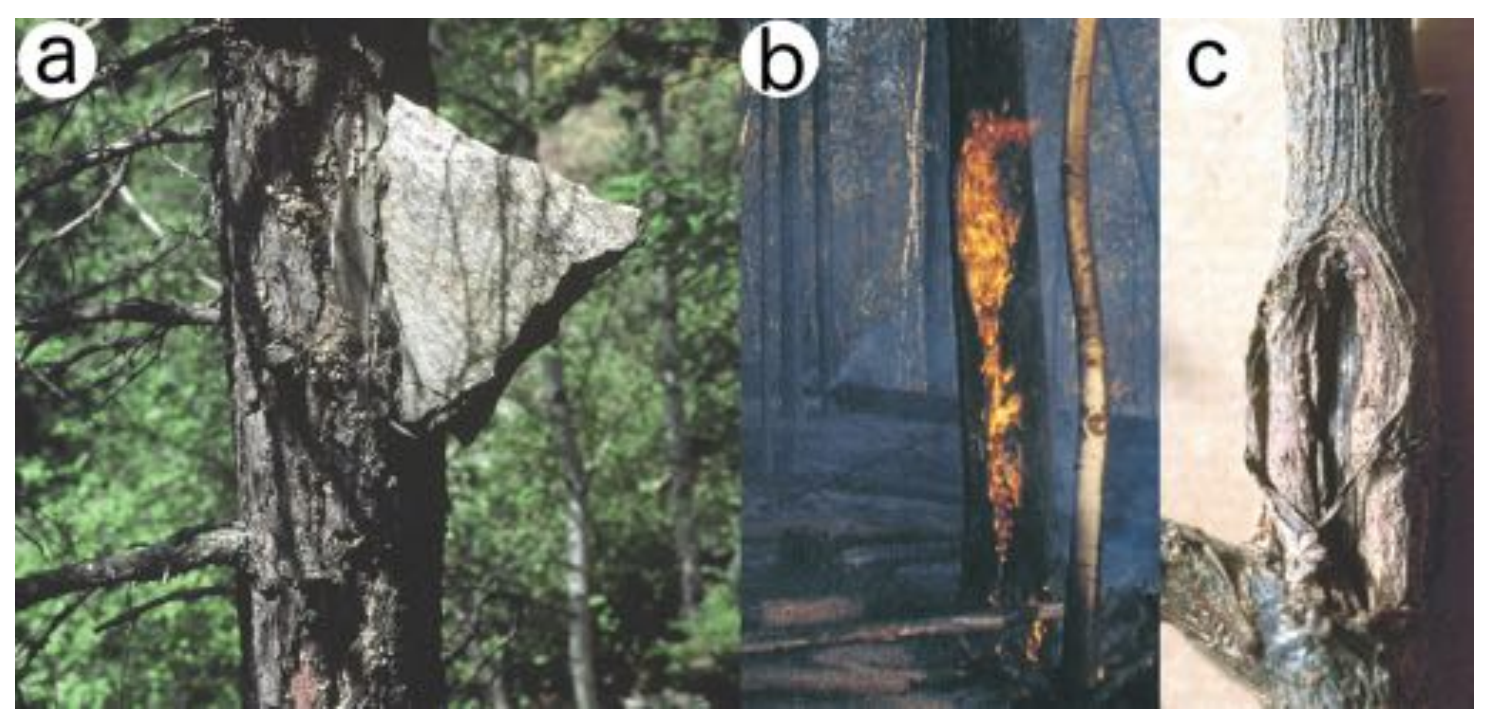

Figure 1. Natural wounding in trees. A) Rock fall causes impact of stones in trees. Here, a stone got stuck in Scots Pine' stem. B) Fire destroys the cambium and causes wounding in Pinus sylvestris. C) Scar produced by hail impact in Quercus petraea. Taken from F. H. Schweingruber, A. Börner, and E-D- Schulze. “Atlas of Woody Plant Stems. Evolution, Structure, and Environmental Modifications”, 2006, Springer.

Usually, wounds produce injuries in bark and inner parts of the tree, which could reach vascular cambium and wood. Depending on the severity of the traumatism, 
sap flow (phloem) and water flow (xylem) can be strongly diminished, compromising survival of higher plants. Wounds are considered as one of the main ways to wood decay, a biological process entailing the degradation of cellulose and lignin, main compounds of wood, by action of pathogens (Merrill and Shigo 1979). Wood decay begins in both live and dying sapwood and spreads into dead heartwood. Wood-decay pathogens are mostly fungi that attack both bark and wood, causing root-rot and canker-rot in belowground and aboveground tissues, respectively. The pathogen kills living cells, and drying cracks on the exposed wood and boreholes and galleries produced by opportunistic insects can promote the further spread of infection inward. Advanced state of decay results in structural weakness of stems.

Wounding and subsequent wood decay in trees reduce drastically wood quality, which is defined by three main factors: colour, texture and figure. Notwithstanding, extrinsic agents continuously affect these three characteristics in nature, and as result colour changes, cells are different and arrangements are altered. This leads to think that high quality woods could have been subjected to few disturbances, or these trees had a highly effective compartmentalization response that kept infections confined to a small volume of wood.

\section{Tree responses to wounding.}

Wounding triggers both systemic and local responses, which include a series of complex physiological and anatomical mechanisms. Local signals activate the defensive machinery in the damaged tissues at early steps after wounding, while mobile signals in the non-wounded areas act over time (León et al. 2001). The breakage of physical and structural barriers caused by wounding leads to infections by pathogenesis and further decay, so that survival of the plant relies on a complete rearrangement of the transcriptional program of the affected tissue. 


\section{Wound closure}

Figure 2. The CODIT model explained in red maple. Numbered arrowheads point the CODIT walls. Wall 1 avoids the spreading of the infection above and below the wound. Wall 2, formed by annual rings of the tree, prevents the advance into the pith. Walls 3 are lateral boundaries, established by parenchymatic rays. Wall 4 is the barrier zone, which is formed by the vascular cambium once the wound has been produced, and separates the inner infected wood from the newly formed wood after the traumatic event. Taken from Alex Shigo "A new tree biology”, 1986, Shigo and Trees, Associates.

Back in the 80's, Dr. Alex Shigo proposed the CODIT (Compartmentalization Of Decay In Trees)

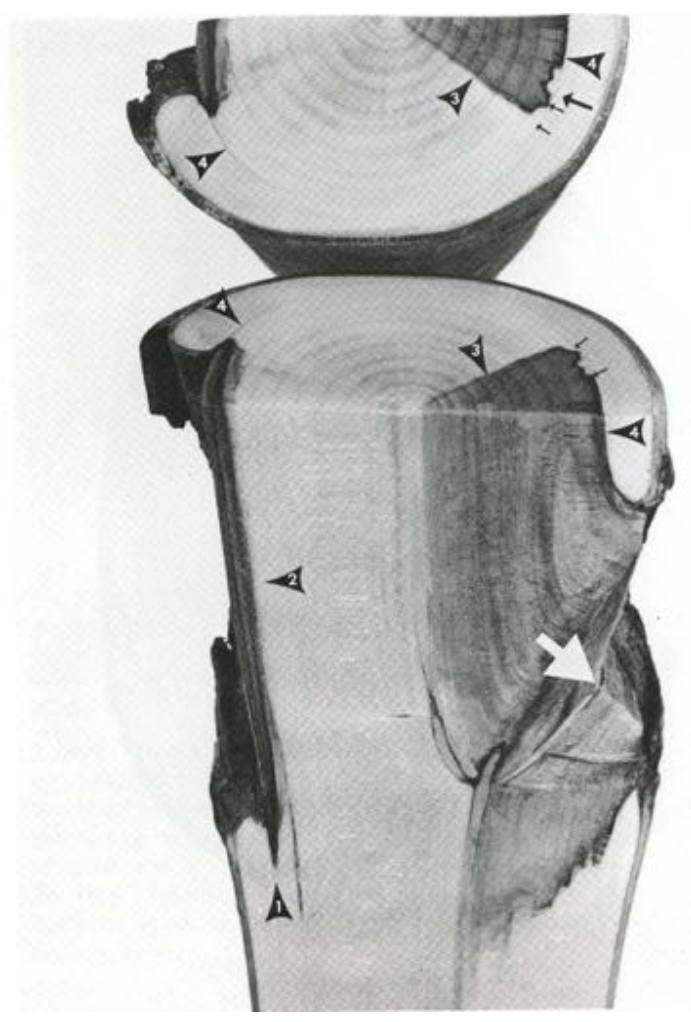
model (Shigo and Marx 1977, Shigo 1984) to describe the response to wounding in wood; this response includes a series of barriers that hamper the spread of pathogens and drives a healing process eventually leading to wound closure (Figure 2). First, energy reserves in living parenchyma cells are mobilized, and defensive substances are produced and gathered in the so-called reaction zone. Accumulation of these substances in xylem rays hinders the expansion of the pathogens to the sides, while latewood inner to the wound acts as a constitutive barrier against the spread of the infection inwards. Finally, new tissues, parenchymatic callus and new vascular tissues are formed covering the surface of the wound. This so-called "barrier zone" confines the possible infection and restricts its expansion into the newly developed healthy tissues, and avoids the entry of new pathogens. The time needed to close the wound depends on the size of the wound, growth rates and the fraction of reserves allocated for wound healing. The woundwood usually expands over the open wound face as spindles or ribs from the lateral margins of the wound. These structures are the proper tree rings overgrowth, produced by the vascular cambium in the lateral margins of the 
Chano, $V$ - Transcriptomics of the response to wounding

wound. As this tissue continues growing, the vascular transport is restored, and the continuity of the vascular cambium is eventually re-established.

Moreover, different works describe callus and woundwood formation directly from the surface of wounds in the stem of angiosperm adult trees. For instance, in Tilia sp. a new cambium is developed from the callus on the surface of the xylem through the open wound, later forming a new phloem (Stobbe 2002). In Populus tomentosa after removing bark, phloem and vascular cambium, the differentiating xylem remaining can reprogram its fate, and new phloem and cambium is formed rebuilding secondary vascular tissue (Zhang et al. 2011b).

Woundwood is frequently formed by distorted cells, in comparison to the regular arrangement of normal wood. It can include a high proportion of parenchymatic cells, as well as resin or gum ducts. The effects of wounding in xylem have been studied in several flowering species such as Acer and Betula (Bauch et al. 1980), Juglans (Smith 1980), Liriodendron (Lowerts et al. 1986) or Eucalyptus (Eyles et al. 2003), as well as in conifers such as Pinus (Kuroda and Shimaji 1984). For instance, Torelli et al. (1994) reported that in Fagus sylvatica the woundwood shows shorter fibers and smaller vessel elements; moreover, axial elements are disoriented in woundwood, which is thus suggested to be a type of juvenile wood. Zajaczkowska (2014a) reported consistent results for Pinus sylvestris, comparing wound spindles and juvenile wound rings. Additionally, the author describes the marked curvature of new annual rings from wound margins caused by an unequal number of tracheids in radial rows, resulting in an oblique orientation of rays as both wound spindles progress and ultimately come into contact. However, most of the studies performed in conifers have focused in the formation of traumatic resin ducts and resin production after wounding (Nagy et al. 2000, Krokene et al. 2003, Gärtner and Heinrich 2009, Schneuwly et al. 2009a, Ballesteros et al. 2010). 


\section{Resprouting process}

Another noticeable response to wounding and mechanical damage is the resprouting process. Capacity of resprouting is considered a tolerance trait evolved in response to defoliation mainly by forest fires (Pausas and Keeley 2014), and confers resilience through the existence of dormant epicormic shoots, i.e., vegetative sprouts in dormancy estate able to produce re-growth and development of a de novo shoot (Zedler et al. 1983). Thus, resprouting process is an interesting tree strategy for recovery of photosynthetic tissue in damaged trees (Higgins et al. 2000, Vesk and Westoby 2004).

Most forest trees can be classified in two categories according to their adaptation to forest fire (Clarke et al. 2013). First ones have tall trunks and many of them show self-prunning (fall of lower and older branches), which allow their crowns to scape of ground fires. Many conifers of this group present also serotine cones whose presence allows seed dispersal after forest fires, assuring the regeneration of the stand if the adult trees do not survive.

On their side, other species show adaptions that increase the capability of adult trees to survive fire. They show a thick bark protecting xylem, phloem and vascular cambium, as well as other meristematic tissues, from necrosis produced by fire damage, one of the principal causes of mortality in trees (Lawes et al. 2011, Michaletz et al. 2012). In addition, their dormant epicormics shoots are also very well protected, being able to resprout after fire. Resprouting species are classified in stem, apical, basal and root resprouters, according to the position of dormant buds. In root resprouters, dormant buds are isolated underground, and actually, root suckering can lead to large clonal populations after fires (James 1984). Actually, coppicing has become in an effective method of woodland management for basal and root resprouting species (McKenney et al. 2011). However, in the rest of resprouting species width of bark is the main and even exclusive protective factor (Choczynska and Johnson 2009). 
Chano, $V$ - Transcriptomics of the response to wounding

Resprouting is not a rare trait in flowering plants. F.i., shrubs and small trees from fire-prone chaparral present this ability, such as the crown-resprouters Ceanothus roderickii (Boyd 2007), and some subspecies of Arctostaphylos glandulosa (Keely et al. 2007). Even though resprouting is considered an ancestral condition that may have been lost in modern plant groups (Bond and Midgley 2003), is noteworthy the scarcity of coniferous species able to resprout.

\section{Role of xylem parenchyma cells in response to traumatism.}

The living parenchyma around the wound has been proposed to play important roles in response to mechanical stress through transdifferentiation into callous tissue, storage and transport of carbohydrates, and energy supply (Spicer and Holbrook 2007), initiating the active responses that contribute to compartmentalization of xylem tissue in wound vicinity (Shigo and Marx 1977, Shortle 1979). Parenchymatic tissue produced by the vascular cambium has been reported to be involved in the response to wounding through restoration of cambial zone and participating in development of callus and woundwood in poplar (Frankenstein et al. 2005). As well, parenchyma cells in differentiated xylem were involved in the outgrowth of tyloses-like structures in response to wounding, through altered pit membranes in neighbouring tracheary elements (Peters 1974, Schmitt and Liese 1994, Oven et al. 2000). Moreover, cortical parenchyma surrounding wounds develop suberin and suberin-like substances to protect exposed cells and tissues (Biggs 1987, Schmitt and Liese 1993). Parenchymatic cells conforming rays were also experimentally induced to expand and enlarge by wounding (Lev-Yadun and Aloni 1992), and Romero and Bolker (2008) pointed that Amazonian tree species with high parenchyma abundance were found to be more effective in wound closure, although decay spreads further through wide dilating rays. Furthermore, and as mentioned above, wound responses rely on resources and energy provision. Nonstructural carbohydrates needed for these developmental and responsive processes are gathered from xylem parenchymatic tissue, especially when photosynthetic tissue is damaged (Kozlowski 1992, Clarke et al. 2013). 
Nonetheless, in gymnosperms xylem parenchyma is much scarcer than in angiosperms, and usually restricted to woody rays and resin ducts, although some Cupressaceae present metatracheal axial parenchyma, detached from axial resin ducts (Esteban and de Palacios 2004). This scarcity could be related with the lower healing and, specially, resprouting ability of most gymnosperms.

\section{Molecular analysis of the wound response}

From a molecular point of view, most studies on wound response have focused on the induction of defensive substances: for instance, see works accomplished in the response to herbivory in agriculture plant species (Falara et al. 2014, Tzin et al. 2017). Moreover, several works were focused in Picea species (Martin et al. 2002, Fäldt et al. 2003, Mckay et al. 2003, Ralph et al. 2006, Porth et al. 2011) regarding to terpene biosynthesis, traumatic resin ducts development, and defensive responses against insects and herbivory in conifers as well, or even in simpler plant species such as moss (Ponce de León and Montesano 2017). On the contrary, much less is known regarding traumatic wood formation and wound closure.

Genetics of normal wood development has been the object of many works since the late 20th and early 21th centuries, when many works were performed using forestry species, including angiosperms (Sterky et al. 1998, Paux et al. 2004) and gymnosperms (Kirst et al. 2003, Le Provost et al. 2003, Egertsdotter et al. 2004). Additionally, other works have focused on reaction wood formation (Allona et al. 1998, Bhandari et al. 2006, Yamashita et al. 2008), or identifying genes involved in different tissue-types development (Foucart et al. 2006). Especially during the last years, the emergence of the Next-Generation Sequencing technology and the rise of Bioinformatics and Computational Biology, has allowed a great increase of curated information about plant science and forestry research in public databases (Wegrzyn et al. 2008, Van Bel et al. 2018). Transcriptomic studies revealed meaningful knowledge regarding gene pathways related to cell wall formation (Li et al. 2006), monolignol biosynthesis (Vanholme et al. 2010), or regulatory mechanisms through transcription factors (Demura and Fukuda 2007, Du and 
Chano, $V$-Transcriptomics of the response to wounding

Groover 2010) or epigenetic regulation (Ong and Wickneswari 2012, Wang et al. 2016). This information has been applied to the analysis of wound wood, mainly in angiosperms. For instance, the roles of specific transcription factors were described in laser-induced wounding studies in Arabidopsis ( $\mathrm{Xu}$ et al. 2006). As well, regenerative reprogramming of entire organs (Sena et al. 2009) and callous tissue (Sugimoto et al. 2010) were analyzed in this species in response to wounding. In addition, other molecular analyses were performed in flowering tree species. Bark regeneration in girdled stems of Eucommia ulmoides and Populus tomentosa was studied through anatomical and gene expression analyses (Pang et al. 2008, Zhang et al. 2011b).

Regarding gymnosperms, several studies have focused on xylogenesis during regular growth, for instance in Pinus pinaster (Le Provost et al. 2003), Pinus taeda (Kirst et al. 2003), and Pinus radiata (Li et al. 2010), or more recently in Cryptomeria japonica (Mishima et al. 2014) and Picea glauca (Raherison et al. 2015, Lamara et al. 2016). However, knowledge on the molecular basis of the healing process in conifers is still very scarce. Additionally, a noticeable proportion of low transcribed genes involved in the xylogenesis process in conifers may have been missed in previous transcriptomic studies, such as those related to less abundant cell types or to juvenile wood formation, which could play relevant roles in this process. Moreover, conifers display certain traits that hamper transcriptomic and genomic analysis, such as huge genomes, a great percentage of gene duplications, and less curated functional information in public databases (Kovach et al. 2010, Lorenz et al. 2012, Nystedt et al. 2013, López de Heredia and Vázquez-Poletti 2016). This fact, together with the large divergence time between angiosperms and gymnosperms (more than 300 million years), causes that the knowledge obtained for the former may be not fully applicable to the latter, and specific molecular tools must be developed for gymnosperms. 
Introduction

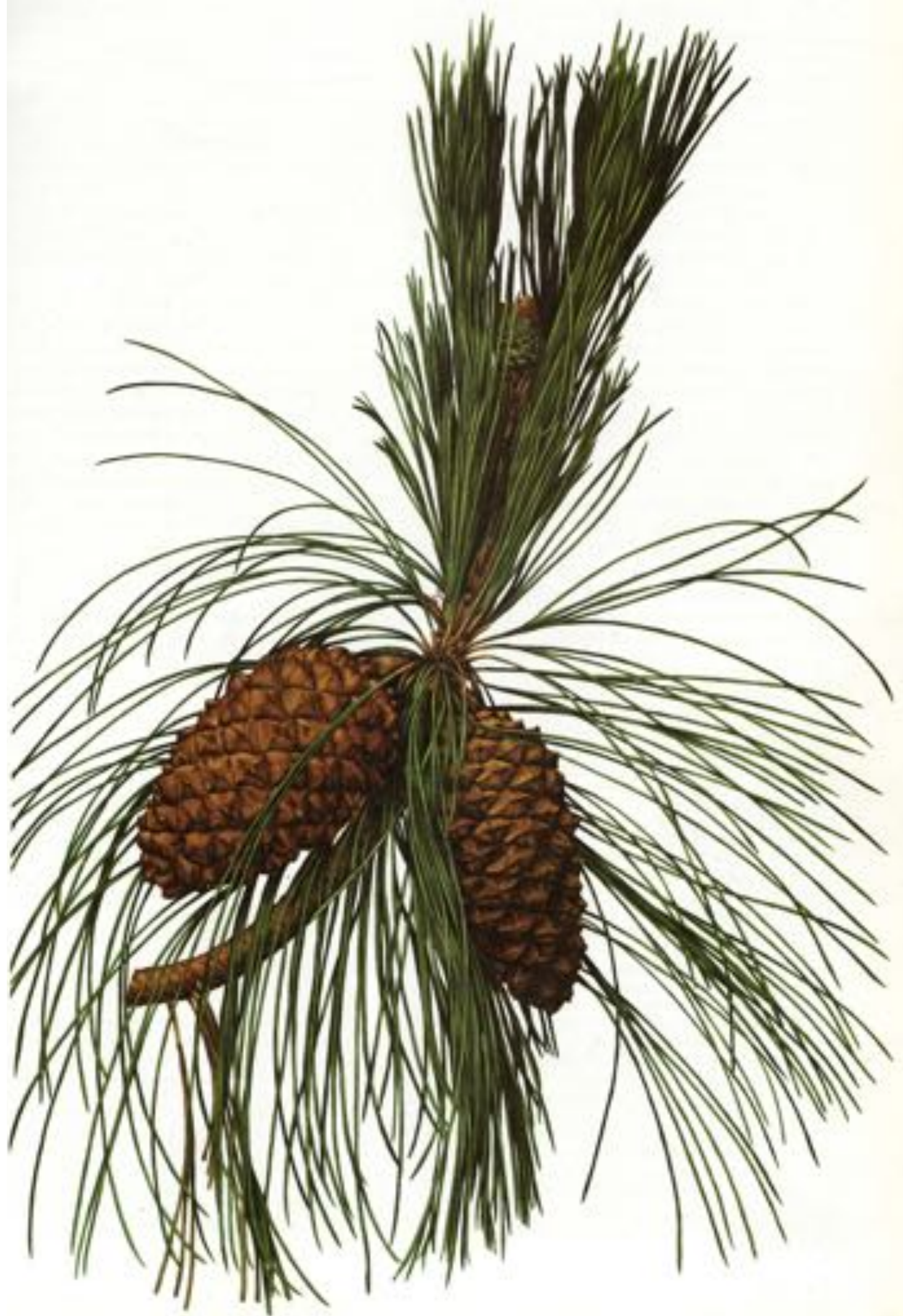

Figure 3. Watercolour of $P$. canariensis by G. Torner. 
Chano, $V$-Transcriptomics of the response to wounding

\section{Pinus canariensis, a model species for the study of tree responses to traumatic events.}

Pinus canariensis C. Sm. ex DC (Figure 3) is one of the most singular endemism of the Canary Archipelago, as well as one of the main forestry species of the islands. This species, included in the so-called “Mediterranean Pines' Clade" (Gernandt et al. 2005, Grivet et al. 2013), together with Pinus halepensis, Pinus pinea, Pinus pinaster, Pinus brutia, and Pinus heldreichii, is closely related to the Himalayan pine, or Chir pine, Pinus roxburghii. The trunk of the Canary Island pine is tall and straight, and use to reach 20-25 m high (occasionally exceeding $60 \mathrm{~m}$ high), conferring a great pyramidal structure. Young needles are simple and pale-green, while adult needles are presented in groups of three per fascicle, with 20-30 cm length and persisting for 2-3 years (Ceballos and Ruiz de la Torre 1971).

The first description of $P$. canariensis' anatomy was made by Fernando Nájera in 1951, and included in the work of Ceballos and Ortuño about vegetation and forest flora of the Canary Island (Ceballos and Ortuño 1976). This study was followed by several reviews and additions, thanks to works accomplished by Peraza (1967), García-Esteban and Guindeo (1988), Wiedenhoeft and Miller (2002), and again, and more comprehensively, García-Esteban et al. (2002). P. canariensis anatomy (Figure 4A) exhibits differential traits comparing to other coniferous species. For instance, a notable trait in the Canary Island pine' anatomy is that its xylem parenchyma is proportionally more abundant, whether forming rays or associated to both constitutive (radial and axial) and traumatic resin ducts (Figure 4B and 4C), which are also more numerous than in other Pinaceae (Climent et al. 1998).

In the face of major disturbances such as fires or volcanic eruptions, Pinus canariensis presents adaptations that allow both the regeneration of the mass and the perpetuation of the affected adult individual. Thus, Canary Island pine bears serotine cones that spread their seeds after fire, and also a thick bark protecting 
the lateral meristems and a tall trunk that separates the crown from ground fires (Climent et al. 2004).

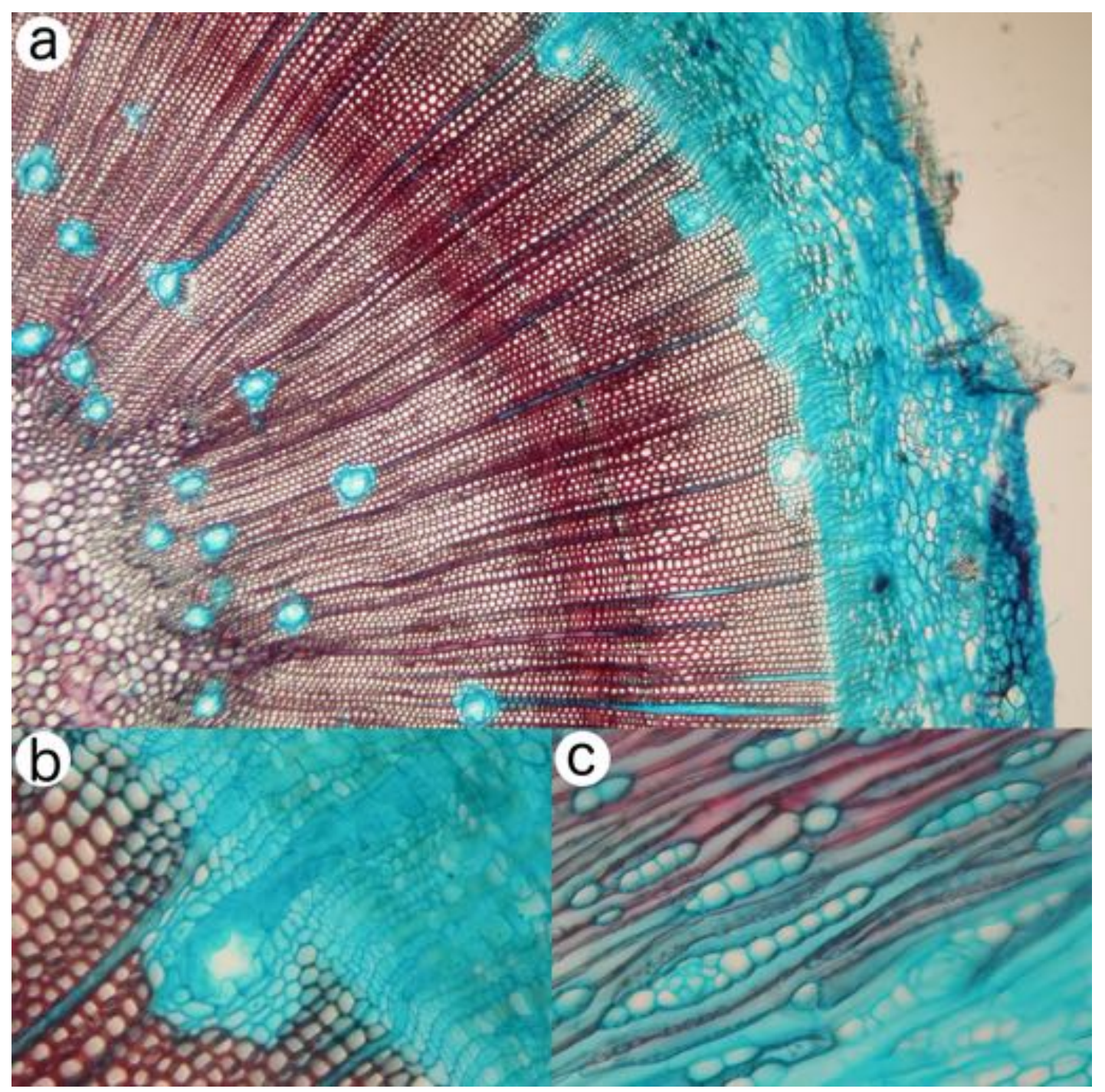

Figure 4. Anatomy of P. canariensis. A) Cross section of Pinus canariensis stem. B) Detail of an axial resin duct, with a great proportion of parenchymatic cells associated. C) Tangential section showing tracheids, parenchymatic rays, and a radial resin duct.

Furthermore, this species stands out because other notable traits, highlighting the ability to resprouting of new epicormic shoots having lost part of its canopy in forest fire, a rare trait in coniferous species that allows recovering the original treetop (Figure 5), as well as a great healing and wound closure capability in response to mechanical stress and after suffering severe traumatisms, such as those produced in forest fires or by pyroclastic impacts (Ceballos and Ortuño 1976). Thus, one or two years after fire have defoliated a stand, it is not uncommon to see how the crowns have regenerated to a great extent. In the same way, 
traumatisms in the trunks and branches can be completely healed after a more or less long time. This resprouting and healing ability can be related with the large amount of parenchyma and storage substances present in the wood. These features make of Pinus canariensis a suitable model species for molecular studies of traumatic responses as well as plant adaptation to environments subjected to extreme disturbances.
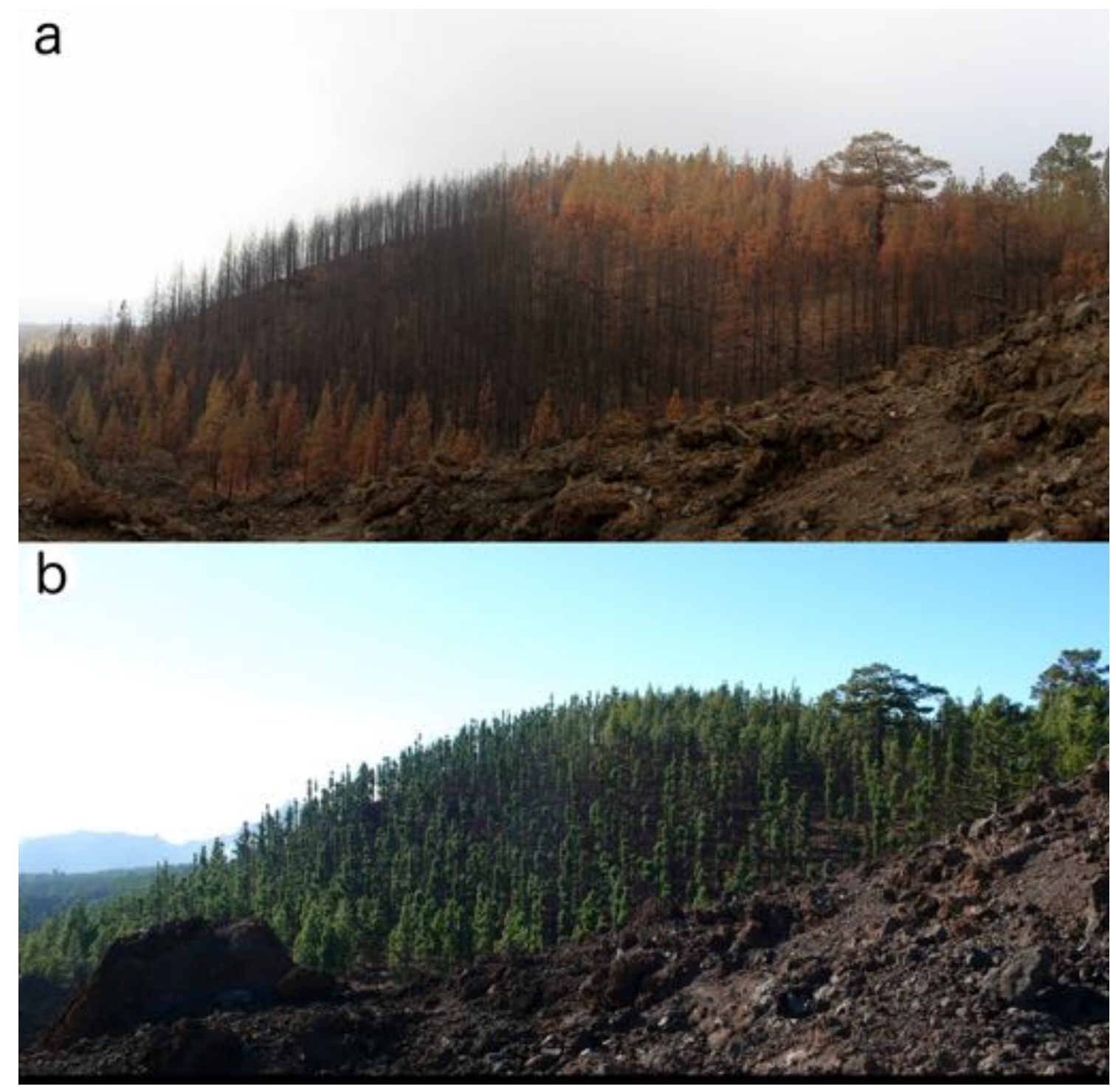

Figure 5. A pinewood affected by the intense fires occurred in Tenerife in 2007. Figure A is about 4 months after the fires, while Figure B is about 2 years after the event. Is highly noticeable how plants recover the photosynthetic tissues. Sources: “080 Inendio verano 2007. 4 meses después” and “IncendioTfe07agosto09i088”, by José Mesa, CC BY 2.5. 


\section{OBJECTIVES}





\section{II.- OBJECTIVES}

The main aim of this thesis is to provide insight in the transcriptomic basis of the formation of traumatic xylem in response to wound, in comparison with normal wood development.

To achieve this goal, we established the following milestones:

1. De novo construction of a normalized transcriptome corresponding to constitutive wood formation in $P$. canariensis, which would include relevant genes presumably missed in previous studies performed in other conifer species.

2. Anatomical characterization of the traumatic xylogenesis process, which would also determine the sampling scheme in the following steps.

3. Gene expression profiling of developing traumatic wood and comparison with early- and latewood formation.

4. Analysis of the effect of wound-induced resprouting in the transcriptomic profile of developing xylem. 



\section{RESULTS}





\title{
Chapter 1.
}

\section{Transcriptomic analysis of juvenile wood formation during the growing season in Pinus canariensis.}

\author{
Chano V, López de Heredia U, Collada C, Soto A
}

G.I. Genética, Fisiología e Historia Forestal. ETSI Montes, Forestal y del Medio Natural. Dpto. Sistemas y Recursos Naturales. Universidad Politécnica de Madrid. Ciudad Universitaria s/n 28040 Madrid, Spain

Published in Holzforschung, 2017; 71(12):919-937, DOI 10.1515/hf-2017-0014.

\begin{abstract}
A noticeable proportion of low transcribed genes involved in wood formation in conifers may have been missed in previous transcriptomic studies. This could be the case for genes related to less abundant cell types, such as axial parenchyma and resin ducts, and genes related to juvenile wood. In this study, two normalized libraries have been obtained from the cambial zone of young individuals of Pinus canariensis C. Sm. ex DC, a species in which such cells are comparatively abundant. These two libraries cover earlywood (EW) and latewood (LW) differentiation, and reads have been de novo meta-assembled into one transcriptome. A high number of previously undescribed genes have been found. The transcriptional profiles during the growing season have been analyzed and several noticeable differences with respect to previous studies have been found. This work contributes to a more complete picture of wood formation in conifers. The genes and their transcription profiles described here provide a useful molecular tool for further studies focused on relevant developmental issues, such as wound response and the formation of traumatic wood, re-sprouting, etc., presumably related to those cells.
\end{abstract}

Keywords: cDNA libraries, earlywood (EW), genetic, juvenile wood, latewood (LW), microarrays, Pinus canariensis, transcriptome, wood formation 
Chano, $V$-Transcriptomics of the response to wounding

\section{INTRODUCTION}

In the last two decades, several works have approached the transcriptome basis of wood formation. Most of these works have been performed in angiosperm species (Sterky et al. 1998, Paux et al. 2004), including studies in the nonwoody model Arabidopsis thaliana (L.) Heynh. (Zhang et al. 2011a). Nevertheless, conifer and angiosperm woods display important differences, which support the need for specific studies on each group.

Unfortunately, gymnosperms, and more specifically conifers, display certain characteristics, which hamper transcriptomic and genomic analysis. They have huge genomes (10 000-40 $000 \mathrm{Mbp}$ ), usually with a high percentage of repeated sequences and pseudo genes (Kovach et al. 2010, Lorenz et al. 2012, Nystedt et al. 2013). Additionally, a much lower number of sequences are available on public databases for conifers than for angiosperms, decreasing the proportion of successful annotations in these studies (López de Heredia and Vázquez-Poletti 2016).

Nevertheless, several studies have addressed wood formation in conifers. For instance, genes involved in wood formation have been identified in Pinus pinaster Ait. (Le Provost et al. 2003), Pinus taeda L. (Kirst et al. 2003) and Pinus radiata D. Don (Li et al. 2010). More recently, Raherison et al. (2015) and Lamara et al. (2016) described networks of co-expressed genes involved in wood formation in Picea glauca (Moench) Voss, and Mishima et al. (2014) published a transcriptomic analysis of wood formation in a Taxodiaceae, Cryptomeria japonica (Thunb. ex L.f.) D. Don. Other works have focused on the identification of genes involved in reaction wood formation (e.g. Allona et al. 1998, Yamashita et al. 2008), characterized by tracheids with thick and strongly lignified secondary walls and by a low proportion of parenchymatic cells or have used molecular markers to search for differences in wood quality associated with population genetics (Sandak et al. 2015). Many of these works had mature wood in focus. However, as recently reported by Li et al. (2017) in Larix kaempferi (Lamb.) Carr., wood 
transcriptome varies along the life of the tree, so transcripts related to juvenile wood formation could have been missed in those studies.

This works reports a transcriptome analysis of juvenile wood formation in Pinus canariensis C. Sm. ex DC. This is not a common model species for this purpose, although it has noteworthy characteristics: it shows a remarkable healing capacity (described in Chapter 2, Chano et al. 2015, and López et al. 2015) and produces abundant resinous heartwood, which prevents putrefaction and reaches high market values, due to its aesthetic characteristics and its durability even under outdoor conditions (Climent et al. 1998, Taylor et al. 2002). A special feature of its secondary xylem, i.e. the comparatively abundant presence of axial parenchyma (Climent et al. 1998) may have been missed in previous studies in other conifer species (even in Pinaceae). Two cDNA libraries from the P. canariensis C. Sm. ex DC cambial zone have been prepared and analyzed, in order to cover the transcriptional profiles both of earlywood (EW) and latewood (LW) differentiation, aiming at obtaining a more complete picture of wood formation in conifers.

\section{MATERIAL AND METHODS}

\section{Plant material}

Three-year-old unrelated Canary Island pines grown in a nursery at the UPM facilities were investigated. Trees were grown in 3:1 (v/v) peat:vermiculite, in 650 $\mathrm{ml}$ cone-containers first and, after the first year, they were grown outdoor without watering. At the collecting dates, the trees were approximately $150 \mathrm{~cm}$ high, with a diameter at breast height of 2-3 cm. Three different unrelated trees were harvested independently at each sampling date. The stems were debarked and the cambial zone and differentiating xylem were scrapped with a sterile scalpel. These samples were immediately frozen in liquid nitrogen and stored at $-80^{\circ} \mathrm{C}$ for further RNA extraction. For the construction of the libraries, samples were collected on 5 May and 12 July. To evaluate gene expression during the growing season, samples were collected on 7 March, 6 April, 6 May, 6 June, 6 July and 5 
Chano, $V$-Transcriptomics of the response to wounding

September. A 2-cm long portion of the stem of each plant was reserved for anatomical observation.

\section{Anatomical observation}

Cross-sections $20 \mu \mathrm{m}$ thick were obtained from stem portions with a Leica SM2400 microtome (Leica Biosystems, Nussloch, Germany). Sections were treated with sodium hypochlorite, washed with distilled water 2-3 times, and then stained for 2 min with $1 \%$ safranin (v/v) and for 1 min with $1 \%$ alcian blue (w/v), washed with distilled water and dehydrated with an ethanol series. Finally, sections were mounted on slides for bright-field microscopy.

\section{RNA isolation}

Total RNA was isolated from differentiating xylem samples stored at $-80^{\circ} \mathrm{C}$, while the CTAB-LiCl precipitation method (Chang et al. 1993) was applied, and it was purified with the RNeasy Plant Mini Kit (Qiagen, CA, USA). The quantity of total RNA for each sample was measured with a Nanodrop model ND-1000 (Thermo Scientific, MA, USA), and RNA quality was checked by the Experion Bioanalyzer (Bio-Rad, CA, USA).

\section{Libraries construction and transcriptome assembly}

Two RNA pools (corresponding to spring and summer) were obtained by mixing equal amounts of RNA from each of the three plants collected at the sampling date. SMART approach (Zhu et al. 2001) was used for cDNA synthesis from each RNA pool. Amplified cDNA was purified with a QIAquick PCR Purification KIT (Qiagen, CA, USA) and concentrated by ethanol precipitation. DNA pellets were diluted with MilliQ water to a final cDNA concentration of $50 \mathrm{ng} \mu \mathrm{l}-1$. These cDNA samples were then normalized via the DSN normalization approach (Zhulidov et al. 2004).

Sequencing was performed by means of a Roche 454 Genome Sequencer FLX Titanium System (Roche/454 Life Sciences, CT, USA) by the Life Sequencing service (Universidad de Valencia, Spain). Read files were pre-processed to improve read 
quality via sequential PRINSEQ- lite v.0.20.4 (Schmieder and Edwards 2011) and SnoWhite v.1.1.4 (Barker et al. 2010), a cleaning pipeline for cDNA sequences that is based on SeqClean (http://sourceforge.net/projects/seqclean/) and trims polyA/T. Reads obtained were deposited in the National Center of Biotechnology Information (NCBI) Sequence Read Archive (SRA) database (http://www.ncbi.nlm.nih.gov/sra; accession no SRP075611, BioProject PRJNA322445).

Assembly was done by Newbler v.2.5 (Roche/454 Life Sciences, CT, USA), based on the overlap layout consensus (OLC) paradigm, which first identifies all pairs of reads that show good overlap and then generates graphs where every read corresponds to one node, and there is an edge between any pair of overlapping reads. Preliminary de novo assemblies were pooled into single multi-fasta files, and meta-assembled with CAP3 (Huang and Madan 1999), using default parameters, to remove redundancies and achieve longer contigs. The quality of the final meta-assembled transcriptome was assessed quantitatively by computing the length of the contigs, the GC content and the N50 and L50 parameters using Quast v.2.3 (Gurevich et al. 2013) and rnaQUAST v.1.2.0 (Bushmanova et al. 2016). Additionally, quality of the transcriptome was also checked by aligning the contigs with available transcriptomes from other Pinus species. This transcriptome shotgun assembly project has been deposited at DDBJ/EMBL/GenBank under the accession GESU00000000 v01.

\section{Functional annotation}

The transcriptome assemblies were downstreamed as inputs for the local version of BLASTx (Altschul et al. 1990). The contigs were launched against the Viridiplantae section of the RefSeq database (NCBI), with an e-value threshold of 10-5 and limited to a maximum of 50 hits. The output file was imported into Blast2GO v2.7.2 (Conesa et al. 2005), in order to provide a comprehensive functional annotation and sequences analysis. A statistical assessment of annotation was performed by the Mapping, Annotation, and GO-slim tools 
Chano, $V$ - Transcriptomics of the response to wounding

implemented in Blast2GO. InterPro annotation was also performed in order to retrieve motif/domain information and to improve annotation. Enzyme codes (EC) and Kyoto Encyclopedia of Genes and Genomes (KEGG) pathways were also obtained through Blast2GO by the direct mapping of GOs to the enzyme code equivalents.

\section{Microarray analysis}

The contig library was filtered removing isoforms and sequences shorter than 300 bp. The unigenes served for the design of a one-color $180 \mathrm{~K}$ microarray (Agilent, USA). Furthermore, contigs from other cDNA libraries of Pinus pinaster and Pinus pinea, as well as ESTs and sequences of the loblolly pine from the Pine Gene Index Database (http://www.mgel.msstate.edu/dna_libs.html) were included. Probes included in the microarray are provided in Supplementary Information Table S1.

Three biological replicates (RNA from three different trees) from each sampling point were independently hybridized following the One Color Microarray-Based Gene Expression Analysis Protocol (Agilent Technologies, Palo Alto, CA, USA). Arrays were scanned at a 3-mm resolution on Agilent DNA Microarrays Scanner (G2565BA, Agilent Technologies), and the images were analyzed with Feature Extraction software (Agilent Technologies). Background correction and normalization of expression data were performed using LIMMA (Smyth and Speed 2003). For local background correction and normalization, the methods normexp and loess in LIMMA were applied, respectively (Smyth and Speed 2003). To have similar distribution across arrays and to achieve consistency among arrays, log-ratio values were scaled as a scale estimator for the median-absolutevalue (Smyth and Speed 2003). Hybridizations and first statistical analysis were performed by the Genomics Facility at Centro Nacional de Biotecnología, Madrid. Data were deposited in the NCBI Gene Expression Omnibus (GEO) (http://www.ncbi.nlm.nih.gov/geo accession no GSE82217).

Normalized data were analyzed with Babelomics v.4.2 (Medina et al. 2010), performing a maSigPro (Time/Dosage Series) analysis, a methodology designed for 
the identification of differentially expressed genes (DEGs) in a time-course experiment. maSigPro is based on a regression modeling approach and reports expression changes considering the whole expression profile. The following options were selected for the analysis: (1) polynomial degree $=4$, which determines regression complexity; (2) FDR adjustment; (3) significance level of 0.05; and (4) k-means clustering for cluster method $(k=6)$. Later on, an enrichment analysis of GO terms was performed for each of the six clusters compared to the complete transcriptome obtained from libraries, by means of the Fisher's exact test of the Gossip (Blüthgen et al. 2005) package implemented in Blast2GO, with an FDR value of 0.05 .

A weighted gene co-expression network analysis was performed by means of the WGCNA R package v1.51 (Langfelder and Horvath 2008) with the relative gene expression values for each biological replicate and sampling points. To identify expression modules in WGCNA, a soft threshold power value of 10 was applied and the networks were constructed for connected genes with $r \geq 0.90$. Finally, the co-expression network was visualized by Cytoscape v. 3.5.1 (Shannon et al. 2003).

\section{qRT-PCR}

The expression patterns of eight genes, covering the clusters obtained from the microarray analysis, were confirmed by qRT-PCR using RNA from one of the genotypes as a biological replicate in the microarrays. First-strand cDNA synthesis was performed by SuperScript ${ }^{\mathrm{TM}}$ III reverse trascriptase (Invitrogen, USA) following the manufacturer's instructions, with $4 \mu \mathrm{g}$ of total RNA and random hexamers. Gene-specific primers were designed for the selected genes via the Primer3 software (Untergasser et al. 2012), with a Tm between 60 and $65^{\circ} \mathrm{C}$, and producing amplicons between 80 and $120 \mathrm{bp}$ (Table 1). qRT-PCR was performed in a CFX96 ${ }^{\mathrm{TM}}$ Real-Time PCR Detection System (Biorad, USA), by means of the SsoFast ${ }^{\mathrm{TM}}$ EVAgreen. Supermix (Biorad, USA), according to the manufacturer's protocol, and following the standard thermal profile: $95^{\circ} \mathrm{C}$ for $3 \mathrm{~min}, 40$ cycles of $95^{\circ} \mathrm{C}$ for $10 \mathrm{~s}$ and $60^{\circ} \mathrm{C}$ for $10 \mathrm{~s}$. To compare data from different qRT-PCR runs, the 
CT values were normalized by the Ri18S as housekeeping gene. The expression ratios were then obtained by the delta-delta-CT method corrected for the PCR efficiency for each gene (Pfaffl 2001).

Table 1: Primers used for qRT-PCR verification.

\begin{tabular}{|c|c|c|c|c|c|c|c|}
\hline Contig name & Oligo name & Description & Fwd/Rev & bp & $\mathrm{Tm}$ & GC & Sequence (5’-3') \\
\hline \multirow{2}{*}{ Congit05410 } & Pc_05410_PECTINESTERASE_F1 & \multirow{2}{*}{$\begin{array}{l}\text { Pectinesterase 2-like } \\
\text { protein }\end{array}$} & Forward & 20 & 63.1 & 55 & GTACTCTCGCACGGTCTTCA \\
\hline & Pc_05410_PECTINESTERASE_R1 & & Reverse & 20 & 62.5 & 45 & ATAATAAAGCGTCCCCAACG \\
\hline \multirow{2}{*}{ Contig12050 } & Pc_12050_MYB_F1 & \multirow{2}{*}{ MYB46-like protein } & Forward & 20 & 62.8 & 45 & ATTCCCAACATGGAAGAAGC \\
\hline & Pc_12050_MYB_R1 & & Reverse & 20 & 63.7 & 50 & CTGCATCACCATCACACTCA \\
\hline \multirow{2}{*}{ Contig06513 } & Pc_06513_ATHB15_F1 & \multirow{2}{*}{ ATHB15-like protein } & Forward & 20 & 62.9 & 55 & CCTTGAGGGAAGACGAAGAG \\
\hline & Pc_06513_ATHB15_R1 & & Reverse & 20 & 62.7 & 45 & AGCTCAGAATTCCCTTTGCA \\
\hline \multirow{2}{*}{ Contig02274 } & Pc_02274_NAC_F1 & \multirow{2}{*}{ NAC74-like prtoein } & Forward & 20 & 64.2 & 50 & ACCTTTCTGCTCGAAGCTCA \\
\hline & Pc_02274_NAC_R1 & & Reverse & 20 & 63.9 & 45 & TCAATGGCAGGTGTTGGTTA \\
\hline \multirow{2}{*}{ Contig04961 } & Pc_04961_BEL1_F1 & \multirow{2}{*}{ BEL1-like protein } & Forward & 21 & 64.2 & 48 & TGAAACTTCAGCACCTCATCC \\
\hline & Pc_04961_BEL1_R1 & & Reverse & 20 & 63.9 & 50 & AGCTCTGGCTTAGGCAACAA \\
\hline \multirow{2}{*}{ Contig03225 } & Pc_03225_EXPANSIN_F1 & \multirow{2}{*}{ a-expansin-like protein } & Forward & 20 & 62.8 & 45 & AAGCGGAGCTGATTCTTGAT \\
\hline & Pc_03225_EXPANSIN_R1 & & Reverse & 20 & 63.1 & 60 & CTCAGAGCCACAGAGACGAG \\
\hline \multirow{2}{*}{ Contig04867 } & Pc_04867_WRKY_F1 & \multirow{2}{*}{ WRKY4-like protein } & Forward & 20 & 63.8 & 50 & CCTGTGCTAGCCATTTGTGA \\
\hline & Pc_04867_WRKY_R1 & & Reverse & 20 & 63.7 & 50 & TCAATGGCAGGTGTTGGTTA \\
\hline \multirow{2}{*}{ Contig06476 } & Pc_06476_CCoAOMT_F1 & \multirow{2}{*}{ CCoAOMT-like protein } & Forward & 20 & 64.0 & 50 & GATTGAACAACCGAGGTGCT \\
\hline & Pc_06476_CCoAOMT_R1 & & Reverse & 20 & 63.6 & 45 & TGCAACACCTGAATTCCAAC \\
\hline Housekeeping & Ri18S_FW & \multirow{2}{*}{$18 \mathrm{~S}$ robosomal } & Forward & 19 & 62.4 & 53 & GCGAAAGCATTTGCCAAGG \\
\hline Housekeeping & Ri18S_RV & & Reverse & 21 & 62.4 & 48 & ATTCCTGGTCGGCATCGTTTA \\
\hline
\end{tabular}

Tm. Melting temperature. GC: guanine-cytosine content. bp: base pair

\section{RESULTS AND DISCUSSION}

\section{De novo transcriptome assembly}

Two normalized cDNA libraries were obtained from the differentiating xylem, i.e. (1) in spring, when the growth rate is at its maximum and xylematic cells produced by periclinal divisions of cambial cells mostly differentiate into tracheids; and (2) in mid-summer, when the growth rate decreases and eventually stops, and a higher proportion of resin ducts and their associated axial parenchyma are produced. 
Table 2: Summary of transcriptome quality assessment.

\begin{tabular}{lc}
\hline Number of transcripts & 44,849 \\
\hline Number of transcripts > $500 \mathrm{bp}$ & 26,377 \\
\hline Number of transcripts > $1000 \mathrm{bp}$ & 10,565 \\
\hline Total length (bp) & $25,836,041$ \\
\hline Largest contig (bp) & 3,518 \\
\hline GC content (\%) & 42.15 \\
\hline N50 contig size (bps) & 1,101 \\
\hline L50 (contig number) & 8,755
\end{tabular}

Sequencing of this cDNA produced 458498 reads in spring and 474393 in summer. These two separate libraries were meta-assembled into a single transcriptome, removing redundancies, and 44849 contigs and 103764 singletons (i.e. short reads that are not assembled into contigs). The size distribution of the contigs and singletons are presented in Figure 1a. The total length of the final transcriptome was $25836041 \mathrm{bp}$ and the largest contig had a length of 3518 bp. The GC content was $42.15 \%$ and the N50 and L50 values were 1101 and 8755 bp, respectively (Table 2). This transcriptome is considerably larger than other ones related to wood formation in conifers and available in databases, such as those of Pinus pinaster Ait. (Le Provost et al. 2003), Pinus taeda L. (Kirst et al. 2003) or Pinus radiata D. Don (Li et al. 2010). To check the quality of this de novo transcriptome, contigs were aligned with available transcriptomes from two closely related species, Pinus pinaster Ait. and Pinus halepensis Mill. From the total of Pinus canariensis C. Sm. ex DC contigs, 92.7\%, and 79.3\% were aligned, respectively, to the P. pinaster Ait. and P. halepensis Mill. unigenes.

\section{Functional annotation}

The transcriptome assemblies were aligned to the Viridiplantae section of the RefSeq database (NCBI). The analysis yielded 27576 contigs (61.5\%) and 28542 singletons (27.5\%) matching records of the RefSeq database. The output file from the BLASTx analysis was imported into Blast2GO (Conesa et al. 2005), and a statistical assessment of annotation, including InterProScan, was performed in 
order to retrieve motif/domain information and merge this to the actual annotation.

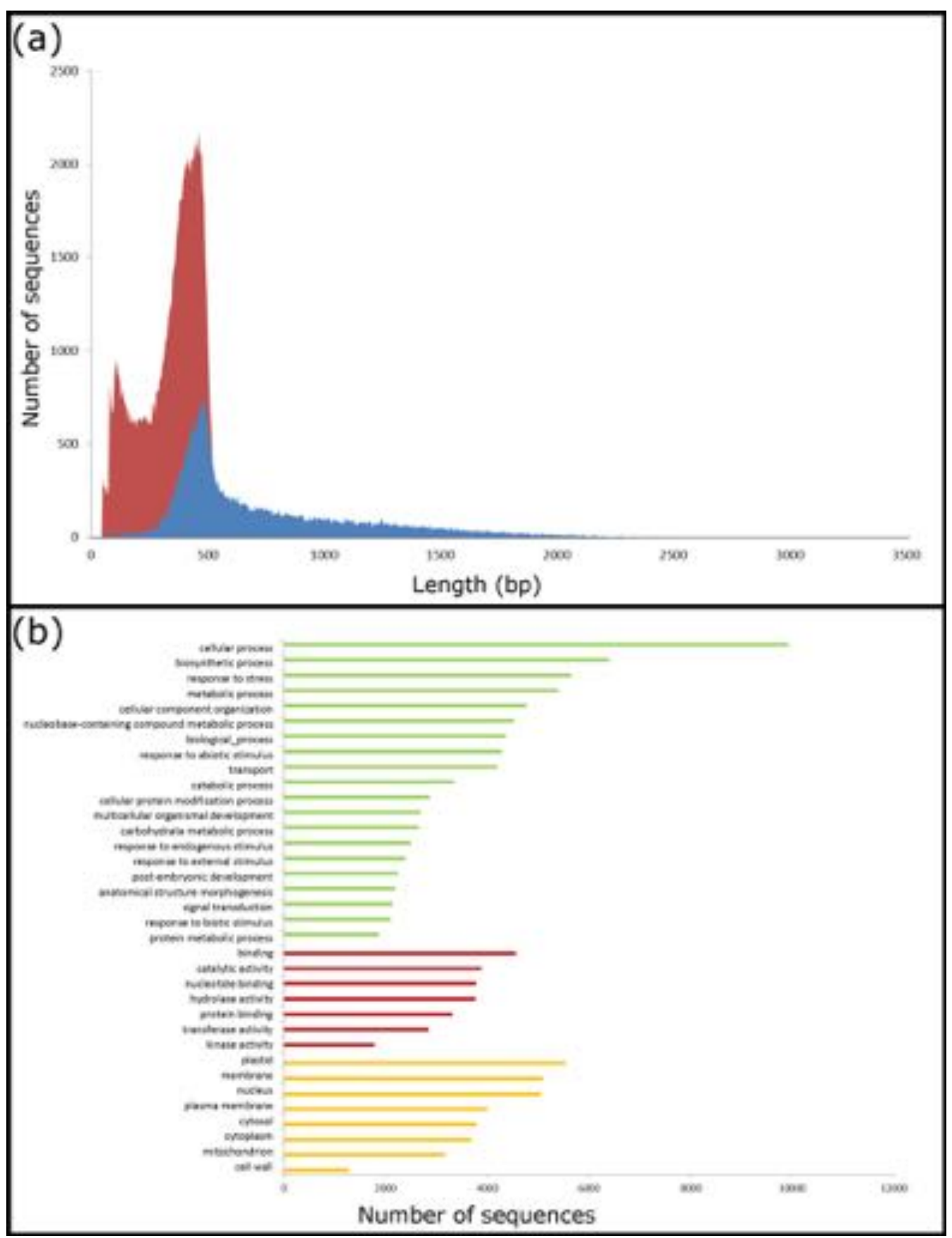

Figure 1. Transcriptome statistics. a) Size distribution of contigs and singletons achieved after meta-assembly with CAP3. The vertical line indicates the number of sequences against their respective length in bp (red graph = singletons; blue graph = contigs). b) Distribution ofthe most abundant GO terms assined to the Pinus canariensis C. Sm. ex DC transcriptome during xylogenesis (green bars: biological process; red bars: molecular function; yellow bars: cellular commponent). 

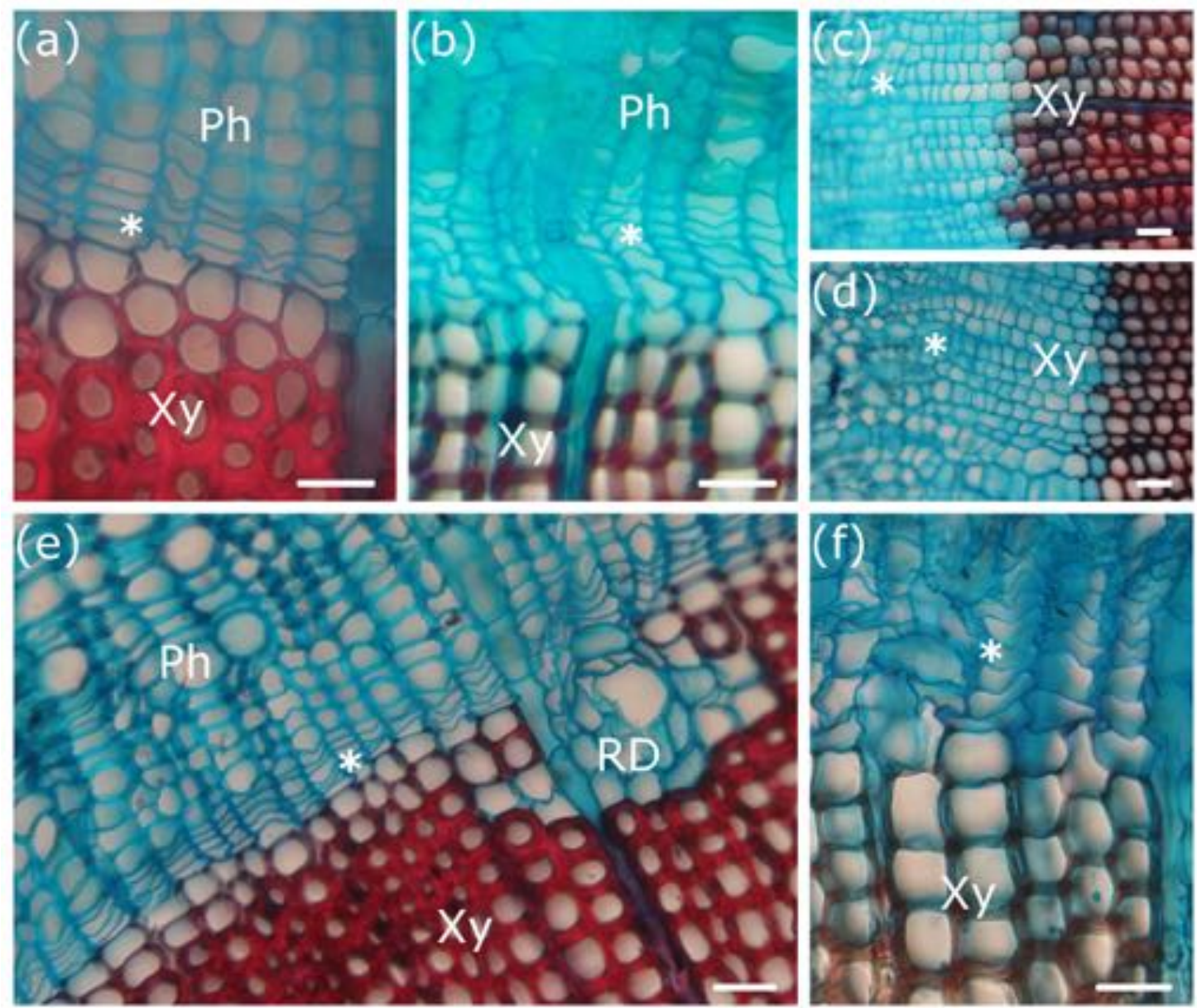

Figure 2. Micrographs in bright-field microscopy of the cambial zone in Pinus canariensis during the growing season (bars $=50 \mathrm{~nm}$; asterisk = cambial zone; $\mathrm{Ph}=$ phloem; $\mathrm{Xy}=\mathrm{xylem} ; \mathrm{RD}=$ resin duct). a-f: March, April, May, June, July and September, respectively. Notice the highest cambial activity in May and June. Several rows of new tracheids, not completely lignified yet, can be observed. Conversely, cambial activity decreases in July and resin ducts and smaller tracheids, with thicker walls, are forming.

GO terms were assigned to 22227 contigs (49.6\% of the total) and 20743 singletons (20.0\% of the total). A total of 172365 GO terms were obtained, which are distributed among different levels for the biological process (BP; 92 988GOs, 54\%), molecular function (MF; 32923 GOs, 19\%) and cellular component (CC; 46454 GOs, 27\%) categories. The main level for BP and MF was level 3 (31 423 and 11914 GO terms, respectively), while it was level 8 for CC (23 680 GOs). Again, this level distribution was consistent with those obtained for Pinus halepensis Mill. (Pinosio et al. 2014), Pinus contorta Douglas ex Loudon (Parchman et al. 2010), or Pinus radiata D. Don (Li et al. 2009). Moreover, Figure 1b shows the most represented GO terms in a direct GO count for the three categories, highlighting cellular process, biosynthetic process, response to stress, cellular component organization 
Chano, $V$ - Transcriptomics of the response to wounding

and biological process for BP, nucleotide binding and kinase activity for MF, or membrane, cell wall and nucleus for CC. The complete annotation of the 44849 contigs is available in Supplementary Information Table S2. Conversely, no homology was found in the public databases for up to 17273 contigs.

\section{Transcription profiles during the growing season}
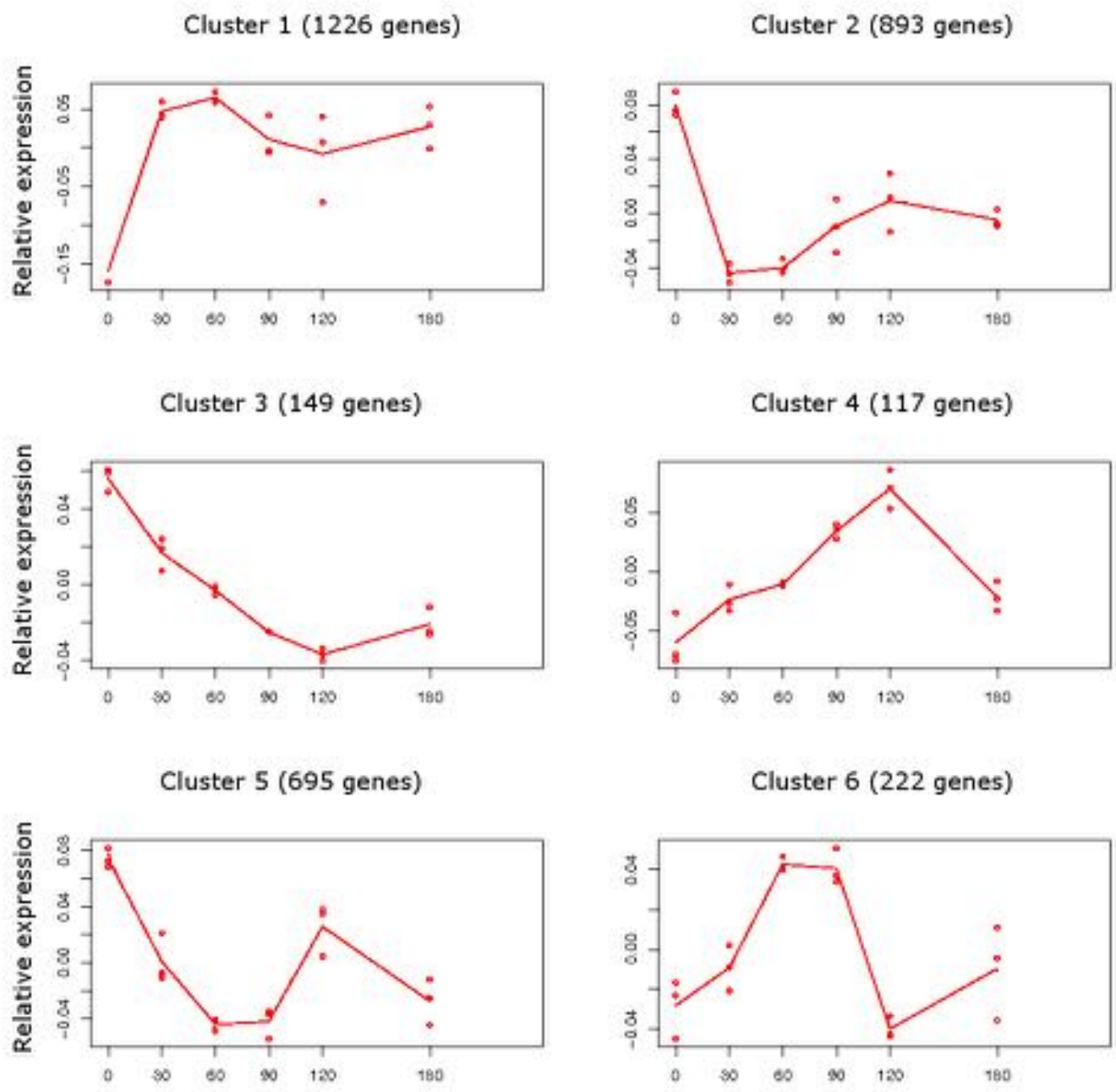

Figure 3. K-means clustering $(\mathbf{k}=6)$ of differentially expressed genes. Clusters represent the main tendencies of gene expression profiles during xylogenesis in Pinus canariensis C. Sm. ex DC after maSigPro analysis. The Y-axis represents the relative expression values and the X-axis represents time in days. The number of genes in each cluster is indicated.

Samples of the cambial zone of Pinus canariensis C. Sm. ex DC collected at six dates from March to September (Figure 2) were hybridized against a microarray including a set of 16455 unigenes from the contig library (removing isoforms and sequences shorter than $200 \mathrm{bp}$ ), in order to examine the transcription patterns 
during the growing season. Correlation among biological replicates is presented in Supplementary Information Figure S1.
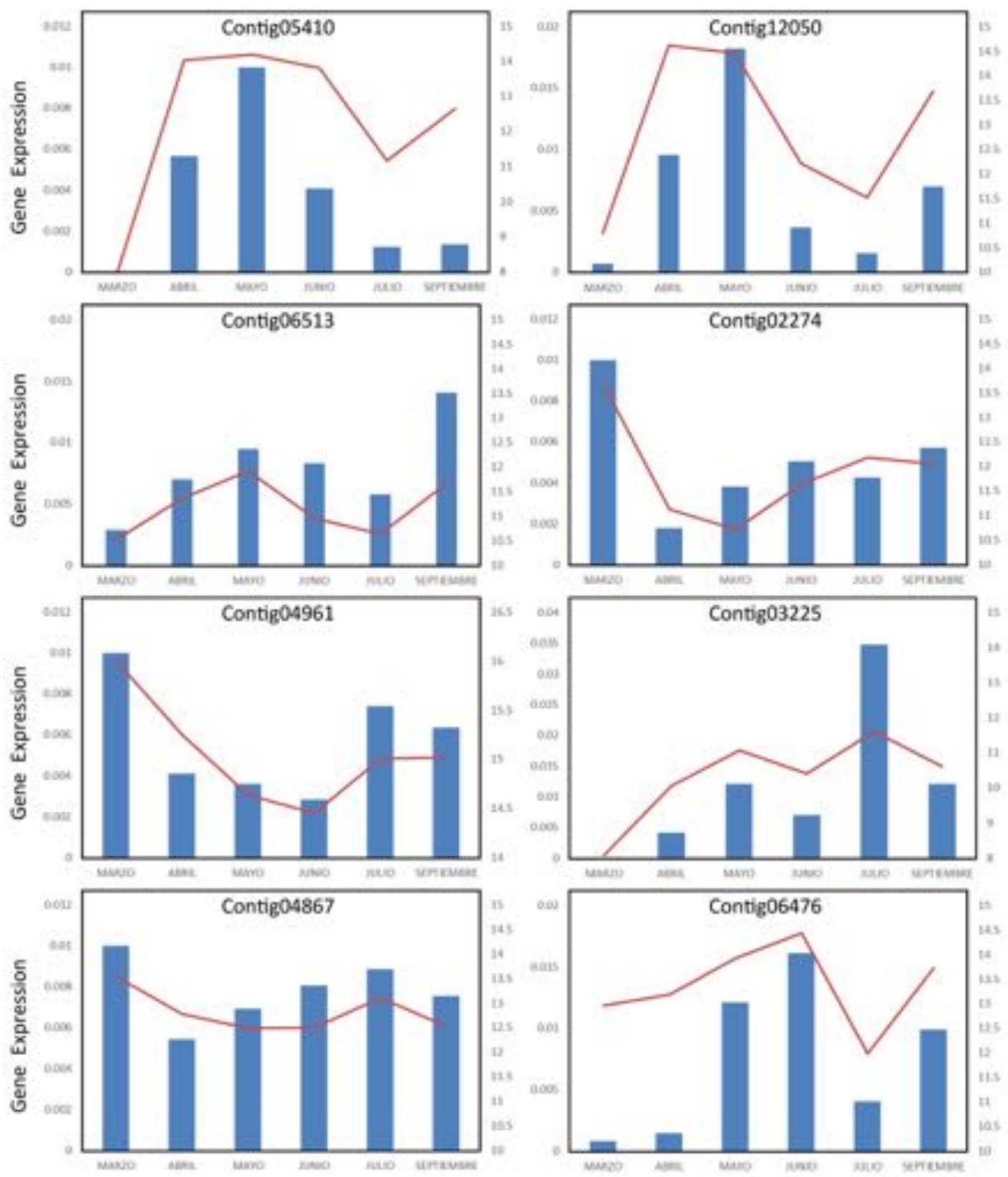

Figure 4. qRT-PCR validation of microarray transcription profiles. X-axis: sampling months Yaxis left: normalized gene expression values of selected DEGs for qRT-PCR (bars). Y-axis right: absolute expression values for microarray experiments (continuous line).

Time-course analysis revealed that 3302 of the contigs included in the microarray (ca. 18\%) showed significant differences in their transcription levels during the growing season, being considered as DEGs. According to their transcription patterns, they were clustered in six main trends (Figure 3). Most of the DEGs correspond to two opposite profiles. First, $43.8 \%$ of the DEGs have shown an 
Chano, $V$ - Transcriptomics of the response to wounding

increase in transcript level during spring, which corresponds to cluster 1 (1226 DEGs; 37.1\%) and cluster 6 (222 DEGs; 6.7\%), highlighting a decrease in the summer and an upturn at September for cluster 6, less prominent in cluster 1.

Conversely, clusters 2, 4 and 5 showed low transcript levels during mid-spring (April and May) and a local maximum in the summer. Thus, cluster 2 (893 DEGs; 27.0\%) and cluster 5 (695 DEGs; 21.1\%) showed a decreasing transcript level during spring (abruptly from March to April for cluster 2, but progressively from March to May-June for cluster 5) and a new upturn in July for both clusters, while cluster 4 showed a continuous increase of transcript level from March to July, turning down in September. Finally, cluster 3 (149 DEGs; 4.5\%) showed a progressive decrease from March to July-September. A complete list of detected DEGs is provided in Supplementary Information Table S3. Additionally, qRT-PCR analysis of the transcription profiles of eight genes, covering the main functional groups and expressional clusters, were performed. High Pearson's correlation values (>80\%) were obtained between microarray and qRT-PCR expression profiles for most genes, thus validating the microarray expression patterns (Figure 4). These patterns are consistent with anatomical observations (Figure 2). The beginning of EW development starts in April through periclinal divisions, and increase noticeably during spring. The growth rate decreases during the summer and resin ducts are formed, setting the period of LW development. Interestingly, the growing season upturns again in September. This growing pattern is not unusual in Mediterranean environments. In northern latitudes, summer is favorable for tree growth, with long days and warm temperatures, so that growth continues during spring and summer, while LW is formed at the beginning of autumn (Li et al. 2010). On the other hand, the drought in Mediterranean summer compromises growth, which can even stop in harsh summers. Wood ring analysis proves that a second growth may occur in years of mild autumns, with mild temperatures and sufficient rainfall (Figure 5). This effect is also known as polycyclism, and can be observed in leaf formation and shoot development too (Verdú and Climent 2007, Bobinac et al. 2012). Polycyclism has been described for 
several Mediterranean conifer species such as Pinus pinaster Ait. (Vieira 2013), Pinus pinea L. (Mutke et al. 2013), or Pinus halepensis Mill. (Liphschitz et al. 1984, de Luis et al. 2007). Interestingly, higher variance has been observed among biological replicates for transcript values in the summer time samples for most genes, which is consistent with the individual variability in response to unfavorable summer conditions (drought, high temperature).

\section{DEGs involved in EW development}

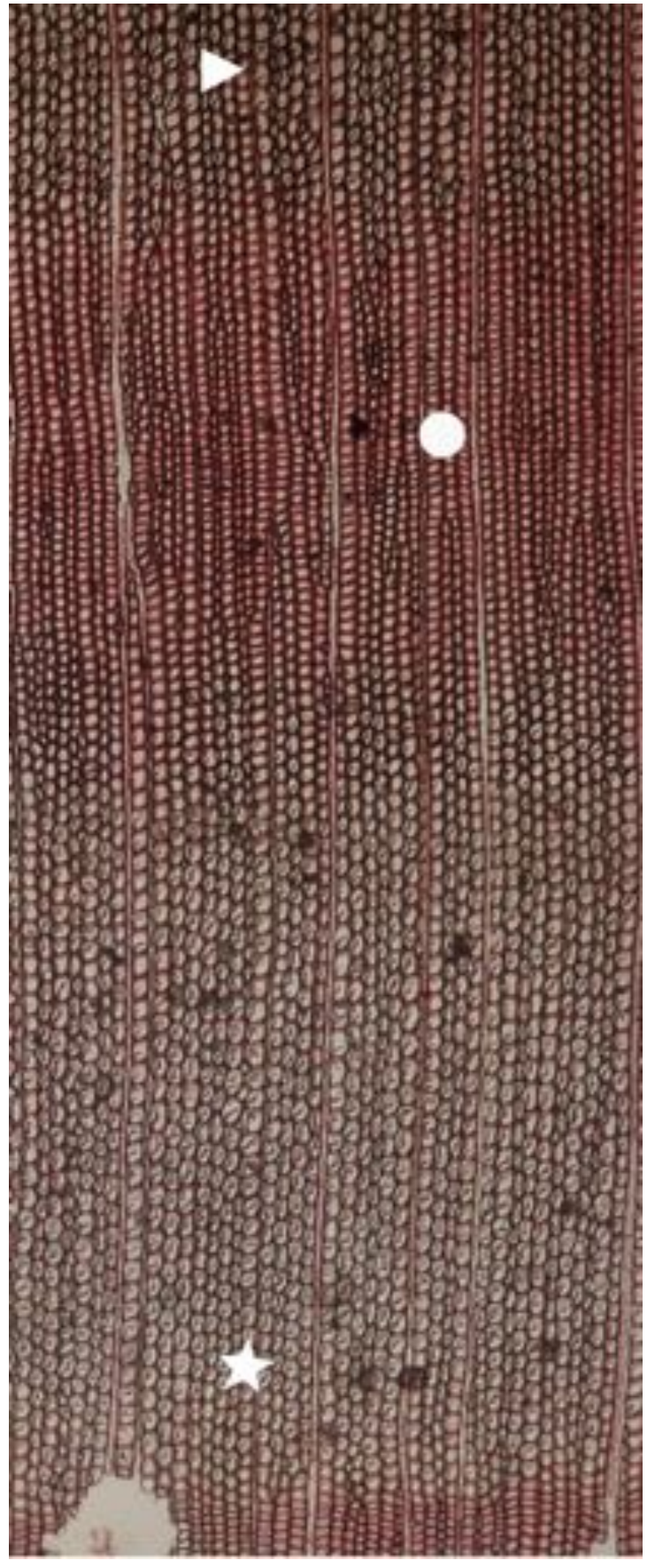

As expected, most of the DEGs with a transcription maximum in April-May (clusters 1 and 6) are related with cell division and cell wall formation processes (Table 3). Thus, an enrichment analysis of GO terms reveals a significant abundance in these clusters of GO terms related to biosynthetic process, cell growth, biogenesis, anatomical structure, morphogenesis and development.

Figure 5. Picture of a Pinus canariensis $\mathrm{C}$. Sm. ex DC wood ring. At the bottom, earlywood formed at the beggining of the growing season can be observed (star). During the summer, the growth rate decreases and smaller tracheids with thicker walls are produced (dot). During autumn, a new increase in cambial activity takes place again producing wider tracheids with thinner walls (arrowhead). 
Chano, $V$-Transcriptomics of the response to wounding

The most abundant DEGs of this group are those putatively involved in cell wall matrix formation and modification, such as genes for coding proteins of the cellulose synthase superfamily (contigs 05245, 06866 and FLPpisotig04143), KORRIGAN endoglucanase-like proteins (contigs 10173, 18777 and FLPpisotig01381), and several genes coding for the Carbohydrate Active enZymes (CAZymes; http://www.cazy.org; (Park et al. 2010a)). These are regulators of the principal biosynthesis pathways of hemicelluloses, such as glycosil transferases and hydrolases (GTs and GHs), along with pectate lyases (PLs). PLs are involved in the degradation of pectin, a principal component of the primary cell walls during the secondary cell wall development, allowing intrusive growth of tracheids ((Marín-Rodríguez et al. 2002)). Expansins, which are regulators of cell growth (Cosgrove et al. 2002) and are related to tracheid elongation, are also present in these clusters. Additionally, some fasciclin like-arabinogalactan proteins associated with xylem development (Andersson-Gunnerås et al. 2006) were also found in cluster 1

Another important group of DEGs present in clusters 1 and 6 comprises genes involved in the phenylpropanoid pathway and lignin biosynthesis, which play a key role in the development of tracheids. These genes have been wellcharacterized in plant models such as Arabidopsis thaliana (L.) Heynh., maize, rice, alfalfa or tobacco, as well as in forest species such as Populus L. and conifers like Pinus L. or Picea Link (reviewed by (Vanholme et al. 2010). Phenylalanine ammonia-lyase (PAL), cinnamate-4-hydroxylase $(\mathrm{C} 4 \mathrm{H})$, hydroxycinnamoyl:CoA shikimate/quinatehydroxy cinnamoyl transferase (HCT), caffeic acid Omethyltransferase (COMT), caffeoyl-CoA O-methyltransferase (CCoAOMT), cinnamoyl-CoA reductase (CCR) and cinnamyl alcohol dehydrogenase (CAD) can be found in clusters 1 and 6 .

Table 3: Most relevant differentially expressed genes (DEGs) presumably involved in earlywood development.

\begin{tabular}{lllll}
\hline Cluster & Contig ID & BLASTx Description & Hit ACC & eValue \\
\hline \multicolumn{2}{ll}{ Cell-wall matrix development } & & \\
\hline \multicolumn{1}{l}{ Cond/or carbohydrate metabolism } & & 0 \\
\hline
\end{tabular}


Chapter 1

\begin{tabular}{|c|c|c|c|c|}
\hline 1 & Contig00603 & beta-xylosidase alpha-l-arabinofuranosidase 2-like & NP_001146416 & $6.55 \mathrm{E}-121$ \\
\hline 1 & Contig00713 & mannan endo-beta-mannosidase 6-like & XP_004249033 & $5.18 \mathrm{E}-169$ \\
\hline 1 & Contig01025 & fasciclin-like arabinogalactan protein 10-like & XP_002320736 & $3.25 \mathrm{E}-105$ \\
\hline 1 & Contig01628 & mannose-1-phosphate guanylyltransferase 1-like & XP_008441398 & 0 \\
\hline 1 & Contig01691 & probable beta-xylosyltransferase irx10l-like & XP_002511079 & 0 \\
\hline 1 & Contig01735 & probable beta-xylosyltransferase irx14-like & XP_006850475 & $3.65 \mathrm{E}-91$ \\
\hline 1 & Contig01867 & probable polygalacturonase & XP_006840361 & 0 \\
\hline 1 & Contig02153 & probable beta-galactosyltransferase 11-like & XP_008791474 & $1.51 \mathrm{E}-118$ \\
\hline 1 & Contig02909 & mannose-1-phosphate guanyltransferase alpha-like & XP_002281959 & $2.55 \mathrm{E}-111$ \\
\hline 1 & Contig03225 & expansin alpha & XP_002315043 & $8.72 \mathrm{E}-125$ \\
\hline 1 & Contig05066 & probable pectate lyase 15 -like & XP_006282594 & 0 \\
\hline 1 & Contig05245 & probable cellulose synthase a catalytic subunit 3 & XP_002283406 & $4.80 \mathrm{E}-177$ \\
\hline 1 & Contig05410 & pectinesterase 2-like & XP_003521940 & 3.37E-143 \\
\hline 1 & Contig05424 & $\begin{array}{l}\text { probable xyloglucan endotransglucosylase hydrolase } \\
\text { protein 8-like }\end{array}$ & XP_002518528 & $2.91 \mathrm{E}-119$ \\
\hline 1 & Contig06866 & cellulose synthase-like protein d3-like & XP_006478929 & $9.89 \mathrm{E}-115$ \\
\hline 1 & Contig07097 & probable beta-d-xylosidase 7-like & XP_002535159 & $3.14 \mathrm{E}-92$ \\
\hline 1 & Contig08356 & udp-glycosyltransferase 85a2-like & XP_008789349 & $7.55 \mathrm{E}-82$ \\
\hline 1 & Contig09025 & $\begin{array}{l}\text { xyloglucan endotransglucosylase hydrolase protein 9- } \\
\text { like }\end{array}$ & XP_002522701 & 1.27E-92 \\
\hline 1 & Contig09397 & alpha-l-arabinofuranosidase 1-like & XP_007028421 & 0 \\
\hline 1 & Contig09434 & fasciclin-like arabinogalactan protein 17-like & XP_002309262 & $2.66 \mathrm{E}-67$ \\
\hline 1 & Contig09435 & fasciclin-like arabinogalactan protein 17-like & XP_004249393 & $5.99 \mathrm{E}-92$ \\
\hline 1 & Contig09907 & $\begin{array}{l}\text { probable xyloglucan endotransglucosylase hydrolase } \\
\text { protein } 32\end{array}$ & XP_002523709 & $4.46 \mathrm{E}-80$ \\
\hline 1 & Contig10110 & xyloglucan galactosyltransferase katamari1-like & NP_001147481 & $2.12 \mathrm{E}-106$ \\
\hline 1 & Contig10173 & endoglucanase 24-like & XP_006487371 & $2.15 \mathrm{E}-124$ \\
\hline 1 & Contig10178 & beta-xylosidase alpha-l-arabinofuranosidase 2-like & XP_006855294 & $1.32 \mathrm{E}-71$ \\
\hline 1 & Contig11436 & $\begin{array}{l}\text { probable polygalacturonase non-catalytic subunit jp650- } \\
\text { like }\end{array}$ & XP_007153633 & $2.34 \mathrm{E}-43$ \\
\hline 1 & Contig11975 & probable beta-xylosyltransferase irx9h & XP_006852709 & $1.55 \mathrm{E}-131$ \\
\hline 1 & Contig12072 & glucomannan 4-beta-mannosyltransferase 9-like & XP_007220072 & 0 \\
\hline 1 & Contig12089 & mannan endo-beta-mannosidase 7-like & XP_006841534 & 5.26E-179 \\
\hline 1 & Contig12414 & expansin-b3-like & XP_007043563 & $1.01 \mathrm{E}-84$ \\
\hline 1 & Contig12926 & xylosyltransferase 1-like & XP_004309761 & $1.14 \mathrm{E}-20$ \\
\hline 1 & Contig13281 & probable pectinesterase 68 -like & XP_007039841 & $8.74 \mathrm{E}-68$ \\
\hline 1 & Contig13724 & $\begin{array}{l}\text { probable xyloglucan endotransglucosylase hydrolase } \\
\text { protein 32-like }\end{array}$ & XP_008805707 & $8.06 \mathrm{E}-98$ \\
\hline 1 & Contig13778 & probable polygalacturonase at1g80170-like & XP_006840713 & $3.72 \mathrm{E}-56$ \\
\hline
\end{tabular}




\section{Chano, $V$-Transcriptomics of the response to wounding}

\begin{tabular}{|c|c|c|c|c|}
\hline 1 & Contig15337 & xylosyltransferase 1-like & NP_198815 & 3.15E-14 \\
\hline 1 & Contig15778 & udp-glycosyltransferase family protein & XP_004306713 & 2.55E-71 \\
\hline 1 & Contig18777 & endoglucanase 24-like & XP_006849270 & 8.04E-82 \\
\hline 1 & Contig18811 & expansin alpha & NP_001281040 & $1.04 \mathrm{E}-56$ \\
\hline 1 & Contig18941 & $\begin{array}{l}\text { probable xyloglucan endotransglucosylase hydrolase } \\
\text { protein } 32\end{array}$ & XP_006424466 & 2.05E-57 \\
\hline 1 & Contig21041 & scopoletin glucosyltransferase-like & XP_006379195 & 2.97E-50 \\
\hline 1 & Contig21066 & polygalacturonase qrt3-like & XP_003554934 & $9.14 \mathrm{E}-61$ \\
\hline 1 & Contig21204 & alpha-expansin 8 & XP_002520863 & $1.99 \mathrm{E}-81$ \\
\hline 1 & Contig22029 & probable pectate lyase 15 -like & XP_002265729 & $1.12 \mathrm{E}-39$ \\
\hline 1 & Contig23968 & mannan endo-beta-mannosidase 7-like & XP_006340651 & $1.49 \mathrm{E}-10$ \\
\hline 1 & FLPpcontig01227 & $\begin{array}{l}\text { probable xyloglucan endotransglucosylase hydrolase } \\
\text { protein } 8\end{array}$ & XP_002518528 & $5.08 \mathrm{E}-119$ \\
\hline 1 & FLPpcontig04143 & cellulose synthase-like protein d3 & NP_001169669 & $6.35 \mathrm{E}-160$ \\
\hline 1 & FLPpisotig01381 & endoglucanase 17-like & XP_006487371 & $5.49 \mathrm{E}-47$ \\
\hline 1 & FLPpisotig01642 & beta-xylosidase alpha-l-arabinofuranosidase 2-like & NP_001146416 & 4.19E-109 \\
\hline 1 & Ppisotig03412 & beta-xylosidase alpha-l-arabinofuranosidase 2-like & XP_006855294 & 4.17E-80 \\
\hline 1 & Ppisotig09772 & alpha-l-arabinofuranosidase 1-like & XP_010904719 & 0 \\
\hline 1 & Ppisotig14238 & fasciclin-like arabinogalactan protein 16 & NP_850253 & $2.92 \mathrm{E}-30$ \\
\hline 1 & Ppnisotig01389 & mannan endo-beta-mannosidase 7-like & XP_008797528 & $1.13 \mathrm{E}-74$ \\
\hline 1 & Ppnisotig07937 & probable beta-xylosyltransferase irx9h & XP_011626438 & $1.72 \mathrm{E}-49$ \\
\hline 1 & Ppnisotig12100 & mannan endo-beta-mannosidase 7 & XP_007046870 & $3.76 \mathrm{E}-23$ \\
\hline 6 & Contig01745 & gdp-mannose dehydratase 1-like & XP_001774456 & $4.81 \mathrm{E}-180$ \\
\hline 6 & Contig22956 & xylosyltransferase 1-like & XP_007222964 & $9.26 \mathrm{E}-61$ \\
\hline 6 & Ppisotig06462 & probable xyloglucan glycosyltransferase 5 & XP_006845528 & $2.24 \mathrm{E}-19$ \\
\hline 6 & Ppnisotig01254 & probable xyloglucan glycosyltransferase 6 & XP_002960657 & $7.08 \mathrm{E}-76$ \\
\hline \multicolumn{5}{|c|}{ Phenylpropanoid biosynthesis pathway } \\
\hline 1 & Contig00537 & caffeoyl- o-methyltransferase & XP_006856484 & $1.48 \mathrm{E}-157$ \\
\hline 1 & Contig01861 & cinnamoyl- reductase 1-like & XP_008228791 & $7.59 \mathrm{E}-174$ \\
\hline 1 & Contig05567 & trans-cinnamate 4-monooxygenase-like & XP_008792249 & $4.55 \mathrm{E}-166$ \\
\hline 1 & Contig12190 & caffeic acid 3-o-methyltransferase-like & XP_006829216 & 5.53E-163 \\
\hline 1 & Contig20935 & shikimate o-hydroxycinnamoyltransferase-like & XP_002303858 & $1.06 \mathrm{E}-135$ \\
\hline 1 & Contig23672 & caffeic acid 3-o-methyltransferase-like & XP_004494877 & $5.02 \mathrm{E}-43$ \\
\hline 6 & Contig06476 & caffeoyl- o-methyltransferase & XP_001766967 & $1.01 \mathrm{E}-50$ \\
\hline 6 & Ppisotig09705 & phenylalanine ammonia-lyase & XP_010246007 & \\
\hline
\end{tabular}

Transcriptional regulation of meristem activity

\begin{tabular}{lllr}
\hline 1 & Contig01410 & transcription factor bhlh130-like & XP_007205257 \\
\hline 1 & Contig01913 & transcription factor myb44-like & XP_003611666
\end{tabular}




\begin{tabular}{|c|c|c|c|c|}
\hline 1 & Contig02039 & gata transcription factor 12-like & XP_006372032 & 5.89E-46 \\
\hline 1 & Contig02356 & exordium like 3 & XP_007038432 & $6.16 \mathrm{E}-121$ \\
\hline 1 & Contig03423 & floricaula leafy homolog & XP_002966714 & 7.09E-69 \\
\hline 1 & Contig03715 & protein argonaute 4-like & XP_002308843 & $4.80 \mathrm{E}-19$ \\
\hline 1 & Contig04966 & transcription factor bhlh144-like & XP_007018175 & $3.83 \mathrm{E}-10$ \\
\hline 1 & Contig06513 & homeobox-leucine zipper protein athb-15-like & XP_006853643 & $1.37 \mathrm{E}-170$ \\
\hline 1 & Contig06617 & homeobox protein knotted-1-like 3-like isoform x2 & XP_006483430 & 4.70E-121 \\
\hline 1 & Contig06813 & wuschel-related homeobox 4-like & XP_006305551 & $3.78 \mathrm{E}-35$ \\
\hline 1 & Contig10039 & transcription factor bhlh61-like & XP_006486517 & 8.59E-07 \\
\hline 1 & Contig12050 & transcription factor myb46-like & XP_007132019 & $1.10 \mathrm{E}-67$ \\
\hline 1 & Contig12421 & transcription factor bhlh63-like & XP_006878569 & $5.93 \mathrm{E}-69$ \\
\hline 1 & Contig14178 & clavata3 esr-related 12 family protein & XP_008785816 & $4.38 \mathrm{E}-08$ \\
\hline 1 & Contig14511 & homeobox-leucine zipper protein hat5-like & XP_007151094 & $6.18 \mathrm{E}-16$ \\
\hline 1 & Contig18903 & transcription factor bhlh155-like & XP_001763347 & $2.03 \mathrm{E}-114$ \\
\hline 1 & Contig20476 & exordium like 2 & XP_002285759 & $5.88 \mathrm{E}-89$ \\
\hline 1 & Contig21473 & nac domain transcriptional regulator superfamily & XP_006852355 & $2.09 \mathrm{E}-10$ \\
\hline 1 & Contig22505 & transcription factor bhlh62-like & XP_006848450 & $4.74 \mathrm{E}-65$ \\
\hline 1 & FLPpisotig02169 & transcription factor myb46-like & XP_007211763 & $2.57 \mathrm{E}-70$ \\
\hline 1 & Ppisotig11335 & myb-related protein 308-like & XP_006854612 & $9.56 \mathrm{E}-71$ \\
\hline 1 & Ppisotig16776 & transcription factor myb24-like & XP_009795062 & $2.76 \mathrm{E}-40$ \\
\hline 1 & Ppisotig19583 & floricaula leafy homolog & XP_001762054 & 5.32E-51 \\
\hline 1 & Ppnisotig10775 & scarecrow-like protein 28 & XP_006477403 & $2.54 \mathrm{E}-14$ \\
\hline 6 & Contig02513 & gata transcription factor 9-like & XP_002319169 & $1.32 \mathrm{E}-38$ \\
\hline
\end{tabular}

Among the transcription factors grouped in these clusters are several members of the MYB family, presumably related to the expression of monolignols and phenylpropanoids biosynthesis genes mentioned above, together with NAC factors such as NAC7 and NAC8 (Duval et al. 2014, Lamara et al. 2016). Contig 01913 encodes for a putative MYB44, which was found to be expressed in Arabidopsis thaliana (L.) Heynh. in response to aphid attacks (Liu et al. 2010). For instance, MYB46 is involved in the regulation of secondary wall biosynthesis and its repression has been reported to cause a drastic reduction in secondary wall thickening in A. thaliana (L.) Heynh. (Zhong et al. 2007). Conversely, overexpression of MYB308, also found in cluster 1, inhibits the production of phenolic compounds in Antirrhinum majus L., which are needed for lignification 
Chano, $V$ - Transcriptomics of the response to wounding

of the secondary cell wall (Tamagnone et al. 1998). Also, a putative MYB24, which belongs to the R2R3-MYB subgroup and is involved in stamen filament development in A. thaliana (L.) Heynh. (Cheng et al. 2009), can be seen in cluster 1.

Other transcription factors, belonging to the homeodomain leucine-zipper (HDZip) family reach a transcript maximum in spring. An ortholog of HAT5 (contig 14511) was found in cluster 1, a HD-Zip class I member proposed to be related with abiotic stress response in Arabidopsis thaliana (Johannesson et al. 2003), but not related with meristem activity up to now. Different members of the HD-ZIP III subfamily group in these clusters. For instance, a putative ortholog of CORONA/ATHB15 factor has been found in this group; interestingly, this gene has been described in Arabidopsis thaliana (L.) Heynh. as a negative regulator of vascular tissue development under the control of miRNA165/166 (Ong and Wickneswari 2012). On the contrary, a miRNAresistant POPCORONA has been suggested to be involved in the upregulation of cellulose biosynthesis-related genes, but also with the down-regulation of lignin deposition-related genes in poplar (Du et al. 2011).

Finally, other genes coding for proteins involved in meristem activity have been detected as DEGs in these clusters. For instance, a putative WOX4-like protein was upregulated at the beginning of the growing season. WOX4 belongs to the WUSCHEL-related HOMEOBOX (WOX) family, which is involved, for instance, in the regulation of proliferation from stem cell niches in root and shoot meristems after embryogenesis (Haecker et al. 2004), together with CLAVATA (CLV) (Miwa et al. 2009), and in the differentiation in the organizing center of the apical shoot (Mayer et al. 1998). WOX4 is involved in procambial and cambial growth, with function in vascular bundle development (Ji et al. 2010b), which is consistent with our results.

It is noteworthy that up to 245 non-annotated contigs from Pinus canariensis C. Sm. ex DC are included in these clusters. Among them, 66 contigs are significantly 
coexpressed with genes involved in the development of the cellulosic matrix and in the synthesis of lignin, according to WGCNA analysis (Figure S2a and Table S4). However, they were not detected in the rather exhaustive analysis of the coexpression networks of NAC and MYB transcription factors during wood formation recently published in Picea glauca (Moench) Voss (Raherison et al. 2015, Lamara et al. 2016). They could correspond to genes expressed exclusively in $P$. canariensis or they could have been missed in previous works.

Another interesting point is that a considerable number of DEGs overexpressed during EW formation show high homology with genes reported to be involved in LW formation in other pine species. This is the case for 337 and 255 DEGs with Pinus taeda L. (Kirst et al. 2003) and Pinus radiata D. Don (Li et al. 2010) LW genes, respectively. Among them, genes related to proliferation and cell expansion, such as EXORDIUM or an expansinlike protein (contig 03225), and genes coding for proteins directly involved in cell wall formation, such as C4H (contig 05567), a CCoAOMT (contig 00537) or a HCT (contig 20935), involved in lignin biosynthesis, a CesA-like protein (contig 05245) or a KORRIGAN endoglucanase-like protein (contig 18777) or several CAZymes, can be found. This discrepancy is also found for several transcription factors, such as two bHLH-like transcription factors (contigs 04966 and 10039), a GATA-like transcription factor (contig 06513), a MYBlike transcription factor (contig 12050), a WOX4-like homeobox protein (contig 06813) or an ortholog of CORONA/ATHB15 (contig 06513).

\section{DEGs involved in LW development}

No homology was found for up to 287 of the DEGs showing a local maximum of transcript level in the summer (clusters 2, 4 and 5; Table 4). For the annotated DEGs, functional groups similar to those of EW were detected. Thus, an important group of these DEGs are involved in cell wall formation. For example, a putative sucrose phosphate synthase gene is included in cluster 5 , as well as genes coding for expansins and genes involved in hemicelluloses (mainly xyloglucans) biosynthesis were included in cluster 2 . This is consistent with the induction of 
Chano, $V$ - Transcriptomics of the response to wounding

xyloglucan endotransglycosylases/hydrolases in dormant meristems of Cryptomeria japonica (Thunb. ex L.f.) D. Don (Mishima et al. 2014). In the same way, a CesA-like gene and several genes putatively coding for CAZymes, such as XET-like proteins, are present in cluster 4. DEGs related with the late steps of the lignin biosynthesis pathway, such as cinnamoyl-CoA reductase (CCR) also appear in these clusters. Considering the higher lignification degree of LW compared to EW, a greater abundance of DEGs related to lignin synthesis could have been expected in this group. Our results could reflect a special characteristic of Pinus canariensis C. Sm. ex DC juvenile wood. Additionally, the restrictiveness for the identification of DEGs can account for this result. In the same way, the presence of highly lignified compression wood, especially in the EW, could also hamper the detection of lignin genes as differentially overexpressed during LW formation. Although the trees did not appear noticeably inclined or distorted, this effect cannot be completely discarded; all the more, a small proportion of compression wood was detectable in certain sections (see, for instance, Figure 2a).

Among the transcription factors included in this group, some putative members of the MYB family and several members of the NAC family are detectable. The NAC (NAM/ATAC/CUC) family is supposed to be involved in multiple roles of plant development, as well as in responses to abiotic (drought, salinity, etc.) or biotic stress (reviewed by (Hu et al. 2010)). Recently, numerous NAC domains were reported to play crucial roles in xylogenesis, fiber development and wood formation in vascular plants, including conifers such as spruce (Duval et al. 2014, Raherison et al. 2015, Lamara et al. 2016). Transcripts encoding for NAC proteins were found in clusters 2 and 5. NAC78 (cluster 2) is putatively related to growth and development functionalities (Park et al. 2010b). Also in cluster 2, NAC29 has been reported to regulate CesA expression via MYB transcription factors in rice, and the interaction between NAC29/31 with SLR1 (SLENDER RICE 1) causes the inhibition of this regulatory pathway (Huang et al. 2015). A contig encoding for NAC2 was found as well in cluster 5. In Capsicum annuum L., a CaNAC2 belonging to the NAC2 subgroup was induced by cold, salt and abscisic acid treatments, 
suggesting its involvement in the response to abiotic stress (Guo et al. 2015). Also, in this group, a DEG coding for a putative NAC74, contig 02274, which has not been associated to any functionality yet, was found.

As in cluster 1, a putative CORONA/ATHB15 coding gene is present in cluster 5. Consistently, Du et al. (Du et al. 2011) and Ong and Wickneswari (Ong and Wickneswari 2012) reported this gene as being a negative regulator of xylem development in poplar and acacia, respectively. In a similar way, among the WOX family, a WOX8-like gene was detected in cluster 2. WOX8 has been proposed in Arabidopsis thaliana (L.) Heynh. to have a specific role in the very early stages of embryo development, while it was not detected in postembryonic phases (Haecker et al. 2004). Palovaara et al. (2010) reported similar results for Picea abies (L.) H. Karst., where the homolog PaWOX8/9 is involved in embryo formation, differentiation and patterning. Analogously, this Pinus canariensis C. Sm. ex DC ortholog could be involved in the adjustments previous to cell proliferation, according to its transcription profile: it showed maximum transcript levels in March and July, prior to major meristem activity corresponding to the two periods of seasonal growth described in this work.

The three-amino-acid-loop-extension (TALE) homeodomain proteins are involved in the control of meristem activity (Traas and Vernoux 2002) and are classified into two family groups: the KNOTTED-like homeodomain (KNOX) and the BEL1like homeodomain (BELL) subfamilies. Two transcripts coding for putative BEL1like proteins (contigs 20447 and FLPpisotig03105) were grouped in cluster 5. A third member appears in cluster 3 (contig 04961), which shows a profile opposed to that of cluster 4. Other transcription factors found in cluster 4 were bZIP-like and zinc-finger protein motifs, as well as TOPLESS-like proteins, reported to repress root-promoting genes in the top half of the embryo in Arabidopsis thaliana (L.) Heynh. (Szemenyei et al. 2008).

EXORDIUM (EXO) is another relevant gene found in this work, previously described in proliferating cells (Farrar et al. 2003). First, it was suggested to be a 
negative regulator of cell division control and meristem maintenance. Further experiment revealed that EXO gene expression is brassinosteroid-dependent (CollGarcia et al. 2004) and mediates growth through cell expansion promoted by brassinosteroids (Schröder et al. 2009). A putative EXO-like gene is seen in cluster 2 and two more in cluster 4. However, two additional EXO-like proteins are present in cluster 1.

Several of the DEGs with a maximum transcript level in summer are putatively related to abiotic stresses, mainly drought, which is typical under Mediterranean summertime conditions. For instance, an ortholog gene encoding a putative WRKY4 was found in cluster 5 . This gene has been reported to be induced by stress conditions in Arabidopsis thaliana (L.) Heynh. (Lai et al. 2008). Furthermore, many NAC transcription factors, mainly present in clusters 2 and 5, are also supposed to be involved in stress response.

Table 4: Most relevant differentially expressed genes (DEGs) presumably involved in latewood development.

\begin{tabular}{|c|c|c|c|c|}
\hline Cluster & Contig ID & BLASTx Description & Hit ACC & eValue \\
\hline \multicolumn{5}{|c|}{ Cell-wall matrix development and/or carbohydrate metabolism } \\
\hline 2 & Contig12274 & galactinol-sucrose galactosyltransferase-like & XP_004232319 & 9.53E-143 \\
\hline 4 & Contig01916 & xyloglucan glycosyltransferase 4-like & XP_006845528 & 1.63E-101 \\
\hline 4 & Contig06122 & $\begin{array}{l}\text { probable xyloglucan endotransglucosylase hydrolase protein 8- } \\
\text { like }\end{array}$ & NP_001241628 & $9.09 \mathrm{E}-96$ \\
\hline 4 & Contig14263 & mannan endo-beta-mannosidase 7-like & XP_006841534 & $6.55 \mathrm{E}-20$ \\
\hline 4 & Contig15857 & cellulose synthase-like protein $\mathrm{d} 3$ & NP_001169669 & 4.04E-92 \\
\hline 4 & Contig17013 & probable xyloglucan endotransglucosylase hydrolase protein 23 & NP_001149692 & $2.66 \mathrm{E}-13$ \\
\hline 4 & Ppisotig00266 & probable xyloglucan endotransglucosylase hydrolase protein 23 & XP_012447657 & $3.64 \mathrm{E}-75$ \\
\hline 5 & Ppnisotig11614 & probable sucrose-phosphate synthase 3 & XP_008794597 & 7.64E-105 \\
\hline \multicolumn{5}{|c|}{ Phenylpropanoid biosynthesis pathway } \\
\hline
\end{tabular}




\begin{tabular}{|c|c|c|c|c|}
\hline 2 & Contig02951 & gata transcription factor 9-like & XP_001778541 & $8.26 \mathrm{E}-14$ \\
\hline 2 & Contig04889 & wuschel-related homeobox 8-like & XP_001777634 & 2.93E-43 \\
\hline 2 & Contig05450 & transcription factor bhlh96-like & XP_006829211 & 8.27E-84 \\
\hline 2 & Contig05803 & homeobox protein knotted-1-like 3-like & XP_008802010 & $3.28 \mathrm{E}-116$ \\
\hline 2 & Contig06152 & exordium like 2 & XP_007042914 & $1.68 \mathrm{E}-109$ \\
\hline 2 & Contig11838 & homeobox protein knotted-1-like 2-like & XP_002285521 & $5.26 \mathrm{E}-99$ \\
\hline 2 & Contig13895 & nac transcription factor 29-like & XP_001771652 & $6.28 \mathrm{E}-27$ \\
\hline 2 & Contig16468 & scarecrow-like protein 6-like & XP_006440333 & 9.19E-15 \\
\hline 2 & Contig19392 & nac domain-containing protein 78-like & XP_006855883 & $2.86 \mathrm{E}-18$ \\
\hline 2 & Contig21263 & transcription factor bhlh121-like & XP_006859207 & 3.87E-86 \\
\hline 2 & Contig23724 & myb family transcription factor family protein & XP_008784286 & 4.36E-10 \\
\hline 2 & Ppnisotig00673 & nac transcription factor 29-like & XP_012440667 & $3.44 \mathrm{E}-13$ \\
\hline 4 & Contig01331 & myb-like protein $\mathrm{x}$-like isoform $\mathrm{x} 2$ & XP_006380820 & 2.40E-09 \\
\hline 4 & Contig02773 & topless-related protein 4-like isoform x1 & XP_002960294 & $1.90 \mathrm{E}-135$ \\
\hline 4 & Contig04552 & bzip domain class transcription factor & XP_008813601 & $4.81 \mathrm{E}-133$ \\
\hline 4 & Contig09007 & exordium like 2 & XP_007018740 & $4.46 \mathrm{E}-112$ \\
\hline 4 & Ppisotig11957 & protein exordium-like 2 & XP_009760896 & $1.38 \mathrm{E}-91$ \\
\hline 5 & Contig01876 & myb-like protein $x$-like & XP_007034235 & 4.30E-26 \\
\hline 5 & Contig04867 & probable wrky transcription factor 4 & XP_008227105 & $6.96 \mathrm{E}-84$ \\
\hline 5 & Contig05634 & nac domain-containing protein 2-like & XP_008792531 & $3.49 \mathrm{E}-86$ \\
\hline 5 & Contig12675 & myb-related protein 3r-1-like isoform x1 & XP_008800229 & 1.34E-19 \\
\hline 5 & Contig20447 & bel1-like homeodomain protein 1 & XP_002275098 & $2.74 \mathrm{E}-53$ \\
\hline 5 & Contig22932 & homeobox-leucine zipper protein athb-15-like & XP_001762557 & $3.65 \mathrm{E}-43$ \\
\hline 5 & FLPpisotig03105 & bel1-like homeodomain protein 1 & XP_010247184 & $4.56 \mathrm{E}-58$ \\
\hline 5 & Ppnisotig08121 & myb-related transcription partner of profilin-like & XP_001751813 & $1.64 \mathrm{E}-34$ \\
\hline \multicolumn{5}{|c|}{ Defense and stress related genes } \\
\hline 2 & Contig04363 & wound-responsive family protein isoform 1 & XP_001781658 & $2.12 \mathrm{E}-40$ \\
\hline 2 & Contig20190 & pathogenesis-related homeodomain & XP_002269263 & 2.93E-11 \\
\hline 2 & Contig22601 & probable disease resistance protein at4g33300-like & XP_008377462 & $1.01 \mathrm{E}-20$ \\
\hline 2 & Ppnisotig04165 & late embryogenesis abundant protein d-34-like & XP_002965692 & $1.84 \mathrm{E}-64$ \\
\hline 2 & Ppnisotig09289 & pathogenesis-related homeodomain protein isoform x1 & XP_009349156 & $1.46 \mathrm{E}-43$ \\
\hline 2 & Ppnisotig10670 & protein enhanced disease resistance 2-like & XP_013458134 & 3.73E-76 \\
\hline 2 & Ppnisotig10692 & late embryogenesis abundant protein family protein & XP_011628884 & $1.58 \mathrm{E}-51$ \\
\hline 3 & Ppnisotig11932 & $11 \mathrm{kda}$ late embryogenesis abundant protein & XP_010275352 & 1.02E-06 \\
\hline 4 & Contig40036 & peroxidase 55 & XP_006399923 & 5.33E-08 \\
\hline 5 & Contig00602 & defensin ec-amp-d2-like & XP_006647552 & $1.21 \mathrm{E}-13$ \\
\hline 5 & Contig01697 & heat shock 70 kda protein 8 -like & XP_008375010 & $1.42 \mathrm{E}-150$ \\
\hline
\end{tabular}


Chano, $V$ - Transcriptomics of the response to wounding

\begin{tabular}{llllr}
\hline $\mathbf{5}$ & Contig01723 & heat stress transcription factor a-1-like & XP_008800101 & $6.86 \mathrm{E}-15$ \\
\hline $\mathbf{5}$ & Contig01763 & heat shock protein binding & XP_004494547 & $2.88 \mathrm{E}-41$ \\
\hline $\mathbf{5}$ & Contig03816 & heat shock protein 83-like & XP_008801780 & 0 \\
\hline $\mathbf{5}$ & Contig03998 & defensin ec-amp-d2-like & XP_006647552 & $1.58 \mathrm{E}-17$ \\
\hline $\mathbf{5}$ & Contig05454 & disease resistance protein & XP_0068444417 & $3.09 \mathrm{E}-154$ \\
\hline $\mathbf{5}$ & Contig09453 & pathogenesis-related protein 5-like & XP_006847064 & $7.78 \mathrm{E}-12$ \\
\hline $\mathbf{5}$ & Contig14467 & heat shock 70 kda mitochondrial-like & XP_006471142 & $4.62 \mathrm{E}-17$ \\
\hline $\mathbf{5}$ & Contig17617 & defensin ec-amp-d2-like & XP_006647552 & $1.24 \mathrm{E}-17$ \\
\hline $\mathbf{5}$ & Contig19071 & heat shock protein 83-like & XP_006660235 & $1.89 \mathrm{E}-66$ \\
\hline $\mathbf{5}$ & Contig20815 & heat shock 70 kda mitochondrial-like & XP_001763121 & $3.91 \mathrm{E}-126$ \\
\hline $\mathbf{5}$ & Contig23170 & heat shock protein 83-like & XP_006290250 & $1.59 \mathrm{E}-42$ \\
\hline
\end{tabular}

The presence of stress-related genes in the LW clusters is consistent with the results of Mishima et al. (2014), who described the abundance of "defense mechanism genes" in the "cessation of growth clusters" obtained for the cambial zone and differentiating xylem in Cryptomeria japonica (Thunb. ex L.f.) D. Don. LW differentiation is partly a consequence of a lower availability of water and resources at the end of the growing season, which detracts cell development compared to conditions for EW cell development in spring. Actually, lignin deposition and carbohydrate compounds involved in cell wall formation differ in EW and LW cells (Antonova et al. 2014). LW is also a constitutive, inner barrier for pathogen expansion. Therefore, it is not surprising that genes involved in stress response show high expression values during LW development.

WGCNA revealed another network of co-expressed LW DEGs including contigs related to ubiquitination and degradation of proteins and RNA, as well as two nonannotated contigs (Figure S2b). Among them, the following genes were found: one coding for an ubiquitin regulatory $\mathrm{X}$ (UBX) domain-containing protein, which is presumably involved in proteolysis (Vale 2000), one coding for an ubiquitin carboxyl-terminal hydrolase 13-like (UBP13), another one regulating protein degradation via lysosome and proteasome (Glickman and Ciechanover 2002) and a U-box domain containing protein 44-like (PUB44), which is presumably involved in ubiquitin ligation (Azevedo et al. 2001). 
It is noteworthy that a low number of genes related to resin production were detected. Several genes involved in terpene biosynthesis are included in the transcriptome obtained from the libraries, such as abietadiene synthase, geranylgeranyl phosphate synthase, 1-deoxy-d-xylulose- 5-phosphate reductoisomerase, 2-C-methyl-D-erythritol 2,4-cyclodiphosphate synthase and 3hydroxy-3-methylglutaryl-CoA reductases. Only three contigs with this latter annotation were differentially overexpressed during LW formation. This may be partially explained by the construction of libraries, as those samples were collected in May and July. At this later point, resin ducts are differentiating, but they are not completely filled with resin. Other genes involved in resin production and secretion would be expressed later on and, therefore, are not included in the microarray, which was intended for xylem cell differentiation analysis.

As reported above, in the EW DEGs' section, a substantial number of Pinus canariensis C. Sm. ex DC LW DEGs were detected to be homologous to genes involved in EW formation in other pine species, such as Pinus taeda L. (181 DEGs) or Pinus radiata D. Don (90 DEGs). In this group, two different EXORDIUM-like genes (contigs 06152 and 09007), involved in cell proliferation, can be seen, as well as genes related to cell wall biosynthesis and lignin deposition, such as CAZymes or a putative CCR-like gene (contig 18416). Several transcription factors are also in this group, namely a GATA-like (contig 02951) and a MYB-like transcription factor (contig 01331), as well as a putative KNOT-like (contig 05803) or a TIFY-8-like transcription factor (contig 11973), reported to act as a repressor of primary growth in roots of Arabidopsis thaliana (L.) Heynh. (Cuéllar Pérez et al. 2014). These discrepancies in the expression patterns among pine species could underlie the anatomic differences in their secondary xylem and their specific wood characteristics.

Finally, it is noteworthy that genes of the same family are found in clusters with opposite patterns. The abundance of duplications is typical for conifer genomes (Kovach et al. 2010, Lorenz et al. 2012), which can lead to the specialization of different closely related genes, as reported for WRKY transcription factors (Zhang 
Chano, $V$ - Transcriptomics of the response to wounding

and Wang 2005), terpene synthases (Trapp and Croteau 2001), etc. For instance, an ortholog of CORONA/ATHB15 is in cluster 1, but another ortholog is present in cluster 5, consistent with its role as an inhibitor of vascular tissue development in Arabidopsis thaliana (L.) Heynh. Another example is the presence of different genes putatively coding for expansins and hemicelluloses in EW- and LW-related DEGs, which would be consistent with differences between them not only in terms of cell expansion and wall thickness but also in cell wall composition throughout the growing season (Mellerowicz and Sundberg 2008).

\section{CONCLUSION}

To minimize the loss of less abundant transcripts, two normalized libraries were obtained from the cambial zone of young Pinus canariensis C. Sm. ex DC individuals, i.e. a species, in which axial parenchyma and resin ducts are comparatively abundant. Samples were collected in spring (during EW formation) and summer (when resin ducts and LW are formed). A high number of contigs without homology in the public databases have been identified. The transcription patterns during the growing season of approximately 16500 unigenes, more than 300-bp long, have been analyzed. Three thousand three hundred and two genes showed significant variations in their transcript levels during this period. Approximately half of the genes displaying variable transcription levels during the growing season (DEGs) show a transcript level peak in spring, and are putatively involved in EW formation. The other DEGs show a peak during summer, when xylem growth decreases and lignification begins. Most of the DEGs in both groups are involved in cell wall biosynthesis. Interestingly, some genes presumably related to abiotic stress appear among the LW DEGs, which is related to the summer drought typical of the Mediterranean climate. Expectedly, several genes with antagonistic effects are found in both EW and LW. The presence of closely related DEGs with contrasting and even opposite expression profiles suggests the specialization of diverse members of gene families, involved in the different composition of EW and LW. Of note, results for P. canariensis C. Sm ex DC show several discrepancies with those obtained for other species, even within 
the Pinaceae group. The differences may be partly species-specific. Additionally, no homology was found in Viridiplantae databases for more than 1000 DEGs identified in P. canariensis C. Sm. ex DC. Future studies on cell-type-specific expression patterns should give further insight on conifer wood formation. Moreover, the transcriptome reported here will constitute valuable information for further investigation of relevant issues such as the formation of traumatic wood in conifers. 



\title{
Chapter 2.
}

\section{Proliferation of axial parenchymatic xylem cells is a key step in wound closure of girdled stems in Pinus canariensis}

\author{
Chano V, López R, Pita P, Collada C, Soto A. \\ G.I. Genética, Fisiología e Historia Forestal. ETSI Montes, Forestal y del Medio Natural. Dpto. Sistemas \\ y Recursos Naturales. Universidad Politécnica de Madrid. Ciudad Universitaria s/n 28040 Madrid, \\ Spain
}

Published in BMC Plant Biology, 2015; 15:64, DOI 10.1186/s12870-015-0447-z

\begin{abstract}
Background. Wounds caused by fire, herbivorism, rock impacts, etc. cause the direct loss of photosynthetic, storage and/or vascular tissue. In addition, they may entail other damages, such as desiccation of the exposed internal parts, or become a gateway to infection by fungi and other pathogens. To successfully overcome such injuries, plants must reorganize their meristems or even differentiate new ones, producing new traumatic tissues to cover the wound and restore the vascular connection.
\end{abstract}

Results. In this work we analyse the anatomical growth response in conifers after debarking and injuring the vascular cambium, using Pinus canariensis as model species, due to its high wound recovery ability. Conversely to angiosperm woody species, this process is initiated and largely driven by the damaged vascular cambium and not by proliferation in the wound surface. We have detected alterations and switches in the divisions of cambial cells, associated to their position relative to the surface and edges of the wound, resulting in disordered traumatic xylem. We also describe the formation of column-like structures, after girdling, which are in part formed by the proliferation of xylem parenchymatous cells, associated to axial resin ducts. 
Chano, $V$-Transcriptomics of the response to wounding

Conclusions. Abundant resinosis on the wound surface, typical of conifers, is an efficient barrier against opportunistic fungi, insects, etc. but it also hinders the healing process directly from the surface. Thus, wound closure must be largely carried out from the wound margins, being a much slower process, which very often remains unconcluded for long years. This work also describes for the first time the proliferation of inner parenchymatous cells to form column-like structures, which accelerates wound closure in girdled $P$. canariensis. Irregularities in the surface of the healing edge or column-like structures result in the production of disordered vascular tissues, compromising their future functionality, and which must be overcome through the fast restoration of the proper polarity in vascular cambium.

Keywords: Wound closure, Vascular cambium, Parenchymatic xylem cells, Conifers

\section{BACKGROUND}

Throughout their usually long lives, trees can be affected by traumatic injuries caused by different agents, from herbivorism to forest fires, from avalanches in mountain environments to impacts from rocks and other material carried by floods or even from pyroclasts propelled by volcanic eruptions. In addition to the direct loss of photosynthetic and vascular tissues, these events can ease the entry and spread of fungi or other pathogens in the plant. The wound triggers a set of anatomical and physiological responses which avoid or hamper the possible expansion of the infection. Shigo (Shigo 1984, 1989) proposed the CODIT (Compartmentalization of Decay In Trees) model to depict the response to wound displayed in secondary xylem. This model describes a series of radial, transverse and tangential walls in the xylem that ultimately confine the putative pathogen and its damages, resisting their spread. According to CODIT, chemical barriers are first developed in tissues existing prior to injury (constituting the so-called reaction zone), whereas further barrier is constituted by the newly formed tissues 
(barrier zone), which close the wound, leaving a more or less extensive scar in the xylem.

Many of the studies on the traumatic response have used angiosperm model species, especially those focusing in the molecular aspects of wound closure and regeneration (f.i. Xu et al. 2006, Sena et al. 2009, or Sugimoto et al. 2010), its hormonal control (f.i. Wan et al. 2006, Asahina et al. 2011) or the anatomical process (f.i. Stobbe 2002, Pang et al. 2008, Hamada et al. 2009, Zhang et al. 2011b). Regarding this latter issue, different works describe callus and woundwood (new xylem contributing to wound closure) formation directly from the surface of a wound in the stem of angiosperm adult tress. For instance, Stobbe et al. (2002), after removing a rectangular portion of bark, phloem and cambium in Tilia, report the formation of a disordered callus from the proliferation of immature xylem cells as a first protective layer, and the differentiation of a new vascular cambium within this callus. A similar process is described by Pang et al. (2008) after completely debarking the trunk of Eucommia ulmoides. On its side, Zhang et al. (2011b) report that the protective callus is produced by the proliferation of ray cells in Populus tomentosa, followed also by differentiation of a new traumatic vascular cambium within the callus. However, the contrasting anatomical characteristics of gymnosperm and angiosperm xylem may underlie different healing processes leading to the lower regenerating capability of the former.

In gymnosperms, most of the works in this area have focused in the formation of resin ducts in conifers in response to mechanical or insect-mediated injuries and fungal infection, particularly from a molecular point of view (Martin et al. 2002, Fäldt et al. 2003, Mckay et al. 2003, in Picea), or in the effect on wood growth patterns (early-late wood ratio, ring width, formation of traumatic resin ducts...; Nagy et al. 2000, Krokene et al. 2003, in Picea, Gärtner and Heinrich 2009, in Picea and Larix, Schneuwly et al. 2009b, 2009a, in Picea, Abies and Larix, Ballesteros et al. 2010, Rodríguez-García et al. 2014, in Pinus pinaster, Arbellay et al. 2014, in Pseudotsuga, Larix and Pinus ponderosa). Very recently, Stoffel and Klinkmuller (2013) applied 3D X-ray computed tomography to analyze the long-term effects of 
Chano, $V$ - Transcriptomics of the response to wounding

wounding on xylem in Abies alba, Larix decidua and Picea abies. Conversely, very few studies have addressed the wound closure process itself from an anatomical point of view in conifers. Especially noteworthy are the paramount works of Mullick (1975), Oven and Torelli (1994, 1999) or Wahlström and Johansson (1992), in different conifers.

Most of these works have focused on alpine species, which are often damaged by rockfall impacts, while very few works have focused on species with higher regeneration capacity, such as those adapted to volcanic environments (Rodríguez Martín et al. 2013). In this work we analyze the anatomical healing in Pinus canariensis. This pine, with a comparatively abundant xylem parenchyma, is a suitable model species to study wound response in conifers, since it shows an extraordinary healing and even resprouting ability, highly uncommon among gymnosperms, particularly in the adult stage (Keeley and Zedler 1998; Del Tredici 2001). These features could be linked to $P$. canariensis evolutionary history, driven by the successive volcanic eruptions and subsequent re-colonizations in the Canary Islands (López de Heredia et al. 2014). We have used younger plants than previous works, analyzing the response not only in the xylem or phloem but also in the cortical parenchyma, and have performed both fenestration wounds and complete girdling.

From another point of view, several works in the last decades have paid attention to the establishment of polarity and organization of tissues in the developing embryo and apical meristems and differentiation of primary vascular tissues focusing on the balance and hormonal signals that determine these processes (f.i. Berleth and Sachs 2001, Carlsbecker and Helariutta 2005, Kania et al. 2014). However, little is still known about the reorganization of traumatic tissue, mainly when it affects the lateral meristem. In this work we focus on the anatomical aspects of this reorganization. Additionally, we describe for the first time the formation of column-like structures, as essential elements of the wound closure process after girdling. 


\section{MATERIAL AND METHODS}

\section{Plant material and mechanical wounding.}

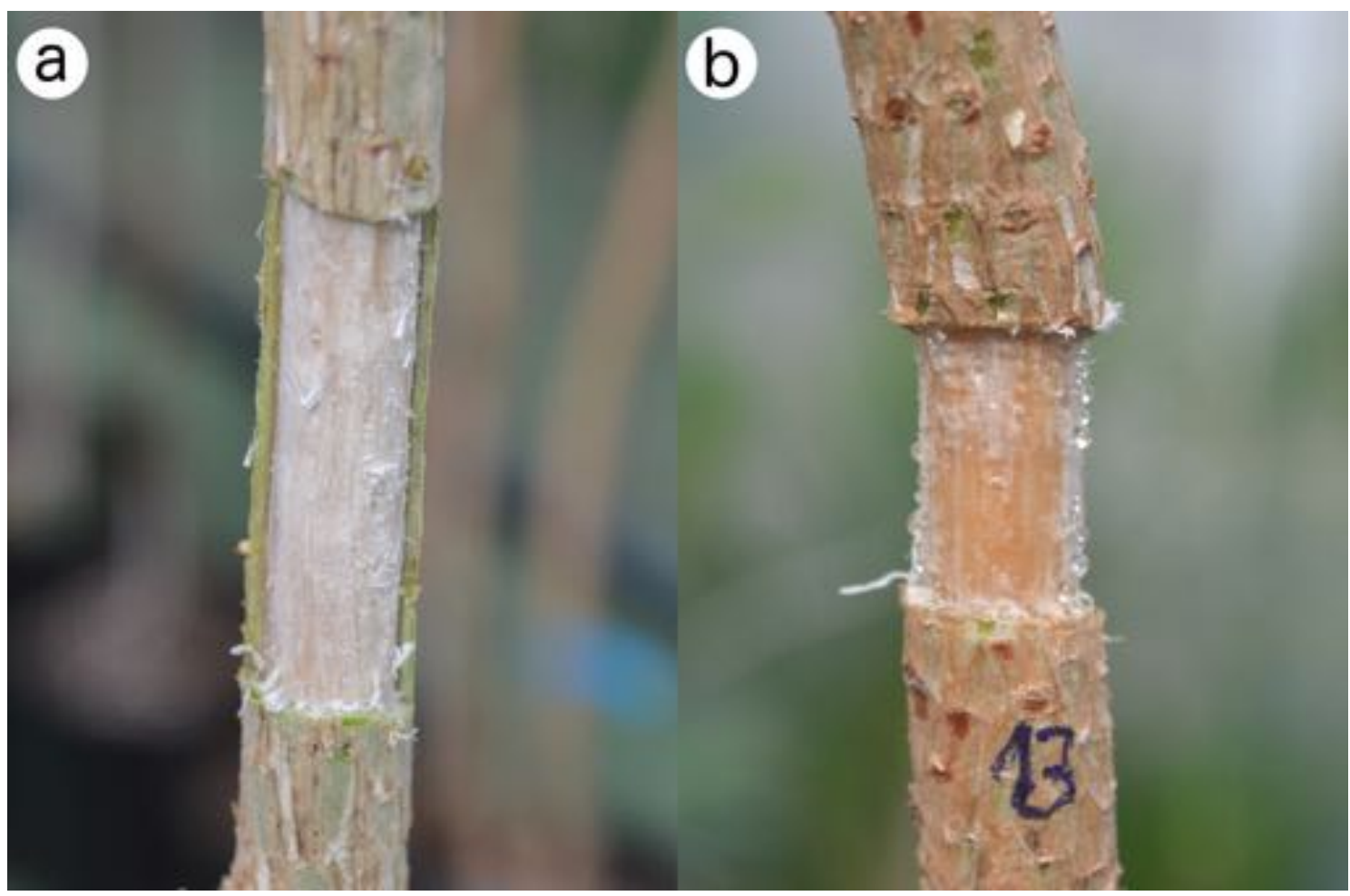

Figure 1. Mechanical wounds. A: Fenestration wound, removing bark, phloem and vascular cambium from a rectangular window $4 \mathrm{~cm}$ high and spanning half the circumference of the stem. B: Girdled stem $2 \mathrm{~cm}$ high. Abundant resinosis in wound surface is clearly visible.

Three years old Canary Island pines grown in nursery at UPM facilities were used for this study. Twenty four trees were grown in 3:1 (v/v) peat:vermiculite, in 650 $\mathrm{ml}$ cone-containers first and 5 liters containers after the first year. At the moment of this study trees were approximately $150 \mathrm{~cm}$ high, with a diameter of $2-3 \mathrm{~cm}$.

Two kinds of mechanical wounds were performed on the stem of pines with a scalpel (twelve trees per treatment). We performed fenestration wounds in 12 trees, removing bark, phloem and vascular cambium from a rectangular window $4 \mathrm{~cm}$ high and spanning half the circumference (Figure 1A). Another set of 12 trees were completely girdled, and bark, phloem and vascular cambium were removed from a $2 \mathrm{~cm}$ high ring (Figure 1B). 
Chano, $V$ - Transcriptomics of the response to wounding

\section{Bright-field and UV microscopy}

In the laboratory, three samples of fenestrated stem were collected for microscopy analysis at four dates during the healing process, based on macroscopic observation: 8, 15, 28 and 50 days after wounding. As well, two stems were collected and processed at 10, 40, 60, 100 and 150 days after girdling. All samples were cut with a Leica SM2400 microtome the same day they were collected. For bright-field microscopy, cross and longitudinal sections (20-30 $\mu \mathrm{m}$ thick) were treated with sodium hypochlorite, washed with distilled water and then stained for 2 min with $1 \%$ safranine (v/v) and 1 min with $1 \%$ alcian blue (w/v), washed with distilled water, and dehydrated with ethanol series, based on Heijari et al. (2005).

Additional 20-30 $\mu \mathrm{m}$ thick cross sections of wounded stem were stained for tannins, callose and suberin observation, using a fluorescence microscope (excitation at 340-380 nm, and 410-450 nm barrier filters) (Olympus BX51). The phloroglucinol-HCl test (Nêmec 1962) was performed for visualization of lignified and suberized cell walls under tungsten and UV light. We first poured a drop of $1 \%$ phloroglucinol:ethanol solution (w/v), and then added a drop of $35 \% \mathrm{HCl}$. While lignin appears stained in red under white light, quenching of lignin autofluorescence under UV light by phloroglucinol-HCl allows the identification of suberized tissues (Biggs 1985, Martin et al. 2005). For tannins detection, sections were stained with a drop of vanillin alcohol saturated, following by adding a drop of $\mathrm{HCl}$ 35\%, based in Vanillin- $\mathrm{HCl}$ test performed by Gardner (1975). For callose detection, sections were stained with 1:1 (v/v) mix of $0.005 \%$ anilin blue $(\mathrm{w} / \mathrm{v})$ and 0.15M K3PO4 pH 8.2, based on Currier \& Strugger (Currier and Strugger 1956).

\section{RESULTS AND DISCUSSION}

As occurs in most conifers, the first response to wounding in P. canariensis is an abundant resinosis in the wound surface, but the wound closure process takes place mostly from the wound edges. Certain differences have been detected between healing from the upper and from the side margins. 


\section{Wound closure from lateral edges}

When the tree suffers fenestration wounding, and the stem is not completely girdled, most of the wound closure takes place from the lateral wound edges. Different steps can be distinguished in the process:

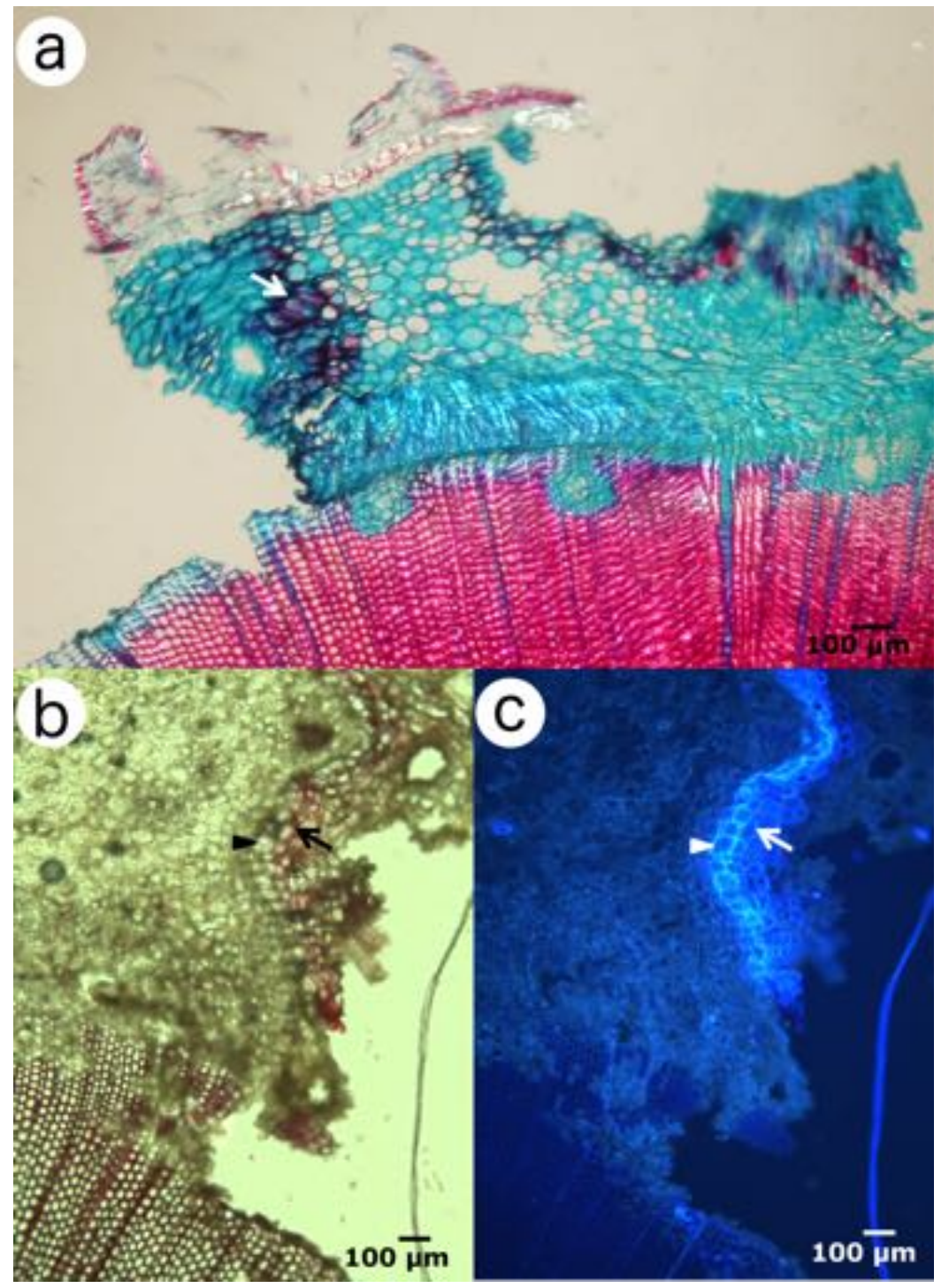

Figure 2. Lignification and suberization of cortical parenchymatous cells. A: Cross section of the lateral margin of a fenestration wound, 8 days after wounding, stained with safranine and alcian blue and seen in bright-field microscopy. Cortical parenchymatous cells in the border got lignified (arrow). B-C: Lateral edge of the wound seen by bright-field (B) and fluorescence microscopy (C), stained with phloroglucinol-HCl. Protective barrier of lignified (arrow) and suberized (arrowhead) parenchymatous cells in the cortex. Reddish staining under white light reveals the presence of lignin, while higher fluorescence intensity under UV light corresponds to suberin deposits in cell walls. 
1) Lignification and suberization of cortical parenchymatous cells. The first observable response was detected in the cortex, 8 days after wounding. Approximately 2-8 cells behind the lateral edge of the wound, a 3-5 cells wide line of parenchymatous cells got lignified (Figure 2A), providing a first barrier to minimize water loss and the possible entrance of opportunistic pathogens in the cortex, as first described by Mullick (Mullick 1975) for injuries in the bark of fir, hemlock and thuja. Seven days later, suberin is also detected (Figure 2B-C). This time of response is similar to the ones reported for other conifers (Rittinger et al. 1987, Wahlstrom and Johansson 1992). However, while for young twigs of Picea

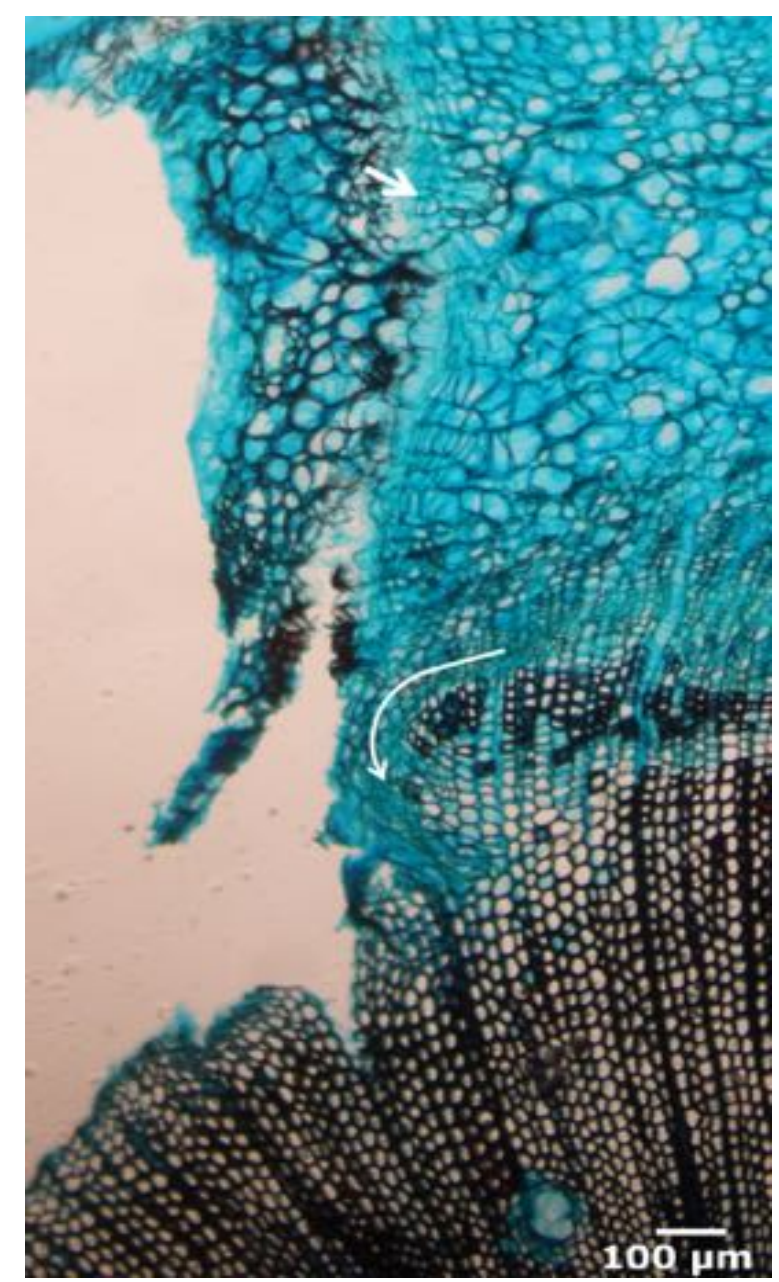

Figure 3. New traumatic periderm and initiation of healing callus. Cross section in bright-field microscopy of the lateral edge 15 days after wounding. New traumatic periderm (arrow) in the cortex. Proliferation in the cambial zone, curving the cambium inwards (white curved line). abies, Thuja orientalis or Metasequoia glyptostroboides just a tenuous lignification can be observed in the injury boundary seven-ten days after wounding (Rittinger et al. 1987), a layer of strongly suberized cortical parenchymatous cells is already detectable by that time in $P$. canariensis.

2) Development of traumatic periderm in the cortex. Two to four weeks after wounding a traumatic phellogen differentiates just behind the first lignified boundary and starts to divide (Figure 3). This traumatic periderm contacts with the original periderm and the llignified and suberized cells of the callus (see below), forming a continuous impervious barrier. The cells outside this phellem dry out and die, isolating 
the pathogens that could have infected the exposed cortical cells and blocking the infection.

3) Development of traumatic periderm in the cortex. Two to four weeks after wounding a traumatic phellogen differentiates just behind the first lignified boundary and starts to divide (Figure 3). This traumatic periderm contacts with the original periderm and the llignified and suberized cells of the callus (see below), forming a continuous impervious barrier. The cells outside this phellem dry out and die, isolating the pathogens that could have infected the exposed cortical cells and blocking the infection.

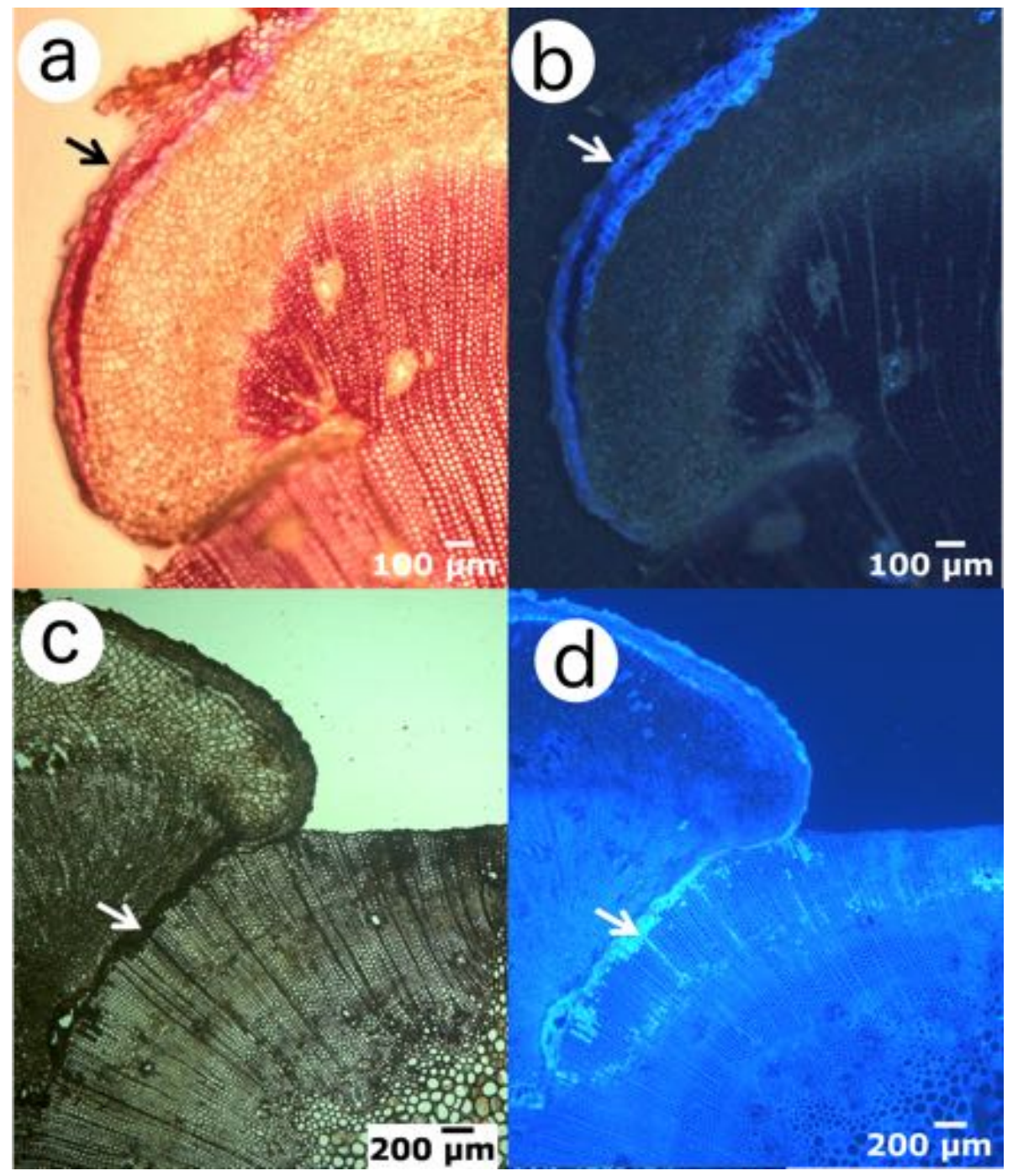

Figure 4. Progress of the healing callus. Cross sections of the lateral edge 28 days after wounding, in bright-field ( $A$ and $C$ ) and fluorescence microscopy (B and D), showing the new suberized periderm (A, B, arrows; stained with phlorogucinol-HCl). Close to the ventral part of the healing tissue, several xylem cells appear filled with tannins (C, D, arrow; stained with vanillin- $\mathrm{HCl}$ ). 
4) Initiation of a healing callus. Approximately at the same time as the formation of the traumatic periderm within the cortical parenchyma, initial proliferation in the cambial zone, close to the lateral edge of the wound, is also perceptible (Figure 3). The cambium twists inwards, heading the surface of the wound, probably due to a very high number of multiplicative, radial anticlinal divisions, which generate additional cambial cells, as discussed by Zajaczkowska (2014a) in P. sylvestris. The proportion of radial anticlinal divisions is related negatively with the distance to the healing border, i. e., they are more frequent near the border, and ultimately would lead to the reconstruction of the cambial circumference. Simultaneously, first periclinal divisions give rise to parenchymatous cells outwards, which form a protecting callus. As occurs with the first response in the cortical parenchyma, the outer part of this callus gets lignified and suberized. Soon after, a new traumatic phellogen differentiates in the outer part of the parenchymatous healing edge, developing a new periderm (Figure 4A-B). As reported by Oven \& Torelli (1999), no periderm is formed in the ventral part of the healing callus. In this surface, several tracheids are filled with tannins (Figure 4C-D).

5) Differentiation of vascular tissues. As the end of the cambium spreads further away towards the centre of the wound due to radial anticlinal divisions, new vascular tissues are generated by additive periclinal divisions of cambial cells. Xylem development via centripetal divisions forces the cambium to recover its normal position, parallel to the organ surface (Figure 5). This first traumatic xylem shows a high proportion of resin ducts, axial parenchyma, and irregular shaped tracheids, as already described for other species (e.g. Oven and Torelli 1999, Zajaczkowska 2014a, Arbellay et al. 2014). On its side, phloem starts to differentiate later than xylem.

6) Wound closure. The stages 3 and 4 may continue for several growing seasons (depending on the size of wound and vigour of the tree), making the lateral healing edges to grow over the wound surface, until they finally get in contact and merge. As described by Hamada et al. (2009), a high proportion of 
parenchymatous cells is appreciable in the ventral part of the traumatic xylem. The cells of the thin traumatic periderm and the parenchymatous callus cells in the edges collapse as cambium gets closed again and wood formation progresses in this area (Figure 6).

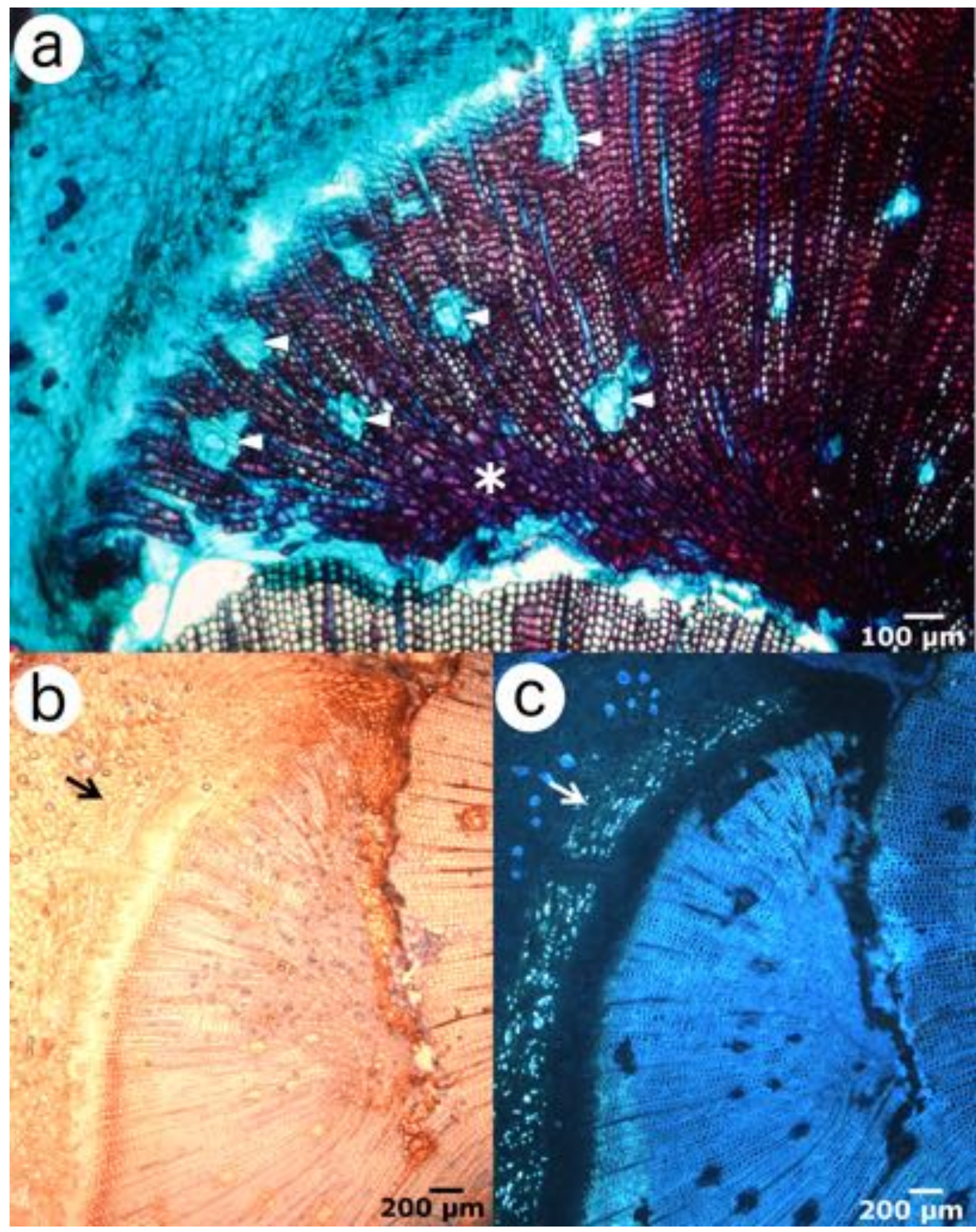

Figure 5. Differentiation of vascular tissues. A: Cross section in bright-field microscopy of the lateral edge 50 days after wounding. Healing vascular tissues show a high proportion of resin ducts (arrowheads), axial parenchyma and irregular shaped tracheids (asterisk). B-C: Cross sections after staining with aniline blue for callose detection in bright-field (B) and fluorescence microscopy (C) showing the presence of differentiated secondary phloem (arrow). 


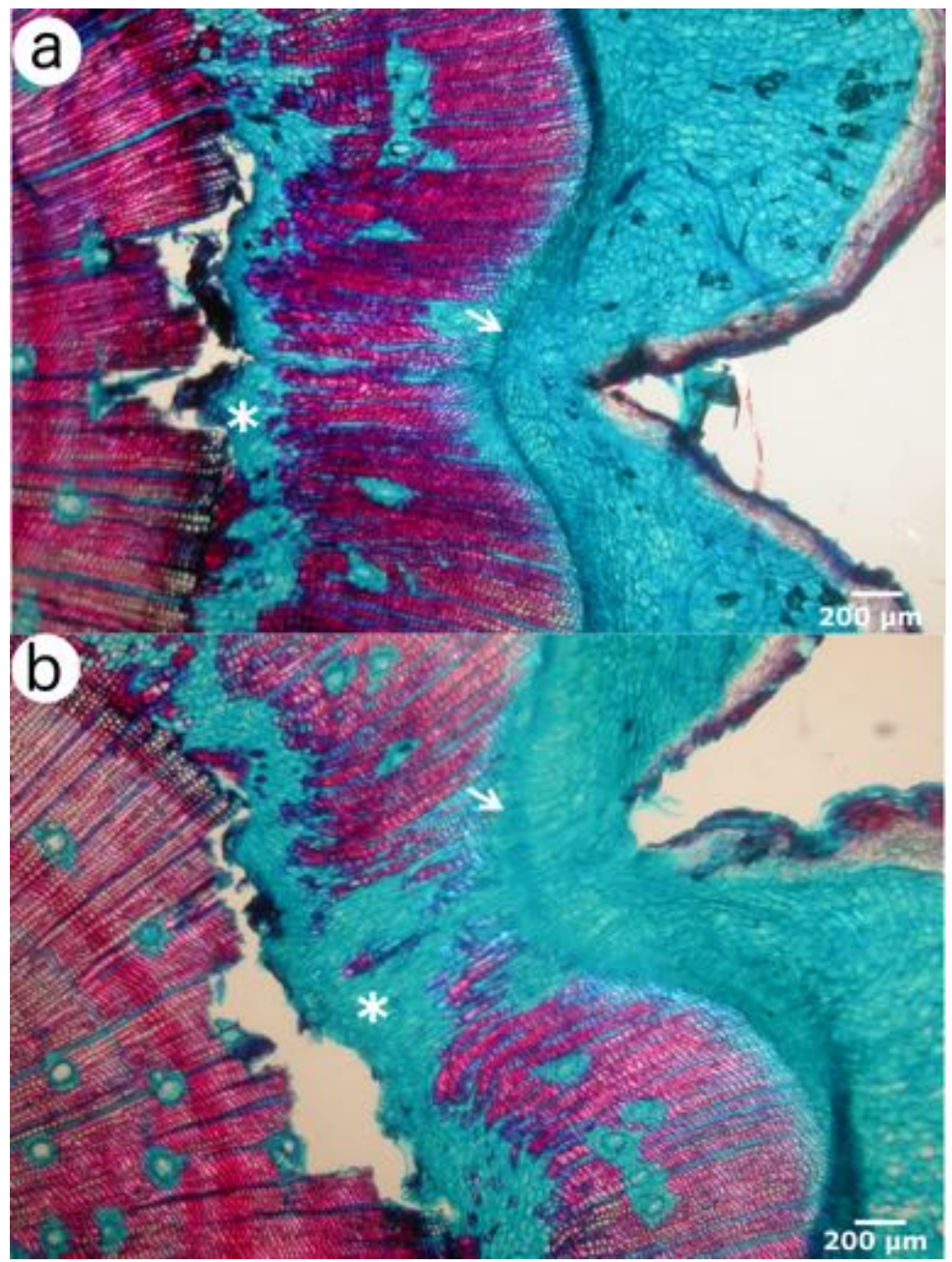

Figure 6. Wound closure. Microscopic view in bright-field microscopy of cross sections of a recently closed wound. Both lateral edges have met and the vascular cambium circumference is closed (arrows). A high proportion of parenchymatous cells in the ventral part of traumatic xylem is appreciable (asterisks).

\section{Wound closure from the upper margin}

When the stem is completely girdled and there is no lateral edge left, healing is expected to be accomplished from the upper and lower edges of the wound. These injuries are usually much more dangerous and difficult for the tree to overcome, 
since phloem sap flow is entirely interrupted by the wound. Most trees cannot survive such damage, even among angiosperms.

Conversely, after girdling, Pinus canariensis displays an active growth from the upper edge, being often able to reconnect the phloem and surmount the injury if the removed ring is not too wide. The sequence of tissue differentiation in the upper edge is similar to the one described for the lateral edges. However, this downwards process shows some differences, with easily recognizable steps (Figure 7).

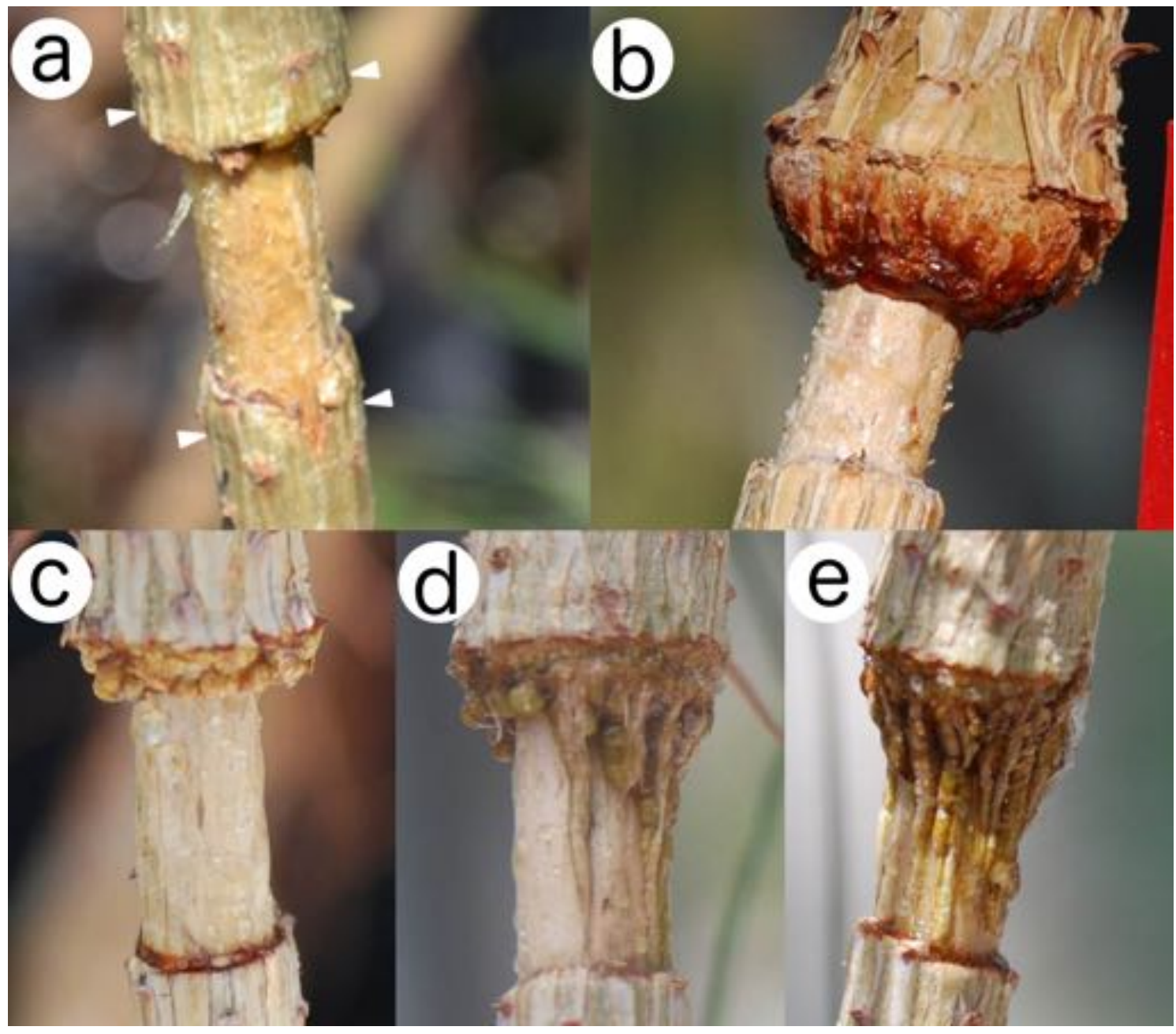

Figure 7. Macroscopic view of the healing process in girdled stems. A: Increase of stem diameter above the wound 10 days after girdling. B: First growth of parenchymatous tissue causes a bulge in the upper edge of the wound (40 days after girdling). C: Lumpy appearance 60 days after girdling, caused by the development of numerous protuberances in the upper edge. D: Column-like structures developed from the protuberances in the upper edge and axial parenchyma (see text for details) (100 days after girdling). E: Column-like structures reaching the lower margin and restoring the vascular connection (150 days after girdling). 


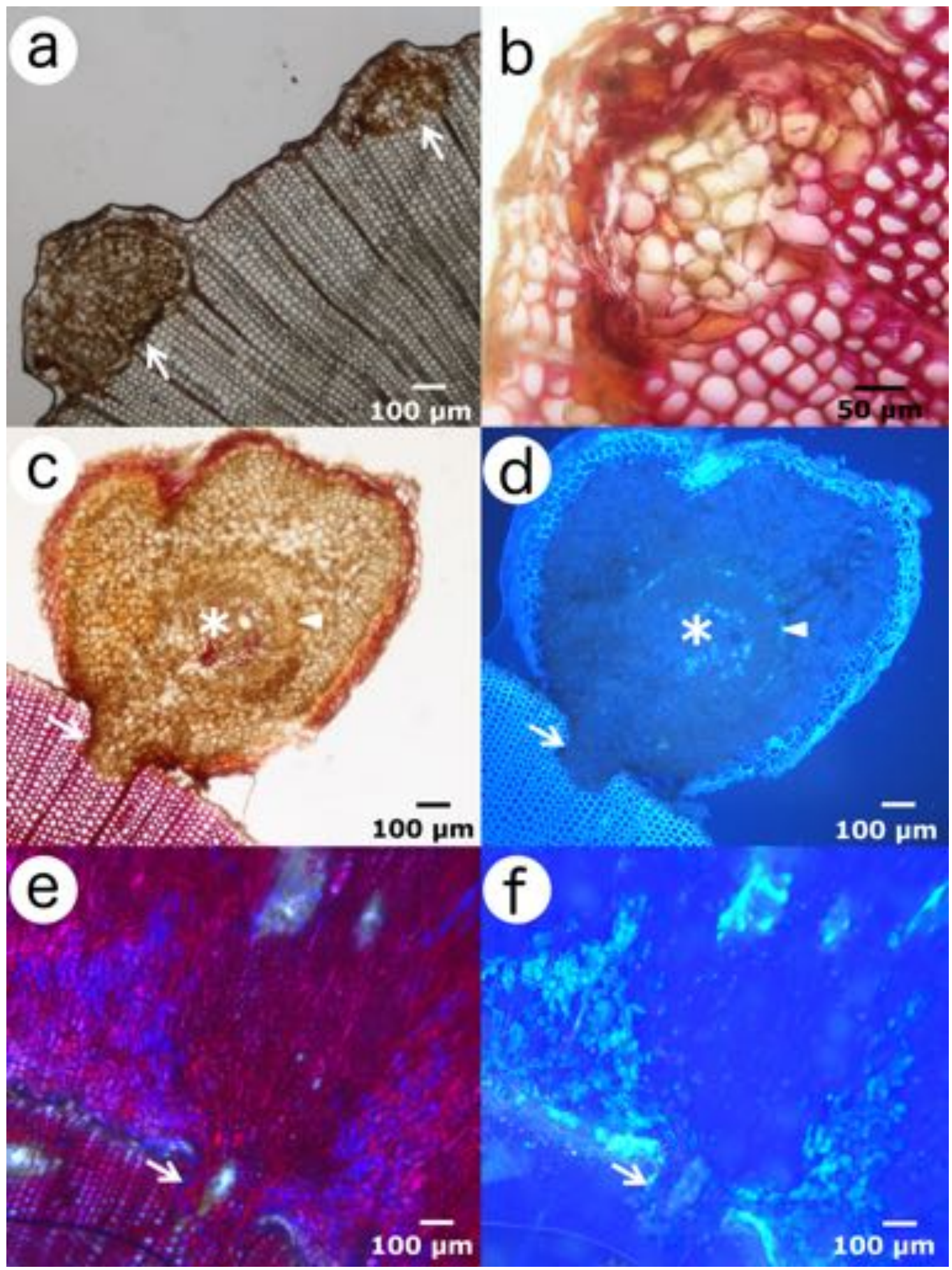

Figure 8. Microscopic view of the column-like structures. A-B: Early steps of development of column-like structures, in bright-field microscopy. C-D: Cross section of a column-like structure in bright-field (C) and fluorescence microscopy (D) showing differentiation of vascular tissues in a fanshapped disposition. At this stage, few cells are completely lignified (asterisk). Arrowhead in D indicates the position of phloem, stained with aniline blue. The arrows show the union zone with the pre-wound xylem. E-F: Cross sections in bright-field and fluorescence microscopy, respectively, showing a column-like structure embedded in the healing tissue. The arrow in both pictures indicates the union zone. 
1) Swelling of the upper section. Immediately after wounding sieve cells are sealed, hampering the loss of sap. The resulting sap accumulation leads to a conspicuous bulge in the upper part of the wound (Figure 7A, 10 days after girdling), as described by Singh et al. (2003) or de Schepper et al. (2010).

2) First traumatic growth. Shortly after that, a growing border analogous to the one produced in the lateral edges of fenestration wounds is formed in the upper edge (Figure 7B, 40 days after girdling). Conversely, no traumatic growth is detected in the lower margin, and even a slight reduction in diameter due to desiccation of the first layers of exposed cells can be observed, which can be related to the profuse resprouting induced below the injury in P. canariensis. In fenestration wounds, growth from the upper margin does not go further this step and final wound closure must be achieved from lateral edges, as described above.

3) Protuberances. Later on, the upper growing edge acquires a lumpy appearance, with the development of numerous protuberances in it (Figure 7C, 60 days after girdling).

4) Column-like structures. Those protuberances develop downwards in column-like structures, which eventually achieve the lower edge of the wound, restoring the vascular connection (Figure 7D-E, 100 and 150 days after girdling, respectively). These structures do not only develop through the basipetal growth of the protuberances in the upper edge. Instead, we have observed that they also originate 5-6 cells below the wound surface, by means of the proliferation of parenchymatous cells surrounding constitutive axial resin ducts (Figure 8). We observed a first proliferation of parenchymatous cells and an early development of a periderm in the outer face of this structure (Figure 8A-B). The growth of this structure makes it break through the remaining tracheids to the wound surface. Subsequently, a column of vascular tissues differentiates, which can be observed with an approximately semicircular shape in a cross section, with phloem surrounding the outer face of xylem (Figure 8C-D). Subsequent growth of woundwood from the upper edge finally engulfs these structures (Figure 8E-F). 
Chano, $V$ - Transcriptomics of the response to wounding

Interestingly, these structures have only been detected after girdling, and not in fenestration wounds. This observation is consistent with a hormonal control of the regeneration process. Thus, it is well known that a high cytokinin/auxin ratio can lead to the development of shoots from a callus, while the opposite can induce roots (Skoog and Miller 1957). In this case, the interruption of phloematic sap flow causes a noticeable increase of auxin in the upper margin on the wound and alters the cytokinins flow from the roots (Domec and Pruyn 2008), which can underlie the formation of protuberances and column-like structures.

Contrarily to Oven and Torelli (Oven and Torelli 1999) in mature trees of other conifer species, we have not detected perceptible proliferation from phloem cells, neither in fenestration nor in girdling wounds. In the same way, we have not detected hyperplasia and proliferation from radial cells in the wound surface, as reported in Populus tomentosa (Zhang et al. 2011b). Notwithstanding, radial parenchymatous cells keep their proliferating capability in pines. Thus, Kuroda and Shimaji (1984) described how after sticking a needle deep in the xylem and removing it, an axially oriented bubble is formed within the xylem, not exposed to open air; subsequently, affected radial parenchymatous cells proliferate, filling the bubble and, finally, forming a resin pocket. On the contrary, open wounds as the ones made here, debarking the stem, break preexisting axial and radial canals, whose resin covers immediately the wound surface, preventing the entry of pathogens, but hindering further proliferation from immature xylem cells and radial parenchyma in this area, as occurs in angiosperms.

Although Ballesteros et al. (2010) report that "Pinus do not normally form traumatic ducts and individual canals appear dispersed and only rarely in tangential bands", there is a noticeable increase in the formation of axial parenchyma and resin ducts in tangential rows in the healing tissues and surrounding the wound (appreciable in Figures 4 and 5), especially above it, as already reported for other conifers, as Pinus nigra (Luchi et al. 2005), Picea abies (Nagy et al. 2000, Stoffel 2008), Larix decidua (Bollschweiler et al. 2008, Stoffel 2008), Cedrus libani (Fahn et al. 1979). Actually, one of the main induced direct 
defenses in conifers after mechanical wounding, herbivore damage of fungal elicitation is the formation of traumatic resin ducts in the xylem, arranged in tangential rows (Krokene et al. 2008) and this is the basis of resin exploitation, an important industry in the past, superseded in the 20th century by the use of petroleum derivatives, but with increasing interest in the last years.

\section{Xylem and phloem differentiation}

A noticeable feature, differing from other species, is the delayed differentiation of traumatic phloem. While in angiosperms phloem reconnection is achieved shortly after wounding through the differentiation of phloem elements within the parenchymatous callus (as in Populus tomentosa, Zhang et al. 2011b) or even by transdifferentiation of immature xylem elements (as in Eucommia ulmoides, Pang et al. 2008), before the development of a new traumatic vascular cambium, we have observed that in $P$. canariensis wound phloem starts to differentiate only after xylem. After severe stem wounding, the plant still needs to supply with nutrients the living tissues below the injury for survival. Additionally, as reviewed by Clarke et al. (2013), one of the main factors enabling resprouting after trauma (a common response in angiosperms, but rare among gymnosperms, being $P$. canariensis a remarkable exception) is an efficient resourcing of a viable bud bank. In the same way, healing tissues also constitute an important resource sink. In fenestration wounds this supply could be accomplished by the remaining phloem on both sides of the injury. Nevertheless, in natural conditions $P$. canariensis endures large injuries, usually together with intense defoliations, as the ones caused by volcanic eruptions, so that very often foliage cannot provide enough nutrients to healing or resprouting tissues or to the root and stem below the injuries. In these cases, it is very likely that the reserves stored in the comparatively abundant radial and axial parenchyma (García Esteban et al. 2005), are used to provide these tissues with the required nutrients. However, if the damage is too intense or if the reserves are starved by previous, recent stresses, regeneration ability is reduced and the tree ultimately cannot heal the wound. 


\section{Orientation of healing tissues}

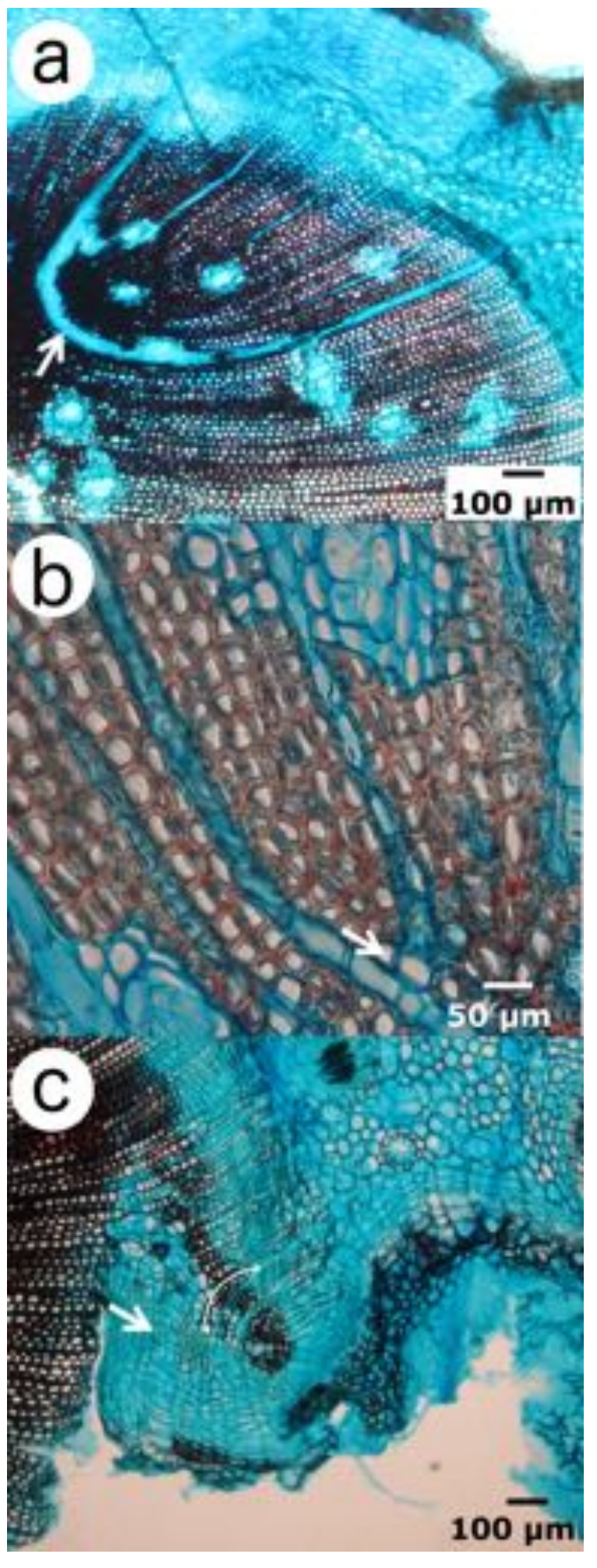

Figure 9. Abnormal orientation in healing tissues. A-B: Cross sections of lateral edges. The arrows indicate $\mathrm{U}$ - and Y-shaped rays, respectively. C: Cross section of a lateral edge few days after wounding. The white arrow indicates the thick parenchymatous callus developed inwards. The white curve line marks a U-shaped cell alignment.

Cambial cells must perceive somehow their position relative to the surface of the organ. Thus, additive divisions, which yield new xylem and phloem elements, usually take place according to a plane parallel to the surface of the organ, and they are also known as periclinal divisions. On the other side, multiplicative divisions, giving raise to new cambial cells, occur according to an axial anticlinal plane, perpendicular to the surface. Our results suggest that the position of the surface closest to the cambial zone determines the direction of periclinal and radial anticlinal divisions. Thus, close to the end of the wounded, open cambium, periclinal divisions go parallel to the wound lateral edge and perpendicular to the wound surface, and to normal, non-traumatic periclinal divisions. Nevertheless, due to the curvature of the cambium there can be a zone where the closest organ surface is detected in two different directions. In this case, 
sometimes a switch in the polarity of orientation of periclinal and radial anticlinal divisions takes place, leading to abnormal U- and Y-shaped arrays of cells coming from the same cambial initial. (Figure 9A-B).

Many works report the incidence of the alteration of hormone flux caused by wounds in the orientation, directionality of cell division and subsequent disorganization of wound xylem (e.g., auxins are involved in the specification of polarity in primary meristems, as reviewed by Berleth and Sachs in 2001; ethylene production is induced by mechanical stress, as reported by Telewski and Jaffe in 1986, in P. taeda). However, mechanoperception also determines the directionality of divisions, as shown in thigmomorphogenesis studies and reviewed by Telewski (2006). The eminent work of Brown and Sax (1962) shows that mechanoperception of the pressure exerted by surrounding cells determines the differentiation of phloem and xylem. Our results support the involvement of mechanoperception in the alteration of the normal pattern of cambium additive divisions, probably concomitantly with hormone flux and maybe even other factors, such as, for instance, the incidence of light.

If the injury penetrates in the xylem, parallel to the cambium, a similar switch in the direction of divisions can take place, and the very first multiplicative division can occur inwards; further periclinal additive divisions producing xylem will separate cambial cells, giving rise to U-shaped cell alignments in the xylem and forcing the cambium to acquire a "hairpin" shape (Figure 9C). The inner part of the "cambial hairpin" undergoes additive divisions inwards, producing a comparatively large cells, with thin primary cellulosic walls, consistently with the results of Brown \& Sax (1962) for P. strobus. In that work, after partially removing a longitudinal strip of bark, keeping it attached at the acropetal end, the vascular cambium in the inner face of the strip produced a parenchymatous callus inwards. In our case, these divisions are very profuse, resulting in a thick callus advancing from the side edges to the center of the wound surface. These cells, coming from the vascular cambium, are not as disordered as the callus formed in angiosperm, which comes from the proliferation of radial parenchyma or 
Chano, $V$-Transcriptomics of the response to wounding

immature xylem elements (Stobbe 2002, Pang et al. 2008, Zhang et al. 2011b). On the contrary, these cells in $P$. canariensis appear aligned perpendicularly to the surface, as corresponds to the result of periclinal divisions of the cambium (Figure 9C).

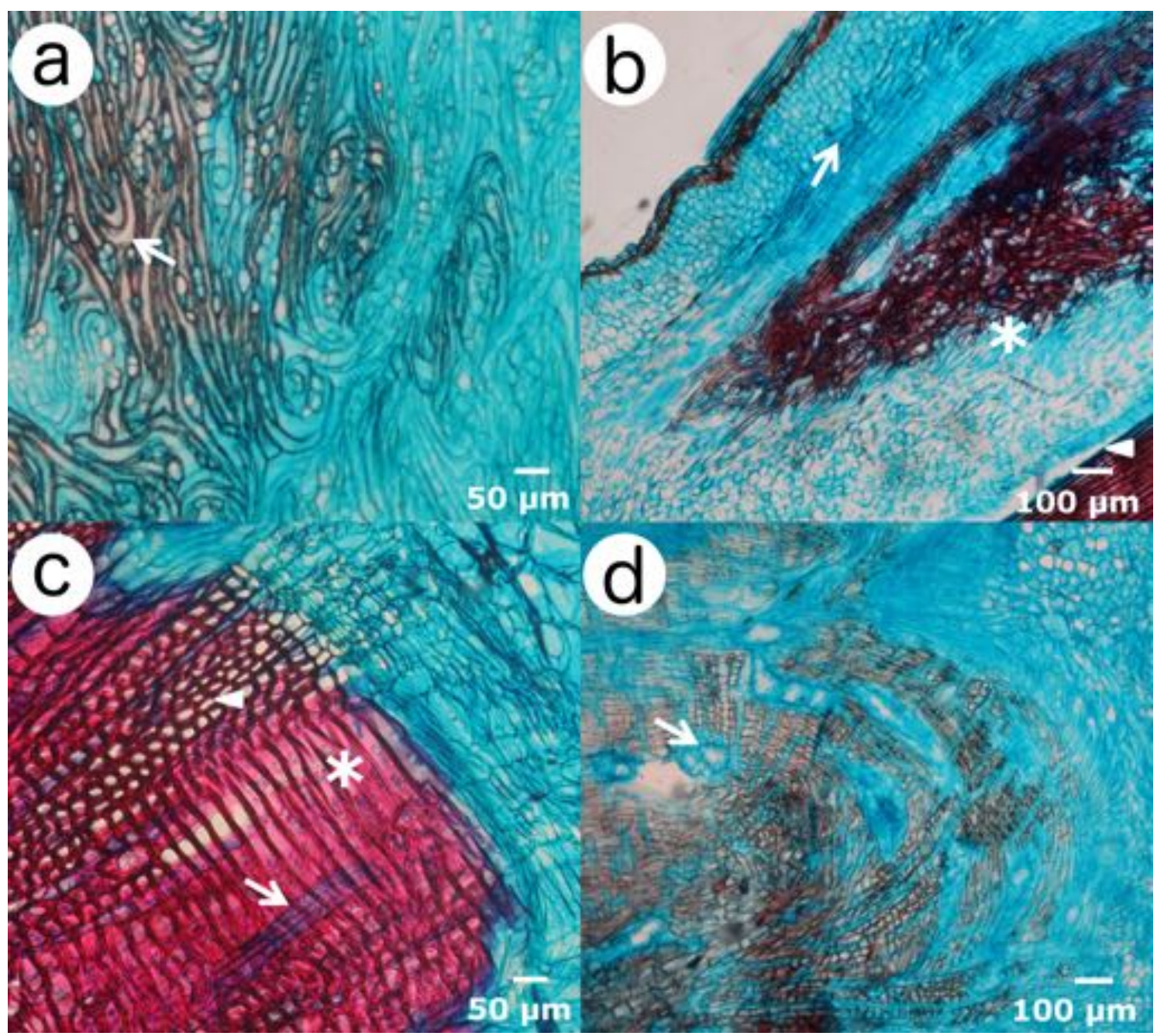

Figure 10. De-orientation of tracheids. A: Irregular and de-oriented tracheids (arrow), as seen in a tangential section of a healing upper margin B: Radial section of a column-like structure, showing the wound surface (arrowhead), the ventral zone with disordered tracheids and parenchymatous cells (asterisk) and normal, axially oriented xylem and phloem, (arrow), as well as the outer periderm. C: Series of axial tracheids (arrowhead) next to horizontally disposed tracheids (asterisk) and radius (arrow) in a cross section. D: Resin ducts tangentially oriented (arrows), as seen in a radial section of the upper margin.

In the irregular upper margin of girdling wounds and in the extreme of columnlike structures highly crooked and disordered tracheids develop (Figure 10A). This feature can be due to the perception of surface in different direction and to the altered hormone flux, as reported by Sachs \& Cohen (1982) or Kurczynska and 
Heinowicz (1991). This process can ultimately lead even to the differentiation of radial series of normal, axially oriented tracheids next to tangentially oriented ones. In these regions, also tangential resin ducts are developed, perpendicular both to axial and radial canals (Figure 10B-D).

Malformation and disorganization of tracheids in woundwood, as well as the later recovery of a normal pattern has been recently described in fire scars in different conifers (Arbellay et al. 2014) or in mechanical injuries in the stem of Pinus sylvestris (Zajaczkowska 2014a), or even in overgrown stumps of felled Pseudotsuga menziensii (Zajaczkowska 2014b). This disorganized xylem, with an increased proportion of resin ducts and associated parenchyma imply an evident disadvantage for the circulation of water and nutrients through the traumatic xylem (Arbellay et al. 2014). However, the fast restoration of the proper cambial polarity after reconnection allows the stem to successfully recover its hydraulic efficiency and surmount the injury. Meanwhile, if the injury is not too deep, water can be transported via the xylem of the previous years, which in conifers remain fully functional for several years, as well as through the unwounded sector of the stem.

\section{CONCLUSION}

Vigorous and fast healing ability makes $P$. canariensis a suitable model species for the study of the response to wound stress in conifers. Thus, we have detected a faster response than previously reported for other gymnosperms with an initial lignification and suberization of cortical parenchymatous cells and the development of a traumatic periderm in the cortex. Conversely to angiosperms, the wound margins constitute the main regenerating focuses, through increased periclinal and radial anticlinal divisions of the cambium, while no significant proliferation from other tissues, such as phloem or radial parenchyma, has been detected.

More interestingly, this work includes the first description of column-like structures, developed after girdling, developed both from the upper healing 
Chano, $V$-Transcriptomics of the response to wounding

margin and from the resin duct-associated parenchymatous cells below the wound surface. These structures enable fast reconnection of the vascular tissues, being subsequently embedded by the advance of the upper healing edge; additionally, they anchor the healing tissue to the wound surface.

Cambial cells perceive the relative position of the surface of the stem, which drives the orientation of additive and multiplicative divisions, and, together with altered hormone flux, leads to the formation of disordered traumatic xylem in the woundwood. While perception of verticality by plant cells (for instance, by the action of amyloplasts and/or hydrostatic gravisensing and polarly localized PIN proteins, causing geotropism in the root tip) is comparatively well known, as well as some molecular aspects of the polar differentiation of xylem and phloem (reviewed in Schuetz et al. 2013, or Prasad and Dhonukshe 2013), the exact mechanism underlying this "horizontal" perception remains unrevealed. Although it is probably related to hormone flux and to the pressure exerted by surrounding cells, the involvement of other factors cannot be excluded. Further research is needed to clarify this point. 


\title{
Chapter 3.
}

\section{Transcriptomic analysis of wound xylem formation in Pinus}

\section{canariensis}

\author{
Chano V, Collada C, Soto A.
}

G.I. Genética, Fisiología e Historia Forestal. ETSI Montes, Forestal y del Medio Natural. Dpto. Sistemas y Recursos Naturales. Universidad Politécnica de Madrid. Ciudad Universitaria s/n 28040 Madrid, Spain

Published in BMC Plant Biology, 2017; 17:234, DOI 10.1186/s12870-017-1183-3

\begin{abstract}
Background. Woody plants, especially trees, usually must face several injuries caused by different agents during their lives. Healing of injuries in stem and branches, affecting the vascular cambium and xylem can take several years. In conifers, healing takes place mainly from the remaining vascular cambium in the margin of the wound. The woundwood formed in conifers during healing usually presents malformed and disordered tracheids as well as abundant traumatic resin ducts. These characteristics affect its functionality as water conductor and its technological properties.
\end{abstract}

Results. In this work we analyze for the first time the transcriptomic basis of the formation of traumatic wood in conifers, and reveal some differences with normal early- and latewood. Microarray analysis of the differentiating traumatic wood, confirmed by quantitative RT-PCR, has revealed alterations in the transcription profile of up to 1408 genes during the first healing. We have grouped these genes in twelve clusters, according to their transcription profiles, and have distinguished accordingly two main phases during the first healing.

Conclusions. Wounding induces a complete rearrangement of the transcriptional program in the cambial zone close to the injuries. At the first instance, radial growth is stopped, and a complete set of defensive genes, mostly related to biotic 
Chano, $V$-Transcriptomics of the response to wounding

stress, are induced. Later on, cambial activity is restored in the lateral borders of the wound, even at a high rate. During this second stage certain genes related to earlywood formation, including genes involved in cell wall formation and transcription factors, are significantly overexpressed, while certain latewood related genes are repressed. Additionally, significant alterations in the transcription profile of abundant non annotated genes are reported.

Keywords: Wound, Healing, Conifers, Transcriptome, Wood, Pinus canariensis

\section{INTRODUCTION}

Organisms usually suffer injuries throughout their life. In multicellular organisms these injuries can cause the damage or loss of differentiated tissues or organs, and ease the entry and spread of pathogens. The analysis of the similarities and differences in the regeneration process in animals and plants has been on the spotlight in recent years (Birnbaum and Sánchez Alvarado 2008, Sugimoto et al. 2011, Sánchez Alvarado and Yamanaka 2014). Animals can often regenerate these damaged tissues and even, in certain cases, the lost organs, and due to constant regeneration of certain tissues such as skin, eventually no signal of the injury remains after some time.

On their side, plants do not regenerate continuously their tissues. Proliferation is usually limited to certain niches: the root and shoot apical meristems (including axillary buds) and the vascular cambium and the phellogen in woody plants. If damage occurs, the plant generates new tissues and organs from these meristems or eventually develops new meristematic niches from living cells, usually parenchymatic ones (Sena et al. 2009, Sena and Birnbaum 2010). This is the case of the traumatic periderms developed, for instance, from cortical parenchyma or from mesophyll to seal a wound in a young stem or a leave.

When a woody branch or stem suffers a deep wound, affecting the secondary xylem, the vascular cambium must be restored. In certain angiosperms proliferation from xylem parenchyma or from immature xylem conducting 
elements has been described, as in Tilia (Stobbe 2002), Eucommia (Pang et al. 2008) or Populus (Zhang et al. 2011b). These cells can reverse their differentiation pathway and divide profusely, giving rise to a parenchymatic callus. Later on, a new, traumatic vascular cambium differentiates within this callus, and new secondary xylem and phloem are produced.

On the contrary, this proliferation from (partially) differentiated cells is not usual in conifers. In these species healing takes place mainly from the remaining vascular cambium in the margins of the wound, as described in Chapter 2 for Pinus canariensis (Chano et al. 2015).

Anyway, the traumatic wood formed this way can be easily distinguished from normal wood. Traumatic wood usually presents malformed tracheary elements and fibers, with altered lignification patterns, and with a high proportion of parenchymatic cells. Orientation of these elements is also very often distorted (Zajaczkowska 2014a, 2014b, Arbellay et al. 2014, Chano et al. 2015), probably due to altered hormonal flux, and also to altered mechanical signals, as suggested in Chapter 2 (Chano et al. 2015). This disorganized xylem implies an evident disadvantage for water and nutrient transport (Arbellay et al. 2014). In the case of conifers, especially Pinaceae, traumatic wood also presents a very high proportion of resin ducts, as described for Cedrus libani (Fahn et al. 1979), Larix decidua (Bollschweiler et al. 2008, Stoffel 2008), Picea abies (Nagy et al. 2000, Stoffel 2008), Pinus nigra (Luchi et al. 2005) or Pinus pinaster (Rodríguez-García et al. 2014). Actually, formation of traumatic resin ducts is the basis of traditional resin exploitation, very common in the past for several species of Mediterranean pines, and with increasing interest in the last years (Rodríguez-García et al. 2014).

Since plants do not renew their secondary xylem, but generate new sheets of xylem, centrifugally, year after year, traumatic xylem also remains in the damaged branch or stem, leaving a "scar" in the wood. These scars have proven to be very useful, for instance, for dendrochronology studies (Stoffel 2008, Stoffel and Klinkmüller 2013). However, traumatic wood presents undesirable 
Chano, $V$-Transcriptomics of the response to wounding

characteristics from a technological point of view. Although the higher density due to the increase in resin content can improve certain mechanical qualities of wood it also causes problems at machining and blunting (García-Iruela et al. 2016). In addition, disordered and not properly formed traumatic tracheids contribute to alter the physico-mechanical properties of wood. Therefore, lumber dealers consider traumatic wood as a defect, lowering the price and reducing the applicability of wood pieces with important scars.

Several works have focused in the consequences of traumatisms on wood development in conifers: early-late wood ratio, ring width, formation of traumatic resin ducts (Gärtner and Heinrich 2009, Schneuwly et al. 2009b, 2009a, Ballesteros et al. 2010, Arbellay et al. 2014), and a few others in the description of the healing process from an anatomical point of view (Mullick 1975, Oven and Torelli 1994, 1999, Chano et al. 2015). However, although the molecular aspects of the response to traumatism has been analysed in different angiosperms (f.i., Wan et al. 2006, Xu et al. 2006, Sena et al.2009, Sugimoto et al. 2010, Asahina et al. 2011), the process has been less studied in gymnosperms, where most works have focused in the induction of traumatic resin ducts by traumatism, insect attack or fungal infections (Fäldt et al. 2003, Mckay et al. 2003, Krokene et al. 2008, Zulak and Bohlmann 2010). In this work we focus on the molecular basis of traumatic wood formation in a gymnosperm, $P$. canariensis, known for its extraordinary healing ability. For this purpose, we have performed deep wounds in the stem of $P$. canariensis trees, affecting the vascular cambium, and have assessed the transcriptomic profile during the healing process and traumatic wood growth.

\section{RESULTS AND DISCUSSION}

\section{Identification of genes induced and repressed in response to wounding}

In order to analyse the transcriptomic response in the cambial zone and differentiating xylem in the borders of deep wounds performed in the stem of pine trees, we hybridized a 60K two-color cDNA microarray (Agilent, USA) which includes genes involved in $P$. canariensis xylogenesis described in Chapter 1 
(Chano et al. 2017b). Samples were collected at three dates during wound response: i) $\mathrm{H} 1$ was collected seven days after wounding, ii) $\mathrm{H} 2$ after 75 days, when development of traumatic wood was evident and while the trees outside the wound area were still forming early wood, and finally iii) H3 92 days after wounding, when the trees were already forming late wood. Controls for each sample were collected at the same sampling dates from branches distant from the wound, in order to distinguish local effects caused by wound response from constitutive changes in gene expression during the vegetative season.
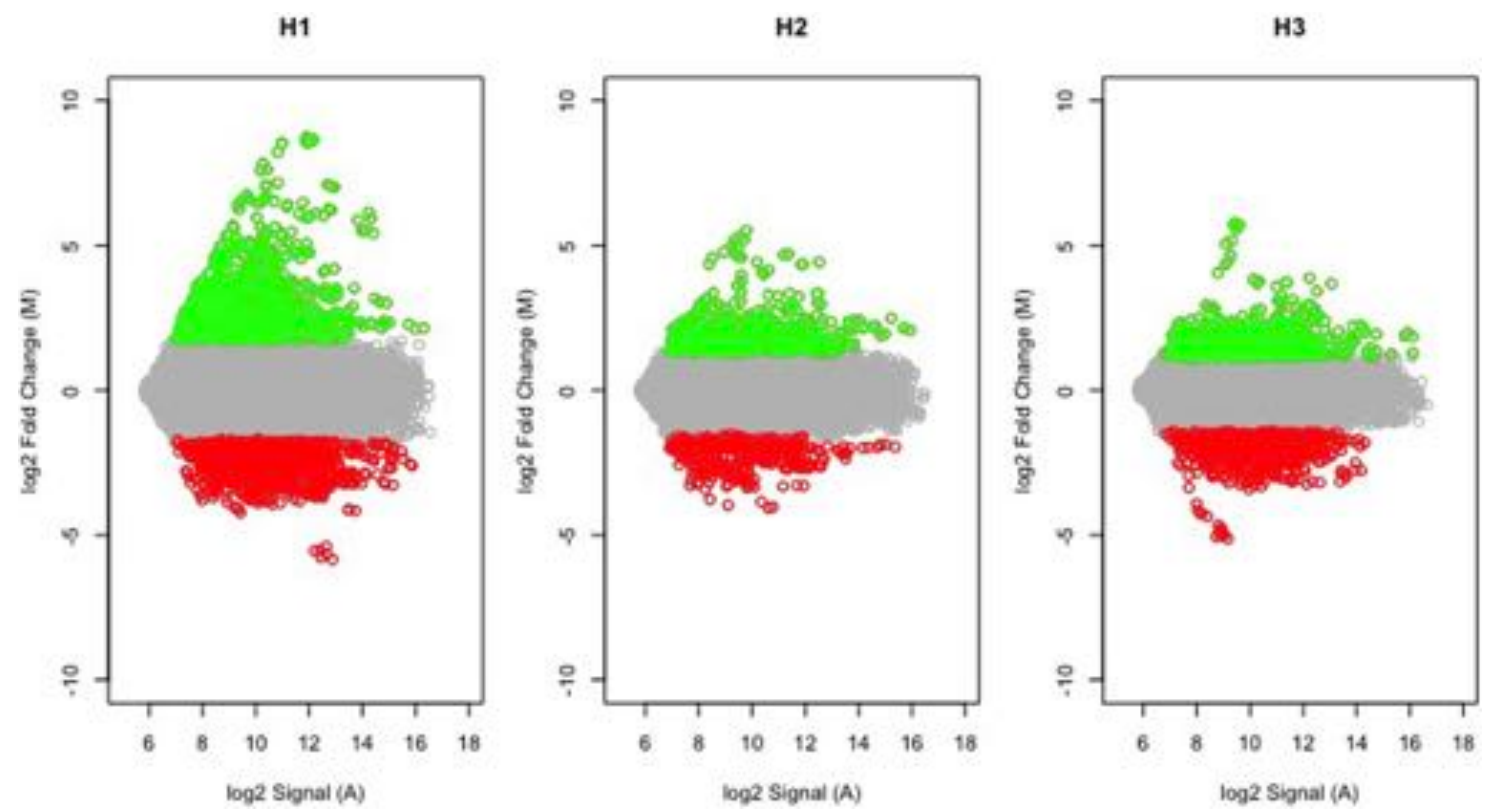

Figure 1. MA plot of microarray normalized data during wound-response. X-axis: Log2 of microarray signals; $Y$-axis: Log2 of Fold Change values; Green dots: probes selected as overexpressed (FC $>2$, FDR $<0.05$, between treatment and control RNA samples); Red dots: probes selected as underexpressed (FC $<-2$, FDR $<0.05$ between treatment and control RNA samples).

Figure 1 shows the distribution of genes selected as over- and underexpressed at each sampling point. We identified 1408 differentially expressed genes (DEG), genes significantly overexpressed or repressed compared to normal wood formation. Table 1 shows a selection of 91 DEGs with the strongest response (induction or repression), grouped following the functional processes they are presumably related to, according to their top BLASTx hit, as previously described in Chapter 1 (Chano et al. 2017b). The complete table can be found in a supplementary table (Additional file 1). 


\section{Chano, $V$ - Transcriptomics of the response to wounding}

Tabla 1. Selected wound-responsive DEGs, grouped according to their putative role and their expression profile clustering.

\begin{tabular}{|c|c|c|c|c|c|c|c|c|}
\hline \multirow[t]{2}{*}{ Cluster } & \multirow[t]{2}{*}{ ID } & \multirow[t]{2}{*}{ Seq. Description } & \multicolumn{2}{|l|}{ H1 } & \multicolumn{2}{|l|}{ H2 } & \multicolumn{2}{|l|}{ H3 } \\
\hline & & & FC & FDR & FC & FDR & FC & FDR \\
\hline \multicolumn{9}{|c|}{ Defense and stress response genes } \\
\hline $\mathbf{A}$ & Contig18804 & $\begin{array}{l}\text { disease resistance response } \\
\text { protein 206-like }\end{array}$ & 395.78 & 0.00 & 37.14 & 0.00 & 52.52 & 0.00 \\
\hline A & Contig19053 & $\begin{array}{l}\text { pathogenesis-related protein pr- } \\
\text { 4b-like }\end{array}$ & 96.55 & 0.00 & 23.91 & 0.00 & 19.77 & 0.00 \\
\hline A & Contig22185 & major allergen pru ar 1-like & 138.29 & 0.00 & 13.75 & 0.00 & 4.94 & 0.01 \\
\hline $\mathbf{A}$ & Contig22375 & $\begin{array}{l}\text { pathogenesis-related protein pr-4- } \\
\text { like }\end{array}$ & 343.24 & 0.00 & 7.69 & 0.00 & 7.38 & 0.00 \\
\hline A & Ppnisotig12265 & antimicrobial peptide 1-like & 72.52 & 0.00 & 16.88 & 0.00 & 12.84 & 0.00 \\
\hline A & Ppnisotig13133 & $\begin{array}{l}\text { pathogenesis-related protein pr-4- } \\
\text { like }\end{array}$ & 206.36 & 0.00 & 6.43 & 0.00 & 5.13 & 0.00 \\
\hline A & Ppnisotig13431 & $\begin{array}{l}\text { disease resistance response } \\
\text { protein 206-like }\end{array}$ & 133.78 & 0.00 & 24.75 & 0.00 & 31.68 & 0.00 \\
\hline B & Contig00602 & defensin ec-amp-d2-like & 11.27 & 0.00 & 2.07 & 0.12 & -1.42 & 0.65 \\
\hline B & Contig02906 & nematode resistance hspro2-like & 7.81 & 0.01 & -1.23 & 0.94 & -2.12 & 0.11 \\
\hline B & Contig03079 & $\begin{array}{l}\text { lactoylglutathione lyase glyoxalase } \\
\text { i family protein }\end{array}$ & 3.96 & 0.04 & 1.97 & 0.20 & -1.36 & 0.75 \\
\hline B & Contig09180 & thioredoxin h-type & 6.82 & 0.01 & 1.52 & 0.44 & 1.39 & 0.55 \\
\hline B & Contig19857 & nematode resistance hspro2-like & 9.88 & 0.00 & -1.33 & 0.83 & -2.56 & 0.06 \\
\hline $\mathbf{B}$ & Contig20555 & phenylalanine ammonia-lyase-like & 14.41 & 0.00 & 3.19 & 0.03 & -1.08 & 1.11 \\
\hline C & Contig13499 & $\begin{array}{l}\text { (-)-camphene tricyclene } \\
\text { chloroplastic-like }\end{array}$ & 2.17 & 0.17 & 2.14 & 0.12 & 2.81 & 0.01 \\
\hline D & Contig00126 & basic endochitinase a-like & 15.25 & 0.00 & -1.20 & 0.55 & 0.34 & 1.13 \\
\hline D & Contig10307 & endochitinase a-like & 65.05 & 0.00 & 3.40 & 0.02 & 1.49 & 0.47 \\
\hline D & Contig17617 & defensin ec-amp-d2-like & 44.89 & 0.00 & 1.32 & 0.40 & -1.23 & 0.69 \\
\hline D & Contig21216 & endochitinase a-like & 92.45 & 0.00 & 2.28 & 0.08 & 2.51 & 0.02 \\
\hline D & Contig23442 & chitinase 1-like & 29.31 & 0.00 & 2.12 & 0.37 & -1.65 & 0.41 \\
\hline D & Ppnisotig00751 & endochitinase pr4-like & 85.39 & 0.00 & 3.16 & 0.02 & 1.28 & 0.78 \\
\hline $\mathbf{D}$ & Ppnisotig01747 & peroxidase 12 -like & 97.76 & 0.00 & 1.74 & 0.28 & 1.53 & 0.37 \\
\hline D & Ppnisotig06171 & glutathione s-transferase f9-like & 41.49 & 0.00 & 2.48 & 0.05 & 1.55 & 0.36 \\
\hline $\mathbf{D}$ & Ppnisotig08058 & endochitinase pr4-like & 89.60 & 0.00 & 1.15 & 1.04 & 1.12 & 1.08 \\
\hline $\mathbf{H}$ & Contig03270 & $\begin{array}{l}\text { geranylgeranyl pyrophosphate } \\
\text { chloroplastic-like }\end{array}$ & 1.61 & 0.46 & 1.48 & 0.45 & 2.57 & 0.03 \\
\hline $\mathbf{H}$ & Contig08417 & $\begin{array}{l}\text { abietadienol abietadienal oxidase- } \\
\text { like }\end{array}$ & 1.10 & 1.12 & 2.08 & 0.11 & 2.64 & 0.02 \\
\hline $\mathbf{H}$ & Ppnisotig10634 & $\begin{array}{l}\text { geranylgeranyl pyrophosphate } \\
\text { chloroplastic-like }\end{array}$ & -1.26 & 1.00 & 2.54 & 0.04 & 2.92 & 0.01 \\
\hline
\end{tabular}




\begin{tabular}{|c|c|c|c|c|c|c|c|c|}
\hline \multicolumn{9}{|c|}{ Cell-wall matrix development and/or carbohydrates metabolism } \\
\hline G & Contig06476 & caffeoyl- o-methyltransferase & -1.27 & 0.97 & -3.59 & 0.04 & -1.44 & 0.61 \\
\hline G & Contig15857 & cellulose synthase-like protein d3 & 1.38 & 0.78 & -1.14 & 1.08 & -3.00 & 0.04 \\
\hline G & Contig17013 & $\begin{array}{l}\text { probable xyloglucan } \\
\text { endotransglucosylase hydrolase } \\
\text { protein } 23\end{array}$ & -1.24 & 0.93 & -6.29 & 0.00 & -7.64 & 0.00 \\
\hline G & Contig21865 & $\begin{array}{l}\text { galactinol--sucrose } \\
\text { galactosyltransferase-like }\end{array}$ & 2.27 & 0.18 & -2.03 & 0.21 & -3.39 & 0.03 \\
\hline $\mathbf{H}$ & Contig00603 & $\begin{array}{l}\text { beta-xylosidase alpha-l- } \\
\text { arabinofuranosidase 2-like }\end{array}$ & -0.57 & 1.10 & 2.46 & 0.07 & 2.58 & 0.03 \\
\hline $\mathbf{H}$ & Contig03225 & expansin alpha & -2.10 & 0.20 & 2.64 & 0.04 & 1.99 & 0.13 \\
\hline $\mathbf{H}$ & Contig05066 & probable pectate lyase 15 -like & -5.21 & 0.01 & 2.08 & 0.20 & 3.24 & 0.01 \\
\hline $\mathbf{H}$ & Contig05424 & $\begin{array}{l}\text { probable xyloglucan } \\
\text { endotransglucosylase hydrolase } \\
\text { protein 8-like }\end{array}$ & -1.78 & 0.37 & 2.55 & 0.04 & 2.18 & 0.06 \\
\hline $\mathbf{H}$ & Contig09907 & $\begin{array}{l}\text { probable xyloglucan } \\
\text { endotransglucosylase hydrolase } \\
\text { protein } 32\end{array}$ & -1.86 & 0.32 & 2.14 & 0.09 & 2.95 & 0.01 \\
\hline $\mathbf{H}$ & Contig10173 & endoglucanase 24-like & -3.26 & 0.05 & 1.58 & 0.46 & 2.58 & 0.03 \\
\hline $\mathbf{H}$ & Contig13281 & probable pectinesterase 68-like & -1.56 & 0.60 & 2.18 & 0.09 & 3.40 & 0.01 \\
\hline $\mathbf{H}$ & Contig18777 & endoglucanase 24-like & -1.69 & 0.41 & 2.54 & 0.04 & 5.32 & 0.00 \\
\hline $\mathbf{H}$ & Contig18811 & expansin alpha & -1.59 & 0.58 & 3.42 & 0.01 & 4.98 & 0.00 \\
\hline I & Contig00766 & $\begin{array}{l}\text { xyloglucan endotransglucosylase } \\
\text { hydrolase protein 9-like }\end{array}$ & -17.49 & 0.00 & -1.36 & 0.72 & -1.24 & 0.78 \\
\hline $\mathbf{I}$ & Contig02447 & caffeoyl- o-methyltransferase-like & -6.41 & 0.01 & 1.17 & 0.75 & -1.58 & 0.34 \\
\hline $\mathbf{I}$ & Contig03231 & probable carboxylesterase 15 -like & -4.22 & 0.03 & -1.63 & 0.38 & -1.39 & 0.68 \\
\hline I & Contig08356 & udp-glycosyltransferase 85a2-like & -44.90 & 0.00 & 1.62 & 0.28 & 1.45 & 0.46 \\
\hline I & Contig11436 & $\begin{array}{l}\text { probable polygalacturonase non- } \\
\text { catalytic subunit jp650-like }\end{array}$ & -13.41 & 0.00 & 1.46 & 0.47 & 1.52 & 0.44 \\
\hline $\mathbf{I}$ & Contig13611 & $\begin{array}{l}\text { beta-xylosidase alpha-l- } \\
\text { arabinofuranosidase 2-like }\end{array}$ & -4.92 & 0.02 & 0.35 & 1.08 & 1.39 & 0.56 \\
\hline I & Contig19457 & $\begin{array}{l}\text { xyloglucan endotransglucosylase } \\
\text { hydrolase protein 9-like }\end{array}$ & -14.61 & 0.00 & -1.41 & 0.66 & -1.31 & 0.68 \\
\hline $\mathbf{L}$ & Contig00654 & $\begin{array}{l}\text { cellulose synthase a catalytic } \\
\text { subunit } 3\end{array}$ & -8.70 & 0.00 & -1.86 & 0.26 & -1.57 & 0.54 \\
\hline $\mathbf{L}$ & Contig01405 & protein cobra-like & -6.74 & 0.01 & -2.06 & 0.20 & -2.27 & 0.09 \\
\hline $\mathbf{L}$ & Contig01916 & $\begin{array}{l}\text { xyloglucan glycosyltransferase 4- } \\
\text { like }\end{array}$ & -1.45 & 0.71 & -1.36 & 0.60 & -4.36 & 0.01 \\
\hline \multicolumn{9}{|c|}{ Hormone signalling } \\
\hline B & Contig00715 & $\begin{array}{l}\text { 1-aminocyclopropane-1- } \\
\text { carboxylate oxidase-like }\end{array}$ & 5.91 & 0.01 & 1.63 & 0.51 & 1.77 & 0.19 \\
\hline B & Contig03482 & $\begin{array}{l}\text { salicylic acid-binding protein 2- } \\
\text { like }\end{array}$ & 5.92 & 0.01 & 1.99 & 0.14 & 1.40 & 0.57 \\
\hline
\end{tabular}




\section{Chano, $V$-Transcriptomics of the response to wounding}

\begin{tabular}{|c|c|c|c|c|c|c|c|c|}
\hline C & Contig00524 & $\begin{array}{l}\text { 1-aminocyclopropane-1- } \\
\text { carboxylate oxidase-like }\end{array}$ & 1.69 & 0.38 & 3.80 & 0.02 & 2.65 & 0.02 \\
\hline C & Ppnisotig12073 & $\begin{array}{l}\text { 1-aminocyclopropane-1- } \\
\text { carboxylate oxidase-like isoform } \\
\text { x1 }\end{array}$ & 3.27 & 0.05 & 2.48 & 0.05 & 2.29 & 0.04 \\
\hline $\mathbf{D}$ & Contig14053 & $\begin{array}{l}\text { salicylic acid-binding protein 2- } \\
\text { like }\end{array}$ & 22.28 & 0.00 & 3.04 & 0.04 & 3.76 & 0.00 \\
\hline $\mathbf{I}$ & Contig16100 & $\begin{array}{l}\text { 1-aminocyclopropane-1- } \\
\text { carboxylate oxidase }\end{array}$ & -4.81 & 0.02 & 2.54 & 0.04 & 2.45 & 0.04 \\
\hline \multicolumn{9}{|c|}{ Transcriptional regulation of meristem activity } \\
\hline $\mathbf{B}$ & Contig00787 & $\begin{array}{l}\text { nac domain-containing protein 2- } \\
\text { like }\end{array}$ & 9.26 & 0.00 & -1.02 & 0.85 & -1.26 & 0.79 \\
\hline B & Contig12353 & early nodulin-like protein 1 & 9.58 & 0.00 & -1.48 & 0.61 & -2.80 & 0.05 \\
\hline B & Contig20304 & $\begin{array}{l}\text { homeobox-leucine zipper protein } \\
\text { athb-13-like }\end{array}$ & 3.82 & 0.04 & 1.31 & 0.72 & 1.24 & 0.86 \\
\hline $\mathbf{D}$ & Contig13895 & nac transcription factor 29-like & 22.81 & 0.00 & 1.08 & 1.07 & 1.20 & 0.64 \\
\hline G & Contig09007 & exordium like 2 & -0.36 & 1.17 & -3.66 & 0.03 & -4.59 & 0.01 \\
\hline $\mathbf{H}$ & Contig06813 & wuschel-related homeobox 4-like & -1.76 & 0.34 & 1.49 & 0.47 & 2.61 & 0.02 \\
\hline $\mathbf{H}$ & Contig14178 & $\begin{array}{l}\text { clavata3 esr-related } 12 \text { family } \\
\text { protein }\end{array}$ & -3.46 & 0.05 & 1.70 & 0.41 & 2.45 & 0.03 \\
\hline $\mathbf{L}$ & Contig05551 & $\begin{array}{l}\text { probable wrky transcription } \\
\text { factor 51-like }\end{array}$ & -2.28 & 0.19 & -3.39 & 0.04 & -2.23 & 0.15 \\
\hline $\mathbf{L}$ & Contig12050 & transcription factor myb46-like & -9.05 & 0.00 & -2.05 & 0.18 & -2.11 & 0.22 \\
\hline \multicolumn{9}{|c|}{ Non annotated genes and unknown functions } \\
\hline A & Contig03506 & $\begin{array}{l}\text { hypothetical protein } \\
\text { SELMODRAFT_115352 }\end{array}$ & 63.88 & 0.00 & 20.85 & 0.00 & 12.74 & 0.00 \\
\hline B & Contig09209 & ---NA--- & 13.90 & 0.00 & 1.35 & 0.82 & -1.67 & 0.36 \\
\hline B & Contig22448 & ---NA--- & 12.00 & 0.00 & 1.31 & 0.68 & -1.40 & 0.64 \\
\hline B & Contig24621 & ---NA--- & 12.34 & 0.00 & 0.36 & 1.01 & -1.81 & 0.30 \\
\hline D & Contig19474 & ---NA--- & 22.81 & 0.00 & 1.49 & 0.64 & 0.36 & 1.09 \\
\hline D & Contig20761 & predicted protein & 24.06 & 0.00 & 1.29 & 0.75 & 1.80 & 0.20 \\
\hline D & Contig22397 & ---NA--- & 31.25 & 0.00 & 2.29 & 0.09 & 1.10 & 1.10 \\
\hline D & Contig23569 & ---NA--- & 36.23 & 0.00 & 2.55 & 0.06 & -2.05 & 0.27 \\
\hline $\mathbf{F}$ & Contig03012 & ---NA--- & 7.04 & 0.01 & -7.98 & 0.00 & -4.60 & 0.01 \\
\hline $\mathbf{F}$ & Contig03111 & ---NA--- & 5.57 & 0.02 & -3.12 & 0.12 & -2.77 & 0.05 \\
\hline G & Contig12685 & uncharacterized loc101213469 & 1.34 & 0.82 & -1.79 & 0.31 & -6.43 & 0.00 \\
\hline G & Contig20076 & ---NA--- & 2.71 & 0.12 & 0.11 & 1.03 & -7.76 & 0.00 \\
\hline G & Contig23934 & ---NA--- & 1.31 & 0.79 & -2.74 & 0.08 & -9.51 & 0.00 \\
\hline G & Contig24690 & ---NA--- & 1.55 & 0.53 & -2.30 & 0.17 & -8.11 & 0.00 \\
\hline $\mathbf{H}$ & Contig12627 & ---NA--- & -1.94 & 0.28 & 4.42 & 0.00 & 8.62 & 0.00 \\
\hline $\mathbf{H}$ & Contig21346 & ---NA--- & -1.02 & 1.19 & 7.69 & 0.00 & 7.90 & 0.00 \\
\hline
\end{tabular}




\begin{tabular}{|c|c|c|c|c|c|c|c|c|}
\hline I & Contig02729 & ---NA--- & -11.85 & 0.00 & 2.03 & 0.19 & 1.70 & 0.23 \\
\hline I & Contig13781 & ---NA--- & -12.25 & 0.00 & -1.08 & 1.01 & 1.09 & 0.88 \\
\hline I & Contig16419 & ---NA--- & -13.45 & 0.00 & 1.55 & 0.31 & -0.45 & 0.83 \\
\hline I & Contig19504 & ---NA--- & -12.31 & 0.00 & -1.05 & 1.03 & 1.13 & 0.90 \\
\hline L & Contig02798 & uncharacterized loc101210414 & -1.25 & 0.99 & -1.78 & 0.29 & -5.06 & 0.01 \\
\hline $\mathbf{L}$ & Contig10360 & ---NA--- & -9.23 & 0.00 & -2.42 & 0.12 & -1.69 & 0.36 \\
\hline $\mathbf{L}$ & Contig12514 & $---\mathrm{NA}---$ & -9.36 & 0.00 & -2.14 & 0.17 & -1.35 & 0.33 \\
\hline $\mathbf{L}$ & Contig14134 & ---NA--- & -1.64 & 0.55 & -9.50 & 0.00 & -3.12 & 0.04 \\
\hline L & Contig14477 & ---NA--- & -10.08 & 0.00 & -2.38 & 0.12 & -2.15 & 0.12 \\
\hline $\mathbf{L}$ & Contig20478 & ---NA--- & -1.33 & 0.86 & -5.43 & 0.01 & -2.76 & 0.04 \\
\hline $\mathbf{L}$ & Contig34794 & $\begin{array}{l}\text { PREDICTED: uncharacterized proteir } \\
\text { LOC101509257 }\end{array}$ & -10.94 & 0.00 & -3.20 & 0.04 & -2.59 & 0.10 \\
\hline
\end{tabular}

FC: Fold-change. FDR: adjusted p-value by False Discovery Rate. In bold, statistically significant values

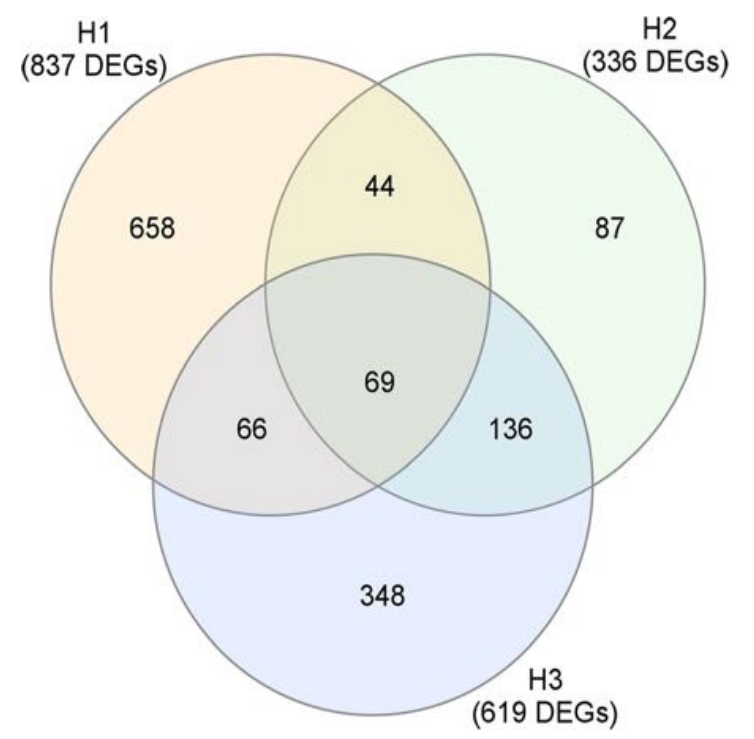

Figure 2 Differentially expressed genes during first healing. Venn's diagram of woundresponsive DEGs at 7 (H1), 78 (H2) and $92(\mathrm{H} 3)$ days after wounding
Immediate response $\mathrm{H} 1$ included 837 DEGs; 619 DEGs were detected for H3, while only 336 DEGs were detected at H2. Just 69 genes were identified as DEG for the three sampling dates, $\mathrm{H} 1, \mathrm{H} 2$ and $\mathrm{H} 3$. Moreover, just 87 genes were identified as DEGs exclusively for H2, while 348 were exclusive DEGs for H3 and up to 658 for H1 (Figure 2).

Enrichment analysis of DEGs pointed out an increase of mRNA levels for the categories "defense response", "response to stress" and different forms of "response to stimulus", as "response to abiotic stimulus" or "response to biotic stimulus”, among others, in the Biological Process (BP) category. As well, other enriched GO terms were "nucleic acid binding transcription factor activity" and "sequence-specific DNA binding transcription factor activity", for the Molecular Function (MF) category, and "extracellular region”, “cell wall”, “cell 
Chano, $V$-Transcriptomics of the response to wounding

periphery" and "external encapsulating structure" GO terms of the Cellular Component category.

\section{Hierarchical clustering of DEGs}

a

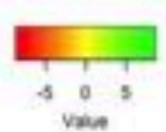

HEALING Differentially Expressed Genes
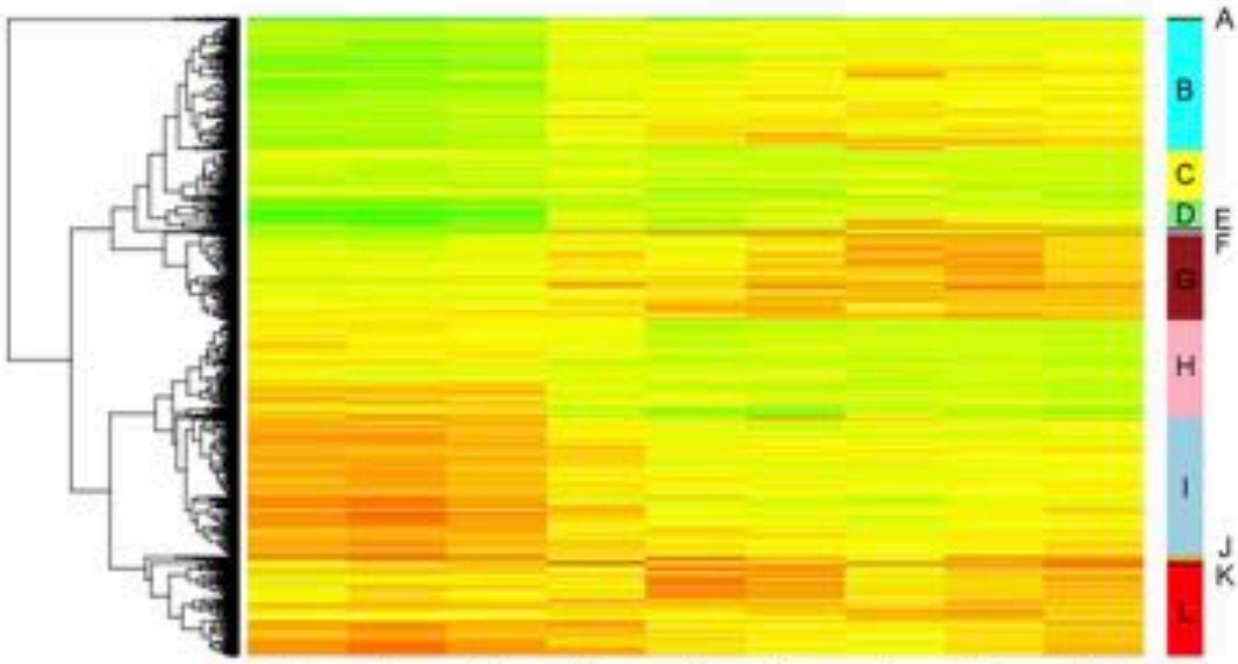

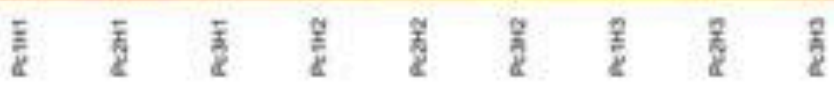

b
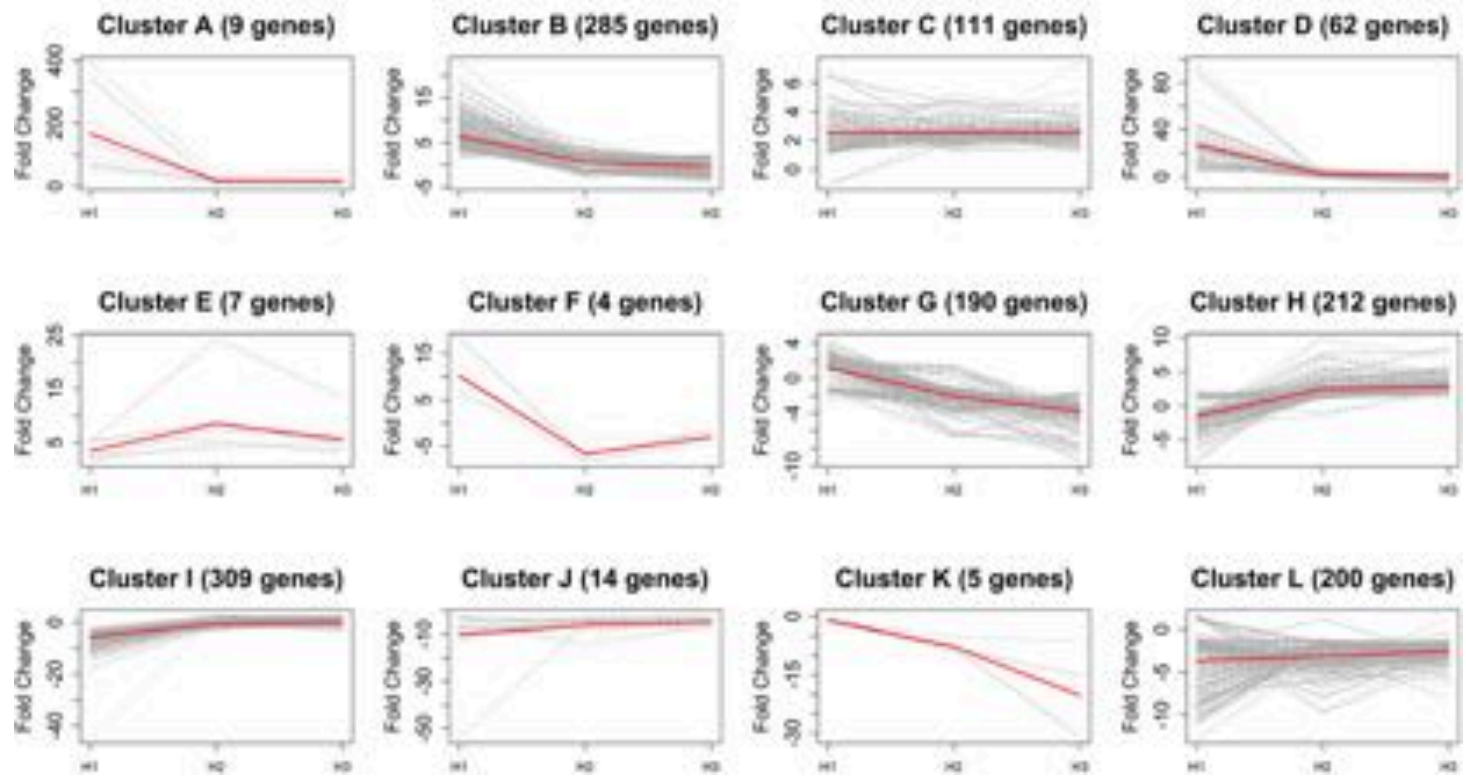

Figure 3. Clustering of DEGs according to expression patterns. a) Hierarchical clustering of 1408 DEGs for three biological replicates (PC1, -2 and -3), identifying 12 clusters (A - L). b) Gene expression profiling of clusters, showing Fold Change variations along sampling dates. 
Twelve clusters were established according to the transcription patterns detected for DEGs throughout H1, H2 and H3 (Figure 3). Cluster A includes genes clearly induced at H1, which keep high transcription levels during $\mathrm{H} 2$ and H3, although at a minor degree. Genes included in clusters B, D and F were also overexpressed at $\mathrm{H} 1$, but later on their transcription levels decrease, being even repressed at $\mathrm{H} 2$ and/or H3. Genes in cluster C show a faint overexpression throughout the three phases, while clusters $\mathrm{E}$ and $\mathrm{H}$ show an increasing overexpression at $\mathrm{H} 2$ and $\mathrm{H} 3$. The opposite pattern is reflected by clusters $\mathrm{G}$ and $\mathrm{K}$, with an increasing repression at $\mathrm{H} 2$ and $\mathrm{H} 3$. Genes in cluster I show a significant repression at H1, followed by a recovery of transcription to normal levels at H2 and H3. Finally, clusters $\mathrm{J}$ and $\mathrm{L}$ are characterized by a general repression during the three phases.

Clustering of samples revealed consistency among biological replicates, as shown in a supplementary Figure (Additional file 2). Samples harvested at H1 clustered together and separated from the other sampling dates; on their side, $\mathrm{H} 2$ and $\mathrm{H} 3$ samples were included in the same group. Slight irregularities (for instance, sample $\mathrm{Pc} 3 \mathrm{H} 2$ is closer to $\mathrm{H} 3$ samples than to the other $\mathrm{H} 2$ ones) can be due to the genetic variability among trees. This result supports the differentiation of two major phases ( $\mathrm{H} 1$ and $\mathrm{H} 2 / \mathrm{H} 3$ ) in the response to wounding, as discussed below.

To validate the reliability of the transcription profiles obtained from microarray hybridization, we selected 12 genes for qRT-PCR analysis, covering the main tendencies described above and the putative function of the genes. Thus, we selected three genes directly involved in cell growth and cell wall formation, as an expansin (Contig 03225, cluster H), a CeSA-like (Contig 00654, cluster L) and a CCoAOMT (Contig 06476, cluster G), transcription factors also involved in xylogenesis, as a MYB46-like (Contig 12050, cluster L), a WOX4-like (Contig 06813, cluster H), a bHLH35-like (Contig 05923, cluster C)an ATHB13-like (Contig 20304, cluster B), a NAC2-like (Contig 00787, cluster B), and a WRKY51-like (Contig 05551, cluster L). Finally, we also analysed a gene coding for a PAL protein (Contig 20555, cluster B), involved in salicylic acid biosynthesis and presumably related to defense, an EXORDIUM-like protein (Contig 09007, cluster G), presumably 
involved in cell proliferation, and a Major Allergen Pru AR1-like (Contig 22185, cluster A), putatively involved in defensive response. Profiles obtained by qRTPCR for these genes match the ones obtained from microarray hybridization, with high correlation coefficients, thus validating the general tendencies described above for microarray analysis (Figure 4).
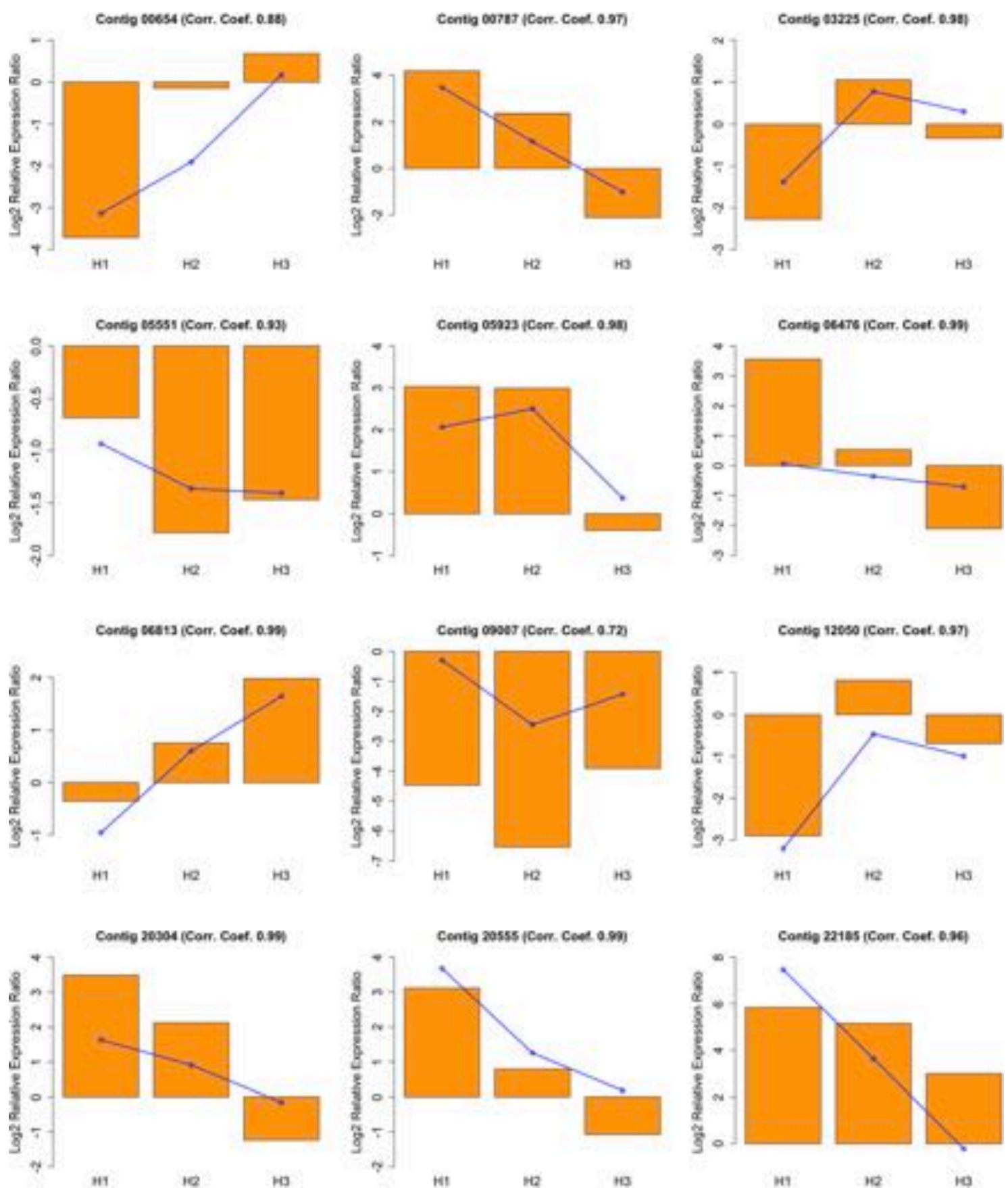

Figure 4. qRT-PCR validation of microarray transcription profiles. X-axis: sampled times; Y-axis: normalized gene expression values of selected DEGs for qRT-PCR (bars) validation of microarray expression profiling (continuous lines). 
Detailed analysis of the transcription patterns of the differentially expressed genes (DEGs) leads to the identification of two major phases in the response to wounding.

\section{H1. Immediate response}

A complete rearrangement of the transcriptional program takes place as immediate response to wounding. At H1, a general repression of genes involved in the normal development of early wood is detected. In particular, genes related to meristematic activity, cell division or synthesis of cell wall show their transcription levels significantly lowered. This is consistent with anatomical observations: in Chapter 2 (Chano et al. 2015) we described how cambial activity is stopped in response to a recent wound, and no growth in the cambial zone is further detected up to approximately 4 weeks after wounding.

On the contrary, numerous genes putatively involved in the defense against stress (including biotic stress) are significantly induced at this point, serving as a defense against opportunistic pathogens infecting the wound. Noteworthy, many of these genes were reported to show their transcript maximum in normal xylogenesis during late wood formation in Chapter 1 (Chano et al. 2017b). Expression of genes related to stress and defense processes in differentiating late wood has also been reported in other species. For instance, Mishima et al. (2014) described the abundance of "defense mechanism genes" in the "cessation of growth clusters" obtained from cambial zone and differentiating xylem in Cryptomeria japonica In normal late wood formation, these genes could act as a preventive defense against putative pathogens infecting the tree just before dormancy, since dormancy could hamper the display of an induced response during winter. Later on, well differentiated late wood constitutes a barrier against eventual infections that could take place during winter, as described by the CODIT (Compartmentalization Of Decay In Trees) model (Shigo 1984).

Thus, among the genes involved in cell wall development typically overexpressed during early wood development and repressed at $\mathrm{H} 1$ we can find 
Chano, $V$-Transcriptomics of the response to wounding

transcription factors such as the HD-ZIP class III family member ATHB15-like or a MYB46-like transcription factor, reported to be involved in cell wall biosynthesis in Arabidopsis (Zhong et al. 2007), included in clusters I and L, respectively (Figure 3). Other genes directly involved in the cell wall biosynthesis and repressed at this stage, were some CAZymes (f.i., Contigs 03231, 11436, 13611, 19457, 00766, or 08356), COBRA or KORRIGAN endoglucanase (Contigs 01405, or 10173, as well as a CCOAOMT (Contig 02447), involved in lignin biosynthesis and deposition. As well, a homologous of the rice NAC29 transcription factor (Contig 13895) has been found to be locally induced at $\mathrm{H} 1(\mathrm{FC}=22.81)$. This gene was reported in Chapter 1 to participate in normal latewood development in the Canary Island pine (Chano et al. 2017b), coexpressed with a putative cellulose synthase-like protein, consistently with its reported role as activator of CesA in rice (Huang et al. 2015). However, no significant induction of CesA was found in H1. This fact can be due to the observed repression at this point of MYB546, another activator of CesA (Zhong et al. 2007). Additionally, NAC29 could be also involved in other routes related to wound stress, and not only in the synthesis of cellulose, since no growth was detected at H1. Actually, this gene has been described to be involved in the response to stress caused by high salinity and drought in bread wheat (Xu et al. 2015).

Conversely, among the genes significantly overexpressed at $\mathrm{H} 1$ we can find genes related to oxidative stress, hydrolytic enzymes and hormonal signaling. Oxidative stress is one of the main effects of mechanical damage and infections. Cell lysis results in the production of hydrogen peroxide, which is toxic for pathogens, but also for plant cells, triggering the hypersensitive response (Levine et al. 1994). Peroxidases are then induced for ROS (reactive oxygen species) detoxification (Diehn et al. 1993, Mohan et al. 1993). Interestingly, in addition to their role in response to pathogens (Gunnar Fossdal et al. 2001, Wang et al. 2013), peroxidases are also involved in lignin biosynthesis and suberization (Hiraga et al. 2001, Valério et al. 2004, Passardi et al. 2005). Although some peroxidases were repressed at $\mathrm{H} 1$, several contigs coding for different isoforms of a peroxidase12- 
like protein were overexpressed at this time (f.i., Ppnisotig 01747 with FC value of 97.76, cluster D). In the same way, other genes involved in oxidative stress were induced at this stage, as Contig 03079 (cluster B), putatively coding for a lacoylglutathione lyase, involved in the glutathione-based detoxification (Thornalley 1998) and in the response to drought and cold stress (Seki et al. 2001). In the same way, a glutathione-S-transferase (Ppnisotig 06171 found in cluster D) or a thioredoxin (Contig 09180, cluster B), also involved in the anti-oxidative plant defense (Meyer et al. 2008), were also overexpressed at H1.

Another important group of genes induced at this stage are those coding for hydrolytic enzymes that attack pathogen cell wall. Among them we find Contig 18804 and Ppnisotig 13431 in cluster A, homologous to PI206, a disease resistance response protein firstly described in Pisum sativum, where is induced after inoculation with Fusarium solani (Riggelman et al. 1985, Culley et al. 1995). In the same way, and also in cluster A, the putative PR-4-like proteins Contig 22375, Ppnisotig 13133 and Contig 19053 are highly induced at H1 (FC values of 343.24, 206.36 and 96.55, respectively). PR-4 protein was first described in Solanum tuberosum (Stanford et al. 1989), named also win-1 and win-2 for "woundinducible genes”. In Capsicum chinense L., PR-4 was found to have both RNAse and DNAse activity in the extracellular space during stress conditions (GuevaraMorato et al. 2010). Other putative PR4-like proteins with endochitinase activity (Seo et al. 2008), as Ppnisotig 08058 and Ppnisotig 00751, were also induced at H1 and found in cluster D. This cluster also includes other chitinases, such as endochitinase a-like proteins (Contig 21216, Contig 10307 and Contig 00126), and chitinase 1-like protein (Contig 23442). A major allergen pru ar1 homologous (Contig 22185) was also found in cluster A, strongly induced at H1 (FC 138.29). This protein was first described in Prunus armeniaca during ripening and annotated as a pathogenesis-related protein (Mbéguié-A-Mbéguié et al. 1997). Ppnisotig 12265, found in cluster G, corresponds to a putative antimicrobial peptide 1 , which are widely present in living organisms, and possess antifungal and antibacterial properties (Castro and Fontes 2005). Finally, we can also mention Contig 00602 
Chano, $V$-Transcriptomics of the response to wounding

(cluster B) and Contig 17617 (cluster D), coding for two defensins, the most abundant antimicrobial peptides in plants, involved in defense-related processes, biotic stress response and plant development (Tam et al. 2015), which were also reported in Chapter 1 to be expressed during normal late wood differentiation in P. canariensis (Chano et al. 2017b).

In the first stage after wounding the plant displays an extensive hormonal signaling. For instance, Contig 00715 and Ppnisotig 12073, included in clusters B and $\mathrm{C}$, respectively, encode for putative 1-aminocyclopropane-1-carboxilate oxidase (ACO) proteins, involved in the synthesis of ethylene, known to be involved in different stress- and defense-related processes (Hudgins et al. 2006, Yuan et al. 2010).

Jasmonic acid (JA) is known to trigger a complex signaling network, both locally, activating the expression of wound-induced genes, and systemically, via the systemin peptide (Rojo et al. 1999), mediated by ethylene (O’Donnell et al. 1996). However, we have not detected any DEG related to JA biosynthesis. The restrictive criteria used in this work to select DEGs can account for this result. Additionally, a local repression of the JA-dependent pathway by ethylene production has been reported in Arabidopsis (León et al. 2001), where the existence of an additional JAindependent pathway has also been described. This could also be the case for Pinus canariensis.

Two genes coding for salicylic acid-binding protein 2-like (SABP2-like) proteins were overexpressed at H1 (Contig 03482, cluster B) and at H1 and H2 (Contig 14053, cluster D). These proteins are involved in the plant immune response, through their salicylic acid (SA)-stimulated lipase activity (Kumar and Klessig 2003). SA is also involved in the expression of plant pathogenesis-related genes (Ward et al. 1991), and is thought to be an antagonistic of JA (Vidhyasekaran 2015), blocking its synthesis (Pena-Cortés et al. 1993, Spoel et al. 2003). This would also be consistent with the lack of detection of DEGs related to the JA-dependent wound response pathway in this work. 
Several non-annotated genes differentially overexpressed at H1 showed high levels of overexpression, specifically 63 DEGs in cluster B, 11 in cluster D, as many of the DEGs related to defense and stress mentioned above, and 2 in cluster $F$ (f.i., Contigs 09209, 22448 or 24621 in cluster B, Contigs 23569, 22397 or 19474 in cluster D, with FC values over 20, or Contigs 03012 and 03111 in F). In addition, other nonannotated DEGs were repressed at H1, mainly grouped in clusters I (86 DEGs, with FC values below -10 for Contigs 02729, 13781, 19504 and 16419), and L (30 DEGs, with FC values close to -10 for Contigs 10360, 12514 or 14477). Additionally, other poorly annotated genes can be found among the H1-related DEGs. For instance, Contig 03506 was strongly induced at H1, with a FC value of 63.88 , and kept overexpressed in $\mathrm{H} 2$ and $\mathrm{H} 3$. This sequence was annotated as homologous of the hypothetical protein SELMODRAFT_115352, predicted in the clubmoss Selaginella moellendorfii (Banks et al. 2011). As well, other remarkable contigs poorly annotated were Contig 20761 (cluster D), a predicted protein with FC value of 24.06 in H1, and Contig 34794 (cluster L), repressed to -10.94 at H1 and annotated as homologous to chickpea uncharacterized protein LOC101509257 (Varshney et al. 2013).

H2/H3: Development of traumatic wood.

In Chapter 2 (Chano et al. 2015) we described that noticeable formation of traumatic xylem begins 4 weeks after wounding. Accordingly, we collected traumatic wood samples 11 weeks after wounding (H2), when traumatic growth was visible at healing borders. At this date, early wood was still being formed as reported in Chapter 1 (Chano et al. 2017b). Two weeks later, when the trees were already differentiating late wood (Chano et al. 2017b), another samples of traumatic wood were collected in independent wounds (H3).

As expected, after the first phase, characterised by the cessation of growth and by the expression of defensive genes, cambial activity resumes at the wound margins and development of traumatic wood is evident. Consistently, genes related to cell 
proliferation and cell wall biosynthesis are expressed. Thus, transcription patterns are more similar between $\mathrm{H} 2$ and $\mathrm{H} 3$, and differ more from $\mathrm{H} 1$.
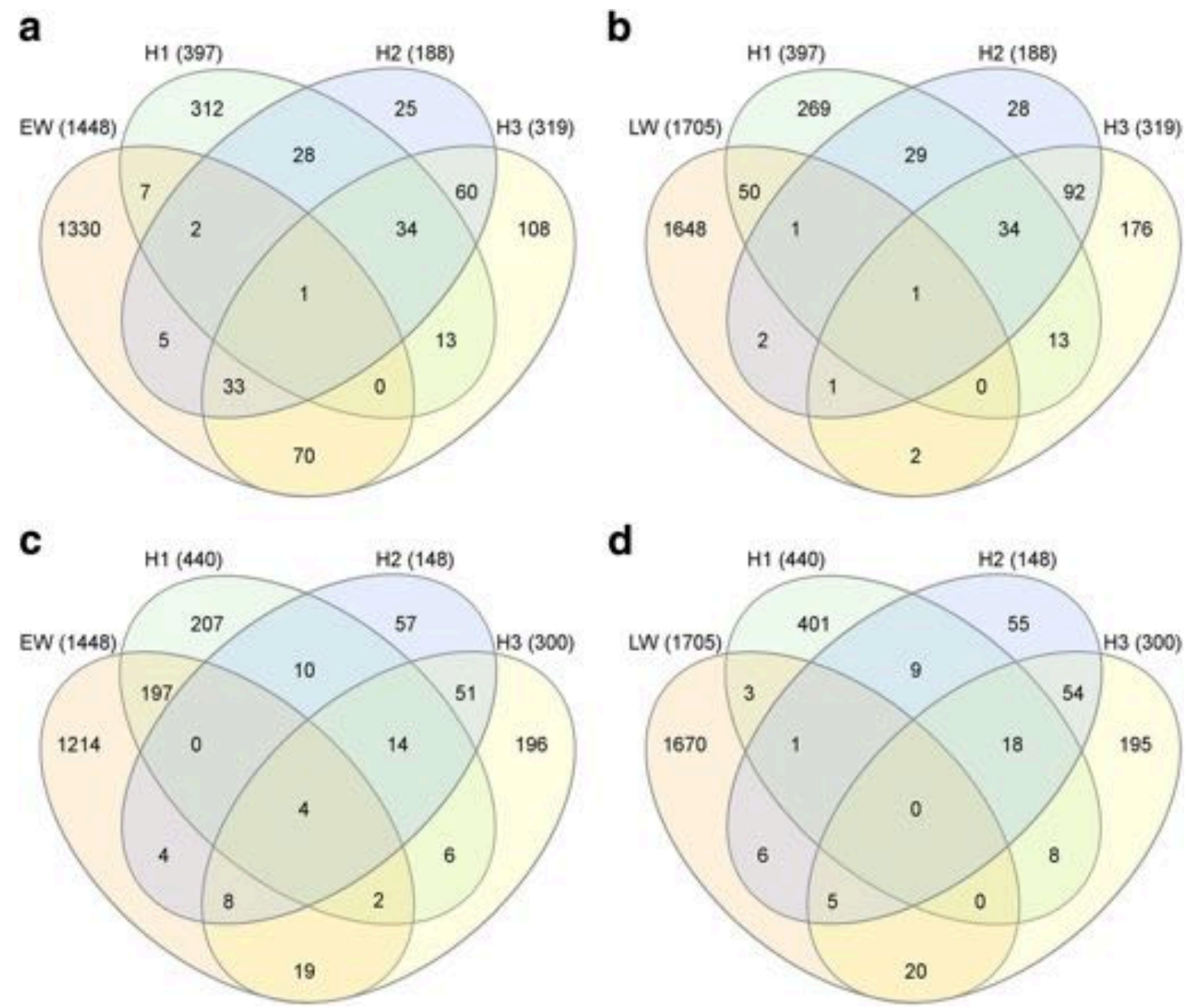

Figure 5. Expression of xylogenesis-related genes during wound response. Venn's diagrams of wound-induced DEGs and early-(a) and latewood (b) genes, and of wound-repressed DEGs and early(c) and latewood (d) genes.

While most of the genes involved in xylogenesis during latewood formation do not change their normal transcription patterns, and therefore are not detected as DEG at $\mathrm{H} 2$ or $\mathrm{H} 3$, several genes characteristic of early wood formation appear as overexpressed at these phases. This is the case for Contig 06813 (cluster H), encoding for a WOX4-like transcription factor. WOX4 belongs to the WUSCHELrelated НОМЕОВОХ (WOX) family, which is involved in the differentiation in the organizing center of the apical shoot (Mayer et al. 1998), in procambial and cambial growth with function in vascular bundles development (Ji et al. 2010a, $2010 \mathrm{~b})$ and in the regulation of proliferation from stem cells niches in root and shoot meristems after embryogenesis (Haecker et al. 2004) together with 
CLAVATA (CLV; (Miwa et al. 2009). Moreover, a homologous of the clavata3-like protein (CLV3) was found to be induced at H3 as well (Contig 14178, cluster H), suggesting similar combined roles in response to wounding and meristematic activity during tissue regeneration and traumatic wood development. In the same way, homologues of two expansins (Contigs 03225 and 18811), two KORRIGAN endoglucanases (f.i., Contigs 18777 and 10173) or several CAZymes (f.i., Contigs 00603, 13281, 09907, 05424, or 05066), reported in Chapter 1 to be expressed during early wood formation in P. canariensis (Chano et al. 2017b), are overexpressed at $\mathrm{H} 3$, when late wood is already differentiating in other parts of the stem. On the contrary, other CAZymes (Contigs 01916, 17013 or 21865) or a cellulose synthase (Contig 15857), typically expressed during late wood formation in P. canariensis (Chano et al. 2017b), are repressed at $\mathrm{H} 2$ and $\mathrm{H} 3$, in the same way as an early wood induced CCoAOMT (Contig 06476), crucial in lignin biosynthesis. Repression and overexpression of putative early and late wood genes during H1, $\mathrm{H} 2$ and $\mathrm{H} 3$ are summarized in Figure 5.

These results are consistent with anatomical observations. As shown in Figure 6 not a clear difference between early and late wood is observed in the traumatic wood grown during 18 months after wounding. On the contrary, a high number of resin ducts appear in this traumatic wood, as already reported in Chapter 2 (Chano et al. 2015). Accordingly, several genes related to resin synthesis have been detected as overexpressed at $\mathrm{H} 2$ and $\mathrm{H} 3$. Oleoresins are one of the main conifer defenses against pathogens, avoiding the spread of infections. In this work we have detected DEGs encoding geranyl diphosphate synthase and geranylgeranyl diphosphate synthase (Contig 03270 and Ppnisotig 10634, respectively; cluster H), involved in the synthesis of mono and diterpenes, induced at H3. In the same way, in the same cluster, overexpressed at H3, appears Contig 08417, encoding an abietadienol/abietadienal oxidase-like protein, which catalyzes several oxidative steps in diterpenol biosynthesis (Ro et al. 2005). Contig 13499, encoding a (-)camphene tricyclene synthase-like is also induced at H3, appearing in cluster C. 
This monoterpene synthase is involved in the synthesis of different monoterpenes, as camphene, tricyclene, limonene or myrcene (Falara et al. 2011).

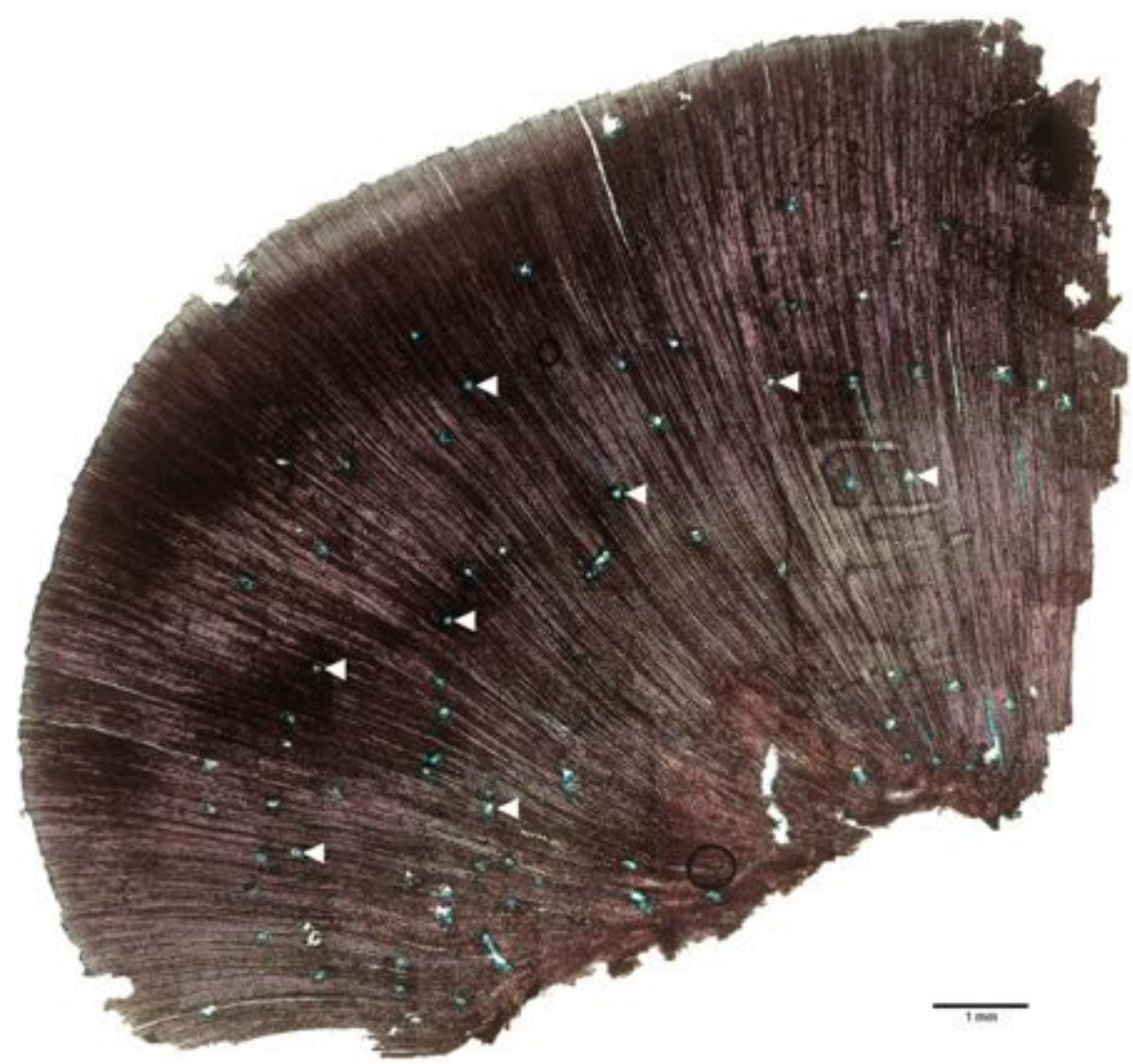

Figure 6. Micrograph of wound-wood. Bright-field microscopy picture of a $20 \mu \mathrm{m}$ thick cross section of traumatic xylem 18 months after wounding.

Also induced at $\mathrm{H} 2 / \mathrm{H} 3$ appear several genes presumably involved in ethylene synthesis, although this hormone is supposed to act in the first steps of the response [62]. This is the case of ACS (1-aminocyclopropane-1-carboxylic acid synthase) or ACO (1-aminocyclopropane-1-carboxilate oxidase). In spruce and Douglas fir, for instance, multiple ACS genes and a single ACO gene were found to be induced during the immediate response to wounding (Ralph et al. 2007). Conversely, we found multiple ACO genes overexpressed during the whole response (from $\mathrm{H} 1$ to H3), such as Contig 00524 (cluster C) and Contig 16100 (cluster I). This result suggests a different response in P. canariensis compared to 
Picea and Pseudotsuga, which could be related with the efficient healing response of Canary Island pine.

On the contrary, transcript levels of many other defensive genes overexpressed at $\mathrm{H} 1$ decrease to normal levels at $\mathrm{H} 2 / \mathrm{H} 3$, or are even repressed at $\mathrm{H} 3$, when latewood is forming in other parts of the tree. During latewood formation defensive genes are expressed, as reported in Chapter 1 in $P$. canariensis (Chano et al. 2017b) or C. japonica (Mishima et al. 2014). This constitutive upregulation of these genes could account for the comparatively lower expression levels detected for traumatic wood formation. This is the case of two HSPRO genes (Contigs 02906 and 19857), induced at $\mathrm{H} 1$ and related to nematode resistance, or a noduline (Contig 12353), presumably involved in plant-microbe interactions, which show lower transcription levels at $\mathrm{H} 2 / \mathrm{H} 3$ in the healing borders than in controls.

As exposed previously for the immediate response, other non-annotated DEGs were significantly overexpressed at $\mathrm{H} 2$ and/or H3. Thus, 26 non-annotated DEGs were included in cluster C, and 80 more in cluster H. For instance, Contig 21346, with FC values over 7 in $\mathrm{H} 2$ and H3, or Contig 12627, with a FC value of 4.42 in H2 and 8.62 in H3). Important numbers of non-annotated sequences were found in clusters $G$ and L, where 58 and 70 DEGs, respectively, showed underexpression for H2 and/or H3 (f.i., Contigs 20076, 23934 or 24690 in cluster G were strongly repressed at H3, with FC values close to -10, or Contigs 14134 and 20478, repressed for $\mathrm{H} 2$ and $\mathrm{H} 3$ with $\mathrm{FC}$ values from -9.5 to -3.12 and from -5.43 to -2.76 , respectively). As well, some poorly annotated contigs were remarkably repressed. For instance, Contig 02798 (cluster L) and Contig 12685 (cluster G), homologous to uncharacterized LOC101210414, and LOC101213469 from Cucumis sativus (Huang et al. 2009), showed FC values of -5.06 and -6.43 at H3, respectively.

\section{CONCLUSIONS}

Wounding induces a complete rearrangement of the transcriptional programme in the cambial zone close to the injuries. In particular, a considerable percentage 
of genes presumably involved in xylogenesis show an altered transcription pattern in response to wound and during healing.

At the first instance, radial growth is stopped in the vicinity of the wound, and a complete set of defensive genes, mostly related to biotic stress, are induced, as a barrier against opportunistic pathogens. Interestingly, some of these genes have also been reported to be preferentially transcribed in differentiating late wood. Later on, cambial activity is restored in the lateral borders of the wound, even at a higher rate than in other parts of the stem. This fast growth, which is dependent on the general health and reserves of the tree, eventually leads to the complete healing of the wound and restoration of the cambial ring. Anatomically, we have not detected a well-defined contrast among early and late wood in the traumatic wood formed during 18 months after wounding. During this period, most of the genes preferentially expressed during normal late wood development do not change their expression pattern, described in Chapter 1 (Chano et al. 2017b). However, a subset of genes shows their transcription levels significantly altered by wound and healing. Among them, it is noteworthy the presence of genes involved in cell wall formation. Thus, genes coding for CAZymes and cellulose synthases overexpressed in normal late wood formation are comparatively repressed in traumatic wood. Conversely, similar genes typical of early wood keep their high transcription levels in traumatic wood, even at the moment of late wood formation. On the contrary, an early wood CCoAOMT, involved in lignin biosynthesis, is also repressed in traumatic wood. These genes, together with many others non-annotated yet, but showing similarly modified transcription patterns in healing tissue, probably underlie the anomalous characteristics of traumatic wood. In the same way, we cannot discard that other genes not detected as DEG due to the restrictive criteria used in this work could still play a biologically significant role in the wound wood formation process.

Our results suggest that the tree, after the synthesis of defensive molecules against eventual pathogens, and once cambial activity is restored at the wound borders, produces a fast growing traumatic wood. This tissue, in which annual rings are 
not clearly distinguished, at least the first year, could be less efficient as preventive barrier than normal late wood regarding secondary wall lignification, but it presents a high proportion of resin ducts, and also provides a good media to heal the wound in the shortest possible time. Further investigations are needed to clarify this point.

\section{MATERIALS AND METHODS}

\section{Plant material and wounding}

For this work we used 3 Pinus canariensis trees, 5 years old. Pines were grown in greenhouse, using $650 \mathrm{ml}$ conical containers with 3:1 (v/v) peat:vermiculite. After the first year, trees were transferred to soil in experimental garden at UPM facilities, and grown under environmental conditions. At the moment of the beginning of this experiment, trees were approximately $2 \mathrm{~m}$ high and 7-10 $\mathrm{cm}$ diameter at the base. Using a sterile scalpel, we performed two wounds, removing bark, phloem, vascular cambium and first rows of xylem from a rectangular window $10 \mathrm{~cm}$ high and spanning half the circumference of the stems (Figure 7). Wounds were performed in opposite sides of the stem and with an interval of approximately three wound heights.

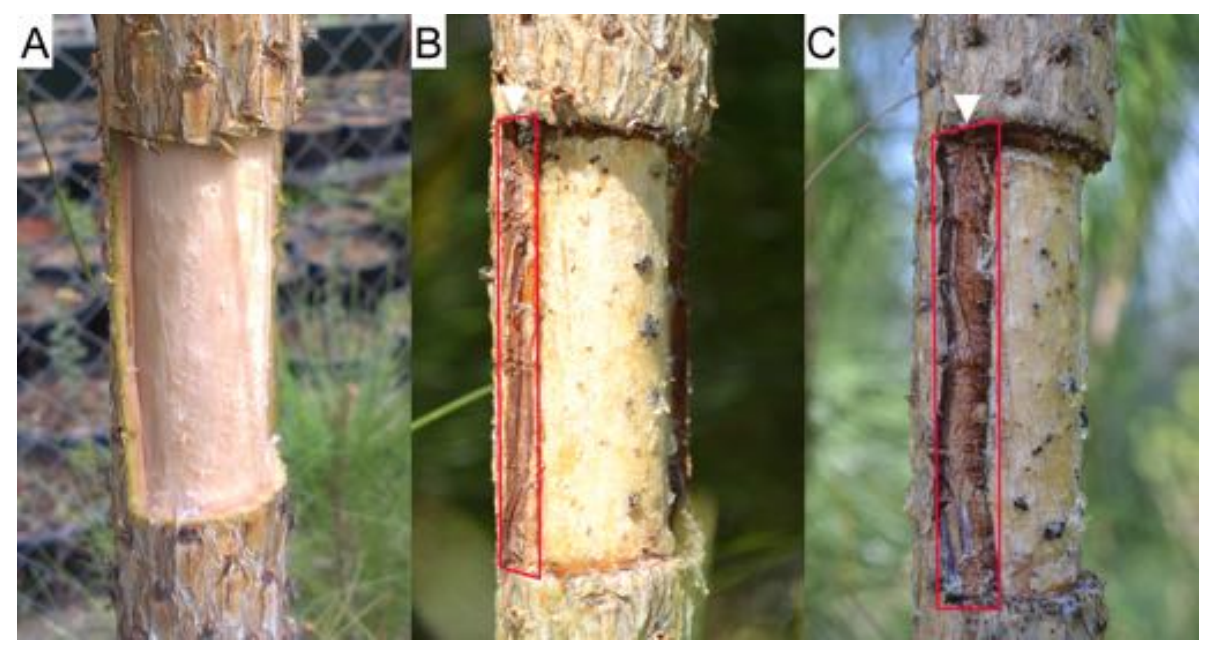

Figure 7. Wounded stem of $\boldsymbol{P}$. canariensis at the sampling dates. A) H1: 7 days after wounding; B) H2: 78 days after wounding; C): 92 days after wounding

Samples were collected according to the described seasonal growth and healing patterns described previously for the species in Chapters 1 and 2 (Chano et al. 
Chano, $V$-Transcriptomics of the response to wounding

2015, 2017b). Wounding was performed on April $9^{\text {th }}$, when cambial activity was ongoing. One week later we collected a frame of tissue from the wound margins in both wounds (H1); at this moment formation of a first traumatic tissue can be expected [9]. On June $25^{\text {th }}$, when the callous tissue was emerging from the margins of wounds and the trees were at the end of the earlywood development period, we collected the tissues growing in the margins of one wound per tree (H2). Later on, on July $9^{\text {th }}$, concurring with the latewood development period described in Chapter 1 (Chano et al. 2017b), we collected the thick callous tissues growing in the frame of remaining wounds (H3).

For each sample, controls were collected at the same sampling dates, from branches away from the wounds, in order to distinguish transcriptomic changes of the vegetative growth of those caused by wounding. The tissue collected for control samples included bark, phloem, vascular cambium and the most external layers of xylem. Collected samples were processed individually, immediately frozen in liquid nitrogen and stored a $-80^{\circ} \mathrm{C}$.

\section{RNA isolation and sequencing}

Total RNA was isolated from each sample, using the CTAB-LiCl precipitation method (Chang et al. 1993), and purified with the RNeasy Plant Mini Kit (Qiagen, CA, USA). Quantity of total RNA for each sample was measured with Nanodrop model ND-1000 (Thermo Scientific, MA, USA), and RNA quality was checked using Experion Bioanalyzer (Bio-Rad, CA, USA).

\section{Microarray analysis}

A set of 15266 contigs involved in meristematic activity of Pinus canariensis, selected from previous work carried out for Chapter 1 (Chano et al. 2017b), was used for the design of a two-color 60K microarray (Agilent, USA). Furthermore, we added 2303 contigs from other cDNA libraries of $P$. pinea, as well ESTs and sequences of the loblolly pine from the Pine Gene Index Database (http://www.mgel.msstate.edu/dna_libs.htm). For each contig, one $60 \mathrm{bp}$ long 
probe was designed and spotted at least 3 times on the slide. Probes designed for Populus, mouse and human ESTs available in public databases were included as negative controls.

For each sampling point (H1, H2, H3), the three biological replicates were hybridized (wound vs. control) following the two-color protocol provided by the manufacturer (Agilent Technologies, CA, USA), and images were captured with a GenePix 4000B (Axon, CA, USA), and spots were quantified using the GenePix software (Axon, CA, USA). Microarray data was uploaded to the NCBI' Gene Expression Omnibus and are accessible through the GEO series accession number GSE102275 (https://www.ncbi.nlm.nih.gov/geo/query/acc.cgi?acc=GSE102275).

Background correction and normalization of expression data were performed using LIMMA (Linear Models for Microarray Data; (Smyth 2004)). For local background correction and normalization, the methods "normexp" and "loess" in LIMMA were used, respectively. To achieve similar distribution across arrays and consistency among arrays, log-ratio values were scaled using the median-absolute value as scale estimator. The non-parametric algorithm "Rank Products", available as a package for Bioconductor in R (Gentleman et al. 2004, Hong et al. 2006, R Core Team 2013), was used for evaluation of Differentially Expressed Genes (DEGs). This method detects genes that are consistently high ranked in a number of replicated experiments independently of their numerical intensities. Results are provided in the form of $P$ adjusted by False Discovery Rate (FDR), defined as the probability of a given gene is ranked in the observed position by chance. Those probes with a FC above 2 and below -2, with a significance level FDR below 0.05, were selected as differentially expressed. Thus, technical replicates were merged into one value per contig, and a datamatrix formed by ratios between experimental and control measurements for selected Differentially Expressed Genes (DEGs), including time sampled and biological replicate, was created. Clustering was performed in R, and the heatmap was plotted using the heatmap.2 function of the gplots package (Warnes et al. 2015). Enrichment analysis of DEGs was performed using Blast2GO v.2.7.2 as well. 


\section{qRT-PCR validation}

The expression patterns of 12 DEGs covering the main profiles obtained from microarrays were confirmed by qRT-PCR using the same RNA employed for microarray hybridizations. First strand cDNA synthesis was performed using SuperScript ${ }^{\mathrm{TM}}$ III reverse transcriptase (Invitrogen, USA) following manufacturer's instructions and using $4 \mu \mathrm{gr}$ of total RNA and random hexamers.

Table 2. Primers used for qRT-PCR

\begin{tabular}{|c|c|c|c|c|c|c|c|}
\hline Contig name & Oligo name & Description & Fwd/Rev & bp & $\mathrm{Tm}$ & GC & Sequence (5'-3') \\
\hline \multirow{2}{*}{ Congit00654 } & Pc_00654_CESA_F1 & \multirow{2}{*}{$\begin{array}{l}\text { cellulose synthase a- } \\
\text { like protein }\end{array}$} & Forward & 20 & 63.0 & 55 & GGACCACACTCCTCATTCCT \\
\hline & Pc_00654_CESA_R1 & & Reverse & 20 & 63.0 & 45 & ACCCCATGACTGAAATCCAT \\
\hline \multirow{2}{*}{ Contig12050 } & Pc_12050_MYB_F1 & \multirow{2}{*}{ MYB46-like protein } & Forward & 20 & 62.8 & 45 & ATTCCCAACATGGAAGAAGC \\
\hline & Pc_12050_MYB_R1 & & Reverse & 20 & 63.7 & 50 & CTGCATCACCATCACACTCA \\
\hline \multirow{3}{*}{ Contig20304 } & Pc_20304_ATHB13_F1 & \multirow{3}{*}{ ATHB13-like protein } & Forward & 20 & 63.2 & 50 & CCCATTCTCATGATGTCTGC \\
\hline & & & & & & & \\
\hline & Pc_20304_ATHB13_R1 & & Reverse & 20 & 63.1 & 50 & CAGAACTGCCTTCACTTCCA \\
\hline \multirow{2}{*}{ Contig00787 } & Pc_00787_NAC_F1 & \multirow{2}{*}{ NAC2-like prtoein } & Forward & 20 & 62.5 & 45 & CTAAATGGCCCTGGGTAAAA \\
\hline & Pc_00787_NAC_R1 & & Reverse & 20 & 62.8 & 50 & ССССТТСТТСТТАССААССА \\
\hline \multirow{2}{*}{ Contig20555 } & Pc_20555_PAL_F1 & \multirow{2}{*}{$\begin{array}{l}\text { phenylalanine } \\
\text { ammonia-lyase-like } \\
\text { protein }\end{array}$} & Forward & 20 & 63.1 & 50 & GAATTGACGTCCTGGTTGTG \\
\hline & Pc_20555_PAL_R1 & & Reverse & 20 & 62.7 & 50 & CAGCCTGGACTATGGTTTCA \\
\hline \multirow[b]{2}{*}{ Contig03225 } & Pc_03225_EXPANSIN_F1 & \multirow[b]{2}{*}{ a-expansin-like protein } & Forward & 20 & 62.8 & 45 & AAGCGGAGCTGATTCTTGAT \\
\hline & Pc_03225_EXPANSIN_R1 & & Reverse & 20 & 63.1 & 60 & CTCAGAGCCACAGAGACGAG \\
\hline \multirow{2}{*}{ Contig05551 } & Pc_05551_WRKY_F1 & \multirow{2}{*}{ WRKY51-like protein } & Forward & 20 & 62.5 & 45 & ACGCAGAGGGGAATAAGAAA \\
\hline & Pc_05551_WRKY_R1 & & Reverse & 20 & 63.2 & 50 & CAGAAAACGTTCACCCACAG \\
\hline \multirow[b]{2}{*}{ Contig06476 } & Pc_06476_CCoAOMT_F1 & \multirow{2}{*}{ CCoAOMT-like protein } & Forward & 20 & 64.0 & 50 & GATTGAACAACCGAGGTGCT \\
\hline & Pc_06476_CCoAOMT_R1 & & Reverse & 20 & 63.6 & 45 & TGCAACACCTGAATTCCAAC \\
\hline \multirow[b]{2}{*}{ Contig06813 } & Pc 06813 WOX_F1 & \multirow[b]{2}{*}{ WOX4-like protein } & Forward & 20 & 63.1 & 50 & TCTCGGCTCATGTTCACTTC \\
\hline & Pc_06813_WOX_R1 & & Reverse & 20 & 63.1 & 50 & TACCAGTGGTTGCAGGTGTT \\
\hline \multirow{2}{*}{ Contig09007 } & Pc_09007_EXO_F1 & \multirow{2}{*}{$\begin{array}{l}\text { exordium 2-like } \\
\text { protein }\end{array}$} & Forward & 20 & 62.9 & 45 & TACCCGATCATGCAAGACAT \\
\hline & Pc_09007_EXO_R1 & & Reverse & 20 & 62.7 & 55 & GCGCCTAAATCTACCTGCTC \\
\hline \multirow[b]{2}{*}{ Contig05923 } & Pc_05923_bHLH_F1 & \multirow[b]{2}{*}{ bHLH35-like protein } & Forward & 20 & 63.9 & 45 & GTGCGAATAGAGGGCAAAAA \\
\hline & Pc 05923 bHLH R1 & & Reverse & 20 & 641 & 45 & CGAAGCAGCAGATGTTTGAA \\
\hline \multirow{2}{*}{ Contig22185 } & Pc_22185_PR_F1 & \multirow{2}{*}{$\begin{array}{l}\text { Major allergen PRU- } \\
\text { like protein }\end{array}$} & Forward & 20 & 65.0 & 60 & GTGGAGGCAAGGAGACTGTG \\
\hline & Pc_22185_PR_R1 & & Reverse & 19 & 64.9 & 63.2 & CTGCCTACGCCTCCATCTC \\
\hline \multirow[b]{2}{*}{ Housekeeping } & Ri18S_FW & \multirow[b]{2}{*}{$18 \mathrm{~S}$ robosomal } & Forward & 19 & 62.4 & 53 & GCGAAAGCATTTGCCAAGG \\
\hline & Ri18S RV & & Reverse & 21 & 62.4 & 48 & ATTCCTGGTCGGCATCGTTTA \\
\hline
\end{tabular}

Tm. Melting temperature. GC: guanine-cytosine content. bp: base pair 
Gene specific primers were designed for twelve selected DEGs (Table 2) using the Primer3 software (Untergasser et al. 2012), with a melting temperature between 60 and $65^{\circ} \mathrm{C}$, and producing amplicons between 80 and 120 bp. qRT-PCR was performed in a CFX96 ${ }^{\mathrm{TM}}$ Real-Time PCR Detection System (Biorad, USA), using the SsoFast ${ }^{\mathrm{TM}}$ EVAgreen $^{\circledR}$ Supermix (Biorad, USA), according to manufacturer's protocol, and following the standard thermal profile: $95^{\circ} \mathrm{C}$ for $3 \mathrm{~min}, 40$ cycles of $95^{\circ} \mathrm{C}$ for $10 \mathrm{~s}$ and $60^{\circ} \mathrm{C}$ for $10 \mathrm{~s}$. In order to compare data from different qRT-PCR runs, the CT values were normalized using the Ri18S as housekeeping gene, whose specific primers were FW 5'-GCGAAAGCATTTGCCAAGG-3' and REV 5'ATTCCTGGTCGGCATCGTTTA-3'. This genes has been previously proved to be useful for this purpose in pine species (f.i., see Perdiguero et al. 2013). The expression ratios were then obtained using the delta-delta-CT method corrected for the PCR efficiency for each DEG (Pfaffl 2001). 



\title{
Chapter 4.
}

\section{Differential gene expression analysis provides new insights of the resprouting process in Pinus canariensis}

\author{
Chano V, Collada C, Soto A
}

G.I. Genética, Fisiología e Historia Forestal. ETSI Montes, Forestal y del Medio Natural. Dpto. Sistemas y Recursos Naturales. Universidad Politécnica de Madrid. Ciudad Universitaria s/n 28040 Madrid, Spain

\section{ABSTRACT}

Resprouting, one of the main fire-adaptive traits, is crucial in population dynamics in response to wildfires. Pinus canariensis is one of the few conifers in the Old World able to resprout in response to damage. In order to analyze gene expression profiling during lateral shoot resprouting and its effect on secondary xylem growth, 5 year-old Canary Island pine trees were wounded and RNA from the resprouting area was extracted at three sampling dates during response: i) R1 as immediate control after wounding, ii) R2 for the initiation of the resprouting process, and iii) R3 when new resprouts had completely emerged. Gene expression during the process was analyzed using a microarray including over 15000 cDNAs from Pinus canariensis transcriptome of meristematic activity. Over the period of response, 1164 genes changed significantly its expression compared to normal growth and were considered Differentially Expressed Genes (DEGs). They were grouped in 7 clusters according to their expression profile. During the R1 stage, genes involved in the development of this tissue showed repression in the vicinity of wounds despite trees were forming earlywood. Conversely, defense- and stress-responses caused by wounding were mainly overexpressed at this time. F.i., some of them were antimicrobial peptide 1-like, disease resistance response protein 206-like, or pathogenesis-related protein PR-4b-like, among others. Along R2 and R3, when new shoots were emerging, genes putatively coding for transcription factors such as GROWTH-REGULATING FACTOR (GRF), FLOWERING-PROMOTING FACTOR (FPF), and members of the HOMEODOMAIN 
Chano, $V$-Transcriptomics of the response to wounding

LEUCINE ZIPPER Class IV subfamily were found as DEGs. As well, we found homologues of YABBY and LEAFY transcription factors, overexpressed at R2 and R3 respectively. Moreover, two different members of the AP2/ERF transcription factors were differentially expressed during R2 and R3, but showing opposing expression patterns. This data was compared to differential gene expression during apical shoot growth, founding similarities and differences between resprouting shoots and normal growth from vegetative apical shoots, allowing the identification of genes specific for resprouting. Thus, we found ATHB13-like homeobox protein to be overexpressed exclusively in the R3 stage of resprouting together with members of the TIFY family of transcription factors. Based in our data and the bibliography available, we suggest functional key roles of these candidate genes in regulation of de novo lateral shoot development in a coniferous species, Pinus canariensis, in response to mechanical wounding.

Keywords: Wound, Resprouting, Conifers, Transcriptome, Apical Growth, Pinus canariensis

\section{INTRODUCTION}

Resprouting capability is considered as a tolerance trait against traumatisms and mechanical stress caused by herbivory, forest fires, etc. (Clarke et al. 2013), conferring resilience to plants due to the presence of epicormic shoots, (i.e. vegetative latent buds that can be induced to develop a new shoot), especially in response to stress caused by fire effects and mechanical damage. Most forest trees can endure low intensity fires by protecting their vascular cambium with a more or less thick, isolating bark. Their shoot apical meristems (SAM), mainly those located in the top part of the crown, can avoid fire damages unless it reaches the crowns (usually, high intensity fires). Even more, many forest tree species present self-pruning trunks which hampers the setting up of crown-fires. On the contrary, many arbustive species and small trees have evolved in fire-prone environments thanks to their resprouting capability. According to Clarke's review (2013), latent shoots are classified depending on their position as stem, apical, basal or root 
resprouts. While below-ground tissues are well protected and isolated by soil, for above-ground resprouters bark thickness is the main protection factor for xylem, phloem and vascular cambium (Choczynska and Johnson 2009).

Although the resprouting process has been recognized as an important factor in population dynamics (Loehle 2000, Hoffmann et al. 2009), few works have focused on this feature. Some of them have approached anatomy and ontogeny of resprouting (reviewed by Clarke et al. 2013) but mechanisms driving the resprouting process are complex and remain not well understood. In Meier's review (2012), resprouting was proposed to be a response to a physiological disequilibrium in the plant, with hormones driving regulatory signaling pathways during the response, as a necessity to expand foliar coverage and recover of canopy for the capture of nutrients and recourses as much as possible (Nicolini et al. 2001, Sprugel 2002, Ishii 2011). Nevertheless, local resprout can also be induced by small injuries not affecting the crown and which do not compromise the photosynthetic capacity of the plant. New resprouts may be formed by dedifferentiation of mature cells into stem cells, which can revert into new celltypes (Savidge 2001). Additionally, in several species new shoots develop from buds located in leaf axils. For example, in Wollemi Pine (Wollemia nobilis) epicormic shoots arise from small meristems located in axils (Burrows et al. 2003).

Resprouting is not a rare trait in flowering plants. F.i., shrubs from fire-prone chaparral present this ability, such as the crown-resprouters Ceanothus roderickii (Boyd 2007), and some subspecies of Arctostaphylos glandulosa (Keely et al. 2007). Even though resprouting has been considered an ancestral condition that may have been lost in modern plant groups (Bond and Midgley 2003), is noteworthy the scarcity of coniferous species able to resprout. Notwithstanding, the Canary Island pine is one of the few conifers able to resprout in both juvenile and adult stages, together with the Himalayan pine and other conifers from North and Central America (He et al. 2012, Keeley 2012). This resprouting capability in the first is strongly linked to its evolutionary history in the volcanic Archipelago, subjected to recurrent forest-fires that drove the dynamics of its populations 
Chano, $V$-Transcriptomics of the response to wounding

under perturbation regimes (Climent et al. 2004). Thus, we propose Pinus canariensis as a suitable model species for the study of this singular trait in conifers.

In this work, we aim a better understanding of the gene expression dynamics of induced resprouting in conifers, in response to mechanical damage. We analyzed the local response in vascular tissue during the resprouting process and how it affects the regular development of secondary growth in the vicinity of the injury. For this a microarray designed using a normalized transcriptome of the meristematic activity during xylogenesis in the Canary Island pine described in Chapter 1 was used (Chano et al. 2017b). We analyzed gene expression profiles after wounding and during the very early steps of the resprouting process, and compared these results with those obtained during apical growth, as a first approximation to identify resprouting specific genes.

\section{RESULTS AND DISCUSSION}

\section{Anatomical Analysis of the Resprouting}

We induced resprouting by performing fenestration wounds in the stem of 5-yearold pines. Unlike adventitious sprouts, which arise from dedifferentiation and redifferentiation of cells with a huge inversion of energy and reserves, epicormic shoots result from preformed buds whose activation presumably require lower costs. Furthermore, axillary buds remain in contact to the inner vascular tissues by the trace (Figure 1A-D), enabling the assimilation and allocation of resources and assimilates through flow-conducting tissues (Schweingruber 2007).

In this case, new shoots emerged from axillary buds placed in brachyblast scars around the wound and also in the opposite side of the stem as shown in Figure 1EG. In older sections of the stem, as its circumference increases, these axillary buds get embedded and isolated by the growing bark, and become predominantly nonviable, which results in a poor resprouting capability (Fink 1984). Notwithstanding, in some cases this meristematic niche remains viable and 
protected by bark, being able to develop an epicormic resprout in response to damage, as reported for Wollemi pine (Burrows et al. 2003) or as shown in Figure 1H-I for P. canariensis.

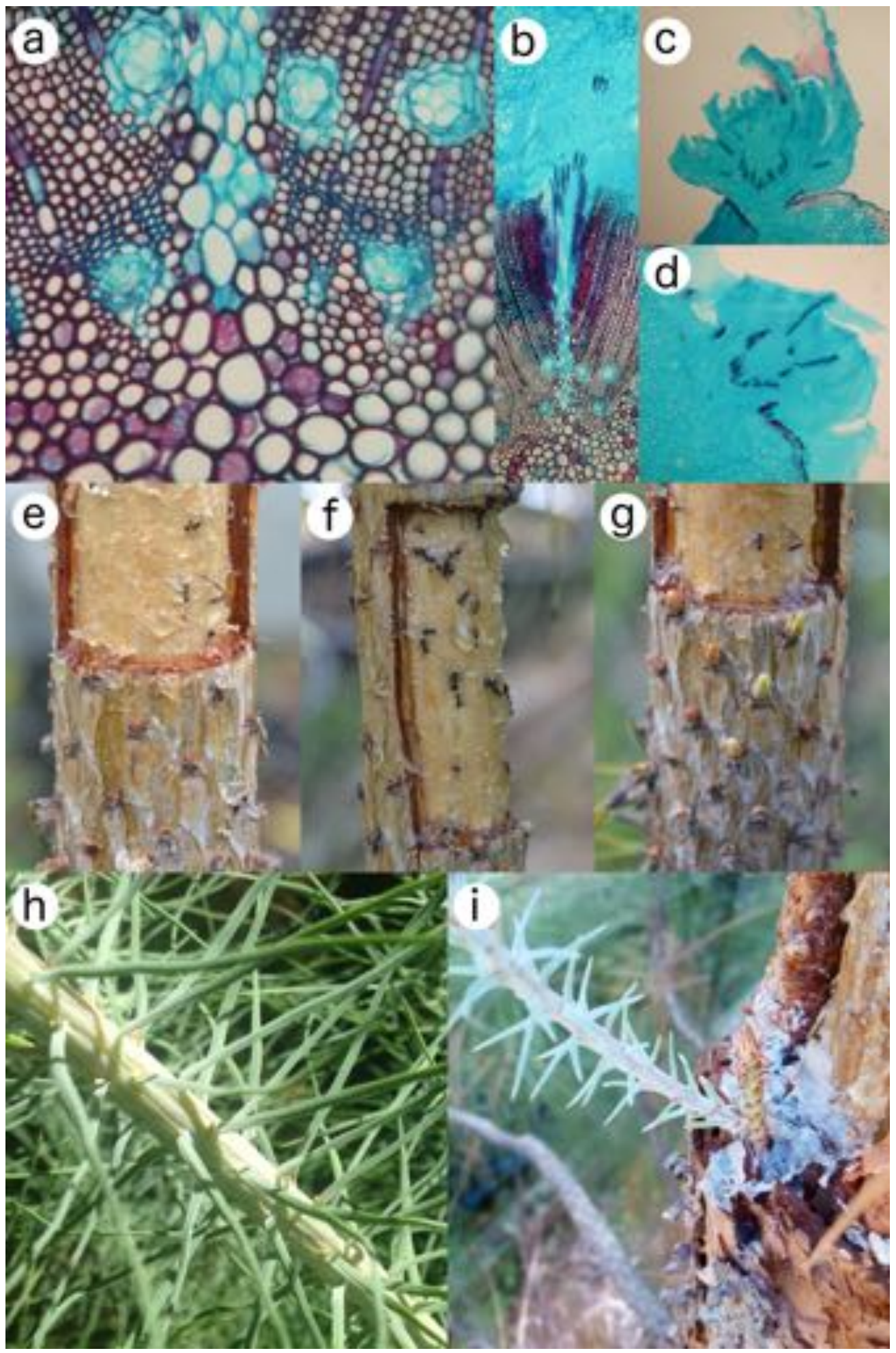

Figure 1. Description of the resprouting process and sample collection. A - D) Anatomy of resprouts. E-G) Sampling phases. H) Axil buds located in the axils of young needles. I) Two resprouts emerging from the lower margin of a wound. 
Chano, $V$-Transcriptomics of the response to wounding

\section{Selection of Differentially Expressed Genes During Resprouting}

A 60K two-color cDNA microarray (Agilent, USA) was hybridized in order to analyze gene expression in the Canary Island pine during the induced resprouting process. This cDNA microarray includes genes involved in meristematic activity during the xylogenesis process described in Chapter 1 in P. canariensis (Chano et al. 2017b). Samples were taken during three stages over the response period from three resprouting phenotypes (Figure 1E-G), namely i) R1 as immediate response to wounding, prior to the emergence of resprouts, ii) R2, when new emerging resprouts were observed, and iii) R3, during the elongation of resprouts. Controls were collected at the same sampling dates from branches away from the wound of the same trees, in order to avoid confusion with constitutive changes during the seasonal growth.
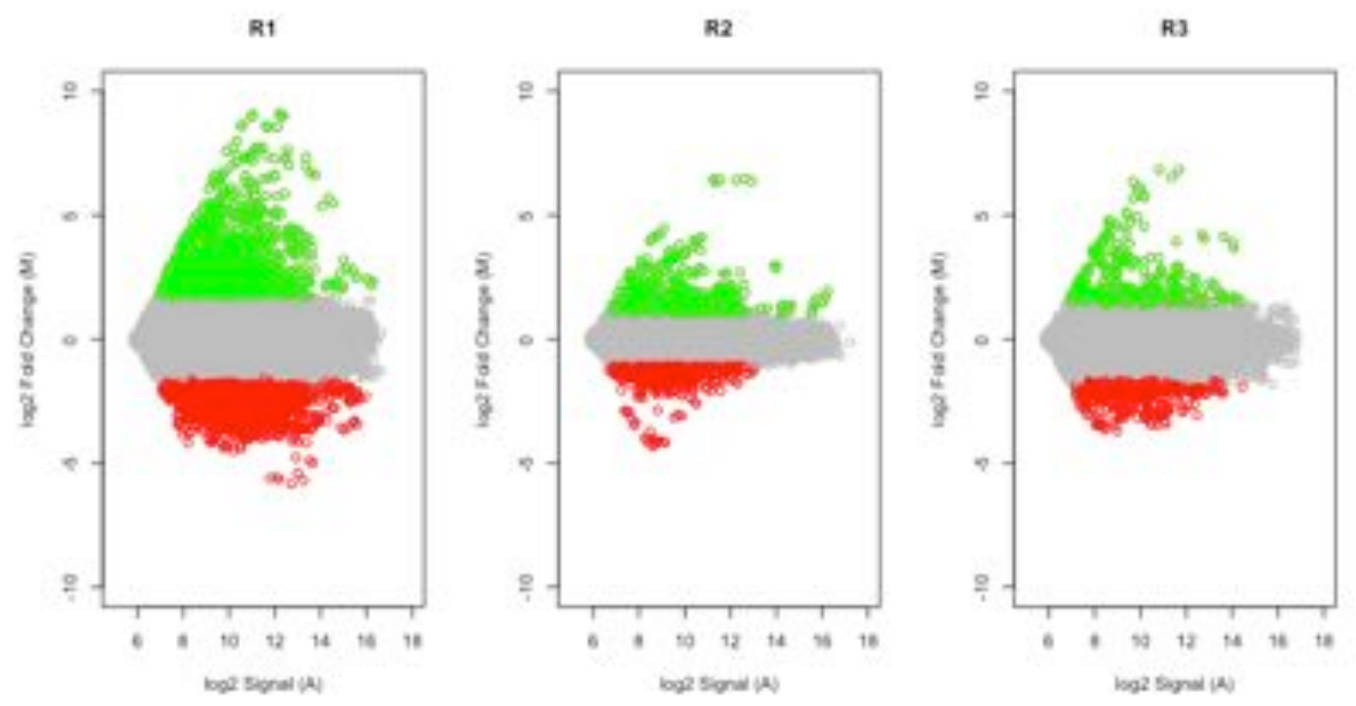

Figure 2. MA plot of microarray normalized data during resprouting process. X-axis: Log2 of microarray signals; Y-axis: Log2 of Fold Change values; Green dots: probes selected as overexpressed (FC $>2$, FDR $<0.05$, between treatment and control RNA samples); Red dots: probes selected as underexpressed (FC $<-2$, FDR $<0.05$ between treatment and control RNA samples).

The analysis resulted in 1164 DEGs (Table S1), and using Blast2GO (Conesa and Götz 2008) we generated combined graphs of the annotated DEGs for Biological Process (BP) category in order to explore graphical representation of ontology, 


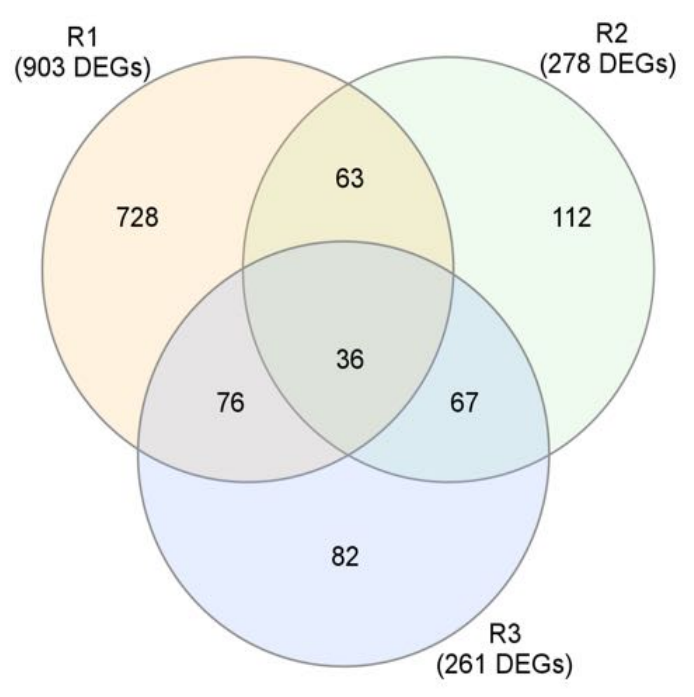

Figure 3. Differentially expressed genes during resprouting in response to wounding.

and visualize the combined annotation for groups (Figure S2). We found remarkable GO terms at levels 2 and 3 , related with developmental activity, such as "growth”, "anatomical structure development” or "biosynthetic process”. These GO term annotations resulted more specific as deeper levels were explored, we found more specific GO terms, like "shoot system development” in level 6 (BP), a specific GO term that describes the process of resprouting, and "flower development" at level 8, indicative of de novo lateral organogenesis as well. MA Plot in Figure 2 presents the distribution of those genes selected as over- and underexpressed at each sampling date. Table 1 presents a selection of DEGs with strong responses, and associated to functional processes of interest, according to their top BLASTx hit, as previously described in Chapter 1 (Chano et al. 2017b).

Figure 3 shows a Venn diagram with the significant genes for each sampling date. R1 included 903 DEGs, the largest group, while R2 and R3 included 278 and 261 DEGs, respectively. The differences between R1 and R2 or R3 suggest that the immediate response to wounding involved a great number of DEGs. Around one hundred of DEGs were shared between R1 and R2, R2 and R3, and R1 and R3, and 36 of them were common to the three stages. As shown in Supplementary Figure 1, the hierarchical clustering of samples reveals that R1 was significantly different to R2 and R3 according to their expression patterns. Thus, we defined two main processes actives during the whole response analyzed, which may underlie those differences observed at R1 (immediate effects in growth rates and defense/stress responses) and R2/R3 (emerging and development of epicormic shoots). The 67 
Chano, $V$-Transcriptomics of the response to wounding

DEGs shared between R2 and R3, and not R1, are presumably related to the resprouting response.

\section{Clustering and Gene Expression Profiling of DEGs}

A RESPROUTING Differentially Expressed Genes
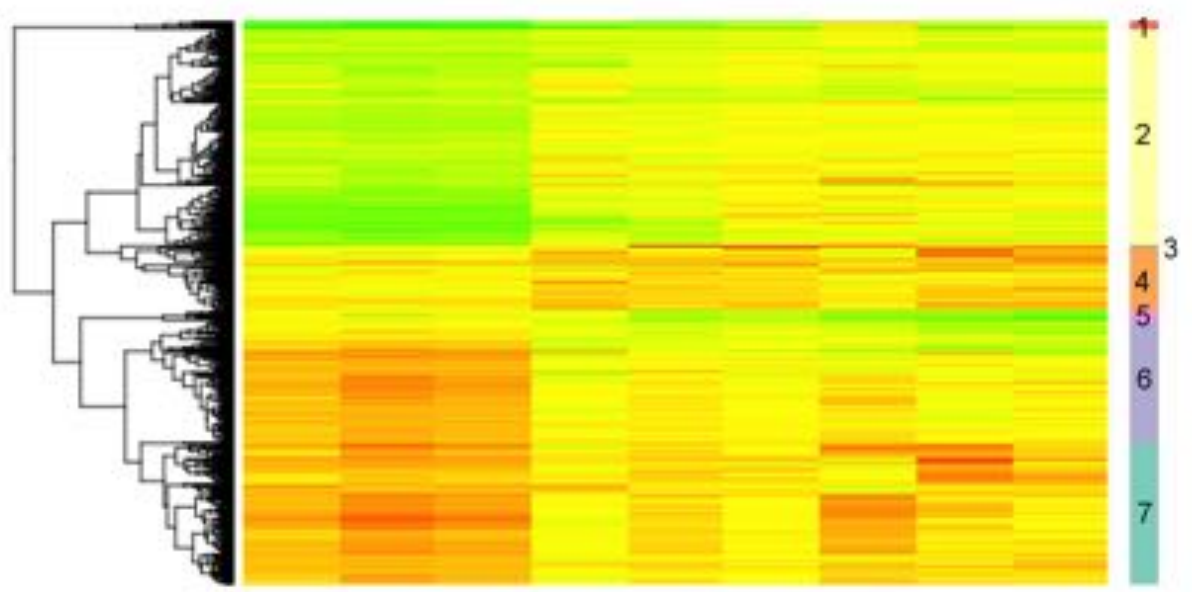

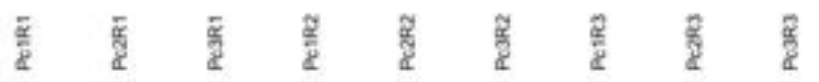

B

Cluster RSP-1 (18 genes) Cluster RSP-3 (445 genes)
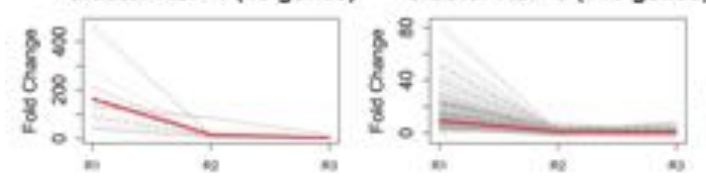

Cluster RSP.3 (5 genes)

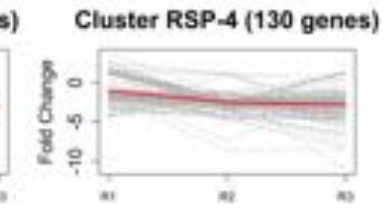

Cluster RSP.5 (21 genes)

Cluster RSP-6 (252 genes)
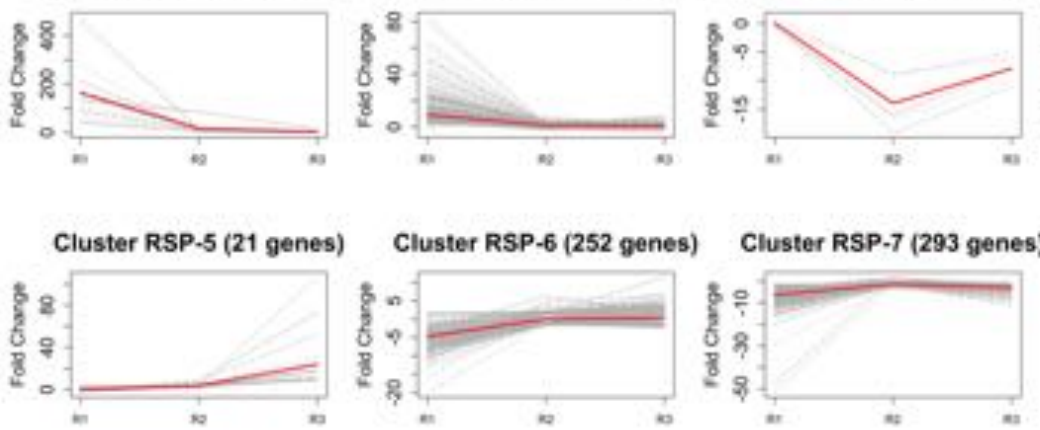

Figure 4. Clustering of DEGs according to expression patterns. A) Hierarchical clustering of 1064 DEGs for three biological replicates (PC1, -2 and -3), identifying 7 clusters (RSP1 - 7). b Gene expression profiling of clusters, showing Fold Change variations along sampling dates.

DEGs were clustered in 7 groups (Figure 4A-B), according to their transcriptional variation along the process. First, transcription levels of many genes were significantly altered during R1, mainly including the overexpression of 18 and 445 DEGs grouped in clusters RSP-1 and -2, respectively. At the same time, 463 genes 
mainly grouped in clusters RSP-6 and RSP-7 showed repression at this stage compared to control samples of regular growth.
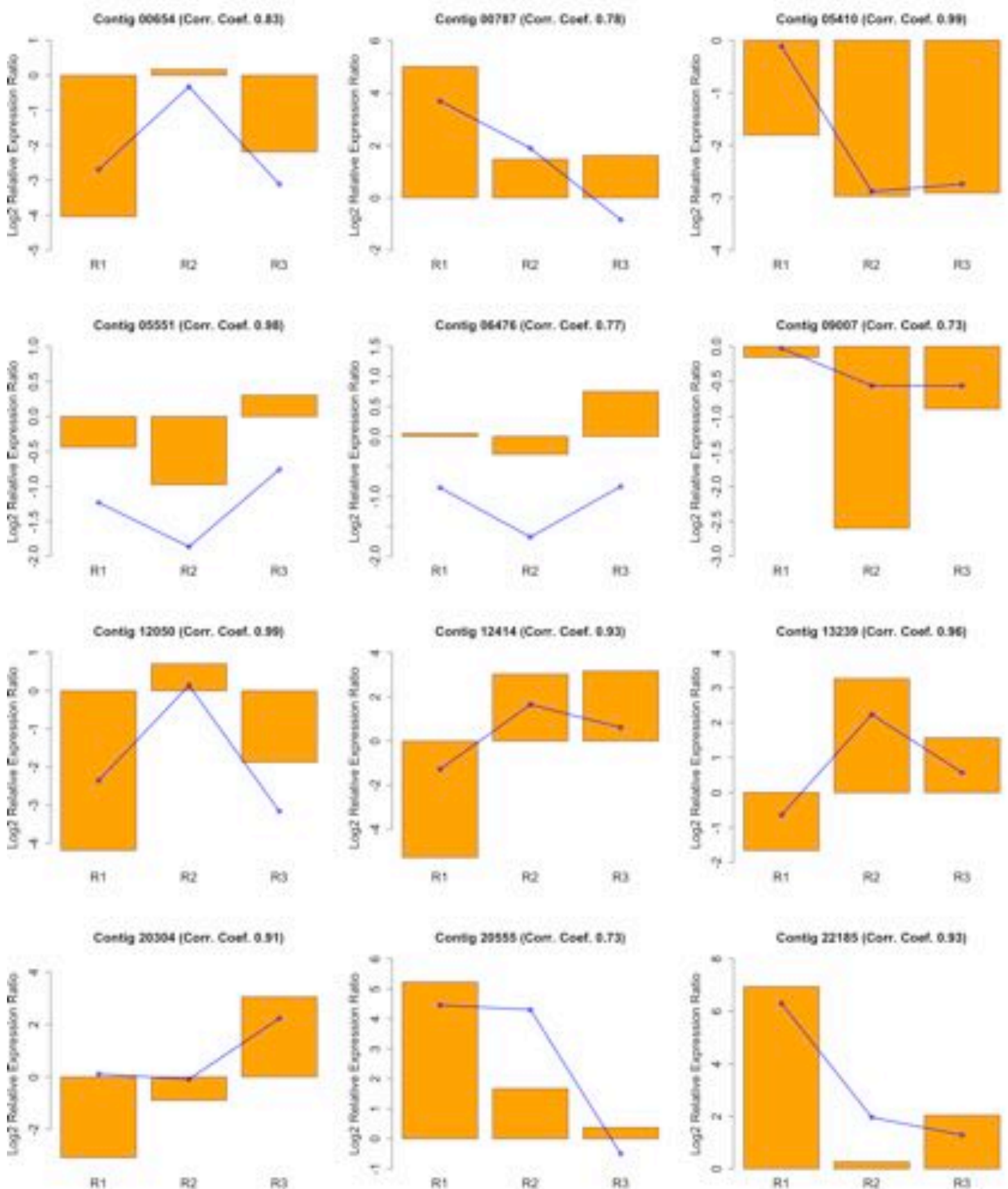

Figure 5. qRT-PCR validation of microarray transcription profiles. X-axis: sampled times; Y-axis: normalized gene expression values of selected DEGs for qRT-PCR (bars) validation of microarray expression profiling (continuous lines).

On the other hand, many genes were differentially expressed at R2 and/or R3, corresponding to the resprout development. While some DEGs showed repression (5 in cluster RSP-3 and a great proportion of those included in cluster RSP-4), other 
genes were induced during these stages, as those grouped in cluster RSP-5 (21 DEGs), and other groups of genes included in clusters RESP-6 and -7.

Reliability of the transcription profiles obtained from microarray hybridization was validate through qRT-PCR analysis. Thus, 12 genes presumably relevant for the processes described above, covering the main expression patterns were selected. From them, 4 genes were directly involved in cell growth and cell wall formation and lignin deposition, coding for the proteins pectinesterase-like (Contig05410, cluster RSP-4), expansin-like (Contig12414, cluster RSP-6), CeSA-like (Contig00654, cluster RSP-7) and CCoAOMT (Contig06476, cluster RSP-7). As well, we checked transcription factors also involved in developmental processes, as MYB46-like (Contig12050, cluster RSP-7), ATHB13-like (Contig20304, cluster RSP2), NAC2-like (Contig00787, cluster RSP-2), WRKY51-like (Contig05551, cluster RSP4), and YAB5-like (Contig13239, cluster RSP-6). Finally, we also analysed genes coding for a PAL-like protein (Contig20555, cluster RSP-2), presumably related to defense, EXORDIUM-like protein (Contig09007, cluster RSP-4), presumably involved in cell proliferation, and Major Allergen Pru AR1-like (Contig22185, cluster RSP-1), putatively involved in defensive response. Profiles obtained by qRT-PCR for these genes match the ones obtained from microarray hybridization, with high correlation coefficients, thus validating the general tendencies described above for microarray analysis (Figure 5).

Table 1. Selected resprouting DEGs, grouped according to their putative role and their expression profile clustering

\begin{tabular}{|c|c|c|c|c|c|c|c|c|}
\hline \multirow[t]{2}{*}{ Cluster } & \multirow[t]{2}{*}{ ID } & \multirow[t]{2}{*}{ Seq. Description } & \multicolumn{3}{|c|}{$\mathbf{R 1}$} & \multicolumn{2}{|l|}{$\mathbf{R 2}$} & \multirow[b]{2}{*}{ FDR } \\
\hline & & & FC & FDR & FC & FDR & FC & \\
\hline \multicolumn{9}{|c|}{ Cell-wall matrix development and/or carohydrates metabolism } \\
\hline RSP-2 & Contig08531 & probable pectate lyase 15 -like & 39.65 & 0.00 & 1.50 & 0.52 & -0.34 & 0.76 \\
\hline RSP-2 & Contig17005 & probable pectate lyase 12 -like & 41.21 & 0.00 & 1.55 & 0.43 & 0.36 & 0.94 \\
\hline RSP-2 & Contig21204 & alpha-expansin 8 & 21.30 & 0.00 & 2.55 & 0.09 & 1.18 & 1.05 \\
\hline RSP-2 & Ppnisotig00677 & expansin-a8-like & 39.38 & 0.00 & 1.86 & 0.26 & 1.57 & 0.61 \\
\hline RSP-3 & Contig10110 & $\begin{array}{l}\text { xyloglucan galactosyltransferase } \\
\text { katamari1-like }\end{array}$ & 1.10 & 1.16 & -9.10 & 0.01 & -5.00 & 0.03 \\
\hline RSP-3 & Contig11855 & galactan synthase 1 & 0.39 & 0.96 & -16.84 & 0.00 & -9.68 & 0.00 \\
\hline RSP-3 & Contig12945 & germin-like protein 2-1-like & -0.34 & 1.20 & -8.71 & 0.01 & -6.08 & 0.01 \\
\hline
\end{tabular}




\begin{tabular}{|c|c|c|c|c|c|c|c|c|}
\hline RSP-4 & Contig05410 & pectinesterase 2-like & -1.71 & 0.56 & -8.61 & 0.00 & -8.48 & 0.00 \\
\hline RSP-4 & Contig12739 & expansin-like a1-like & 1.48 & 0.45 & -2.00 & 0.05 & -4.81 & 0.04 \\
\hline RSP-4 & Contig17013 & $\begin{array}{l}\text { probable xyloglucan } \\
\text { endotransglucosylase hydrolase protein } \\
23\end{array}$ & -1.22 & 0.90 & -2.26 & 0.05 & -1.31 & 1.04 \\
\hline RSP-4 & Contig17876 & expansin-like a1-like & 1.53 & 0.43 & -1.98 & 0.09 & -4.95 & 0.04 \\
\hline RSP-4 & Ppnisotig08645 & expansin-b3-like & -4.48 & 0.03 & 1.07 & 1.04 & 0.33 & 1.01 \\
\hline RSP-5 & Contig20345 & wat1-related protein at5g07050-like & 4.13 & 0.10 & 3.24 & 0.03 & 18.49 & 0.00 \\
\hline RSP-6 & Contig02447 & caffeoyl- o-methyltransferase-like & -10.28 & 0.00 & -1.54 & 0.37 & 1.68 & 0.50 \\
\hline RSP-6 & Contig05066 & probable pectate lyase 15 -like & -4.35 & 0.03 & -0.39 & 0.91 & 0.26 & 0.95 \\
\hline RSP-6 & Contig12414 & expansin-b3-like & -2.73 & 0.13 & 1.71 & 0.30 & 3.70 & 0.03 \\
\hline RSP-6 & Contig20721 & cellulose synthase a catalytic subunit 3 & -3.65 & 0.05 & -1.26 & 0.72 & -1.01 & 1.00 \\
\hline RSP-6 & Contig23434 & cinnamoyl- reductase 1-like & -2.34 & 0.19 & 1.30 & 0.79 & 3.98 & 0.01 \\
\hline RSP-6 & Ppnisotig01389 & mannan endo- -beta-mannosidase 7-like & -7.65 & 0.01 & -1.19 & 0.87 & -1.72 & 0.41 \\
\hline RSP-7 & Contig00260 & cellulose synthase a catalytic subunit 4 & -11.21 & 0.00 & -1.58 & 0.36 & -3.94 & 0.04 \\
\hline RSP-7 & Contig00654 & cellulose synthase a catalytic subunit 3 & -10.66 & 0.00 & -1.65 & 0.21 & -3.16 & 0.05 \\
\hline RSP-7 & Contig01025 & $\begin{array}{l}\text { fasciclin-like arabinogalactan protein 10- } \\
\text { like }\end{array}$ & -4.14 & 0.03 & -1.62 & 0.23 & -3.18 & 0.04 \\
\hline RSP-7 & Contig01405 & protein cobra-like & -8.51 & 0.00 & -1.53 & 0.39 & -3.73 & 0.05 \\
\hline RSP-7 & Contig02909 & $\begin{array}{l}\text { mannose-1-phosphate guanyltransferase } \\
\text { alpha-like }\end{array}$ & -7.90 & 0.01 & -1.41 & 0.60 & -3.01 & 0.07 \\
\hline RSP-7 & Contig06476 & caffeoyl- o-methyltransferase & -1.58 & 0.55 & -2.42 & 0.03 & -5.63 & 0.02 \\
\hline RSP-7 & Contig08356 & udp-glycosyltransferase 85a2-like & -51.71 & 0.00 & -1.29 & 0.77 & -4.17 & 0.03 \\
\hline RSP-7 & Contig09025 & $\begin{array}{l}\text { xyloglucan endotransglucosylase } \\
\text { hydrolase protein 9-like }\end{array}$ & -9.47 & 0.00 & -2.74 & 0.01 & -3.97 & 0.04 \\
\hline RSP-7 & Contig11436 & $\begin{array}{l}\text { probable polygalacturonase non-catalytic } \\
\text { subunit jp650-like }\end{array}$ & -14.26 & 0.00 & -0.42 & 0.96 & -1.78 & 0.49 \\
\hline RSP-7 & Contig12072 & $\begin{array}{l}\text { glucomannan 4-beta- } \\
\text { mannosyltransferase 9-like }\end{array}$ & -4.51 & 0.03 & -1.25 & 0.84 & -2.06 & 0.32 \\
\hline RSP-7 & Contig13778 & $\begin{array}{l}\text { probable polygalacturonase at1g80170- } \\
\text { like }\end{array}$ & -7.29 & 0.01 & -1.25 & 0.91 & -3.12 & 0.13 \\
\hline RSP-7 & Contig41981 & cellulose synthase a catalytic subunit 3 & -9.20 & 0.00 & -2.14 & 0.05 & -4.67 & 0.03 \\
\hline \multicolumn{9}{|c|}{ Defense and stress response genes } \\
\hline RSP-1 & Contig10307 & endochitinase a-like & 88.54 & 0.00 & 9.25 & 0.00 & 1.84 & 0.20 \\
\hline RSP-1 & Contig17617 & defensin ec-amp-d2-like & 45.72 & 0.00 & 2.98 & 0.01 & -1.11 & 1.00 \\
\hline RSP-1 & Contig18804 & $\begin{array}{l}\text { disease resistance response protein 206- } \\
\text { like }\end{array}$ & 450.31 & 0.00 & 15.09 & 0.00 & 1.46 & 0.77 \\
\hline RSP-1 & Contig19053 & pathogenesis-related protein pr-4b-like & 161.48 & 0.00 & 10.17 & 0.00 & 6.14 & 0.01 \\
\hline RSP-1 & Contig21216 & endochitinase a-like & 163.54 & 0.00 & 6.78 & 0.00 & -1.15 & 1.02 \\
\hline RSP-1 & Contig22185 & major allergen pru ar 1-like & 212.01 & 0.00 & 10.10 & 0.00 & 3.14 & 0.03 \\
\hline RSP-1 & Contig22375 & pathogenesis-related protein pr-4-like & 475.82 & 0.00 & 19.71 & 0.00 & 3.95 & 0.04 \\
\hline RSP-1 & Ppnisotig00751 & endochitinase a-like & 156.62 & 0.00 & 8.46 & 0.00 & 2.03 & 0.20 \\
\hline RSP-1 & Ppnisotig01747 & peroxidase 12-like & 161.51 & 0.00 & 5.71 & 0.00 & 1.10 & 1.09 \\
\hline
\end{tabular}




\section{Chano, $V$-Transcriptomics of the response to wounding}

\begin{tabular}{|c|c|c|c|c|c|c|c|c|}
\hline RSP-1 & Ppnisotig02901 & glutathione s-transferase f9-like & 110.72 & 0.00 & 6.95 & 0.00 & 2.91 & 0.03 \\
\hline RSP-1 & Ppnisotig06171 & glutathione s-transferase f9-like & 91.32 & 0.00 & 7.76 & 0.00 & 2.64 & 0.05 \\
\hline RSP-1 & Ppnisotig12265 & antimicrobial peptide 1-like & 158.54 & 0.00 & 84.25 & 0.00 & 16.86 & 0.00 \\
\hline RSP-1 & Ppnisotig13133 & pathogenesis-related protein pr-4-like & 277.44 & 0.00 & 13.79 & 0.00 & 3.87 & 0.05 \\
\hline RSP-1 & Ppnisotig13431 & $\begin{array}{l}\text { disease resistance response protein 206- } \\
\text { like }\end{array}$ & 143.94 & 0.00 & 11.34 & 0.00 & 1.54 & 0.77 \\
\hline RSP-2 & Contig00126 & basic endochitinase a-like & 22.86 & 0.00 & 1.97 & 0.09 & -1.52 & 0.63 \\
\hline RSP-2 & Contig00602 & defensin ec-amp-d2-like & 14.04 & 0.00 & 3.62 & 0.01 & 2.14 & 0.27 \\
\hline RSP-2 & Contig02383 & peroxidase 44 -like & 3.13 & 0.05 & 3.30 & 0.00 & 2.35 & 0.18 \\
\hline RSP-2 & Contig02586 & probable glutathione s-transferase & 4.50 & 0.03 & 1.21 & 0.94 & 1.29 & 0.97 \\
\hline RSP-2 & Contig06170 & peroxidase 12 -like & 10.44 & 0.00 & 4.43 & 0.00 & 0.40 & 1.08 \\
\hline RSP-2 & Contig06950 & probable glutathione s-transferase-like & 2.28 & 0.16 & 2.39 & 0.03 & 2.56 & 0.11 \\
\hline RSP-2 & Contig08118 & cationic peroxidase 1-like & 64.34 & 0.00 & 1.93 & 0.20 & 1.55 & 0.51 \\
\hline RSP-2 & Contig08224 & $\begin{array}{l}\text { probable glutathione s-transferase gstu6- } \\
\text { like }\end{array}$ & 5.50 & 0.02 & -2.67 & 0.02 & -0.35 & 0.95 \\
\hline RSP-2 & Contig12556 & $\begin{array}{l}\text { probable 1-deoxy-d-xylulose-5-phosphate } \\
\text { synthase chloroplastic-like }\end{array}$ & 2.64 & 0.11 & -1.07 & 1.03 & 2.78 & 0.04 \\
\hline RSP-2 & Contig13391 & cationic peroxidase 1-like & 5.19 & 0.02 & -1.27 & 0.66 & -2.21 & 0.25 \\
\hline RSP-2 & Contig14047 & $\begin{array}{l}\text { disease resistance response protein 206- } \\
\text { like }\end{array}$ & 3.89 & 0.04 & -1.11 & 0.84 & 1.37 & 0.80 \\
\hline RSP-2 & Contig16597 & phenylalanine ammonia-lyase & 4.35 & 0.04 & 1.90 & 0.34 & -0.38 & 1.02 \\
\hline RSP-2 & Contig17069 & endochitinase a-like & 4.77 & 0.03 & 5.19 & 0.00 & 1.18 & 0.53 \\
\hline RSP-2 & Contig17710 & basic endochitinase a-like & 4.59 & 0.03 & 2.78 & 0.04 & 1.40 & 0.91 \\
\hline RSP-2 & Contig20552 & peroxidase 12 -like & 3.99 & 0.03 & 2.23 & 0.11 & 1.57 & 0.75 \\
\hline RSP-2 & Contig20555 & phenylalanine ammonia-lyase-like & 36.91 & 0.00 & 3.64 & 0.04 & -1.42 & 0.68 \\
\hline RSP-2 & Contig20817 & phenylalanine ammonia-lyase-like & 6.67 & 0.02 & 2.06 & 0.21 & 1.09 & 1.10 \\
\hline RSP-2 & Contig21755 & peroxidase 12-like & 24.74 & 0.00 & 4.38 & 0.01 & 1.15 & 1.03 \\
\hline RSP-2 & Contig23442 & chitinase 1-like & 44.00 & 0.00 & 3.48 & 0.04 & 1.10 & 1.01 \\
\hline RSP-2 & Contig40036 & peroxidase 55 & 4.91 & 0.02 & 1.26 & 0.89 & 1.21 & 1.02 \\
\hline RSP-2 & Ppnisotig08058 & chitinase 6-like & 83.29 & 0.00 & 1.44 & 0.59 & 1.11 & 1.05 \\
\hline RSP-2 & Ppnisotig10090 & endochitinase ep3-like & 8.50 & 0.01 & 1.35 & 0.64 & 1.13 & 1.01 \\
\hline RSP-2 & Ppnisotig11516 & pathogenesis-related protein pr-4-like & 7.13 & 0.01 & 1.52 & 0.29 & 1.24 & 0.96 \\
\hline RSP-5 & Ppnisotig00872 & endoglucanase 17-like & -1.92 & 0.36 & 4.37 & 0.00 & 26.49 & 0.00 \\
\hline RSP-7 & Contig01914 & chitinase-like protein 1 & -12.06 & 0.00 & -1.59 & 0.26 & -4.08 & 0.04 \\
\hline \multicolumn{9}{|c|}{ Transcriptional regulation of meristem activity } \\
\hline RSP-1 & Contig06361 & protein tify $10 a-l i k e$ & 64.22 & 0.00 & 8.34 & 0.00 & 2.86 & 0.04 \\
\hline RSP-2 & Contig00787 & nac domain-containing protein 2-like & 10.24 & 0.01 & 2.30 & 0.03 & 1.80 & 0.29 \\
\hline RSP-2 & Contig01913 & transcription factor myb44-like & 3.60 & 0.05 & -1.84 & 0.12 & -1.10 & 1.06 \\
\hline RSP-2 & Contig02808 & probable wrky transcription factor 31 & 17.90 & 0.00 & 1.57 & 0.41 & 1.09 & 0.83 \\
\hline RSP-2 & Contig02956 & probable wrky transcription factor 7 & 4.01 & 0.03 & 1.29 & 0.73 & 1.62 & 0.56 \\
\hline
\end{tabular}




\begin{tabular}{|c|c|c|c|c|c|c|c|c|}
\hline RSP-2 & Contig04787 & protein tify $6 \mathrm{~b}$-like & 3.54 & 0.04 & 1.15 & 0.99 & 1.13 & 1.04 \\
\hline RSP-2 & Contig05465 & nac domain-containing protein 2-like & 6.42 & 0.01 & 1.63 & 0.20 & 1.72 & 0.54 \\
\hline RSP-2 & Contig05634 & nac domain-containing protein 2-like & 35.61 & 0.00 & 4.56 & 0.00 & 1.16 & 1.04 \\
\hline RSP-2 & Contig05923 & transcription factor bhlh35 & 3.59 & 0.04 & 1.71 & 0.14 & 1.75 & 0.41 \\
\hline RSP-2 & Contig06152 & exordium like 2 & 55.72 & 0.00 & 3.21 & 0.06 & -1.20 & 0.77 \\
\hline RSP-2 & Contig06230 & protein tify 10a-like & 22.88 & 0.00 & 2.56 & 0.12 & 1.39 & 0.93 \\
\hline RSP-2 & Contig12753 & myb-related protein 308-like & 6.51 & 0.01 & -0.33 & 1.00 & 0.38 & 1.06 \\
\hline RSP-2 & Contig13870 & platz transcription factor family protein & 1.69 & 0.38 & 1.66 & 0.33 & 3.92 & 0.02 \\
\hline RSP-2 & Contig13895 & nac transcription factor 29-like & 24.73 & 0.00 & 1.57 & 0.44 & 1.50 & 0.89 \\
\hline RSP-2 & Contig15806 & probable wrky transcription factor 75-like & 8.60 & 0.01 & -1.12 & 0.94 & -1.14 & 1.01 \\
\hline RSP-2 & Contig17882 & protein tify 10a-like & 22.53 & 0.00 & 3.72 & 0.00 & 1.96 & 0.26 \\
\hline RSP-2 & Contig18538 & nac domain-containing protein 2-like & 11.99 & 0.00 & 2.33 & 0.13 & 1.77 & 0.58 \\
\hline RSP-2 & Contig20304 & $\begin{array}{l}\text { homeobox-leucine zipper protein athb-13- } \\
\text { like }\end{array}$ & 3.61 & 0.06 & 1.74 & 0.15 & 2.83 & 0.04 \\
\hline RSP-2 & Contig20472 & probable wrky transcription factor 2 & 3.59 & 0.05 & 1.23 & 0.94 & -1.05 & 0.99 \\
\hline RSP-2 & Contig20599 & protein tify $10 a-$ like & 26.56 & 0.00 & 2.12 & 0.14 & 1.55 & 0.72 \\
\hline RSP-2 & Contig20931 & protein tify 10 a-like & 3.98 & 0.04 & 1.51 & 0.75 & 1.24 & 1.03 \\
\hline RSP-2 & Contig25517 & protein tify $10 a$ & 9.46 & 0.01 & 1.87 & 0.18 & 1.56 & 0.75 \\
\hline RSP-2 & Contig30708 & low quality protein: protein tify 10b-like & 9.06 & 0.01 & 2.01 & 0.05 & 1.88 & 0.43 \\
\hline RSP-2 & Ppnisotig00498 & nac domain-containing protein 2-like & 4.02 & 0.03 & 1.59 & 0.22 & 1.52 & 0.52 \\
\hline RSP-2 & Ppnisotig05388 & protein exordium-like 2 & 14.03 & 0.00 & 1.26 & 0.84 & 1.11 & 1.03 \\
\hline RSP-2 & Ppnisotig06078 & protein exordium-like 2 & 4.36 & 0.03 & 1.33 & 0.70 & 0.41 & 1.04 \\
\hline RSP-4 & Contig05551 & probable wrky transcription factor 51-like & -2.66 & 0.13 & -3.91 & 0.00 & -3.69 & 0.04 \\
\hline RSP-4 & Contig09007 & exordium like 2 & -1.15 & 1.10 & -2.35 & 0.03 & 1.10 & 1.11 \\
\hline RSP-4 & Contig14511 & $\begin{array}{l}\text { homeobox-leucine zipper protein hat5- } \\
\text { like }\end{array}$ & -1.61 & 0.46 & -4.42 & 0.00 & -3.80 & 0.04 \\
\hline RSP-4 & Contig20476 & exordium like 2 & 1.78 & 0.34 & -3.07 & 0.01 & 1.41 & 0.72 \\
\hline RSP-5 & Contig03401 & $\begin{array}{l}\text { flowering-promoting factor } 1 \text {-like protein } \\
\text { 3-like }\end{array}$ & 1.79 & 0.43 & 2.59 & 0.03 & 9.31 & 0.00 \\
\hline RSP-5 & Ppnisotig04954 & growth-regulating factor 1-like & -1.15 & 1.11 & 2.68 & 0.02 & 18.01 & 0.00 \\
\hline RSP-5 & Ppnisotig05462 & $\begin{array}{l}\text { homeobox-leucine zipper protein } \\
\text { meristem l1-like }\end{array}$ & -0.33 & 1.15 & 3.16 & 0.01 & 16.06 & 0.00 \\
\hline RSP-5 & Ppnisotig07853 & $\begin{array}{l}\text { homeobox-leucine zipper protein hdg11- } \\
\text { like }\end{array}$ & -0.41 & 1.15 & 1.94 & 0.10 & 11.42 & 0.00 \\
\hline RSP-5 & Ppnisotig08430 & protodermal factor 1-like & -1.22 & 1.06 & 8.48 & 0.00 & 73.43 & 0.00 \\
\hline RSP-6 & Contig02588 & transcription repressor myb5-like & -4.46 & 0.03 & -1.62 & 0.21 & -1.41 & 0.72 \\
\hline RSP-6 & Contig03423 & floricaula leafy homolog & -2.25 & 0.20 & 1.61 & 0.21 & 5.78 & 0.00 \\
\hline RSP-6 & Contig12416 & transcription factor myb12-like & -4.82 & 0.01 & 1.76 & 0.51 & 1.36 & 0.96 \\
\hline RSP-6 & Contig12421 & transcription factor bhlh63-like & -4.09 & 0.04 & -1.22 & 0.85 & -1.44 & 0.75 \\
\hline RSP-6 & Contig13239 & axial regulator yabby 5-like & -3.82 & 0.05 & 2.44 & 0.03 & 1.20 & 1.01 \\
\hline RSP-6 & Contig15411 & transcription factor bhlh68 & -5.23 & 0.02 & 1.14 & 0.94 & -1.37 & 0.84 \\
\hline
\end{tabular}


Chano, $V$-Transcriptomics of the response to wounding

\begin{tabular}{|c|c|c|c|c|c|c|c|c|}
\hline RSP-6 & Contig23326 & transcription factor myb12-like & -2.89 & 0.09 & 1.36 & 0.71 & 3.06 & 0.03 \\
\hline RSP-6 & Contig24637 & platz transcription factor family protein & -1.67 & 0.41 & 1.37 & 0.54 & 3.06 & 0.04 \\
\hline RSP-6 & Ppnisotig07889 & platz transcription factor family protein & -1.46 & 0.60 & 1.20 & 0.83 & 3.56 & 0.02 \\
\hline RSP-6 & Ppnisotig12838 & $\begin{array}{l}\text { probable indole-3-pyruvate } \\
\text { monooxygenase yucca4 }\end{array}$ & -3.15 & 0.04 & 1.65 & 0.17 & 3.50 & 0.01 \\
\hline RSP-7 & Contig01739 & $\begin{array}{l}\text { homeobox-leucine zipper protein athb-14- } \\
\text { like }\end{array}$ & -5.43 & 0.02 & -1.18 & 0.97 & -2.06 & 0.27 \\
\hline RSP-7 & Contig12050 & transcription factor myb46-like & -10.79 & 0.00 & -1.27 & 0.71 & -2.86 & 0.13 \\
\hline \multicolumn{9}{|c|}{ Hormone signalling } \\
\hline RSP-2 & Contig24730 & auxin-responsive protein iaa26-like & 3.51 & 0.05 & -0.02 & 0.91 & 1.82 & 0.36 \\
\hline RSP-2 & Ppnisotig06916 & auxin-responsive protein iaa26-like & 3.48 & 0.05 & 1.07 & 1.01 & 1.68 & 0.50 \\
\hline RSP-4 & Contig12053 & $\begin{array}{l}\text { ethylene-responsive transcription factor } \\
\text { rap2-4-like }\end{array}$ & -1.28 & 0.85 & -2.96 & 0.01 & -3.74 & 0.04 \\
\hline RSP-4 & Contig15238 & auxin-responsive protein iaa13-like & 1.42 & 0.65 & 1.26 & 0.73 & -3.35 & 0.05 \\
\hline RSP-5 & Contig14132 & non-specific lipid-transfer protein 2-like & -3.02 & 0.15 & 3.66 & 0.01 & 106.88 & 0.00 \\
\hline RSP-6 & Contig39240 & $\begin{array}{l}\text { ethylene-responsive transcription factor } \\
\text { rap2-12-like }\end{array}$ & 1.47 & 0.58 & 2.65 & 0.02 & 3.80 & 0.01 \\
\hline \multicolumn{9}{|c|}{ Non annotated genes and unknown functions } \\
\hline RSP-1 & Contig03506 & $\begin{array}{l}\text { hypothetical protein } \\
\text { SELMODRAFT_115352 }\end{array}$ & 129.97 & 0.00 & 85.55 & 0.00 & 15.08 & 0.00 \\
\hline RSP-2 & Contig11518 & ---NA--- & 28.49 & 0.00 & -0.37 & 0.14 & 1.27 & 0.80 \\
\hline RSP-2 & Contig22230 & ---NA--- & 33.54 & 0.00 & 3.91 & 0.03 & -1.24 & 0.97 \\
\hline RSP-2 & Contig22397 & ---NA--- & 30.95 & 0.00 & 1.89 & 0.17 & 0.44 & 1.07 \\
\hline RSP-2 & Contig23569 & ---NA--- & 79.79 & 0.00 & 2.66 & 0.09 & 1.05 & 1.01 \\
\hline RSP-2 & Contig43786 & ---NA--- & 28.79 & 0.00 & 1.61 & 0.46 & 1.86 & 0.32 \\
\hline RSP-3 & Contig08604 & ---NA--- & -0.46 & 0.96 & -16.10 & 0.00 & -7.68 & 0.01 \\
\hline RSP-6 & Contig03452 & ---NA--- & -11.39 & 0.00 & 5.01 & 0.00 & 6.61 & 0.00 \\
\hline RSP-6 & Contig13782 & ---NA--- & $\begin{array}{l}-15.68 \\
\end{array}$ & 0.00 & 1.31 & 0.69 & 2.20 & 0.13 \\
\hline RSP-7 & Contig13781 & ---NA--- & -15.86 & 0.00 & -1.39 & 0.55 & -2.35 & 0.15 \\
\hline RSP-7 & Contig19504 & ---NA--- & -15.59 & 0.00 & -1.38 & 0.60 & -2.16 & 0.21 \\
\hline
\end{tabular}

FC: Fold-change, FDR: adjusted p-value by False Discovery Rate. In bold, statistically significant values

Overexpressed genes in the immediate response to wounding

As expected, most of DEGs induced at R1, and regardless of their level of statistical significance at R2 and R3, were involved in defense and stress responses induced by mechanical damage. Among them, some genes presented the highest levels of transcriptional activity, with FC (fold change) values for R1 going from 32.41 to over 450 (cluster RSP-1). These genes encode proteins related to oxidative stress, such as peroxidases (Ppnisotig01747) needed for ROS (Reactive Oxygen Species) 
detoxification in response to pathogenesis (Gunnar Fossdal et al. 2001), or two glutathione-S-transferase-like proteins (Ppnistoig02901 and -06171), also involved in the anti-oxidative plant defense (Meyer et al. 2008). Furthermore, another important group of genes induced at this stage code for hydrolytic enzymes needed for defense against opportunistic pathogens. F.i., Contig18804 and Ppnisotig13431 putatively code for PI206, a disease resistance response protein described in Pisum sativum during the response to inoculation of Fusarium solani (Culley et al. 1995). Also, putative PR-4-like proteins (Contig22375, -19053 and Ppnisotig13133) were also strongly induced at R1 in response to wounding. According to literature, this gene was firstly named as win-1 and win-2, for "wound-inducible genes", in Solanum tuberosum (Stanford et al. 1989). Cluster RSP-1 also indicates endochitinases-like proteins overexpression at R1 (Contig10307, -21216 and Ppnisotig00751), with important roles in plant defense (Seo et al. 2008), induction of antimicrobial peptide 1-like (Ppnisotig12265), with antifungal and antibacterial properties (Castro and Fontes 2005), defensin-like protein (Contig17617), involved in defense-related processes, biotic stress response and plant development (Tam et al. 2015), and a major allergen pru ar1 homologous (Contig22185), a pathogenesis-related protein involved in the response to ripening in Prunus armeniaca (Mbéguié-A-Mbéguié et al. 1997). These results are consistent with those reported in Chapter 3 for the healing process (Chano et al. 2017a). We also found a gene coding for a TIFY 10a-like protein (Contig06361), member of the large TIFY family of transcription factors, a group previously known as Zinc-finger Inflorescence Meristem (ZIM; Vanholme et al. 2007)). More DEGs showing overexpression at R1 through defense response and tolerance to stress were found in RSP-2, such as those coding for chitinases or peroxisades (f.i., Contig00126 and -20552), as well as three transcripts (Contig 20555, -20817 and -16597) for phenylalanine ammonia-lyase-like proteins (PAL). This protein, involved in the phenylpropanoid biosynthesis pathway, has important roles in plant defense (Ohl et al. 1990, Kervinen et al. 1998, Kim and Hwang 2014). Other transcriptional regulators such as NACs (f.i., Contig00787, 05634 and -13895) and WRKYs (f.i. Contig02808 and -15806), both involved in 
Chano, $V$ - Transcriptomics of the response to wounding

response to stress (Zhang and Wang 2005, Hu et al. 2010) were also detected as overexpressed at this stage.

Interestingly, and although no visible growth was detected at this stage, we also detected induction of certain genes which could be related to cell proliferation. For instance, two expansins involved in cell wall loosening and cell expansion (Cosgrove et al. 2002) were induced in R1 as well (Contig21204 and Ppnisotig08645). In this case, their overexpression could be related with expansion and swelling previous to resprouting. However, we also found in cluster RSP-2 three contigs encoding for a putative exordium 2-like protein (Contig06152, Ppnisotig05388 and Ppnisotig06078), which has been related to cell proliferation and meristem activity in Arabidopsis thaliana (Farrar et al. 2003), as well as two MYB-like proteins (Contig01913 and -12753), reported to be involved in regulation of secondary cell wall biosynthesis (Zhong and Ye 2007).

\section{Down regulation of regular radial growth}

Conversely to the abovementioned, several genes shown repression at R1, especially those included in clusters RSP-6 and RSP-7 (204 out of 252 and 259 out of 293 DEGs, respectively). Interestingly, genes involved in xylogenesis were included in this group. For instance, 189 DEGs out of 237 genes involved in earlywood related genes reported in Chapter 1 (Chano et al. 2017b) were repressed at R1, including transcripts coding for catalytic subunits of the cellulose synthase (f.i., Contig20721, -00654 and -41981), and members of the CAZymes superfamily such as pectate lyase-like (Contig05066), mannan-endo-beta-mannosidase 7-like (Ppnisotig01389), xyloglucan endotransglucosylase hydrolase protein 9-like (Contig09025), or polygalacturonase-like (Contig13778) proteins. Also, a fasciclinlike arabinogalactan protein (Contig01025), or a Caffeoyl-CoA Omethyltransferase-like protein (Contig06476), involved in the phenylpropanoid biosynthesis pathway (Fraser and Chapple 2011), were repressed at this time. Additionally, transcription factors related to cell wall biosynthesis such as MYB12like (Contig12416 and -23326), MYB5-like (Contig02588) and MYB46-like 
(Contig12050), as well as bHLH63-like (Contig12421) and bHLH63-like (Contig15411), were also found repressed at R1. As well, we also found repressed at R1 a homologous of Arabidopsis ATHB14 (Contig01739), also known as PHABULOSA (PHB), which belongs to the HD Zip Class III family of transcription factors (Ariel et al. 2007). This gene, included in cluster RSP-7, was described as mediator during adaxial/abaxial polarization in ovule primordium (Sieber et al. 2004), the establishment of the SAM and the apical bilateral symmetry (Prigge et al. 2005), and the perception of radial positional information in leaf primordium (McConnell et al. 2001). Down-regulation of xylogenesis-related genes seems to be a trending keynote in the immediate response to wounding, with 99 (cluster RSP6) and 90 (cluster RSP-7) DEGs. This result is consistent with the rearrangement of the xylogenesis transcriptional program described in Chapter 3 (Chano et al. 2017a), where wounding also induced the cessation of meristematic activity and growth.

Later on, when diametrical growth is resumed, we have detected several genes involved in cell growth and cell wall development are still significantly repressed, compared to controls. This is the case of putative xyloglucan galactosyltransferase katamari1-like (Contig10110), galactan synthase 1-like (Contig11855) and laccase 17-like proteins (Contig17480), in cluster RSP3, together with a germin 2-like (Contig12945) and a non-annotated sequence (Contig08604) or putative expansin a1-like proteins (Contig12739 and -17876; Cosgrove et al. 2002) and some members of the CAZyme superfamily (Contig05410 and -17013; Park et al. 2010a) in cluster RSP4. Similar transcription profiles were found for transcription factors such as WRKY51-like (Contig05551) and HAT5-like (Contig14511), which belongs to the Homeodomain Leucine Zip Class I. This latter gene was also found in Chapter 1 to be transcriptionally active during earlywood formation in the Canary Island pine (Chano et al. 2017b). This feature could be related to a reduced cambial activity in the resprouting area, although an experimental artifact due to signal dilution cannot be discarded. 
Chano, $V$-Transcriptomics of the response to wounding

Differentially Expressed Genes putatively involved in resprout elongation

Resprout elongation corresponds to R2 and R3 stages, when the new epicormic shoots arose from stem. Several genes were found with differential expression at these two sampled points, whether if they were significantly over- or underexpressed.

Cluster RSP-5 includes 21 DEGs overexpressed at R2 and even more at R3, with high FC values going from 8 to over 100. For instance, Contig14132, which putatively codes for a non-specific lipid-transfer 2-like protein, presented the highest expression value at R3 ( $\mathrm{FC}=106.88)$. Also noteworthy are those belonging to the HD Zip Class IV family of transcription factors, such as PROTODERMAL FACTOR1-like (PDF1; Ppnisotig08430) and MERISTEM LAYER1-like (ML1; Ppnisotig05462) proteins, which are likely involved together in the resprouting process. PDF1 is a proline-rich cell wall protein expressed exclusively in the L1 layer of shoot meristems in Arabidopsis, controlling cell differentiation in the epidermis of new buds (Abe et al. 2003). In Gossypium spp. was found that GbPDF1 protein has an important role during fiber initiation in early steps of elongation (Deng et al. 2012). Moreover, the functional role of PDF1 was found under regulation of two HD Zip Class IV members in Arabidopsis, the PROTODERMAL FACTOR2 (PDF2) and the MERISTEM LAYER1 (ATML1) (Abe et al. 1999, 2003). This last one, first suggested to be expressed only in the first layer (L1) of the SAM (Lu et al. 1996), was found in this cluster to be co-expressed together with PDF1. Also, a HOMEODOMAIN GLABROUS 11-like protein (HDG11; Ppnisotig07853) was found in this cluster, a protein reported to be implicated in trichomes development in Arabidopsis. Mutants in hdg11 showed more trichome branches than wild types, therefore is supposed to repress the outgrowth of trichomes (Nakamura et al. 2006). Pines do not show trichomes, so this gene may have suffered functional diversification in flowering plants.

The GROWTH-REGULATING FACTOR1 (GRF1) is a plant specific transcription factor family involved in multiple developmental processes in different tissues 
and organs, such as leaves, stems, roots, seeds and flowers (Omidbakhshfard et al. 2015). Recently, GRFs and part of the microRNA regulatory machinery of GRFs were reported to be involved in floral organ development, determining the sepal/petal identity (Pajoro et al. 2014). We found that the transcript Ppnisotig04954, encoding for a P. canariensis orthologous of a GRF member, showed increasing FC values in R2 and especially in R3. As well, a FLOWERINGPROMOTING FACTOR1-like protein, encoded by Contig03401 (FPF1), was not repressed in R1 but had similar expression profile than GFR. Interestingly, increasing transcription of this gene was found in Chapter 1 during latewood formation in the Canary Island pine (Chano et al. 2017b); additionally, Arabidopsis FPF1 was described to cause a strong effect on wood formation under constitutive overexpression in transgenic Populus (Hoenicka et al. 2012).

Additionally, other remarkable DEGs presumably involved in resprouting were found in other clusters. A sequence putatively coding for a homolog of Arabidopsis ATHB13-like protein (Contig20304) was found overexpressed at R3 (Cluster RSP-2; $\mathrm{FC}=2.83$ ). This gene is suggested to be involved in regulation of cotyledon and leaf development in Arabidopsis (Henriksson et al. 2005). Finally, other transcription factors of interest were found in cluster RSP-6. Contig13239, encoding for a YABBY5-like protein, was found in Cluster RSP-6 repressed at stage R1, but overexpressed at stages R2 and R3 of the resprouting process, although just presented statistical signification at R2. This suggests that this homologous of YAB5 is involved during the development of latent shoots, but not in the immediate response to mechanical injuries. The YABBY family of TFs is implicated in regulation of the lamina development of lateral organ growth (Floyd and Bowman 2007, Sarojam et al. 2010), and were present in the last common ancestor of seed plants (Yamada et al. 2011). Therefore, is proposed to be a relevant candidate in the resprouting process in this coniferous species. Although this family has been described in angiosperms, very little is known about its role in gymnosperms due to the lack of appropriate model species. Recently, Finet et al. (Finet et al. 2016) reported the characterization of this gene family in Ginkgo and 
Chano, $V$ - Transcriptomics of the response to wounding

Pseudotsuga, and proposed that YABBY genes act as polarity genes in the last common ancestor of extant seed plants, with important role in the evolution of laminar leaves. Considering the differences between resprouts and laminar leaves, our findings suggest an important role in the very early steps of the resprouting process.

Moreover, a YUCCA4-like transcription factor was also found in Cluster RSP-6 (Ppnisotig12838). The YUCCA family of transcription factors shows overlapping roles in the synthesis of auxins, an important plant growth hormone (Cheng et al. 2006). Particularly, the YUCCA4 has been described to play important roles in auxin increase during floral organogenesis in A. thaliana (Cheng et al. 2006). We also found in Cluster RSP-6, significantly overexpressed at R3, a homologous of LEAFY (Contig03423), a plant-specific transcription factor controlling flower development from lateral meristems in A. thaliana (Schultz and Haughn 1991, Weigel et al. 1992), and, therefore, another suitable candidate gene to be involved in this process. This gene was also found in Chapter 1 to be involved in EW formation in P. canariensis (Chano et al. 2017b).

The AP2/ERF transcription factor WOUND INDUCED DEDIFFERENTIATION1 (WIND1), also known as RAP2.4, has been proposed as a central regulator of wound-induced cell dedifferentiation in thale cress for callus formation and shoot regeneration in wound sites (Iwase et al. 2011, 2016). We found a putative RAP2.4like (Contig 12053) in cluster RSP-4, showing repression in both R2 and R3 ( $F c=-$ 2.96 and FC $=-3.74$, respectively). On the contrary, we found overexpressed in the same samples another member of the AP2/ERF superfamily, RAP2.12-like coded by Contig 39240 (Cluster RSP-6, FC = 2.65 and FC $=3.80$ ). This latter gene is involved in adaptation to low oxygen concentration in A. thaliana (Paul et al. 2016), and no specific role in regeneration process in response to mechanical stress has been found so far. Additionally, none of the two AP2 members were found in Chapter 3 significantly expressed during the woundwood formation in response to wounding (Chano et al. 2017a). However, further research focused on this gene seems to be necessary. Not surprisingly, RAP2.4 has been suggested to be involved 
both in plant regeneration and in abiotic stress response (Figueroa-Yañez et al. 2016). Moreover, we found transcription factors not well characterized yet, with increasing transcripts levels during the process. Two PLATZ (plant AT-rich sequence- and zinc binding protein) were included in cluster RSP-6 (Contig24637 and Ppnisotig07889). This gene was described for the first time by Nagano et al. (2001), and reported as stress-inducible in Glycine max (So et al. 2015). In our study, we also detected a third member of this TF family (Contig13870) in cluster RSP-2, all of them significantly overexpressed at R3.

Interestingly, many DEGs overexpressed during R2 and R3 stages are homologous to genes involved in flowering in angiosperms. The switch from vegetative organs development to reproductive organs development may be driven under disturbance regimes in order to promote survival by early flowering and seed production (Verslues and Juenger 2011). For instance, flower development in Arabidopsis can be induced by drought stress; this process is mediated by upregulation of LEAFY expression (Su et al. 2013), a homolog of which shows significant overexpression at R3 in resprouting $P$. canariensis. However, these genes have not been reported so far to be involved in strobili development in conifers. At any rate, this result could be an example of functional diversification of homologous genes in different taxa.

\section{Transcriptomics of Apical Growth in Pinus canariensis}

Resprouting of new epicormic shoots is cognate to apical growth, including the activation, enlargement and elongation of its own shoot apical meristem, and development of different tissue-types such as epidermal and sub-epidermal cell layers in early steps of bud elongation. For this reason, we analyzed the meristematic activity during apical growth in $P$. canariensis, and compared gene dynamics of both apical growth and resprouting, trying to distinguish the genes specifically involved in resprouting from those related to general shoot elongation. 
Differential expression patterns were checked at five sampling dates during the vegetative apical growth (A1, A2, A3, A4 and A5), representing different stages of the apex (Figure 6). Time-course analysis revealed that 7,170 genes showed significant differences in their transcription levels during the season, being considered as DEGs (Table S2). Gene expression profiling resulted in 6 main clusters, summarized in three main profiles and their opposites (Figure 7).

A1 samples represented the beginning of apical shoot development, during primary growth. Primary xylem is being formed in individual vascular bundles, together with primary phloem, and is derived from early differentiating fascicle cambium. Cluster API-2 included genes with high transcription levels at this sampling time, smoothly decreasing at A2 and so on, as well as cluster API4, although with a sharp fall of transcription levels at A2. As the plant continues growing, and primary xylem and primary phloem

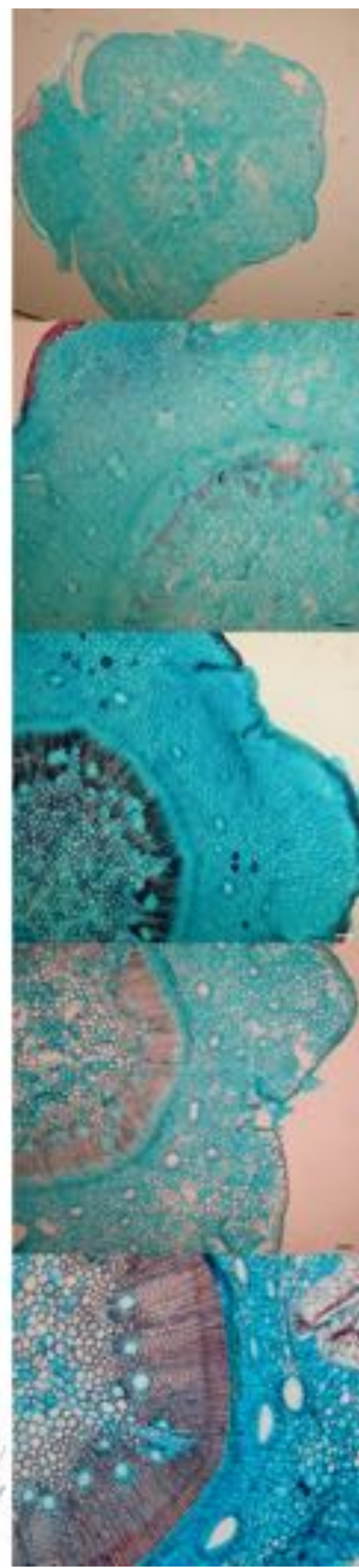

Figure 6. Anatomy of the five developmental stages of apex sampled during seasonal growth. A1: $15^{\text {th }}$ April; A2: $30^{\text {th }}$ April; A3: $22^{\text {nd }}$ May; A4: $3^{\text {rd }}$ July; A5: $11^{\text {th }}$ September. 
are formed, fascicle cambium within vascular bundles originate the vascular cambium, which starts to produce secondary growth (Baucher et al. 2007). At A2 stage this vascular cambium is complete, while from A3 onwards secondary growth goes on. Cluster API-1 showed a transition from down- to up-regulation of gene expression between A2 and A3 samples, while cluster API-3 showed a strong increase of the expression level from A1 to A2, followed by a mild decrease from this point to A5. As well, cluster API-5 showed repression from A1 to A2, induction during A3 and A4, and transcript levels are maintained at A5, while cluster API-6 displayed exactly the opposite pattern.
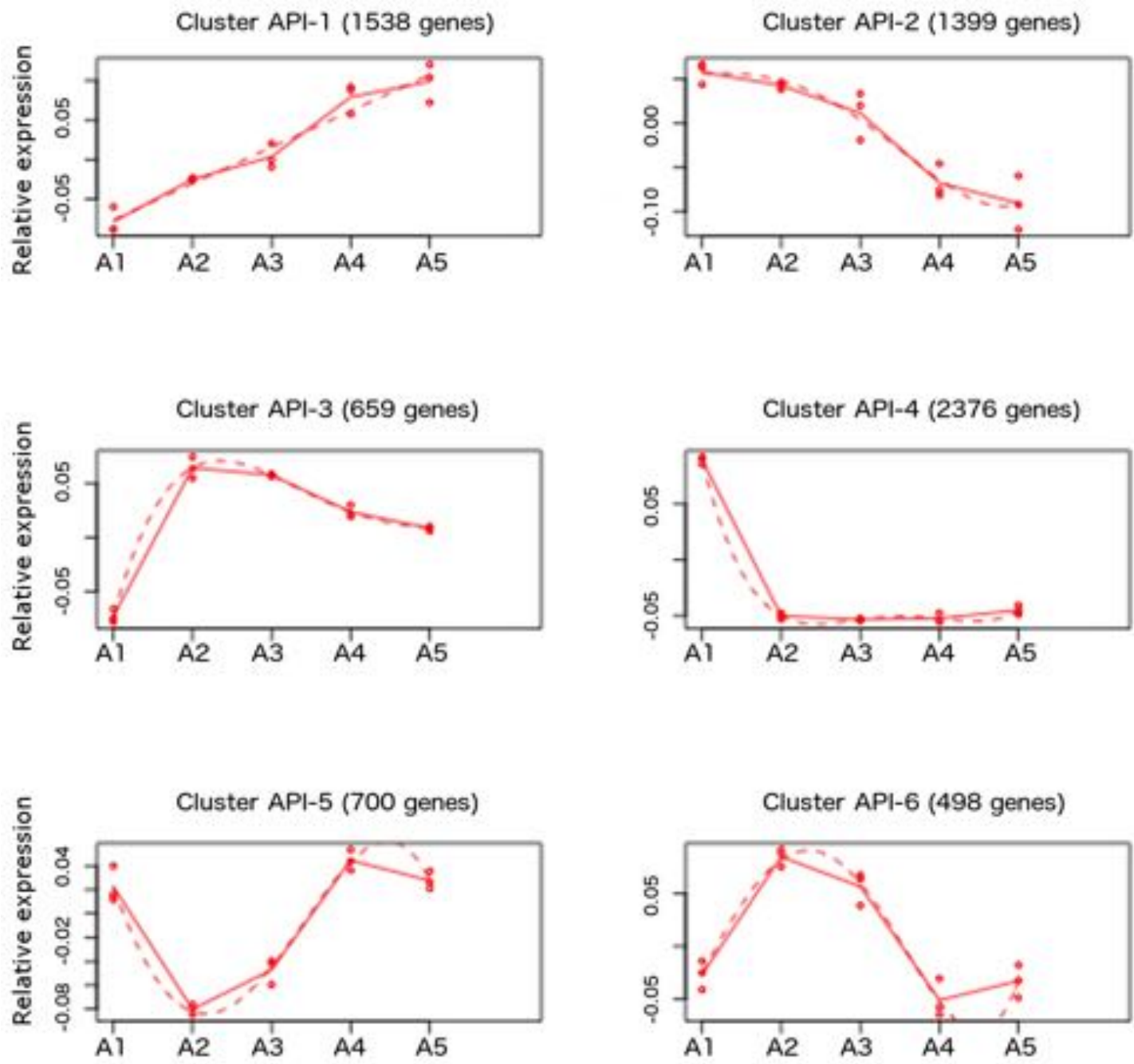

Figure 7. K-means clustering $(\mathbf{k}=\mathbf{6})$ of Differentially Expressed Genes. Clusters represent the main tendencies of gene expression profiles during apical development in Pinus canariensis after maSigPro analysis. The Y-axis represents the relative expression values and X-axis represents developmental stages. The number of genes included in each cluster is indicated. 
Accuracy of gene expression profiles for apical growth was also validated by qRTPCR analyses of 9 genes (Figure 8). As well, these genes were also selected covering the main expressional profiles obtained by microarray analysis, and according to their implication in the processes described in this work, such as genes coding for the proteins pectinesterase-like (Contig05410, cluster API-1), expansin-like (Contig12414, cluster API-2), CCoAOMT-like (Contig06476, Cluster API-3), PAL-like (Contig20555, cluster API-1), and Major Allergen Pru AR1-like (Contig22185, cluster API-4), as well as for the transcriptions factors NAC2-like (Contig00787, cluster API-1), WRKY51-like (Contig05551, cluster API-1) and YAB5-like (Contig13239, cluster API-2). As well, we included another DEG coding for the transcription factor BEL1-like (Contig04961, cluster API-1) in the analysis, member of the TALE (three-aminoacid-loop-extension) homeodomain family and implicated in control of apical shoot meristem activity (Traas and Vernoux 2002).
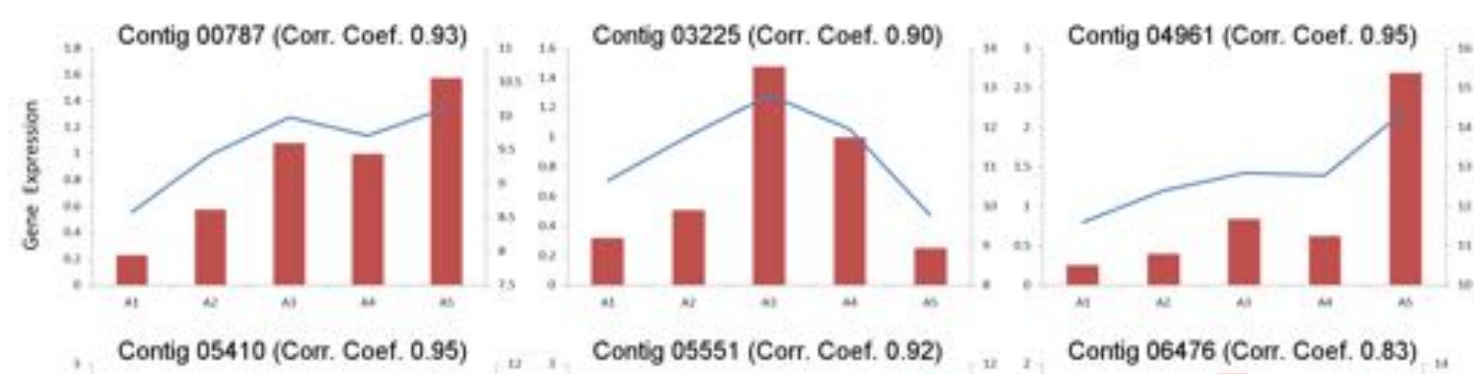

Contig 05551 (Corr. Coef. 0.92)
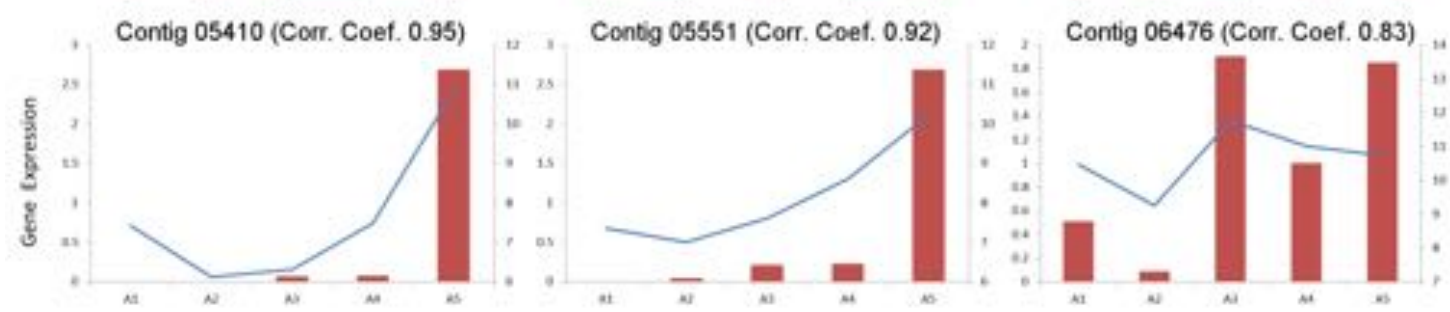

Contig 13239 (Corr. Coef. 0.83)

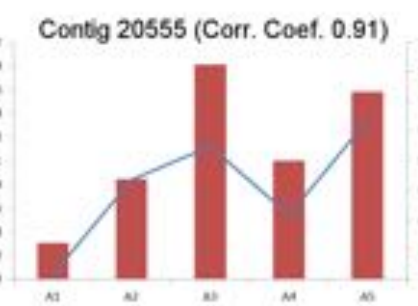

Contig 22185 (Corr. Coef. 0.87)
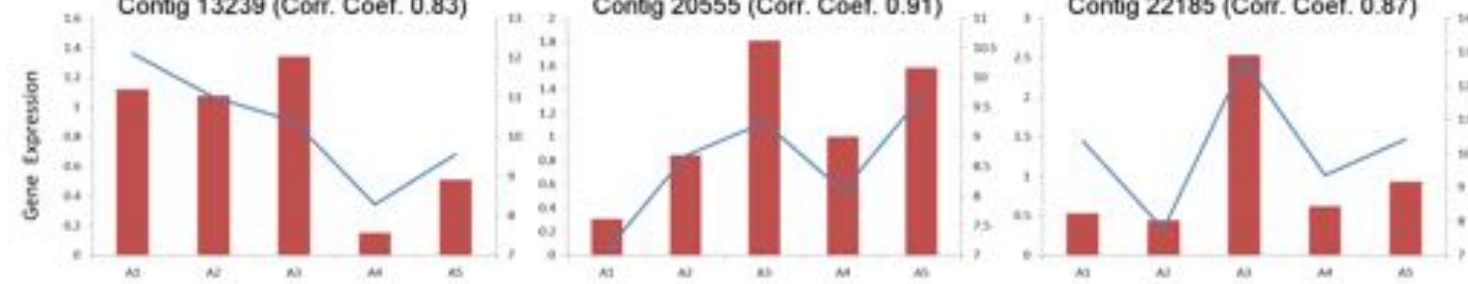

Figure 8. qRT-PCR validation of microarray expression profiles. X-axis: developmental stages. Yaxis left: normalized gene expression values of selected DEGs for qRT-PCR (bars). Y-axis right: absolute expression values ofr microarray experiments (continuous line) 


\section{Profiling Comparison Reveals Common DEGs Between Processes}

As Figure 9 illustrates, from 1164 DEGs involved in the Canary Island pine' resprouting process, 571 were shared with apical growth. Correspondingly, 6599 DEGs were exclusive for the apical growth, while other set of 593 genes were differentially expressed just for resprouting. From common DEGs, 250 were shared for both resprouting R2/R3 and apical development, although overexpression of some of them during R2/R3 could be due to their high inducement levels in the immediate response. Genes overexpressed at R2 and R3 and also found as DEG during apical growth (108 contigs) may be involved in shoot elongation per se. Conversely, 142 genes differentially expressed during apical growth showed repression at R2 and R3. For instance, about 50 DEGs overexpressed at R1 were also differentially expressed during apical growth, and 32 of whom were highly expressed during primary growth (A1) and 19 of them also the beginning of secondary growth (A2 and A3) of the apex, but decreasing along the following steps of apical elongation (A4 and A5). This reveals important activity in early steps of both resprouting process and apical development.

Conversely, about 70 genes significantly repressed during resprouting R2/R3 were mainly overexpressed at A4 and A5 phases, which represent last steps of seasonal apical growth, although some of them (11 DEGs) also showed a peak of expression at A2. One of this genes was the homologous of the HD Zip Class I member HAT5 (Contig14511), which responds to environmental conditions (Henriksson et al. 2005), but with important functions in leaf cell fate determination (Aoyama et al. 1995). In our study, this gene is suggested to be repressed during the first steps of the resprouting process (FC values of -4.42 and -3.80 , respectively), but induced in the transition to secondary growth in apical development (from A1 to A2).

Among 74 resprouting-DEGs significantly overexpressed at R2/R3, those genes showing overexpression at the beginning of apical growth (A1 and A2) are worth to be remarked. These genes could be involved in the first steps of shoot development, both in resprout and apical shoot, and their expression would decay 
Chano, $V$-Transcriptomics of the response to wounding

during the transition to secondary growth, as revealed by the analysis of stages A3-A5 of apical development.

This is the case of the co-expressed HD Zip IV transcription factors PDF1-like and ML1-like, which were strongly induced during resprouting (FC values for R2 and R3 of 8.48 and 73.43, and 3.16 and 16.06, respectively), while their transcriptional levels decrease throughout apical growth. In the same way, the other member of this gene family, HDG11, was overexpressed at R3 ( $F C=11.42)$ and showed decreasing presence during apical shoot elongation, as FPF1 and GRF1.

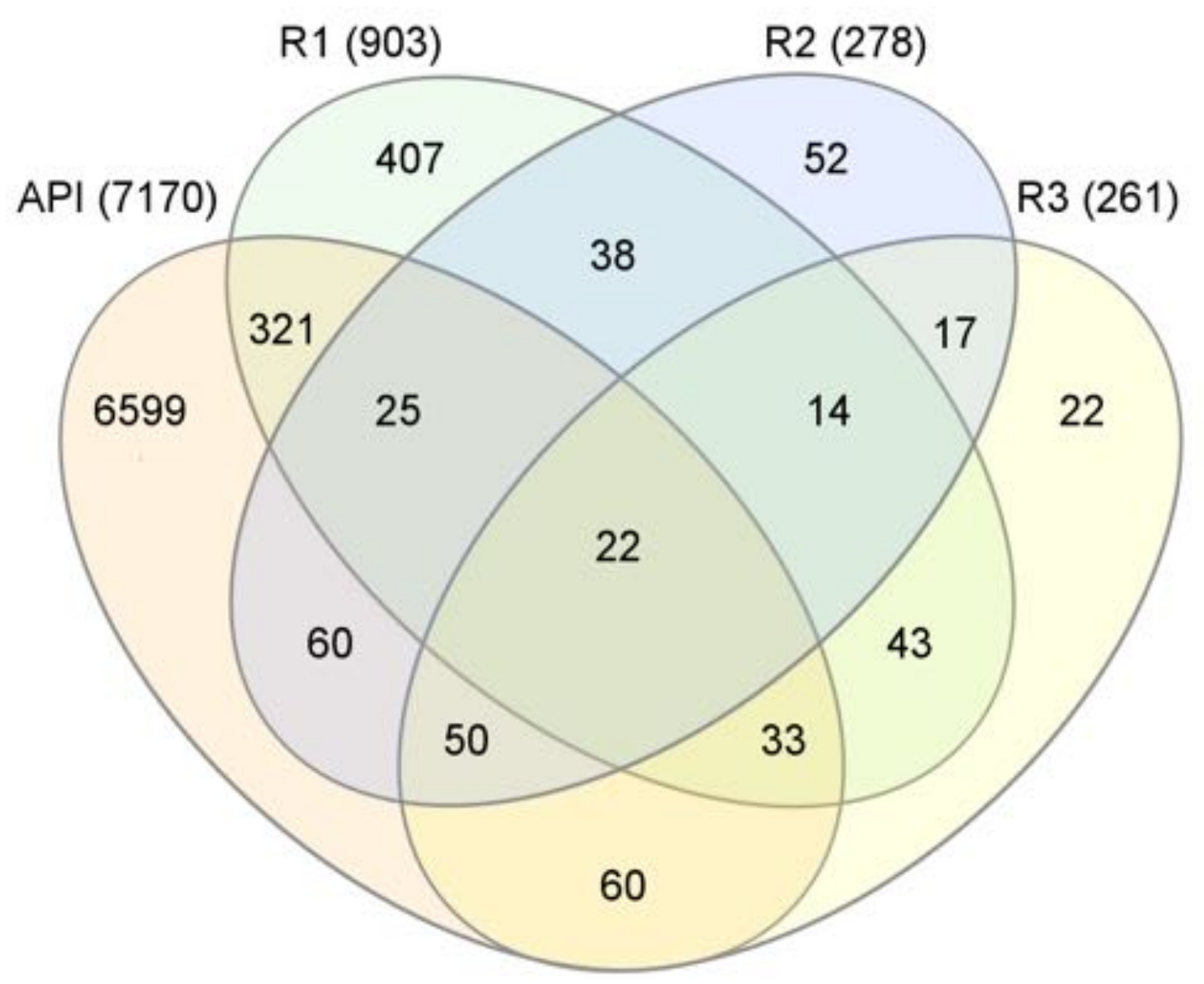

Figure 9. Expression of apical growth genes during resprouting in response to wounding in $P$. canariensis. Venn's diagram of resprouting DEGs and apical growth genes.

As exposed previously, LFY and YAB5 have been reported to have remarkable roles in lateral organ development. However, both genes differ in the moment of induction, being YAB5 overexpressed at R2 ( $\mathrm{FC}=2.44)$ and $\mathrm{LFY}$ at R3 ( $\mathrm{FC}=5.78)$. YAB5 was reported to participate in fate and maintenance of meristem activity 
during lateral organogenesis in rice (Tanaka et al. 2012). As well, YAB5 acts redundantly in Arabidopsis with FIL/YAB3 and YAB2 in the polar establishment of abaxial surface, activating laminar programs, repressing SAM programs and forming the marginal domain in leaves (Sarojam et al. 2010). Moreover, the homologous YAB5 in Cabomba coraliniana was expressed in the abaxial tissues of the distal leaf primordium, playing an important role during the proliferating cell process, as well as in floral bud development. In vegetative shoots, YAB5 displays a similar expression pattern than FIL/YAB3, expressed in marginal and abaxial tissues in lobe primordial and procambial strands (Yamada et al. 2011). Regarding LFY, it has been recently reported to be involved in development of both reproductive and vegetative tissues during lateral organogenesis in the lycopsid genus Isoetes (Yang et al. 2017).

Moreover, both AP2/ERF members found during the resprouting process were also differentially expressed in apical growth. While RAP.4-like was repressed at R2 and R3, it shows overexpression throughout the apical growth reaching a maximum level of expression at A5. Conversely, RAP2.12-like showed high transcriptional activity just at A1, being repressed along the rest of the process. Table 2 shows a selection of resprouting-genes also differentially expressed in apical growth, gruped by clusters, and indicating the significance level.

Table 2. Selected Differentially Expressed Genes during apical growth

\begin{tabular}{|c|c|c|c|}
\hline Cluster & ID & Seq. Description & $\begin{array}{l}\text { Differential } \\
\text { expression level }\end{array}$ \\
\hline API-1 & Contig00787 & nac domain-containing protein 2-like & $\mathrm{P}<0.001$ \\
\hline API-1 & Contig01739 & homeobox-leucine zipper protein athb-14-like & $\mathrm{P}<0.001$ \\
\hline API-1 & Contig01913 & transcription factor myb44-like & $\mathrm{P}<0.005$ \\
\hline API-1 & Contig02586 & probable glutathione s-transferase & $\mathrm{P}<0.005$ \\
\hline API-1 & Contig03452 & ---NA--- & $\mathrm{P}<0.005$ \\
\hline API-1 & Contig05410 & pectinesterase 2-like & $\mathrm{P}<0.005$ \\
\hline API-1 & Contig05551 & probable wrky transcription factor 51-like & $\mathrm{P}<0.001$ \\
\hline API-1 & Contig08531 & probable pectate lyase 15 -like & $\mathrm{P}<0.001$ \\
\hline API-1 & Contig12053 & ethylene-responsive transcription factor rap2-4-like & $\mathrm{P}<0.005$ \\
\hline API-1 & Contig12416 & transcription factor myb12-like & $\mathrm{P}<0.001$ \\
\hline API-1 & Contig13782 & ---NA--- & $\mathrm{P}<0.001$ \\
\hline
\end{tabular}




\section{Chano, $V$ - Transcriptomics of the response to wounding}

\begin{tabular}{|c|c|c|c|}
\hline API-1 & Contig15238 & auxin-responsive protein iaa13-like & $\mathrm{P}<0.005$ \\
\hline API-1 & Contig15411 & transcription factor bhlh68 & $\mathrm{P}<0.005$ \\
\hline API-1 & Contig17005 & probable pectate lyase 12 -like & $\mathrm{P}<0.001$ \\
\hline API-1 & Contig20472 & probable wrky transcription factor 2 & $\mathrm{P}<0.001$ \\
\hline API-1 & Contig20555 & phenylalanine ammonia-lyase-like & $\mathrm{P}<0.001$ \\
\hline API-1 & Contig20721 & cellulose synthase a catalytic subunit 3 & $\mathrm{P}<0.005$ \\
\hline API-1 & Ppnisotig00498 & nac domain-containing protein 2-like & $\mathrm{P}<0.001$ \\
\hline API-1 & Ppnisotig08430 & protodermal factor 1-like & $\mathrm{P}<0.005$ \\
\hline API-1 & Ppnisotig12838 & probable indole-3-pyruvate monooxygenase yucca4 & $\mathrm{P}<0.001$ \\
\hline API-1 & Ppnisotig13431 & disease resistance response protein 206-like & $\mathrm{P}<0.001$ \\
\hline API-2 & Contig00602 & defensin ec-amp-d2-like & $\mathrm{P}<0.005$ \\
\hline API-2 & Contig02383 & peroxidase 44 -like & $\mathrm{P}<0.005$ \\
\hline API-2 & Contig03401 & flowering-promoting factor 1-like protein 3-like & $\mathrm{P}<0.001$ \\
\hline API-2 & Contig03423 & floricaula leafy homolog & $\mathrm{P}<0.005$ \\
\hline API-2 & Contig03506 & hypothetical protein SELMODRAFT_115352 & $\mathrm{P}<0.001$ \\
\hline API-2 & Contig12414 & expansin-b3-like & $\mathrm{P}<0.005$ \\
\hline API-2 & Contig13239 & axial regulator yabby 5-like & $\mathrm{P}<0.001$ \\
\hline API-2 & Contig13870 & platz transcription factor family protein & $\mathrm{P}<0.001$ \\
\hline API-2 & Contig14132 & non-specific lipid-transfer protein 2-like & $\mathrm{P}<0.005$ \\
\hline API-2 & Contig19053 & pathogenesis-related protein pr-4b-like & $\mathrm{P}<0.001$ \\
\hline API-2 & Contig21216 & endochitinase a-like & $\mathrm{P}<0.005$ \\
\hline API-2 & Contig22230 & ---NA--- & $\mathrm{P}<0.001$ \\
\hline API-2 & Contig23434 & cinnamoyl- reductase 1 -like & $\mathrm{P}<0.005$ \\
\hline API-2 & Contig24637 & platz transcription factor family protein & $\mathrm{P}<0.001$ \\
\hline API-2 & Ppnisotig04954 & growth-regulating factor 1-like & $\mathrm{P}<0.001$ \\
\hline API-2 & Ppnisotig05462 & homeobox-leucine zipper protein meristem l1-like & $\mathrm{P}<0.005$ \\
\hline API-2 & Ppnisotig06078 & protein exordium-like 2 & $\mathrm{P}<0.005$ \\
\hline API-2 & Ppnisotig06171 & glutathione s-transferase f9-like & $\mathrm{P}<0.001$ \\
\hline API-2 & Ppnisotig07853 & homeobox-leucine zipper protein hdg11-like & $\mathrm{P}<0.005$ \\
\hline API-2 & Ppnisotig07889 & platz transcription factor family protein & $\mathrm{P}<0.001$ \\
\hline API-2 & Ppnisotig08058 & chitinase 6-like & $\mathrm{P}<0.001$ \\
\hline API-2 & Ppnisotig08645 & expansin-b3-like & $\mathrm{P}<0.005$ \\
\hline API-2 & Ppnisotig12265 & antimicrobial peptide 1-like & $\mathrm{P}<0.001$ \\
\hline API-3 & Contig01025 & fasciclin-like arabinogalactan protein 10-like & $\mathrm{P}<0.005$ \\
\hline API-3 & Contig06476 & caffeoyl- o-methyltransferase & $\mathrm{P}<0.005$ \\
\hline API-3 & Contig08356 & udp-glycosyltransferase 85a2-like & $\mathrm{P}<0.005$ \\
\hline API-3 & Contig12753 & myb-related protein 308-like & $\mathrm{P}<0.001$ \\
\hline API-3 & Contig14511 & homeobox-leucine zipper protein hat5-like & $\mathrm{P}<0.001$ \\
\hline
\end{tabular}




\begin{tabular}{llll}
\hline API-3 & Contig40036 & peroxidase 55 & $\mathrm{P}<0.005$ \\
\hline API-3 & Ppnisotig10090 & endochitinase ep3-like & $\mathrm{P}<0.001$ \\
\hline API-4 & Contig17069 & endochitinase a-like & $\mathrm{P}<0.001$ \\
\hline API-4 & Contig17710 & basic endochitinase a-like & $\mathrm{P}<0.005$ \\
\hline API-4 & Contig17876 & expansin-like a1-like & $\mathrm{P}<0.005$ \\
\hline API-4 & Contig20931 & protein tify 10a-like & $\mathrm{P}<0.005$ \\
\hline API-4 & Contig21755 & peroxidase 12-like & $\mathrm{P}<0.005$ \\
\hline API-4 & Contig22185 & major allergen pru ar 1-like & $\mathrm{P}<0.001$ \\
\hline API-4 & Contig22397 & --- NA--- & $\mathrm{P}<0.005$ \\
\hline API-4 & Contig39240 & ethylene-responsive transcription factor rap2-12-like & $\mathrm{P}<0.005$ \\
\hline API-4 & Ppnisotig06399 & zinc-finger homeodomain protein 4-like & $\mathrm{P}<0.001$ \\
\hline API-5 & Contig15806 & probable wrky transcription factor 75-like & $\mathrm{P}<0.001$ \\
\hline API-5 & Contig17013 & probable xyloglucan endotransglucosylase hydrolase protein 23 & $\mathrm{P}<0.005$ \\
\hline API-5 & Contig20476 & exordium like 2 & $\mathrm{P}<0.005$ \\
\hline API-5 & Ppnisotig00872 & endoglucanase 17-like & $\mathrm{P}<0.001$ \\
\hline API-6 & Contig13895 & nac transcription factor 29-like & $\mathrm{P}<0.001$ \\
\hline API-6 & Contig23326 & transcription factor myb12-like & $\mathrm{P}<0.001$ \\
\hline API-6 & Ppnisotig11516 & pathogenesis-related protein pr-4-like & $\mathrm{P}<0.005$ \\
\hline & & & \\
\hline
\end{tabular}

A total of 407 resprouting exclusive DEGs (i.e., those not detected as DEG for apical shoot elongation), displayed differential expression only at R1, as immediate response to wound. Among them, most of the 188 overexpressed ones are related, as expected, to defense response, such as peroxidases (Contig08118 or -20552), a putative endochitinase (Contig00126), or two PAL-like proteins (Contig20817 and -16597), as well other transcription factors such as NAC2-like (Congit05634 and 18538), bHLH35-like (Contig05923), or members of the TIFY family (Contig04787, 06230, -20599 and -25517). At the same time, 112 DEGs repressed at R1 correspond to genes involved in early wood formation. This is the case of different members of the CAZyme superfamily (f.i., Contig13778, -11436, -12072 and -02909), or transcription factors such as bHLH63-like (Contig12421) or MYB46-like (Contig12050) and MYB5-like (Contig02588). This result is consistent with the ones reported in Chapters 2 and 3 (Chano et al. 2015, 2017a), who reports that radial growth is arrested and xylogenesis genes are repressed right after wounding, while defensive processes are triggered. 
Chano, $V$ - Transcriptomics of the response to wounding

Other resprouting-exclusive DEGs kept significantly high transcription levels during the subsequent phases of epicormics shoot development. This is the case of transcription factors such as two members of TIFY family, TIFY10a(Contig06361 and -17882) and TIFY10b-like (Contig30708). Concerning to this family of transcription factors, we found several sequences coding for the TIFY10a-like protein, all of them overexpressed at R1 despite they present slight differences during the rest of the response. As mentioned above, Contig06361 showed high overexpression at R1 (FC = 64.22), as well as in R2 and R3 (FC = 8.34 and $\mathrm{FC}=2.86$, respectively), while 5 more sequences were grouped in cluster RSP2, mainly overexpressed at R1. Activity of TIFY10a and TIFY10b have been proposed to regulate interconnection between auxin and JA signaling pathways (Grunewald et al. 2009). Moreover, Contig04787, coding for a putative TIFY6b-like protein, was found as well overexpressed at R1. TIFY6, also known as JAZ3, is a repressor of FILAMENTOUS FLOWER (FIL)/YAB1 during A. thaliana lateral organogenesis in response to jasmonate, which act redundantly with other YAB transcription factors such as YAB5 (Boter et al. 2015).

It is noteworthy the detection as DEG overexpressed at R3 of a putative ATHB13 (Contig20304), also induced during the immediate response to wound in a previous study [35] and not included among apical shoot elongation DEGs. In $A$. thaliana this gene has been reported do show an antagonistic role in stem elongation, while it is usually expressed in tapetum development during pollen formation (Ribone et al. 2015), and upregulated in response to abiotic stress conditions and pathogenesis (Cabello and Chan 2012, Cabello et al. 2012).

\section{CONCLUSIONS}

Resprouting is an important trait induced after wounding in the Canary Island pine. Resprouting is part of a local and systemic response to wound, which involves the mobilization of reserves stored in the xylem to feed the resprouting meristems which otherwise would remain inactive. In this work, we have analyzed the local response at the transcriptomic level in the resprouting area 
using a microarray including genes involved in xylogenesis and meristematic activity. Thus, microarray analysis would allow the detection both of genes involved in epicormics shoot activation and elongation and of genes related to the local effect of resprouting on the radial growth from the vascular cambium. In order to discriminate between both processes, we also compared DEGs detected for resprouting with DEGs expressed in constitutive elongation of apical shoot.

The examination of transcriptional changes during resprouting allowed the identification of genes required for cell signaling, cell identity and cell proliferation sub-processes. The first response to wounding included the overexpression of genes whose biological functions are related to defense and mechanical stress, while genes involved in wood formation were significantly repressed, thus arresting growth. We have not detected significant differences at the transcriptomic level in the xylogenesis process due to resprouting once radial growth is resumed, but a reduced transcription of several genes involved in cell growth and cell wall synthesis compared to control samples. The main variations correspond to genes related to defensive response, constitutively expressed during latewood development and induced as immediate response to wounding.

On the contrary, we reported several gene families that are presumably involved in the resprouting process itself, including laminar outgrowth, and bud emerging. Our data support the relevant role of the YABBY and LEAFY families of transcription factors activity during resprouting, and members of the class IV of the Homeodomain Leucine Zipper, such as PROTODERMAL FACTOR1, MERSITEM LAYER1 and HOMEODOMAIN GLABRA11. As well, other transcription factors implicated were GROWTH-REGULATING FACTOR1 and FLOWERINGPROMOTING FACTOR1 genes. The implication of such transcription factor families, which play important functionalities in leaf and inflorescence development also in flowering plants, suggests underling homologies between cell proliferation and tissue differentiation patterns in many lateral organogenesis processes. 
Chano, $V$-Transcriptomics of the response to wounding

As expected, resprouting shares a big deal of the transcriptomic profiling during the seasonal development of SAM, especially in regard to those genes showing an intense transcriptomic activity at the beginning of apical growth. Notwithstanding, we have also identified for the first time genes exclusively involved in the resprouting process in conifers, such as NAC2 transcription factor, two members of the TIFY family, or a sequence putatively encoding for the ATBH13-like member of the HD-Zip Class I subfamily. Other transcription factors not well characterized yet and mainly overexpressed at R3 and not differentially expressed during normal apical shoot elongation, such as Contig24637 or Ppnisotig07889, can also play a relevant role in resprouting development. In the same way, probably other genes not included in the microarray may also be important for resprouting.

This work is the first insight of the transcriptomics of resprouting process in conifers, a widely spread process in flowering plants but restricted to few coniferous species. Further work is needed to evaluate functionality of the candidate genes proposed here.

\section{MATERIAL AND METHODS}

\section{Plant material, wounding and samples collection, and RNA isolation}

For this work we used three 5 years old Canary Island pine trees. Pines were firstly grown in greenhouse, using $650 \mathrm{ml}$ conical containers with 3:1 (v/v) peat:vermiculite. After the first year, trees were transferred to soil in experimental garden at UPM facilities, and grown under environmental conditions with regular watering. At the moment of the beginning of this experiment, trees were approximately $2.5 \mathrm{~m}$ high and 7-10 cm diameter at the base. Using a sterile scalpel, we performed two wounds, removing bark, phloem, vascular cambium and first rows of xylem from a rectangular window $10 \mathrm{~cm}$ high and spanning half the circumference of the stems (Figure 1E-G). Wounds were performed in opposite sides of the stem and with an interval of approximately three wound heights. 
Wounding was performed on April $9^{\text {th }}, 2013$, when cambial activity was ongoing. One week later we collected a frame of tissue from the wound margins in both wounds (R1). On June $3^{\text {th }}$, when the trees were still forming early wood as reported in Chapter 1 (Chano et al. 2017b), we collected the new resprouts and tissues around them (phloem, cambium and first layers of xylem) emerging near wound margins (R2), and left other new resprouts to continue their development. Later on, on June $25^{\text {th }}$, we collected the rest of new resprouts growing in a more advanced state of development (R3). At each sampling date, controls were collected from each tree, from branches away from the wound.

For apical growth analysis, we collected apical shoots in development at five sampling times during the annual growing on 2013: A1 at the beginning of the season (April $15^{\text {th }}$ ), A2 two weeks later (April $30^{\text {th }}$ ), when apical shoot length initiates to increase, two intermediate states of development (A3 and A4 at May $22^{\text {th }}$ and July $3^{\text {th }}$, respectively), and A5 at September $11^{\text {th }}$, when apical shoot showed an advanced state of development (Figure 6). Collected samples were processed individually, immediately frozen in liquid nitrogen and stored at $-80^{\circ} \mathrm{C}$.

Total RNA was isolated from each sample, using the CTAB-LiCl precipitation method (Chang et al. 1993), and purified with the RNeasy Plant Mini Kit (Qiagen, CA, USA). Quantity of total RNA for each sample was measured with Nanodrop model ND-1000 (Thermo Scientific, MA, USA), and RNA quality was checked using Experion Bioanalyzer (Bio-Rad, CA, USA).

\section{Microarray analysis}

A set of 15266 contigs involved in meristematic activity of Pinus canariensis, selected from Chapter 1 (Chano et al. 2017b), was used for the design of a two-color $60 \mathrm{~K}$ microarray (Agilent, USA). Furthermore, we added 2303 contigs from other cDNA libraries of $P$. pinea, as well ESTs and sequences of the loblolly pine from the Pine Gene Index Database (http://www.mgel.msstate.edu/dna_libs.htm). For each contig, one 60 bp long probe was designed and spotted at least 3 times on the slide. 
Chano, $V$-Transcriptomics of the response to wounding

Probes designed for Populus, mouse and human ESTs available in public databases were included as negative controls.

For each sampling point (R1, R2 and R3), the three biological replicates were hybridized (wound vs. control) following the two-color protocol provided by the manufacturer (Agilent Technologies, CA, USA), and images were captured with a GenePix 4000B (Axon, CA, USA), and spots were quantified using the GenePix software (Axon, CA, USA). Microarray data was uploaded to the Gene Expression Omnibus database (GEO; https://www.ncbi.nlm.nih.gov/geo; Accession number pending of approval).

Statistical analyses of results obtained were carried out using Bioconductor for $\mathrm{R}$ Software (Gentleman et al. 2004), and those probes with a FC above 2 and below 2, with a significance level FDR below 0.05, were selected as differentially expressed. Thus, technical replicates were merged into one value per contig, and a datamatrix formed by ratios between experimental and control measurements for selected Differentially Expressed Genes (DEGs), including time sampled and biological replicate, was created. Clustering was performed using the heatmap.2 function of the gplots package in R (Warnes et al. 2015). Enrichment analysis of DEGs was performed using Blast2GO v.2.7.2 as well.

To perform transcriptomic analysis of apical growth along season, we used the same sequences representing meristematic activity in $P$. canariensis for a onecolor 60K microarray design (Agilent, USA). Three biological replicates from each sampling time were independently hybridized following the One-Color Microarray-Based Gene Expression Analysis Protocol (Agilent Technologies, Palo Alto, CA, USA). Arrays were scanned at a $3-\mathrm{mm}$ resolution on Agilent DNA Microarrays Scanner (G2565BA, Agilent Technologies), and the images were analyzed with Feature Extraction software (Agilent Technologies). Background correction and normalization of expression data were performed using LIMMA (Smyth and Speed 2003). For local background correction and normalization, the methods normexp and loess in LIMMA were applied, respectively (Smyth and 
Speed 2003). To have similar distribution across arrays and to achieve consistency among arrays, log-ratio values were scaled as scale estimator for the medianabsolute-value (Smyth and Speed 2003). Hybridizations and first statistical analysis were performed by the Genomics Facility at Centro Nacional de Biotecnología, Madrid. Data were deposited as well in the GEO database (Accession number pending of approval).

Normalized data were analyzed with maSigPro package in R (Conesa and Nueda 2017), performing a Time/Dosage Series analysis, a methodology designed for the identification of differentially expressed genes in a time-course experiment. maSigPro is based on a regression modeling approach and reports expression changes considering the whole expression profile. The following options were set for the analysis: (1) polynomial degree 4 for regression complexity; (2) FDR adjustment; (3) significance level of 0.05; (4) hierarchical clustering method; and (5) number of clusters $=6$.

\section{qRT-PCR validation}

The expression patterns of 12 DEGs covering the main profiles obtained from microarrays experiments of resprouting process and 9 DEGs selected from apical growth were confirmed by qRT-PCR using the same RNA employed for microarray hybridizations. First strand cDNA synthesis was performed using SuperScript ${ }^{\mathrm{TM}}$ III reverse transcriptase (Invitrogen, USA) following manufacturer's instructions and using $4 \mu \mathrm{gr}$ of total RNA and random hexamers.

Gene specific primers were designed for selected DEGs (Table 3) using the Primer3 software (Untergasser et al. 2012), with a melting temperature between 60 and $65^{\circ}$ C, and producing amplicons between 80 and 120 bp. qRT-PCR was performed in a CFX96 $^{\mathrm{TM}}$ Real-Time PCR Detection System (Biorad, USA), using the SsoFast ${ }^{\mathrm{TM}}$ EVAgreen ${ }^{\circledR}$ Supermix (Biorad, USA), according to manufacturer’s protocol, and following the standard thermal profile: $95^{\circ} \mathrm{C}$ for $3 \mathrm{~min}, 40$ cycles of $95^{\circ} \mathrm{C}$ for $10 \mathrm{~s}$ and $60^{\circ} \mathrm{C}$ for $10 \mathrm{~s}$. In order to compare data from different qRT-PCR runs, the CT values were normalized using the Ri18S as housekeeping gene, whose specific 
primers were FW 5'-GCGAAAGCATTTGCCAAGG-3' and REV 5'ATTCCTGGTCGGCATCGTTTA-3'. The expression ratios were then obtained using the delta-delta-CT method corrected for the PCR efficiency for each DEG (Pfaffl 2001).

Table 3. Primers used for qRT-PCR.

\begin{tabular}{|c|c|c|c|c|c|c|c|}
\hline Contig name & Oligo name & Description & Fwd/Rev & bp & Tm & GC & Sequence (5'-3') \\
\hline \multirow{2}{*}{ Congit00654 } & Pc_00654_CESA_F1 & \multirow{2}{*}{$\begin{array}{l}\text { cellulose synthase a-like } \\
\text { protein }\end{array}$} & Forward & 20 & 63.0 & 55 & GGACCACACTCCTCATTCCT \\
\hline & Pc_00654_CESA_R1 & & Reverse & 20 & 63.0 & 45 & ACCCCATGACTGAAATCCAT \\
\hline \multirow{2}{*}{ Contig12050 } & Pc_12050_MYB_F1 & \multirow{2}{*}{ MYB46-like protein } & Forward & 20 & 62.8 & 45 & ATTCCCAACATGGAAGAAGC \\
\hline & Pc_12050_MYB_R1 & & Reverse & 20 & 63.7 & 50 & CTGCATCACCATCACACTCA \\
\hline \multirow{2}{*}{ Contig20304 } & Pc_20304_ATHB13_F1 & \multirow{2}{*}{ ATHB13-like protein } & Forward & 20 & 63.2 & 50 & CCCATTCTCATGATGTCTGC \\
\hline & Pc_20304_ATHB13_R1 & & Reverse & 20 & 63.1 & 50 & CAGAACTGCCTTCACTTCCA \\
\hline \multirow{3}{*}{ Contig00787 } & Pc_00787_NAC_F1 & \multirow{3}{*}{ NAC2-like prtoein } & Forward & 20 & 62.5 & 45 & CTAAATGGCCCTGGGTAAAA \\
\hline & & & & & & & \\
\hline & Pc_00787_NAC_R1 & & Reverse & 20 & 62.8 & 50 & ССССТТСТТСТТАССААССА \\
\hline \multirow{2}{*}{ Contig20555 } & Pc_20555_PAL_F1 & \multirow{2}{*}{$\begin{array}{l}\text { phenylalanine ammonia- } \\
\text { lyase-like protein }\end{array}$} & Forward & 20 & 63.1 & 50 & GAATTGACGTCCTGGTTGTG \\
\hline & Pc_20555_PAL_R1 & & Reverse & 20 & 62.7 & 50 & CAGCCTGGACTATGGTTTCA \\
\hline \multirow{2}{*}{ Contig03225 } & Pc_03225_EXPANSIN_F1 & \multirow{2}{*}{ a-expansin-like protein } & Forward & 20 & 62.8 & 45 & AAGCGGAGCTGATTCTTGAT \\
\hline & Pc 03225 EXPANSIN_R1 & & Reverse & 20 & 63.1 & 60 & CTCAGAGCCACAGAGACGAG \\
\hline \multirow{2}{*}{ Contig05551 } & Pc_05551_WRKY_F1 & \multirow{2}{*}{ WRKY51-like protein } & Forward & 20 & 62.5 & 45 & ACGCAGAGGGGAATAAGAAA \\
\hline & DOCFC1 WDUY D1 & & Poyrerse & 20 & $622+20$ & 50 & САСААААССТТСАСССАСАG \\
\hline \multirow{3}{*}{ Contig06476 } & Pc 06476 CCoAOMT_F1 & \multirow{3}{*}{ CCoAOMT-like protein } & Forward & 20 & 64.0 & 50 & GATTGAACAACCGAGGTGCT \\
\hline & & & & & & & \\
\hline & Pc_06476_CCoAOMT_R1 & & Reverse & 20 & 63.6 & 45 & TGCAACACCTGAATTCCAAC \\
\hline \multirow{3}{*}{ Contig05410 } & Pc_05410_PECTINESTERASE_F1 & \multirow{3}{*}{ pectinesterase 2-like } & Forward & 20 & 63.1 & 55 & GTACTCTCGCACGGTCTTCA \\
\hline & & & & & & & \\
\hline & Pc_05410_PECTINESTERASE_R1 & & Reverse & 20 & 62.5 & 45 & ATAATAAAGCGTCCCCAACG \\
\hline \multirow{2}{*}{ Contig09007 } & Pc_09007_EXO_F1 & \multirow{2}{*}{ exordium 2-like protein } & Forward & 20 & 62.9 & 45 & TACCCGATCATGCAAGACAT \\
\hline & Pc_09007_EXO_R1 & & Reverse & 20 & 62.7 & 55 & GCGCCTAAATCTACCTGCTC \\
\hline \multirow[b]{2}{*}{ Contig12414 } & Pc_12414_EXPANSIN_F1 & \multirow{2}{*}{ expansin-b3-like } & Forward & 20 & 63.1 & 45 & CAAAGCAAGCAGAAGCACAT \\
\hline & Pc_12414_EXPANSIN_R1 & & Reverse & 20 & 62.9 & 50 & AAGGGTTCCATTCTCCACTG \\
\hline \multirow{2}{*}{ Contig22185 } & Pc_22185_PR_F1 & \multirow{2}{*}{$\begin{array}{l}\text { Major allergen PRU-like } \\
\text { protein }\end{array}$} & Forward & 20 & 65.0 & 60 & GTGGAGGCAAGGAGACTGTG \\
\hline & Pc_22185_PR_R1 & & Reverse & 19 & 64.9 & 63.2 & СTGCCTACGCCTCCATCTC \\
\hline \multirow{2}{*}{ Contig13239 } & Pc_13239_YABBY_F1 & \multirow{2}{*}{ axial regulator yabby 5-like } & Forward & 20 & 62.4 & 45 & AGAGGATCAAAGCCCACAAT \\
\hline & Pc_13239_YABBY_R1 & & Reverse & 20 & 63.4 & 45 & TGTCCATCATCATCCCAAAG \\
\hline \multirow{3}{*}{ Contig04961 } & Pc_04961_BEL1_F1 & & Forward & 21 & 64.2 & 47.6 & TGAAACTTCAGCACCTCATCC \\
\hline & & BEL1-like protein & & & & & \\
\hline & Pc_04961_BEL1_R1 & & Reverse & 20 & 63.9 & 50 & AGCTCTGGCTTAGGCAACAA \\
\hline & Ri18S_FW & & Forward & 19 & 62.4 & 53 & GCGAAAGCATTTGCCAAGG \\
\hline Housekeeping & & $18 \mathrm{~S}$ robosomal & & & & & \\
\hline & Ri18S_RV & & Reverse & 21 & 62.4 & 48 & ATTCCTGGTCGGCATCGTTTA \\
\hline
\end{tabular}

Tm: Melting temperature. GC: guanine-cytosine content. bp: base pair 


\section{GENERAL DISCUSSION}





\section{GENERAL DISCUSSION}

As exposed in the Introduction of this dissertation, several agents may cause traumatic damages in living trees, including natural events such as rock-falls, avalanches, forest fires, or animal such as birds, bears, deer, insects, or anthropic activity such as logging or pruning. Open wounds on trees expose inner tissues to infection and further damage by wood decay, which entails a major problem affecting to all tree species and forest health worldwide. Wood decay leads to weakening of the organism and eventual death, and the capacity to respond to the mechanical stress produced may be critical for tree survival. In this thesis we progress in conifer developmental biology in response to severe traumatisms, and its effect in wood formation.

\section{Anatomical analysis of healing}

Trees defend from damages caused by mechanical injuries in the wood with a series of barriers that hamper the spread of opportunistic pathogens and forming healing tissues that eventually close the wound. Healing of wounds performed in the stem of $P$. canariensis is studied from an anatomical standpoint in Chapter 2 Wound closure in this species shows relevant differences with the process described for several angiosperms. Although a great deal of it takes place from the lateral margins, forming spindles or ribs that expand over the open wound face, healing directly from the wound surface has also been described for different angiosperm species. This is the case, for instance, of Tilia, whose immature xylem cells in the wound surface produce a callus after removal of a portion of bark, phloem and cambium in the trunk (Stobbe 2002). In the same way, living xylem cells in the wound surface proliferates producing a disordered callus in completely debarked stems of Populus tomentosa (from immature axial cells; Zhang et al. 2011b) or Eucommia ulmoides (from parenchymatic radial cells; Pang et al. 2008). Later on, a traumatic vascular cambium differentiates in this callus, producing new phloem and xylem. On the contrary, no such a surface healing has been reported in conifers so far. Our results show that healing of fenestration 
wounds in $P$. canariensis progresses exclusively from the lateral margins, via proliferation of vascular cambium cells, which is perceptible 2-4 weeks after wounding. The cambium twists inwards, heading the surface of the wound, probably due to a very high number of multiplicative, radial anticlinal divisions, which generate additional cambial cells, as discussed by Zajaczkowska (2014a) in P. sylvestris. The proportion of radial anticlinal divisions is related negatively with the distance to the healing border, i.e., they are more frequent near the border, and ultimately would lead to the reconstruction of the cambial circumference. Simultaneously, first periclinal divisions give rise to parenchymatous cells outwards, which form a protecting callus. A new traumatic phellogen differentiates in the outer part of the parenchymatous healing edge, developing a new periderm. As reported by Oven and Torelli (1999), no periderm is formed in the ventral part of the healing callus. New vascular tissues are generated by additive periclinal divisions of cambial cells. Xylem development via centripetal divisions forces the cambium to recover its normal position, parallel to the organ surface. A noticeable feature, differing from other species, is the delayed differentiation of traumatic phloem. While in angiosperms phloem reconnection is achieved shortly after wounding through the differentiation of phloem elements within the parenchymatous callus (as in Populus tomentosa, Zhang et al. 2011b) or even by transdifferentiation of immature xylem elements (as in Eucommia ulmoides, Pang et al. 2008), before the development of a new traumatic vascular cambium, we have observed that in $P$. canariensis wound phloem starts to differentiate only after xylem.

When the stem is completely girdled and there is no lateral edge left, healing is accomplished from the upper edge of the wound. Proliferation from this margin produces several column-like structures with a basipetal development which eventually reconnect the phloem, allowing the tree to surmount this dangerous damage. The most interesting result of our anatomical analysis of this sort of injuries is the involvement of the parenchymatous cells associated to xylem axial resin ducts in this process. The sheath of the resin ducts closest to the wound 
surface proliferates, no matter the resin covering the girdled stem, and contributes to the development of those column-like structures, anchoring them to the wound surface. On the contrary, in fenestration wounds no proliferation from preexisting parenchymatous cells, from radii or from ducts sheaths, has been observed, which suggest this proliferation could be under hormonal control. The interruption of phloematic sap flow in completely girdled stems causes a noticeable increase of auxin in the upper margin on the wound and alters the cytokinins flow from the roots (Domec and Pruyn 2008), which can underlie the formation of protuberances and column-like structures. The abundance of resin ducts typical of his species, and the large size of their parenchymatous sheaths, compared to other conifers, is a key factor in the unique high capability of $P$. canariensis to surmount these dangerous injuries.

Our study also enlightens the positional perception shown by cambial cells. Our results suggest that it is the location of the surface closest to the cambial zone which determines the direction of periclinal and radial anticlinal divisions. Thus, close to the end of the wounded, open cambium, periclinal divisions go parallel to the wound lateral edge and perpendicular to the wound surface, and to normal, non-traumatic periclinal divisions. Nevertheless, due to the curvature of the cambium there can be a zone where the closest organ surface is detected in two different directions. In this case, sometimes a switch in the polarity of orientation of periclinal and radial anticlinal divisions takes place, leading to abnormal U- and Y-shaped arrays of cells coming from the same cambial initial, as reported here for the first time.

Many works report the incidence of the alteration of hormone flux caused by wounds in the orientation, directionality of cell division and subsequent disorganization of wound xylem (e.g., auxins are involved in the specification of polarity in primary meristems, as reviewed by Berleth and Sachs, 2001; ethylene production is induced by mechanical stress, as reported by Telewski and Jaffe, 1986, in P. taeda). However, mechanoperception also determines the directionality of divisions, as shown in thigmomorphogenesis studies and 
Chano, $V$-Transcriptomics of the response to wounding

reviewed by Telewski 2006. Brown and Sax (1962) showed that mechanoperception of the pressure exerted by surrounding cells determines the differentiation of phloem and xylem. Our results also support the involvement of mechanoperception in the alteration of the normal pattern of cambium additive divisions, probably concomitantly with hormone flux and maybe even other factors, such as, for instance, the incidence of light. Thus, where scalpel penetrated in the xylem in parallel to the cambium, a switch in the direction of divisions took place, and the very first multiplicative division occurred inwards; further periclinal additive divisions producing xylem separated cambial cells, giving rise to U-shaped cell alignments in the xylem and forcing the cambium to acquire a "hairpin" shape. In other points of wound margins, where the scalpel did not penetrate in parallel to the cambium, these cellular arrangements were not detected. These differences are more likely attributable to mechanical factors than to hormone flux variation.

Traumatic wood shows a very high proportion of resin ducts and parenchymatic cells, as well as, especially in the irregular upper margin of girdling wounds and in the extreme of column-like structures, highly crooked and disordered tracheids. This feature can be due to the perception of surface in different direction and to the altered hormone flux, as reported by Sachs and Cohen (1982) or Kurczynska and Hejnowicz (1991). This process can ultimately lead even to the differentiation of radial series of normal, axially oriented tracheids next to tangentially oriented ones. In these regions, also tangential resin ducts are developed, perpendicular both to axial and radial canals. Malformation and disorganization of tracheids in woundwood, as well as the later recovery of a normal pattern has been recently described in beetle and fire scars in different conifers (Arbellay et al. 2014, 2017) or in mechanical injuries in the stem of Pinus sylvestris (Zajaczkowska 2014a) or even in overgrown stumps of felled Pseudotsuga menziensii (Zajaczkowska 2014b). This disorganized xylem, with an increased proportion of resin ducts and associated parenchyma imply an evident disadvantage for the circulation of water and nutrients through the traumatic xylem (Arbellay et al. 2014). 
Additionally, traumatic wood presents undesirable characteristics from a technological point of view. Although the higher density due to the increase in resin content can improve certain mechanical qualities of wood it also causes problems at machining and blunting (García-Iruela et al. 2016). In addition, disordered and not properly formed traumatic tracheids contribute to alter the physico-mechanical properties of wood. Therefore, lumber dealers consider traumatic wood as a defect, lowering the price and reducing the applicability of wood pieces with important scars.

This anatomical study allowed us to establish the sampling points and dates for further molecular analysis of the healing process and traumatic wood formation and its comparison with xylogenesis.

\section{Transcriptomics of xylogenesis}

In order to study the effect of wounding in wood formation from a transcriptomic standpoint, it was necessary to develop specific molecular tools and a reference framework related to xylogenesis in $P$. canariensis (Chapter 1). While gymnosperms have huge genomes, with a high percentage of repeated sequences and pseudogenes (Kovach et al. 2010, Lorenz et al. 2012, Nystedt et al. 2013), most of the information available in databases corresponds to angiosperms, hampering transcriptomic and genomic analysis in the former and decreasing the proportion of successful annotations for these studies (López de Heredia and Vázquez-Poletti 2016). Even focusing in xylogenesis, an aspect more profusely studied in gymnosperms than others, many genes, such as those involved in differentiation of parenchyma (a relevant tissue for healing and resprouting), may have been missed in previous studies, due to the scarcity of this tissue in other species. For this reason, we obtained a transcriptome of wood formation, constructing two cDNA libraries covering both early- and latewood. These two separate libraries were meta-assembled into a single transcriptome, yielding 44,849 contigs and 103,764 singletons. The total length of the final transcriptome was 25,836,041 bp, considerably larger than other ones related to wood formation in conifers and 
available in databases, as those of P. pinaster (Le Provost et al. 2003), P. taeda (Kirst et al. 2003) or P. radiata (Li et al. 2010). Just a $61.5 \%$ of the contigs and a $27.5 \%$ of the unigenes matched any record of the RefSeq database. In the same way, GO terms were assigned only to approximately half of the contigs and to one fifth of the singletons. These proportions illustrate the comparatively few information available regarding genomics and transcriptomics of gymnosperms.

Transcript level profiling along the growing season allowed us to cluster differentially expressed genes, identifying DEGs mainly expressed during early or latewood formation. A high number of non-annotated genes have been identified here for the first time as DEGs involved in xylogenesis. Among the annotated ones, most of the DEGs significantly overexpressed during earlywood formation are related with cell division and cell wall formation processes, as expected. The most abundant DEGs of this group are those putatively involved in cell wall matrix formation and modification, such as genes for coding proteins of the cellulose synthase superfamily, KORRIGAN endoglucanase-like proteins and several genes coding for CAZymes (carbohydrate active enzymes) These are regulators of the principal biosynthesis pathways of hemicelluloses, such as glycosil transferases and hydrolases, along with pectate lyases (PLs). PLs are involved in degradation of pectin, a principal component of the primary cell walls during the secondary cell wall development, allowing intrusive growth of tracheids (Marín-Rodríguez et al. 2002). Expansins, which are regulators of cell growth (Cosgrove et al. 2002), and are related to tracheid elongation, are also present in these clusters. In the same way, genes involved in the phenylpropanoid pathway and lignin biosynthesis are also found in this group. Genes involved in the regulation of meristematic activity include transcription factors from different families, such as MYB or HD-Zip I and III, or genes coding for WOX family proteins. Other members of the same functional groups were identified as DEGs involved in latewood development. Additionally, several DEGs of this group are putatively related to the response to different stresses (cold, salt, drought...) response. Among them we can mention transcription factors from the NAC family or homologs of 
WRKY genes, reported to be induced by stress in Arabidopsis (Lai et al. 2008). The presence of stress-related genes in the latewood clusters is consistent with the results of Mishima et al. (2014), who described the abundance of 'defense mechanism genes' in the 'cessation of growth clusters' obtained for the cambial zone and differentiating xylem in $C$. japonica. Latewood differentiation is partly a consequence of a lower availability of water and resources at the end of the growing season, which detracts cell development compared to conditions for earlywood cell development in spring. Actually, lignin deposition and carbohydrate compounds involved in cell wall formation differ in earlywood and latewood cells (Antonova et al. 2014). Latewood is also a constitutive, inner barrier for pathogen expansion. Therefore, it is not surprising that genes involved in stress response show high expression values during latewood development.

The transcriptome reported here show some interesting differences with other ones previously obtained for conifers. Thus, several genes reported to be involved in latewood formation in other pines have been detected as earlywood DEGs in our study, and vice versa. These discrepancies in the expression patterns among pine species could underlie the anatomic differences in their secondary xylem and their specific wood characteristics. The use of mature wood or juvenile wood in these studies can also account for these discrepancies.

\section{Transcriptomics of traumatic wood formation}

Based on this xylogenesis transcriptome and in the expression profiling, we designed a microarray for the transcriptomic analysis of traumatic wood formation (Chapter 3).

Immediately after wounding, and according to the anatomical results obtained in Chapter 2, diametrical growth stops surrounding the wound. Consistently, at this stage (H1) genes related to meristematic activity, cell division or synthesis of cell wall show their transcription levels significantly lowered, such as CAZymes, COBRA of KORRIGAN endoglucanases, or transcription factors from the MYB or HD-ZIP III families. 
Chano, $V$-Transcriptomics of the response to wounding

On the contrary, genes presumabluy involved in the response to biotic and abiotic stress are overexpressed at H1, such as DEGs related to oxidative stress, hydrolytic enzymes and hormonal signaling. Oxidative stress is one of the main effects of mechanical damage and infections. Cell lysis results in the production of hydrogen peroxide, which is toxic for pathogens, but also for plant cells, triggering the hypersensitive response (Levine et al., 1994). Peroxidases are then induced for ROS (reactive oxygen species) detoxification (Diehn et al., 1993; Mohan et al., 1993). In this sense, although some peroxidases were repressed at H1, several contigs coding for different isoforms of a peroxidase12-like protein were overexpressed at this time, as gluthatione-S-transferases, lacoylgluthatine lyases or thioredoxins, involved in antioxidative defense and response to abiotic stress (Seki et al. 2001, Meyer et al. 2008). Among the induced genes coding for hydrolytic enzymes we found homologous to PR-4, for which RNAse and DNAse activity hase been reported and was first described as wound inducible in Solanum tuberosum (Stanford et al. 1989, Guevara-Morato et al. 2010). Other chitinases, defensins and genes coding for putative antimicrobial proteins were also overexpressed. In the same way, many genes related to hormonal signaling are also induced at H1, mainly related to the synthesis of ethylene and the salicylic acid (SA)-mediated response. On the contrary, no DEG related to jasmonic acid (JA) biosynthesis has been detected as overexpressed at this stage, while JA is known to trigger a complex signaling network, both locally, activating the expression of woundinduced genes, and systemically, via the systemin peptide (Rojo et al. 1999), mediated by ethylene (O'Donnell et al. 1996). The restrictive criteria used in this work to select DEGs can account for this result, and also the action of SA, which is thought to be an antagonistic of JA (Vidhyasekaran 2015). Additionally, a local repression of the JA-dependent pathway by ethylene production has been reported in Arabidopsis (León et al. 2001), where the existence of an additional JAindependent pathway has also been described. This could also be the case for Pinus canariensis. Approximately one hundred of non annotated DEGs were overexpressed at $\mathrm{H} 1$, and about as many others repressed. 
Noteworthy, several of these genes related to stress response and overexpressed at $\mathrm{H} 1$ are also related to latewood formation, as discussed above, supporting the role of latewood as preventive barrier against eventual pathogens.

Afterwards, we collected two more samples during traumatic wood formation. The first one, $\mathrm{H} 2$, was sampled 75 days after wounding, when the tree was forming earlywood, while $\mathrm{H} 3$ was collected 92 days after wounding, when the tree was already forming latewood, according to the results described in Chapters 1 \& 2 . As expected, genes related to cell proliferation and cell wall biosynthesis are overexpressed at these stages, and the transcription profiles are more similar between $\mathrm{H} 2$ and $\mathrm{H} 3$, and differ more from $\mathrm{H} 1$. While most of the genes involved in xylogenesis during latewood formation do not change their normal transcription patterns, and therefore are not detected as DEG at H2 or H3, several genes characteristic of early wood formation appear as overexpressed at both of these phases. This is the case of WOX4 transcription factor and CLAVATA proteins, presumably involved in meristematic activity (Miwa et al. 2009, Ji et al. 2010b), of expansins, KORRIGAN endoglucanases and different CAZymes, involved in cell expansion and cell wall development, some of them even more strongly induced at H3. Conversely, other CAZymes and cellulose synthases typical of latewood formation are significantly repressed both at $\mathrm{H} 2$ and $\mathrm{H} 3$. These results are consistent with anatomical observations, since no clear difference between early and late wood is observed in the traumatic wood grown during 18 months after wounding.

On the contrary, a high number of resin ducts appear in this traumatic wood. Accordingly, several genes related to resin synthesis have been detected as overexpressed at $\mathrm{H} 2$ and $\mathrm{H} 3$, as DEGs involved in the synthesis of mono and diterpenes. Interestingly, several genes presumably involved in the synthesis of ethylene have also been detected as overexpressed at these stages, although this hormone is supposed to act in the first steps of the response. This is the case of ACS (1-aminocyclopropane-1-carboxylic acid synthase) or ACO (1aminocyclopropane-1-carboxilate oxidase), whose homologs are induced during 
Chano, $V$ - Transcriptomics of the response to wounding

the immediate response to wounding in Picea and Pseudotsuga (Ralph et al. 2007). Conversely, multiple ACO genes have been found overexpressed during the whole response (from H1 to H3) in P. canariensis. Many defensive genes overexpressed at $\mathrm{H} 1$ decrease to normal levels at $\mathrm{H} 2 / \mathrm{H} 3$ or are even repressed at $\mathrm{H} 3$, although they are typically related to latewood formation. Again, more than one hundred non-annotated DEGs were detected as overexpressed at $\mathrm{H} 2$ and $\mathrm{H} 3$, and even more are repressed at these stages.

Our results suggest that the tree, after the synthesis of defensive molecules against eventual pathogens, and once cambial activity is restored at the wound borders, produces a fast-growing traumatic wood. This tissue, in which annual rings are not clearly distinguished, at least the first year, could be less efficient as preventive barrier than normal late wood regarding secondary wall lignification. These results are consistent with the ones reported very recently by Arbellay et al. (2017) for Pinus ponderosa. In this study, the authors analyze different anatomical and chemical parameters of traumatic wood developed after scolytid attack or after forest fire and report a diminished density of latewood in both cases for the first year after injury. Nevertheless, this traumatic wood presents a high proportion of resin ducts, and also provides a good media to heal the wound in the shortest possible time. Further investigations are needed to clarify this point.

\section{Resprouting and xylogenesis}

Complementarily to wound closure, the Canary Island pine also exhibits the capability of resprouting in response to traumatisms in the zone adjacent to the damaged tissue, which confers resilience against forest fires and traumatic injuries. We have observed that in P. canariensis shoots resprout from dormant, epicormics woods in the axil of braquiblasts, which can even remain embedded in the bark. Thus, buds originating resprout would be classified as preventitious ones; we have not observed de novo formation of adventitious buds.

Wound-induced resprouting takes place close to the injury, and even in the opposite side of the trunk. Of course, since it depends on pre-existing, dormant 
buds, no shoots are formed from the healing tissues. The mechanisms driving the resprouting process remain not well understood, and exceed the objectives of this thesis. Nevertheless, in Chapter 4 we analyse the transcriptomic effect on xylogenesis in the resprouting area, as well as expression in the resprouts compared with the development of apical shoots.

In the resprouting area, as in the immediate surroundings of the injury, diametrical growth is arrested right after wounding. Transcription profile at this stage (R1) is virtually identical to the one described above for H1. These findings suggest that the effect on growth caused by wounding reach not only the damaged tissues but also the neighbouring areas where eventually resprouting takes place.

Later on, when induced shoots are developing (stages R2 and R3), we did not detect severe alterations at the transcriptional level in differentiating wood compared to controls. Only some genes involved in cell growth and cell wall development show reduced transcription levels, which could be related with a diminished cambial activity.

We did identify overexpression at these stages of DEGs presumably related specifically to the development of shoots, according to their annotation. The most remarkable ones correspond to transcription factors. This is the case DEGs coding for PROTODERMAL FACTOR 1 (PDF1) -like and MERISTEM LAYER 1 (ML1) -like proteins (reported to control cell differentiation in the epidermis of new buds in Arabidopsis; Abe et al. 2003). In the same way, a GROWTH-REGULATING FACTOR 1 (GRF1) -like is overexpressed at R2/R3. GRF family is involved in the growth of different organs as leaves, stems, roots or seeds (Omidbakhshfard et al. 2015) and recently has been reported to be involved in flower development (Pajoro et al. 2014). A FLOWERING-PROMOTING FACTOR 1 (FPF) -like gene showed a similar expression pattern. Interestingly, increasing transcription of this gene was found during latewood formation in the Canary Island pine (Chapter 2); additionally, Arabidopsis FPF1 was described to cause a strong effect on wood formation under constitutive overexpression in transgenic Populus (Hoenicka et al., 2012). A 
Chano, $V$ - Transcriptomics of the response to wounding

homolog of ATHB13-like, suggested to be involved in the regulation of the development of cotyledon and leaf in Arabidopsis (Henriksson et al. 2005) was also induced during shoot elongation. This is also the case of other transcription factors involved in the regulation of lateral organ growth, as members of the YABBY family (Yamada et al. 2011) of LEAFY, involved in flower development in A. thaliana (Weigel et al. 1992). Interestingly, the AP2/ERF WOUND INDUCED DEDIFFERENTIATION 1 (WIND1, also known as RAP2.4), which has been proposed as a central regulator of callus formation and shoot regeneration in wounded Arabidopsis (Iwase et al. 2011, 2016), was repressed at R2 and R3.

As can be seen, many of these DEGs are homologous to genes involved in flowering in angiosperms. The switch from vegetative organs development to reproductive organs development may be driven under disturbance regimes in order to promote survival by early flowering and seed production (Verslues and Juenger 2011). For instance, flower development in Arabidopsis can be induced by drought stress; this process is mediated by upregulation of LEAFY expression (Su et al. 2013), a homolog of which shows significant overexpression at R3 in resprouting P. canariensis. However, these genes have not been reported so far to be involved in strobili development in conifers. At any rate, this result could be an example of functional diversification of homologous genes in different taxa.

Taking into account the similarities between normal apical growth and resprouting we analysed and compared the transcript profile of our genes during seasonal elongation form apical meristem. As expected, a great deal of the shared DEGs corresponds to genes overexpressed during resprout elongation (R2\&R3). Among them, several genes overexpressed at the beginning of apical growth (A1\&A2) are worth to be remarked. These genes seem to be involved in the first steps of shoot development although their expression would decay during the transition to secondary growth, as revealed by the analysis of stages A3-A5 of apical development. This is the case of transcription factors such as PDF1-like, ML1-like or HDG11, belonging to the HD-ZIP IV family. On the contrary, other genes significantly repressed during resprouting stages R2/R3 were mainly 
overexpressed at A4 and A5 phases, which represent last steps of seasonal apical growth. These genes are presumably involved in the shoot transition to secondary growth, not sampled in resprouts.

Genes overexpressed at R1 and at the first steps of apical development (A1 and, to a lesser extent, A2 and A3) can be crucial for the early steps of shoot elongation, while their expression decreases with the establishment of secondary growth. In any case, most of the transcriptomic differences detected between resprouting and apical growth correspond to defensive genes overexpressed at R1 as a response to wound, such as peroxidases, chitinases and transcription factors as NAC2 or members of the TIFY family.

Our results give a starting point for future studies to gain more in-depth knowledge to understand the common and differential factors implicated in resprouting and apical growth. 



\section{CONCLUSIONS}





\section{CONCLUSIONS}

1.- We have constructed an almost $26 \mathrm{Mbp}$-long transcriptome of wood formation in P. canariensis. This transcriptome is much longer than others already published for conifer species and includes a high percentage of sequences non-annotated and/or without homologies in available databases.

2.- Based on this transcriptome we have designed a microarray for the analysis of transcription patterns during the growing season, identifying differentially expressed genes (DEGs) related to earlywood and latewood formation.

3- Among latewood genes, it is noteworthy the presence of genes presumably related with defensive response, supporting the role of latewood as a preventive barrier formed at the end of the growth season.

4.- Anatomical analysis of the healing process has shown that local cambial activity is arrested immediately after wounding. Once this activity is resumed (24 weeks later) wound closure takes place from the vascular cambium at the lateral margins of fenestration wounds, and not from sub/superficial xylem cells in the wound surface, as reported for some angiosperms.

5.- In girdled stems, where no lateral margins are left, healing takes place from the upper border. In this case, sub/superficial parenchymatic cells associated to resin ducts plays a key role in the development of column-like structures, crucial for phloematic reconnection and described here for the first time.

6.- Our results support mechanoperception by cambial cells of their relative position, driving directionality of periclinal and anticlinal divisions.

7.- Traumatic wood presents a high amount of parenchymatic cells and resin ducts, as well as distorted tracheids, with reduced hydraulic and technological performance.

8.- Our results also show that, at least during the first year after wounding, traumatic wood does not present a properly differentiated latewood. 
Chano, $V$-Transcriptomics of the response to wounding

9.- Although traumatic wood could be less efficient as preventive barrier than normal late wood regarding secondary wall lignification, it provides a good media to heal the wound in the shortest possible time. Additionally, the abundance of resin ducts hampers the spread of possible pathogens.

10.- At the transcriptomic level, immediate response to wound includes the overexpression of defensive genes usually expressed during latewood formation and the repression of genes involved in cambial proliferation, cell growth and cell wall development.

11.- Once formation of healing tissues begins, these genes are expressed again, even more than in control tissues.

12.- Consistently with anatomical observations, genes related to latewood formation are comparatively repressed in wound area, even when this tissue is being formed in other parts of the tree.

13.- In addition to healing, wounding also induces resprouting close to the injury, even in the opposite side of the stem. Resprouting takes place from preexisting axillary buds, even embedded by the bark.

14.- Repression of several earlywood genes related to proliferation, cell growth and cell wall development during resprout elongation could be related with a diminished diametrical growth at the resprouting area.

15.- As expected, most of the genes induced during resprout elongation are shared with seasonal apical shoot growth. 


\section{BIBLIOGRAPHY}





\section{BIBLIOGRAPHY}

Abe, M., Katsumata, H., Komeda, Y., and Takahashi, T. 2003. Regulation of shoot epidermal cell differentiation by a pair of homeodomain proteins in Arabidopsis. Development 130(4): 635-643. doi:10.1242/dev.00292.

Abe, M., Takahashi, T., and Komeda, Y. 1999. Cloning and characterization of an L1 layer-specific gene in Arabidopsis thaliana. Plant Cell Physiol. 40(6): 571580.

Allona, I., Quinn, M., Shoop, E., Swope, K., St Cyr, S., Carlis, J., Riedl, J., Retzel, E., Campbell, M., Sederoff, R., and Whetten, R. 1998. Analysis of xylem formation in pine by cDNA sequencing. Proc. Natl. Acad. Sci. U. S. A. 95(16): 9693-9698.

Altschul, S., Gish, W., Miller, W., Myers, E., and Lipman, D. 1990. Basic local alignment search tool. J. Mol. Biol. 215(3): 403-410. doi:10.1016/S00222836(05)80360-2.

Andersson-Gunnerås, S., Mellerowicz, E.J., Love, J., Segerman, B., Ohmiya, Y., Coutinho, P.M., Nilsson, P., Henrissat, B., Moritz, T., and Sundberg, B. 2006. Biosynthesis of cellulose-enriched tension wood in Populus: global analysis of transcripts and metabolites identifies biochemical and developmental regulators in secondary wall biosynthesis. Plant J. 45(2): 144-165. doi:10.1111/j.1365-313X.2005.02584.x.

Antonova, G.F., Varaksina, T., and Stasova, V. 2007. The differences in the lignification of earlywood and latewood in larch (Larix sibirica Ldb.). Eurasian J. For. Res. 10(2): 149-161.

Antonova, G.F., Varaksina, T.N., Zheleznichenko, T. V, and Stasova, V. V. 2014. Lignin deposition during earlywood and latewood formation in Scots pine stems. Wood Sci. Technol. 48(5): 919-936. doi:10.1007/s00226-014-0650-3.

Aoyama, T., Dong, C., Wu, Y., Carabelli, M., Sessa, G., Ruberti, I., Morelli, G., and Chua, N. 1995. Ectopic expression of the Arabidopsis transcriptional activator 
Chano, $V$-Transcriptomics of the response to wounding

Athb-1 alters leaf cell fate in tobacco. Plant Cell 7(11): 1773-1785. doi:10.1105/tpc.7.11.1773.

Arbellay, E., Daniels, L.D., Mansfield, S.D., and Chang, A.S. 2017. Cambial injury in lodgepole pine (Pinus contorta): mountain pine beetle vs fire. Tree Physiol. 37(12): 1-11. doi:10.1093/treephys/tpx102.

Arbellay, E., Stoffel, M., Sutherland, E.K., Smith, K.T., and Falk, D.A. 2014. Changes in tracheid and ray traits in fire scars of North American conifers and their ecophysiological implications. Ann. Bot. 114(2): 223-232. doi:10.1093/aob/mcu112.

Ariel, F.D., Manavella, P.A., Dezar, C.A., and Chan, R.L. 2007. The true story of the HD-Zip family. Trends Plant Sci. 12(9): 419-26. doi:10.1016/j.tplants.2007.08.003.

Asahina, M., Azuma, K., Pitaksaringkarn, W., Yamazaki, T., Mitsuda, N., OhmeTakagi, M., Yamaguchi, S., Kamiya, Y., Okada, K., Nishimura, T., Koshiba, T., Yokota, T., Kamada, H., and Satoh, S. 2011. Spatially selective hormonal control of RAP2.6L and ANAC071 transcription factors involved in tissue reunion in Arabidopsis. Proc. Natl. Acad. Sci. USA 108(38): 16128-16132. doi:10.1073/pnas.1110443108.

Azevedo, C., Santos-Rosa, M.J., and Shirasu, K. 2001. The U-BOX protein family in plants. Trends Plant Sci. 6(8): 354-358. doi:10.1016/S1360-1385(01)01960-4.

Ballesteros, J., Stoffel, M., Bodoque, J., Bollschweiler, M., Hitz, O., and Díez-Herrero, A. 2010. Changes in wood anatomy in tree rings of Pinus pinaster Ait. following wounding by flash floods. Tree-Ring Res. 66(2): 93-103. doi:10.3959/2009-4.1.

Banks, J.A., Nishiyama, T., Hasebe, M., Bowman, J.L., Gribskov, M., DePamphilis, C., Albert, V.A., Aono, N., Aoyama, T., Ambrose, B.A., Ashton, N.W., Axtell, M.J., Barker, E., Barker, M.S., Bennetzen, J.L., Bonawitz, N.D., Chapple, C., Cheng, C., 
Correa, L.G.G., Dacre, M., DeBarry, J., Dreyer, I., Elias, M., Engstrom, E.M., Estelle, M., Feng, L., Finet, C., Floyd, S.K., Frommer, W.B., Fujita, T., Gramzow, L., Gutensohn, M., Harholt, J., Hattori, M., Heyl, A., Hirai, T., Hiwatashi, Y., Ishikawa, M., Iwata, M., Karol, K.G., Koehler, B., Kolukisaoglu, U., Kubo, M., Kurata, T., Lalonde, S., Li, K., Li, Y., Litt, A., Lyons, E., Manning, G., Maruyama, T., Michael, T.P., Mikami, K., Miyazaki, S., Morinaga, S., Murata, T., MuellerRoeber, B., Nelson, D.R., Obara, M., Oguri, Y., Olmstead, R.G., Onodera, N., Petersen, B.L., Pils, B., Prigge, M., Rensing, S.A., Riaño-Pachón, D.M., Roberts, A.W., Sato, Y., Scheller, H.V., Schulz, B., Schulz, C., Shakirov, E. V, Shibagaki, N., Shinohara, N., Shippen, D.E., Sørensen, I., Sotooka, R., Sugimoto, N., Sugita, M., Sumikawa, N., Tanurdzic, M., Theissen, G., Ulvskov, P., Wakazuki, S., Weng, J.-K., Willats, W.W.G.T., Wipf, D., Wolf, P.G., Yang, L., Zimmer, A.D., Zhu, Q., Mitros, T., Hellsten, U., Loqué, D., Otillar, R., Salamov, A., Schmutz, J., Shapiro, H., Lindquist, E., Lucas, S., Rokhsar, D., and Grigoriev, I. V. 2011. The Selaginella genome identifies genetic changes associated with the evolution of vascular plants. Science. 332(6032): 960-3. doi:10.1126/science.1203810.

Barker, M.S., Dlugosch, K.M., Dinh, L., Sashikiran Challa, R., Kane, N.C., King, M.G., and Rieseberg, L.H. 2010. Evopipes.net: Bioinformatic tools for ecological and evolutionary genomics. Evol. Bioinforma. 2010: 143-149. doi:10.4137/EBO.S5861.

Bauch, J., Shigo, A., and Starck, M. 1980. Wound effects in the xylem of Acer and Betula species. Holzforschung 34(5): 153-160. doi:10.1515/hfsg.1980.34.5.153.

Baucher, M., El Jaziri, M., and Vandeputte, O. 2007. From primary to secondary growth: Origin and development of the vascular system. J. Exp. Bot. 58(13): 3485-3501. doi:10.1093/jxb/erm185.

Van Bel, M., Diels, T., Vancaester, E., Kreft, L., Botzki, A., Van de Peer, Y., Coppens, F., and Vandepoele, K. 2018. PLAZA 4.0: an integrative resource for functional, evolutionary and comparative plant genomics. Nucleic Acids Res. 46: 119096. doi:10.1093/nar/gkx1002. 
Chano, $V$-Transcriptomics of the response to wounding

Berleth, T., and Sachs, T. 2001. Plant morphogenesis: Long-distance coordination and local patterning. Curr. Opin. Plant Biol. 4(1): 57-62. doi:10.1016/S13695266(00)00136-9.

Bhandari, S., Fujino, T., Thammanagowda, S., Zhang, D., Xu, F., and Joshi, C.P. 2006. Xylem-specific and tension stress-responsive coexpression of KORRIGAN endoglucanase and three secondary wall-associated cellulose synthase genes in aspen trees. Planta 224(4): 828-837. doi:10.1007/s00425-006-0269-1.

Biggs, A. 1985. Suberized boundary zones and the chronology of wound response in tree bark. Phytopathology 75: 1191-1195.

Biggs, A. 1987. Occurrence and location of suberin in wound reaction zones in xylem of 17 tree species. Phytopathology 77(5): 718. doi:10.1094/Phyto-77-718.

Birnbaum, K.D., and Sánchez Alvarado, A. 2008. Slicing across kingdoms: Regeneration in plants and animals. Cell 132(4): 697-710. doi:10.1016/j.cell.2008.01.040.

Blüthgen, N., Kiełbasa, S.M., and Herzel, H. 2005. Inferring combinatorial regulation of transcription in silico. Nucleic Acids Res. 33: 272-279. doi:10.1093/nar/gki167.

Bobinac, M., Batos, B., Miljković, D., and Radulović, S. 2012. Polycyclism and phenological variability in the common oak (Quercus robur L.). Arch. Biol. Sci. 64(1): 97-105. doi:10.2298/ABS1201097B.

Bollschweiler, M., Stoffel, M., Schnewly, D., and Bourqui, K. 2008. Traumatic resin ducts in Larix decidua stems impacted by debris flows. Tree Physiol. 28: 25563. doi:doi: 10.1093/treephys/28.2.255.

Bond, W.J., and Midgley, J.J. 2003. The evolutionary ecology of sprouting in woody plants. Int. J. Plant Sci. 164(S3): S103-S114. doi:10.1086/374191.

Boter, M., Golz, J.F., Giménez-Ibañez, S., Fernandez-Barbero, G., Franco-Zorrilla, 
J.M., and Solano, R. 2015. FILAMENTOUS FLOWER is a direct target of JAZ3 and modulates responses to jasmonate. Plant Cell 27(11): 1-15. doi:10.1105/tpc.15.00220.

Boyd, R.S. 2007. Response to fire of Ceanothus roderickii (Rhamnaceae), a federally endangered California endemic shrub. Madroño 54(1): 13-21. doi:doi.org/10.3120/0024-9637.

Brown, C., and Sax, K. 1962. The influence of pressure on the differentiation of secondary tissues. Am. J. Bot. 49: 683-91.

Burrows, G., Offord, C., Meagher, P., and Ashton, K. 2003. Axillary meristems and the development of epicormic buds in wollemi pine (Wollemia nobilis). Ann. Bot. 92(6): 835-844. doi:10.1093/aob/mcg207.

Bushmanova, E., Antipov, D., Lapidus, A., Suvorov, V., and Prjibelski, A.D. 2016. rnaQUAST: a quality assessment tool for de novo transcriptome assemblies. Bioinformatics: btw218. doi:10.1093/bioinformatics/btw218.

Cabello, J. V., and Chan, R.L. 2012. The homologous homeodomain-leucine zipper transcription factors HaHB1 and AtHB13 confer tolerance to drought and salinity stresses via the induction of proteins that stabilize membranes. Plant Biotechnol. J. 10(7): 815-825. doi:10.1111/j.1467-7652.2012.00701.x.

Cabello, J. V, Arce, A.L., and Chan, R.L. 2012. The homologous HD-Zip I transcription factors HaHB1 and AtHB13 confer cold tolerance via the induction of pathogenesis-related and glucanase proteins. Plant J. 69(1): 141153. doi:10.1111/j.1365-313X.2011.04778.x.

Carlsbecker, A., and Helariutta, Y. 2005. Phloem and xylem specification: Pieces of the puzzle emerge. Curr. Opin. Plant Biol. 8(5): 512-517. doi:10.1016/j.pbi.2005.07.001.

Carpita, N.C., and Gibeaut, D.M. 1993. Structural models of primary-cell walls in flowering plants: Consistency of molecular structure with the physical 
Chano, $V$-Transcriptomics of the response to wounding

properties of the walls during growth. Plant J. 3(1): 1-30.

Castro, M.S., and Fontes, W. 2005. Plant defense and antimicrobial peptides. Protein Pept. Lett. 12(1): 11-16. doi:10.2174/0929866053405832.

Ceballos, L., and Ortuño, F. 1976. Vegetación y flora forestal de las Canarias Occidentales. Santa Cruz de Tenerife.

Ceballos, L., and Ruiz de la Torre, J. 1971. Árboles y arbustos de la España peninsular. Edited byI.F. de I. y E.E.T.S. de I. de Montes. Madrid.

Chang, S., Puryear, J., and Cairney, J. 1993. A simple and efficient method for isolating RNA from pine trees. Plant Mol. Biol. Report. 11: 113-116. doi:10.1007/BF02670468.

Chano, V., Collada, C., and Soto, Á. 2017a. Transcriptomic analysis of wound xylem formation in Pinus canariensis. BMC Plant Biol. 17: 234. doi:10.1186/s12870017-1183-3.

Chano, V., López, R., Pita, P., Collada, C., and Soto, Á. 2015. Proliferation of axial parenchymatic xylem cells is a key step in wound closure of girdled stems in Pinus canariensis. BMC Plant Biol. 15. doi:10.1186/s12870-015-0447-z.

Chano, V., López de Heredia, U., Collada, C., and Soto, Á. 2017b. Transcriptomic analysis of juvenile wood formation during the growing season in Pinus canariensis. Holzforschung aop: 1-19. doi:10.1515/hf-2017-0014.

Cheng, H., Song, S., Xiao, L., Soo, H.M., Cheng, Z., Xie, D., and Peng, J. 2009. Gibberellin acts through jasmonate to control the expression of MYB21, MYB24, and MYB57 to promote stamen filament growth in Arabidopsis. PLoS Genet. 5(3): 20-22. doi:10.1371/journal.pgen.1000440.

Cheng, Y., Dai, X., and Zhao, Y. 2006. Auxin biosynthesis by the YUCCA flavin monooxygenases controls the formation of floral organs and vascular tissues in Arabidopsis. Genes Dev. 20(13): 1790-1799. doi:10.1101/gad.1415106. 
Choczynska, J., and Johnson, E.A. 2009. A soil heat and water transfer model to predict belowground grass rhizome bud death in a grass fire. J. Veg. Sci. 20(2): 277-287. doi:10.1111/j.1654-1103.2009.05757.x.

Clarke, P.J., Lawes, M.J., Midgley, J.J., Lamont, B.B., Ojeda, F., Burrows, G.E., Enright, N.J., and Knox, K.J.E. 2013. Resprouting as a key functional trait: How buds, protection and resources drive persistence after fire. New Phytol. 197(1): 1935. doi:10.1111/nph.12001.

Climent, J., Gil, L., and Pardos, J.A. 1998. Xylem anatomical traits related to resinous heartwood formation in Pinus canariensis Sm. Trees 12: 139-145.

Climent, J., Tapias, R., Pardos, J.A., and Gil, L. 2004. Fire adaptations in the Canary Islands pine (Pinus canariensis). In Plant Ecology. pp. 185-196. doi:10.1023/B:VEGE.0000029374.64778.68.

Coll-Garcia, D., Mazuch, J., Altmann, T., and Müssig, C. 2004. EXORDIUM regulates brassinosteroid-responsive genes. FEBS Lett. 563(1-3): 82-6. doi:10.1016/S0014-5793(04)00255-8.

Conesa, A., and Götz, S. 2008. Blast2GO: A comprehensive suite for functional analysis in plant genomics. Int. J. Plant Genomics 2008: 619832. doi:10.1155/2008/619832.

Conesa, A., Götz, S., García-Gómez, J.M., Terol, J., Talón, M., and Robles, M. 2005. Blast2GO: a universal tool for annotation, visualization and analysis in functional genomics research. Bioinformatics 21(18): 3674-6. doi:10.1093/bioinformatics/bti610.

Conesa, A., and Nueda, M.J. 2017. maSigPro: Significant gene expression profile differences in time course gene expression data. Available from http://bioinfo.cipf.es/.

Cosgrove, D.J., Li, L.C., Cho, H.-T., Hoffmann-Benning, S., Moore, R.C., and Blecker, D. 2002. The growing world of expansins. Plant Cell Physiol. 43(12): 1436-44. 
Chano, $V$-Transcriptomics of the response to wounding

Cuéllar Pérez, A., Nagels Durand, A., Vanden Bossche, R., De Clercq, R., Persiau, G., Van Wees, S.C.M., Pieterse, C.M.J., Gevaert, K., De Jaeger, G., Goossens, A., and Pauwels, L. 2014. The non-JAZ TIFY protein TIFY8 from Arabidopsis thaliana is a transcriptional repressor. PLoS One 9(1): e84891. doi:10.1371/journal.pone.0084891.

Culley, D.E., Horovitz, D., and Hadwiger, L.A. 1995. Molecular characterization of disease-resistance response gene DDR206-d from Pisum sativum (L.). Plant Physiol. 107: 301-302.

Currier, H.B., and Strugger, S. 1956. Aniline blue and fluorescence microscopy of callose in bulb scales of Allium cepa L. Protoplasma 45: 552-559. doi:10.1007/BF01252676.

Dale, V.H., Joyce, L. a, Mcnulty, S., Neilson, R.P., Ayres, M.P., Flannigan, M.D., Hanson, P.J., Irland, L.C., Lugo, a E., Peterson, C.J., Simberloff, D., Swanson, F.J., Stocks, B.J., Wotton, B.M.C.-A.C.C.N.-P. 813564, P, R., and P, M. 2001. Climate change and forest disturbances. Bioscience 51(9): 723-734. doi:10.1641/0006-3568.

Demura, T., and Fukuda, H. 2007. Transcriptional regulation in wood formation. Trends Plant Sci. 12(2): 64-70. doi:10.1016/j.tplants.2006.12.006.

Deng, F., Tu, L., Tan, J., Li, Y., Nie, Y., and Zhang, X. 2012. GbPDF1 is involved in cotton fiber initiation via the core cis-element HDZIP2ATATHB2. Plant Physiol. 158(2): 890-904. doi:10.1104/pp.111.186742.

Diehn, S.H., Burkhart, W., and Graham, J.S. 1993. Purification and partial amino acid sequence of a wound-inducible, developmentally regulated anionic peroxidase from soybean leaves. Biochem Biophys Res Commun 195(2): 928934. doi:10.1006/bbrc.1993.2133.

Domec, J.C., and Pruyn, M.L. 2008. Bole girdling affects metabolic properties and root, trunk and branch hydraulics of young ponderosa pine trees. Tree 
Physiol. 28: 1493-1504. doi:10.1093/treephys/28.10.1493.

Du, J., and Groover, A.T. 2010. Transcriptional regulation of secondary growth and wood formation. J. Integr. Plant Biol. 52(1): 17-27. doi:10.1111/j.17447909.2010.00901.x.

Du, J., Miura, E., Robischon, M., Martinez, C., and Groover, A.T. 2011. The Populus Class III HD ZIP transcription factor POPCORONA affects cell differentiation during secondary growth of woody stems. PLoS One 6(2): 1-14. doi:10.1371/journal.pone.0017458.

Duval, I., Lachance, D., Giguère, I., Bomal, C., Morency, M.-J., Pelletier, G., Boyle, B., MacKay, J.J., and Séguin, A. 2014. Large-scale screening of transcription factor-promoter interactions in spruce reveals a transcriptional network involved in vascular development. J. Exp. Bot. 65(9): 2319-33. doi:10.1093/jxb/eru116.

Egertsdotter, U., Van Zyl, L.M., MacKay, J., Peter, G., Kirst, M., Clark, C., Whetten, R., and Sederoff, R. 2004. Gene expression during formation of earlywood and latewood in loblolly pine: Expression profiles of 350 genes. Plant Biol. 6(6): 654-663. doi:10.1055/s-2004-830383.

Esteban, L.G., and de Palacios, P.P. 2004. Characterisation of the xylem of 352 conifers. Invest Agrar Sist Recur 13(3): 452-478.

Eyles, A., Davies, N.W., and Mohammed, C. 2003. Wound wood formation in Eucalyptus globulus and Eucalyptus nitens: Anatomy and chemistry. Can. J. For. Res. 33(12): 2331-2339. doi:10.1139/X03-149.

Fahn, A., Werker, E., and Ben-Tzur, P. 1979. Seasonal effects of wounding and growth substances on development of traumatic resin ducts in Cedrus libani. New Phytol. 82: 537-44.

Falara, V., Akhtar, T.A., Nguyen, T.T.H., Spyropoulou, E.A., Bleeker, P.M., Schauvinhold, I., Matsuba, Y., Bonini, M.E., Schilmiller, A.L., Last, R.L., 
Chano, $V$-Transcriptomics of the response to wounding

Schuurink, R.C., and Pichersky, E. 2011. The tomato terpene synthase gene family. Plant Physiol. 157(2): 770-789. doi:10.1104/pp.111.179648.

Falara, V., Alba, J.M., Kant, M.R., Schuurink, R.C., and Pichersky, E. 2014. Geranyllinalool synthases in Solanaceae and other angiosperms constitute an ancient branch of diterpene synthases involved in the synthesis of defensive compounds. Plant Physiol. 166(1): 428-441. doi:10.1104/pp.114.243246.

Fäldt, J., Martin, D., Miller, B., Rawat, S., and Bohlmann, J. 2003. Traumatic resin defense in Norway spruce (Picea abies): Methyl jasmonate-induced terpene synthase gene expression, and cDNA cloning and functional characterization of (+)-3-carene synthase. Plant Mol. Biol. 51: 119-133. doi:10.1023/A:1020714403780.

Farrar, K., Evans, I.M., Topping, J.F., Souter, M.A., Nielsen, J.E., and Lindsey, K. 2003. EXORDIUM - A gene expressed in proliferating cells and with a role in meristem function, identified by promoter trapping in Arabidopsis. Plant J. 33(1): 61-73. doi:10.1046/j.1365-313X.2003.01608.x.

Figueroa-Yañez, L., Pereira-Santana, A., Arroyo-Herrera, A., Rodriguez-Corona, U., Sanchez-Teyer, F., Espadas-Alcocer, J., Espadas-Gil, F., Barredo-Pool, F., Castaño, E., and Rodriguez-Zapata, L.C. 2016. RAP2.4a Is transported through the phloem to regulate cold and heat tolerance in papaya tree (Carica papaya cv. Maradol): Implications for protection against abiotic stress. PLoS One 11(10). doi:10.1371/journal.pone.0165030.

Finet, C., Floyd, S.K., Conway, S.J., Zhong, B., Scutt, C.P., and Bowman, J.L. 2016. Evolution of the YABBY gene family in seed plants. Evol. Dev. 18(2): 116-126. doi:10.1111/ede.12173.

Fink, S. 1984. Some cases of delayed or induced development of axillary buds from persisting detached meristems in conifers. Am. J. Bot. 71(1): 44. doi:10.2307/2443622. 
Floyd, S.K., and Bowman, J.L. 2007. The ancestral developmental tool kit of land plants. Int. J. Plant Sci. 168(1): 1-35. doi:10.1086/509079.

Foucart, C., Paux, E., Ladouce, N., San-Clemente, H., Grima-Pettenati, J., and Sivadon, P. 2006. Transcript profiling of a xylem vs phloem cDNA subtractive library identifies new genes expressed during xylogenesis in Eucalyptus. New Phytol. 170(4): 739-752. doi:10.1111/j.1469-8137.2006.01705.x.

Frankenstein, C., Schmitt, U., Waitkus, C., and Eckstein, D. 2005. Wound callus formation - A microscopic study on poplar (Populus tremula L. x Populus tremuloides Michx.). J. Appl. Bot. Food Qual. 79(1): 44-51.

Fraser, C.M., and Chapple, C. 2011. The phenylpropanoid pathway in Arabidopsis. Arab. B. 9: e0152. doi:10.1199/tab.0152.

García-Iruela, A., Esteban, L., de Palacios, P., García-Fernández, F., de Miguel Torres, Á., Vázquez-Iriarte, E., and Simón, C. 2016. Resinous wood of Pinus pinaster Ait.: physico-mechanical properties. Bioresources 11(2): 5230-5241.

García Esteban, L., Gasson, P., Climent, J., Palacios, P. De, and Guindeo, A. 2005. The wood of Pinus canariensis and its resinous heartwood. IAWA J. 26(1): 69-77.

García Esteban, L., and Guindeo, A. 1988. Anatomía e identificación de las maderas de coníferas españolas. AiTiM, Madrid.

García Esteban, L., de Palacios, P., Guindeo, A., García Esteban, L., Lázaro, I., González, L., Rodríguez, Y., García, F., Bobadilla, I., and Camacho, A. 2002. Anatomía e identificación de maderas de coníferas a nivel de especie. FUCOVASA y Ediciones Mundi-Presna, Madrid.

Gardner, R.O. 1975. Vanillin-hydrochloric acid as a histochemical test for tannin. Stain Technol. 50: 315-317. doi:10.3109/10520297509117081.

Gärtner, H., and Heinrich, I. 2009. The formation of traumatic rows of resin ducts in Larix decidua and Picea abies (Pinaceae) as a result of wounding 
Chano, $V$-Transcriptomics of the response to wounding

experiments in the dormant season. IAWA J. 30(2): 199-215.

Gentleman, R.C., Carey, V.J., Bates, D.M., Bolstad, B., Dettling, M., Dudoit, S., Ellis, B., Gautier, L., Ge, Y., Gentry, J., Hornik, K., Hothorn, T., Huber, W., Iacus, S., Irizarry, R., Leisch, F., Li, C., Maechler, M., Rossini, A.J., Sawitzki, G., Smith, C., Smyth, G., Tierney, L., Yang, J.Y.H., and Zhang, J. 2004. Bioconductor: Open software development for computational biology and bioinformatics. Genome Biol. 5(10): R80. doi:10.1186/gb-2004-5-10-r80.

Gernandt, D.S., Geada López, G., Ortiz García, S., and Liston, A. 2005. Phylogeny and classification of Pinus. Taxon 54(1): 29-42. doi:10.2307/25065300.

Glickman, M.H., and Ciechanover, A. 2002. The Ubiquitin-Proteasome proteolytic pathway: Destruction for the sake of construction. Physiol. Rev. 82(2): 373428. doi:10.1152/physrev.00027.2001.

Grivet, D., Climent, J., Zabal-Aguirre, M., Neale, D.B., Vendramin, G.G., and González-Martínez, S.C. 2013. Adaptive evolution of Mediterranean pines. Mol. Phylogenet. Evol. 68(3): 555-566. Elsevier Inc. doi:10.1016/j.ympev.2013.03.032.

Grunewald, W., Vanholme, B., Pauwels, L., Plovie, E., Inzé, D., Gheysen, G., and Goossens, A. 2009. Expression of the Arabidopsis jasmonate signalling repressor JAZ1/TIFY10A is stimulated by auxin. EMBO Rep. 10(8): 923-8. doi:10.1038/embor.2009.103.

Guevara-Morato, M.Á., De Lacoba, M.G., García-Luque, I., and Serra, M.T. 2010. Characterization of a pathogenesis-related protein 4 (PR-4) induced in Capsicum chinense L3 plants with dual RNase and DNase activities. J. Exp. Bot. 61(12): 3259-3271. doi:10.1093/jxb/erq148.

Gunnar Fossdal, C., Sharma, P., and Lönneborg, A. 2001. Isolation of the first putative peroxidase cDNA from a conifer and the local and systemic accumulation of related proteins upon pathogen infection. Plant Mol. Biol. 
47(3): 423-435. doi:10.1023/A:1011615328684.

Guo, W.-L., Wang, S.-B., Chen, R.-G., Chen, B.-H., Du, X.-H., Yin, Y.-X., Gong, Z.-H., and Zhang, Y.-Y. 2015. Characterization and expression profile of CaNAC2 pepper gene. Front. Plant Sci. 6: 1-9. doi:10.3389/fpls.2015.00755.

Gurevich, A., Saveliev, V., Vyahhi, N., and Tesler, G. 2013. QUAST: Quality assessment tool for genome assemblies. Bioinformatics 29: 1072-1075. doi:10.1093/bioinformatics/btt086.

Haecker, A., Gross-Hardt, R., Geiges, B., Sarkar, A., Breuninger, H., Herrmann, M., and Laux, T. 2004. Expression dynamics of WOX genes mark cell fate decisions during early embryonic patterning in Arabidopsis thaliana. Development 131(3): 657-68. doi:10.1242/dev.00963.

Hamada, K., Ogata, T., Fujiwara, S., and Hasegawa, K. 2009. Healing process of the wounds of the branches of the Japanese persimmon that were caused by girdling, scoring, and strangulation. Sci. Hortic. (Amsterdam). 120: 276-281. doi:10.1016/j.scienta.2008.11.014.

He, T., Pausas, J.G., Belcher, C.M., Schwilk, D.W., and Lamont, B.B. 2012. Fireadapted traits of Pinus arose in the fiery Cretaceous. New Phytol. 194(3): 751759. doi:10.1111/j.1469-8137.2012.04079.x.

Heijari, J., Nerg, A.-M., Kainulainen, P., Viiri, H., Vuorinen, M., and Holopainen, J.K. 2005. Application of methyl jasmonate reduces growth but increases chemical defence and resistance against Hylobius abietis in Scots pine seedlings. Entomol. Exp. Appl. 115(1): 117-124. doi:10.1111/j.15707458.2005.00263.x.

Henriksson, E., Olsson, A.S.B., Johannesson, H., Johansson, H., Hanson, J., Engstro, P., Engstrom, P., and Soderman, E. 2005. Homeodomain leucine zipper class I genes in Arabidopsis. Expression patterns and phylogenetic relationships. Plant Physiol. 139(1): 509-518. doi:10.1104/pp.105.063461. 
Chano, $V$-Transcriptomics of the response to wounding

Higgins, S.I., Bond, W.J., and Trollope, W.S.W. 2000. Fire, resprouting and variability: A recipe for grass-tree coexistence in savanna. J. Ecol. 88(2): 213229. doi:10.1046/j.1365-2745.2000.00435.x.

Hiraga, S., Sasaki, K., Ito, H., Ohashi, Y., and Matsui, H. 2001. A large family of Class III plant peroxidases. Plant Cell Physiol. 42(5): 462-468. doi:10.1093/pcp/pce061.

Hoenicka, H., Lautner, S., Klingberg, A., Koch, G., El-Sherif, F., Lehnhardt, D., Zhang, B., Burgert, I., Odermatt, J., Melzer, S., Fromm, J., and Fladung, M. 2012. Influence of over-expression of the Flowering Promoting Factor 1 gene (FPF1) from Arabidopsis on wood formation in hybrid poplar (Populus tremula L. $\times$ P. tremuloides Michx.). Planta 235(2): 359-73. doi:10.1007/s00425-011-1507-8.

Hoffmann, W.A., Adasme, R., Haridasan, M., De Carvalho, M.T., Geiger, E.L., Pereira, M. a B., Gotsch, S.G., and Franco, A.C. 2009. Tree topkill, not mortality, governs the dynamics of savanna-forest boundaries under frequent fire in central Brazil. Ecology 90(5): 1326-1337. doi:10.1890/08-0741.1.

Hong, F., Breitling, R., McEntee, C.W., Wittner, B.S., Nemhauser, J.L., and Chory, J. 2006. RankProd: A bioconductor package for detecting differentially expressed genes in meta-analysis. Bioinformatics 22(22): 2825-2827. doi:10.1093/bioinformatics/btl476.

Hu, R., Qi, G., Kong, Y., Kong, D., Gao, Q., and Zhou, G. 2010. Comprehensive analysis of NAC domain transcription factor gene family in Populus trichocarpa. BMC Plant Biol. 10: 145. doi:10.1186/1471-2229-10-145.

Huang, D., Wang, S., Zhang, B., Shang-Guan, K., Shi, Y., Zhang, D., Liu, X., Wu, K., $\mathrm{Xu}, \mathrm{Z}$. , Fu, X., and Zhou, Y. 2015. A gibberellin-mediated DELLA-NAC signaling cascade regulates cellulose synthesis in rice. Plant Cell 27(6): 1681-96. doi:10.1105/tpc.15.00015.

Huang, S., Li, R., Zhang, Z., Li, L., Gu, X., Fan, W., Lucas, W.J., Wang, X., Xie, B., Ni, 
P., Ren, Y., Zhu, H., Li, J., Lin, K., Jin, W., Fei, Z., Li, G., Staub, J., Kilian, A., van der Vossen, E. a G., Wu, Y., Guo, J., He, J., Jia, Z., Ren, Y., Tian, G., Lu, Y., Ruan, J., Qian, W., Wang, M., Huang, Q., Li, B., Xuan, Z., Cao, J., Asan, Wu, Z., Zhang, J., Cai, Q., Bai, Y., Zhao, B., Han, Y., Li, Y., Li, X., Wang, S., Shi, Q., Liu, S., Cho, W.K., Kim, J.-Y., Xu, Y., Heller-Uszynska, K., Miao, H., Cheng, Z., Zhang, S., Wu, J., Yang, Y., Kang, H., Li, M., Liang, H., Ren, X., Shi, Z., Wen, M., Jian, M., Yang, H., Zhang, G., Yang, Z., Chen, R., Liu, S., Li, J., Ma, L., Liu, H., Zhou, Y., Zhao, J., Fang, X., Li, G., Fang, L., Li, Y., Liu, D., Zheng, H., Zhang, Y., Qin, N., Li, Z., Yang, G., Yang, S., Bolund, L., Kristiansen, K., Zheng, H., Li, S., Zhang, X., Yang, H., Wang, J., Sun, R., Zhang, B., Jiang, S., Wang, J., Du, Y., and Li, S. 2009. The genome of the cucumber, Cucumis sativus L. Nat. Genet. 41(12): 1275-1281. doi:10.1038/ng.475.

Huang, X., and Madan, A. 1999. CAP3: A DNA sequence assembly program. Genome Res. 9: 868-877. doi:10.1101/gr.9.9.868.

Hudgins, J.W., Ralph, S.G., Franceschi, V.R., and Bohlmann, J. 2006. Ethylene in induced conifer defense: cDNA cloning, protein expression, and cellular and subcellular localization of 1-aminocyclopropane-1-carboxylate oxidase in resin duct and phenolic parenchyma cells. Planta 224(4): 865-877. doi:10.1007/s00425-006-0274-4.

Ishii, H. 2011. How do changes in leaf/shoot morphology and crown architecture affect growth and physiological function of tall trees? Tree Physiol. 4: 215232. doi:doi: 10.1007/978-94-007-1242-3_8.

Iwase, A., Harashima, H., Ikeuchi, M., Rymen, B., Ohnuma, M., Komaki, S., Morohashi, K., Kurata, T., Nakata, M., Ohme-Takagi, M., Grotewold, E., and Sugimoto, K. 2016. WIND1 promotes shoot regeneration through transcriptional activation of ENHANCER OF SHOOT REGENERATION1 in Arabidopsis. Plant Cell 29(January): tpc.00623.2016. doi:10.1105/tpc.16.00623.

Iwase, A., Mitsuda, N., Koyama, T., Hiratsu, K., Kojima, M., Arai, T., Inoue, Y., Seki, 
Chano, $V$-Transcriptomics of the response to wounding

M., Sakakibara, H., Sugimoto, K., and Ohme-Takagi, M. 2011. The AP2/ERF transcription factor WIND1 controls cell dedifferentiation in Arabidopsis. Curr. Biol. 21(6): 508-514. doi:10.1016/j.cub.2011.02.020.

James, S. 1984. Lignotubers and burls: Their structure, function and ecological significance in mediterranean ecosystems. Bot. Rev. 50(3): 225-266. doi:10.1007/bf02862633.

Ji, J., Shimizu, R., Sinha, N., and Scanlon, M.J. 2010a. Analyses of WOX4 transgenics provide further evidence for the evolution of the WOX gene family during the regulation of diverse stem cell functions. Plant Signal. Behav. 5(7): 916-20. doi:10.1104/pp.109.149641.

Ji, J., Strable, J., Shimizu, R., Koenig, D., Sinha, N., and Scanlon, M.J. 2010b. WOX4 promotes procambial development. Plant Physiol. 152: 1346-1356. doi:10.1104/pp.109.149641.

Johannesson, H., Wang, Y., Hanson, J., and Engström, P. 2003. The Arabidopsis thaliana homeobox gene ATHB5 is a potential regulator of abscisic acid responsiveness in developing seedlings. Plant Mol. Biol. 51(5): 719-29.

Kania, U., Fendrych, M., and J, F. 2014. Polar delivery in plants; commonalities and differences to animal epithelial cells. Open Biol. 4(4): 140017. doi:https://doi.org/10.1098/rsob.140017.

Keeley, J., and Zedler, P. 1998. Life history evolution in pines. In Ecology and biogeography of Pinus. Edited by D. Richardson. Cambridge University Press. pp. 219-242.

Keeley, J.E. 2012. Ecology and evolution of pine life histories. Ann. For. Sci. 69: 445453. doi:10.1007/s13595-012-0201-8.

Keely, J.E., Vasey, M.C., and Parker, V.T. 2007. Subspecific variation in the widespread burl-forming Arctostaphylos glandulosa. Madroño 54(1): 42-62. doi:10.3120/0024-9637(2007)54[42:SVITWB]2.0.CO;2. 
Kervinen, T., Peltonen, S., Teeri, T.H., and Karjalainen, R. 1998. Differential expression of phenylalanine ammonia-lyase genes in barley induced by fungal infection or elicitors. New Phytol. 139(2): 293-300. doi:10.1046/j.14698137.1998.00202.x.

Kim, D.S., and Hwang, B.K. 2014. An important role of the pepper phenylalanine ammonia-lyase gene (PAL1) in salicylic acid-dependent signalling of the defence response to microbial pathogens. J. Exp. Bot. 65(9): 2295-2306. doi:10.1093/jxb/eru109.

Kirst, M., Johnson, A.F., Baucom, C., Ulrich, E., Hubbard, K., Staggs, R., Paule, C., Retzel, E., Whetten, R., and Sederoff, R. 2003. Apparent homology of expressed genes from wood-forming tissues of loblolly pine (Pinus taeda L.) with Arabidopsis thaliana. PNAS 100(12): 7383-7388.

Kovach, A., Wegrzyn, J.L., Parra, G., Holt, C., Bruening, G.E., Loopstra, C.A., Hartigan, J., Yandell, M., Langley, C.H., Korf, I., and Neale, D.B. 2010. The Pinus taeda genome is characterized by diverse and highly diverged repetitive sequences. BMC Genomics 11: 420. doi:10.1186/1471-2164-11-420.

Kozlowski, T.T. 1992. Carbohydrate sources and sinks in woody plants. Bot. Rev. 58(2): 107-222. doi:10.1007/BF02858600.

Krokene, P., Nagy, N.E., and Solheim, H. 2008. Methyl jasmonate and oxalic acid treatment of Norway spruce: anatomically based defense responses and increased resistance against fungal infection. Tree Physiol. 28: 29-35. doi:10.1093/treephys/28.1.29.

Krokene, P., Solheim, H., Krekling, T., and Christiansen, E. 2003. Inducible anatomical defense responses in Norway spruce stems and their possible role in induced resistance. Tree Physiol. 23(3): 191-197.

Kumar, D., and Klessig, D.F. 2003. High-affinity salicylic acid-binding protein 2 is required for plant innate immunity and has salicylic acid-stimulated lipase 
Chano, $V$-Transcriptomics of the response to wounding

activity. PNAS 100(26): 16101-16106. doi:10.1073/pnas.0307162100.

Kurczynska, E., and Hejnowicz, Z. 1991. Differentiation of circular vessels in isolated segments of Fraxinus excelsior. Physiol Plant 83: 275-80.

Kuroda, K., and Shimaji, K. 1984. Wound effects on xylem cell differentiation in a conifer. IAWA Bull. 5(4): 295-305.

Lai, Z., Vinod, K., Zheng, Z., Fan, B., and Chen, Z. 2008. Roles of Arabidopsis WRKY3 and WRKY4 transcription factors in plant responses to pathogens. BMC Plant Biol. 8: 68. doi:10.1186/1471-2229-8-68.

Lamara, M., Raherison, E., Lenz, P., Beaulieu, J., Bousquet, J., and MacKay, J. 2016. Genetic architecture of wood properties based on association analysis and coexpression networks in white spruce. New Phytol. 210(1): 240-255. doi:10.1111/nph.13762.

Langfelder, P., and Horvath, S. 2008. WGCNA: an R package for weighted correlation network analysis. BMC Bioinformatics 9(1): 559. doi:10.1186/14712105-9-559.

Lawes, M.J., Richards, A., Dathe, J., and Midgley, J.J. 2011. Bark thickness determines fire resistance of selected tree species from fire-prone tropical savanna in north Australia. Plant Ecol. 212(12): 2057-2069. doi:10.1007/s11258-011-9954-7.

León, J., Rojo, E., and Sánchez-Serrano, J.J. 2001. Wound signalling in plants. J. Exp. Bot. 52(354): 1-9. doi:10.1093/jexbot/52.354.1.

Lev-Yadun, S., and Aloni, R. 1992. Experimental induction of dilatation meristems in Melia azederach L. Ann. Bot. 70: 379-386.

Levine, A., Tenhaken, R., Dixon, R., and Lamb, C. 1994. $\mathrm{H}_{2} \mathrm{O}_{2}$ from the oxidative burst orchestrates the plant hypersensitive disease resistance response. Cell 79(4): 583-593. doi:10.1016/0092-8674(94)90544-4. 
Li, L., Lu, S., and Chiang, V. 2006. A genomic and molecular view of wood formation. CRC. Crit. Rev. Plant Sci. 25(3): 215-233.

Li, W.F., Yang, W.H., Zhang, S.G., Han, S.Y., and Qi, L.W. 2017. Transcriptome analysis provides insights into wood formation during larch tree aging. Tree Genet. Genomes 13(1). doi:10.1007/s11295-017-1106-3.

Li, X., Wu, H., Dillon, S., and Southerton, S. 2009. Generation and analysis of expressed sequence tags from six developing xylem libraries in Pinus radiata D. Don. BMC Genomics 10(1): 41. doi:10.1186/1471-2164-10-41.

Li, X., Wu, H.X., and Southerton, S.G. 2010. Seasonal reorganization of the xylem transcriptome at different tree ages reveals novel insights into wood formation in Pinus radiata. New Phytol. 187(3): 764-776. doi:10.1111/j.14698137.2010.03333.x.

Liphschitz, N., Lev-Yadun, S., Rosen, E., and Waisel, Y. 1984. The annual rhythm of activity of the lateral meristems (cambium and phellogen) in Pinus halepensis Mill. and Pinus pinea L. IAWA Bull. 5: 263-274. doi:10.1163/2294193290000944.

Liu, R., Lü, B., Wang, X., Zhang, C., Zhang, S., Qian, J., Chen, L., Shi, H., and Dong, H. 2010. Thirty-seven transcription factor genes differentially respond to a harpin protein and affect resistance to the green peach aphid in Arabidopsis. J. Biosci. 35(3): 435-450. doi:10.1007/s12038-010-0049-8.

Loehle, C. 2000. Strategy space and the disturbance spectrum: A life-history model for tree species coexistence. Am. Nat. 156(1): 14-33. doi:10.1086/303369.

López, R., Brossa, R., Gil, L., and Pita, P. 2015. Stem girdling evidences a trade-off between cambial activity and sprouting and dramatically reduces plant transpiration due to feedback inhibition of photosynthesis and hormone signaling. Front. Plant Sci. 6: 1-13. doi:10.3389/fpls.2015.00285.

López de Heredia, U., López, R., Collada, C., Emerson, B.C., and Gil, L. 2014. 
Chano, $V$-Transcriptomics of the response to wounding

Signatures of volcanism and aridity in the evolution of an insular pine (Pinus canariensis Chr. Sm. Ex DC in Buch). Heredity (Edinb).: 1-10. doi:10.1038/hdy.2014.22.

López de Heredia, U., and Vázquez-Poletti, J.L. 2016. RNA-seq analysis in forest tree species: bioinformatic problems and solutions. Tree Genet. Genomes 12(2): 30. doi:10.1007/s11295-016-0995-x.

Lorenz, W.W., Ayyampalayam, S., Bordeaux, J.M., Howe, G.T., Jermstad, K.D., Neale, D.B., Rogers, D.L., and Dean, J.F.D. 2012. Conifer DBMagic: A database housing multiple de novo transcriptome assemblies for 12 diverse conifer species. Tree Genet. Genomes 8(6): 1477-1485. doi:10.1007/s11295-012-0547-y.

Lowerts, G., Wheeler, E.A., and Kellison, R.C. 1986. Characteristics of woundassociated wood of yellow-poplar (Liriodendron tulipifera L.). Wood Fiber Sci. 18: $537-552$.

Lu, P., Porat, R., Nadeau, J.A., and O’Neill, S.D. 1996. Identification of a meristem L1 layer-specific gene in Arabidopsis that is expressed during embryonic pattern formation and defines a new class of homeobox genes. Plant Cell 8(12): 2155-68. doi:10.1105/tpc.8.12.2155.

Luchi, N., Ma, R., Capretti, P., and Bonello, P. 2005. Systemic induction of traumatic resin ducts and resin flow in Austrian pine by wounding and inoculation with Sphaeropsis sapinea and Diplodia scrobiculata. Planta 221: 75-84. doi:10.1007/s00425-004-1414-3.

de Luis, M., Gričar, J., Cufar, K., Raventós, J., de Luís, M., Gricar, J., Cufar, K., and Raventós, J. 2007. Seasonal dynamics of wood formation in Pinus halepensis from dry and semi-arid ecosystems in Spain. IAWA J. 28(4): 389-404.

Marín-Rodríguez, M.C., Orchard, J., and Seymour, G.B. 2002. Pectate lyases, cell wall degradation and fruit softening. J. Exp. Bot. 53(377): 2115-2119. doi:10.1093/jxb/erf089. 
Martin, D., Tholl, D., Gershenzon, J., and Bohlmann, J. 2002. Methyl jasmonate induces traumatic resin ducts, terpenoid resin biosynthesis, and terpenoid accumulation in developing xylem of Norway spruce stems. Plant Physiol. 129(3): 1003-1018. doi:10.1104/pp.011001.

Martin, J., Solla, A., Woodward, S., and Gil, L. 2005. Fourier transform-infrared spectroscopy as a new method for evaluating host resistance in the Dutch elm disease complex. Tree Physiol. 25: 1331-1338.

Mayer, K., Schoof, H., Haecker, A., Lenhard, M., Jürgens, G., and Laux, T. 1998. Role of WUSCHEL in regulating stem cell fate in the Arabidopsis shoot meristem. Cell 95: 805-815.

Mbéguié-A-Mbéguié, D., Gomez, R.M., and Fils-Lycaon, B. 1997. Sequence of an allergen-, stress-, and pathogenesis-related protein from apricot fruit (Accession No. U93165). Gene expression during fruit ripening. Plant Physiol. 115: 1730.

McConnell, J.R., Emery, J., Eshed, Y., Bao, N., Bowman, J., and Barton, M.K. 2001. Role of PHABULOSA and PHAVOLUTA in determining radial patterning in shoots. Nature 411(6838): 709-13. doi:10.1038/35079635.

Mckay, S.A.B., Hunter, W.L., Godard, K., Wang, S.X., Martin, D.M., Bohlmann, J., and Plant, A.L. 2003. Insect attack and wounding induce traumatic resin duct development and gene expression of (-)-pinene synthase in Sitka spruce. Plant Physiol. 133(9): 368-378. doi:10.1104/pp.103.022723.

McKenney, D.W., Yemshanov, D., Fraleigh, S., Allen, D., and Preto, F. 2011. An economic assessment of the use of short-rotation coppice woody biomass to heat greenhouses in southern Canada. Biomass and Bioenergy 35(1): 374-384. doi:10.1016/j.biombioe.2010.08.055.

Medina, I., Carbonell, J., Pulido, L., Madeira, S.C., Goetz, S., Conesa, A., Tárraga, J., Pascual-Montano, A., Nogales-Cadenas, R., Santoyo, J., García, F., Marbà, M., 
Chano, $V$-Transcriptomics of the response to wounding

Montaner, D., and Dopazo, J. 2010. Babelomics: an integrative platform for the analysis of transcriptomics, proteomics and genomic data with advanced functional profiling. Nucleic Acids Res. 38: W210-3. doi:10.1093/nar/gkq388.

Meier, A.R., Saunders, M.R., and Michler, C.H. 2012. Epicormic buds in trees: A review of bud establishment, development and dormancy release. Tree Physiol. 32(5): 565-584. doi:10.1093/treephys/tps040.

Mellerowicz, E.J., and Sundberg, B. 2008. Wood cell walls: biosynthesis, developmental dynamics and their implications for wood properties. Curr. Opin. Plant Biol. 11(3): 293-300. doi:10.1016/j.pbi.2008.03.003.

Merrill, W., and Shigo, A.L. 1979. An expanded concept of Tree Decay. Phytopathology 69(10): 1158-1160. doi:10.1094/Phyto-69-1158.

Meyer, Y., Siala, W., Bashandy, T., Riondet, C., Vignols, F., and Reichheld, J.P. 2008. Glutaredoxins and thioredoxins in plants. Biochim. Biophys. Acta 1783(4): 589-600. doi:10.1016/j.bbamcr.2007.10.017.

Michaletz, S.T., Johnson, E. a., and Tyree, M.T. 2012. Moving beyond the cambium necrosis hypothesis of post-fire tree mortality: Cavitation and deformation of xylem in forest fires. New Phytol. 194(1): 254-263. doi:10.1111/j.14698137.2011.04021.x.

Mishima, K., Fujiwara, T., Iki, T., Kuroda, K., Yamashita, K., Tamura, M., Fujisawa, Y., and Watanabe, A. 2014. Transcriptome sequencing and profiling of expressed genes in cambial zone and differentiating xylem of Japanese cedar (Cryptomeria japonica). BMC Genomics 15(1): 219. doi:10.1186/1471-2164-15219.

Miwa, H., Kinoshita, A., Fukuda, H., and Sawa, S. 2009. Plant meristems: CLAVATA3/ESR-related signaling in the shoot apical meristem and the root apical meristem. J. Plant Res. 122(1): 31-9. doi:10.1007/s10265-008-0207-3.

Mohan, R., Vijayan, P., and Kolattukudy, P.E. 1993. Developmental and tissue- 
specific expression of a tomato anionic peroxidase (TAP1) gene by a minimal promoter, with wound and pathogen induction by an additional 5'-flanking region. Plant Mol. Biol. 22(3): 475-90.

Mullick, D.B. 1975. A new tissue essential to necrophylactic periderm formation in the bark of four conifers. Can. J. Bot. 53: 2443-2457.

Mutke, S., Gordo, J., Khouja, M.L., and Fady, B. 2013. Low genetic and high environmental diversity at adaptive traits in Pinus pinea from provenance tests in France and Spain. Options Méditerranéennes Série A. Séminaires Méditerranéens 79(105): 72-79.

Nagano, Y., Furuhashi, H., Inaba, T., and Sasaki, Y. 2001. A novel class of plantspecific zinc-dependent DNA-binding protein that binds to A/T-rich DNA sequences. Nucleic Acids Res. 29(20): 4097-105.

Nagy, N.E., Franceschi, V.R., Solheim, H., Krekling, T., and Christiansen, E. 2000. Wound-induced traumatic resin duct development in stems of Norway spruce (Pinaceae): Anatomy and cytochemical traits. Am. J. Bot. 87(3): 302313. doi:10.2307/2656626.

Nakamura, M., Katsumata, H., Abe, M., Yabe, N., Komeda, Y., Yamamoto, K.T., and Takahashi, T. 2006. Characterization of the class IV homeodomain-Leucine Zipper gene family in Arabidopsis. Plant Physiol. 141(4): 1363-1375. doi:10.1104/pp.106.077388.

Nêmec, B. 1962. Botanickà mikrotechnika. House of the Academia of Science of Czechoslovakia, Prague.

Nicolini, E., Chanson, B., and Bonne, F. 2001. Stem growth and epicormic branch formation in understorey beech trees (Fagus sylvatica L.). Ann. Bot. 87(6): 737-750. doi:10.1006/anbo.2001.1398.

Nystedt, B., Street, N.R., Wetterbom, A., Zuccolo, A., Lin, Y.-C., Scofield, D.G., Vezzi, F., Delhomme, N., Giacomello, S., Alexeyenko, A., Vicedomini, R., Sahlin, K., 
Chano, $V$-Transcriptomics of the response to wounding

Sherwood, E., Elfstrand, M., Gramzow, L., Holmberg, K., Hällman, J., Keech, O., Klasson, L., Koriabine, M., Kucukoglu, M., Käller, M., Luthman, J., Lysholm, F., Niittylä, T., Olson, A., Rilakovic, N., Ritland, C., Rosselló, J. a, Sena, J., Svensson, T., Talavera-López, C., Theißen, G., Tuominen, H., Vanneste, K., Wu, Z.-Q., Zhang, B., Zerbe, P., Arvestad, L., Bhalerao, R., Bohlmann, J., Bousquet, J., Garcia Gil, R., Hvidsten, T.R., de Jong, P., MacKay, J., Morgante, M., Ritland, K., Sundberg, B., Thompson, S.L., Van de Peer, Y., Andersson, B., Nilsson, O., Ingvarsson, P.K., Lundeberg, J., and Jansson, S. 2013. The Norway spruce genome sequence and conifer genome evolution. Nature 497(7451): 579-84. doi:10.1038/nature12211.

O’Donnell, P.J., Calvert, C., Atzorn, R., Wasternack, C., Leyser, H.M.O., and Bowles, D.J. 1996. Ethylene as a signal mediating the wound response of tomato plants. Science. 274(5294): 1914-1917. doi:10.1126/science.274.5294.1914.

Ohl, S., Hedrick, S. a, Chory, J., and Lamb, C.J. 1990. Functional properties of a phenylalanine ammonia-lyase promoter from Arabidopsis. Plant Cell 2(9): 837-848. doi:10.1105/tpc.2.9.837.

Omidbakhshfard, M.A., Proost, S., Fujikura, U., and Mueller-Roeber, B. 2015. Growth-Regulating Factors (GRFs): A small transcription factor family with important functions in plant biology. Mol. Plant 8(7): 998-1010. doi:10.1016/j.molp.2015.01.013.

Ong, S.S., and Wickneswari, R. 2012. Characterization of microRNAs expressed during secondary wall biosynthesis in Acacia mangium. PLoS One 7(11): 1-13. doi:10.1371/journal.pone.0049662.

Oven, P., Schmitt, U., and Stobbe, H. 2000. Wundreaktionen im Splintholz der gemeinen Kiefer (Pinus sylvestris L.). In Jahrbuch der Baumpflege. Edited by D. Dujesiefken and P. Kockerbeck. Thalacker Medien, Braunschweig. pp. 208211.

Oven, P., and Torelli, N. 1994. Wound response of the bark in healthy and declining 
silver firs (Abies alba). IAWA J. 15: 407-415.

Oven, P., and Torelli, N. 1999. Response of the cambial zone in conifers to wounding. Phyton (B. Aires). 39: 133-137.

Pajoro, A., Madrigal, P., Muiño, J.M., Matus, J.T., Jin, J., Mecchia, M. a, Debernardi, J.M., Palatnik, J.F., Balazadeh, S., Arif, M., O Maoiléidigh, D.S., Wellmer, F., Krajewski, P., Riechmann, J.-L., Angenent, G.C., and Kaufmann, K. 2014. Dynamics of chromatin accessibility and gene regulation by MADS-domain transcription factors in flower development. Genome Biol. 15(3): R41. doi:10.1186/gb-2014-15-3-r41.

Palovaara, J., Hallberg, H., Stasolla, C., and Hakman, I. 2010. Comparative expression pattern analysis of WUSCHEL-related homeobox 2 (WOX2) and WOX8/9 in developing seeds and somatic embryos of the gymnosperm Picea abies. New Phytol. 188(1): 122-135. doi:10.1111/j.1469-8137.2010.03336.x.

Pang, Y., Zhang, J., Cao, J., Yin, S.Y., He, X.Q., and Cui, K.M. 2008. Phloem transdifferentiation from immature xylem cells during bark regeneration after girdling in Eucommia ulmoides Oliv. J. Exp. Bot. 59(6): 1341-1351. doi:10.1093/jxb/ern041.

Parchman, T.L., Geist, K.S., Grahnen, J. a, Benkman, C.W., and Buerkle, C.A. 2010. Transcriptome sequencing in an ecologically important tree species: assembly, annotation, and marker discovery. BMC Genomics 11: 180. doi:10.1186/1471-2164-11-180.

Park, B.H., Karpinets, T. V., Syed, M.H., Leuze, M.R., and Uberbacher, E.C. 2010a. CAZymes Analysis Toolkit: Web service for searching and analyzing carbohydrate-active enzymes in a newly sequenced organism using CAZy database. Glycobiology 20: 1574-1584. doi:10.1093/glycob/cwq106.

Park, M.R., Yun, K.Y., Mohanty, B., Herath, V., Xu, F., Wijaya, E., Bajic, V.B., Yun, S.J., and de Los Reyes, B.G. 2010b. Supra-optimal expression of the cold-regulated 
Chano, $V$-Transcriptomics of the response to wounding

OsMYB4 transcription factor in transgenic rice changes the complexity of transcriptional network with major effects on stress tolerance and panicle development. Plant, Cell Environ. 33(12): 2209-2230. doi:10.1111/j.13653040.2010.02221.x.

Passardi, F., Cosio, C., Penel, C., and Dunand, C. 2005. Peroxidases have more functions than a Swiss army knife. Plant Cell Rep. 24(5): 255-265. doi:10.1007/s00299-005-0972-6.

Paul, M.V., Iyer, S., Amerhauser, C., Lehmann, M., van Dongen, J.T., and Geigenberger, P. 2016. Oxygen sensing via the ethylene response transcription factor RAP2.12 affects plant metabolism and performance under both normoxia and hypoxia. Plant Physiol. 172(1): 141-153. doi:10.1104/pp.16.00460.

Pausas, J.G. 2004. Changes in fire and climate in the eastern Iberian Peninsula (Mediterranean Basin). Clim. Change 63(3): 337-350. doi:10.1023/B:CLIM.0000018508.94901.9c.

Pausas, J.G., Bradstock, R.A., Keith, D.A., Keeley, J.E., Hoffman, W., Kenny, B., Lloret, F., and Trabaud, L. 2004. Plant functional traits in relation to fire in crownfire ecosystems. Ecology 85(4): 1085-1100. doi:10.1890/02-4094.

Pausas, J.G., and Keeley, J.E. 2014. Evolutionary ecology of resprouting and seeding in fire-prone ecosystems. New Phytol. 204(1): 55-65. doi:10.1111/nph.12921.

Paux, E., Tamasloukht, M.B., Ladouce, N., Sivadon, P., and Grima-Pettenati, J. 2004. Identification of genes preferentially expressed during wood formation in Eucalyptus. Plant Mol. Biol. 55(2): 263-280. doi:10.1007/s11103-004-0621-4.

Pena-Cortés, H., Albrecht, T., Prat, S., Weiler, E.W., and Willmitzer, L. 1993. Aspirin prevents wound-induced gene expression in tomato leaves by blocking jasmonic acid biosynthesis. Planta 191(1): 123-128. doi:10.1007/BF00240903.

Peraza, C. 1967. Estudio de las principales maderas de Canarias. In Instituto 
Forestal de Investigaciones y Experiencias.

Perdiguero, P., Barbero, M.D.C., Cervera, M.T., Collada, C., and Soto, A. 2013. Molecular response to water stress in two contrasting Mediterranean pines (Pinus pinaster and Pinus pinea). Plant Physiol. Biochem. 67: 199-208. Elsevier Masson SAS. doi:10.1016/j.plaphy.2013.03.008.

Peters, W. 1974. Tylosis formation in Pinus tracheids. Bot. Gazzete J. 135(2): 126131.

Pfaffl, M.W. 2001. A new mathematical model for relative quantification in realtime RT-PCR. Nucleic Acids Res. 29(9): e45. doi:10.1093/nar/29.9.e45.

Pinosio, S., González-Martínez, S.C., Bagnoli, F., Cattonaro, F., Grivet, D., Marroni, F., Lorenzo, Z., Pausas, J.G., Verdú, M., and Vendramin, G.G. 2014. First insights into the transcriptome and development of new genomic tools of a widespread circum-Mediterranean tree species, Pinus halepensis Mill. Mol. Ecol. Resour. 14: 846-856. doi:10.1111/1755-0998.12232.

Piñol, J., Terradas, J., and Lloret, F. 1998. Climate warming, wildfire hazard, and wildfire occurrence in coastal eastern Spain. Clim. Change 38(3): 345-357. doi:10.1023/A:1005316632105.

Ponce de León, I., and Montesano, M. 2017. Adaptation mechanisms in the evolution of moss defenses to microbes. Front. Plant Sci. 8: 336. doi:10.3389/fpls.2017.00366.

Porth, I., Hamberger, B., White, R., and Ritland, K. 2011. Defense mechanisms against herbivory in Picea: sequence evolution and expression regulation of gene family members in the phenylpropanoid pathway. BMC Genomics 12(1): 608. doi:10.1186/1471-2164-12-608.

Prasad, K., and Dhonukshe, P. 2013. Polar auxin transport: cell polarity to patterning. In Polar Auxin Transport. Edited by R. Chen and F. Baluska. Springer, Heidelberg. pp. 25-44. 
Chano, $V$-Transcriptomics of the response to wounding

Prigge, M.J., Otsuga, D., Alonso, J.M., Ecker, J.R., Drews, G.N., and Clark, S.E. 2005. Class III homeodomain-leucine zipper gene family members have overlapping, antagonistic, and distinct roles in Arabidopsis development. Plant Cell 17(1): 61-76. doi:10.1105/tpc.104.026161.

Le Provost, G., Paiva, J., Pot, D., Brach, J., and Plomion, C. 2003. Seasonal variation in transcript accumulation in wood-forming tissues of maritime pine (Pinus pinaster Ait.) with emphasis on a cell wall glycine-rich protein. Planta 217(5): 820-830. doi:10.1007/s00425-003-1051-2.

R Core Team. 2013. R: A Language and Environment for Statistical Computing. R Foundation for Statistical Computing, Vienna, Austria. Available from http://www.r-project.org/.

Raherison, E.S.M., Giguère, I., Caron, S., Lamara, M., and Mackay, J.J. 2015. Modular organization of the white spruce (Picea glauca) transcriptome reveals functional organization and evolutionary signatures. New Phytol. 207(1): 172-187. doi:10.1111/nph.13343.

Ralph, S.G., Hudgins, J.W., Jancsik, S., Franceschi, V.R., and Bohlmann, J. 2007. Aminocyclopropane carboxylic acid synthase is a regulated step in ethylenedependent induced conifer defense. Full-length cDNA cloning of a multigene family, differential expression, and cellular and subcellular localization in spruce and Douglas fir. Plant Physiol. 143: 410-424.

Ralph, S.G., Yueh, H., Friedmann, M., Aeschliman, D., Zeznik, J. a., Nelson, C.C., Butterfield, Y.S.N., Kirkpatrick, R., Liu, J., Jones, S.J.M., Marra, M. a., Douglas, C.J., Ritland, K., and Bohlmann, J. 2006. Conifer defence against insects: microarray gene expression profiling of Sitka spruce (Picea sitchensis) induced by mechanical wounding or feeding by spruce budworms (Choristoneura occidentalis) or white pine weevils (Pissodes strobi). Plant, Cell Environ. 29(8): 1545-1570. doi:10.1111/j.1365-3040.2006.01532.x.

Ribone, P.A., Capella, M., and Chan, R.L. 2015. Functional characterization of the 
Homeodomain Leucine Zipper I transcription factor AtHB13 reveals a crucial role in Arabidopsis development. J. Exp. Bot. 66(19): 5929-5943. doi:10.1093/jxb/erv302.

Riggelman, R., Fristensky, B., and Hadwiger, L. 1985. The disease resistance response in pea is associated with increased levels of specific mRNAs. Plant Mol. Biol. 4: 81-86.

Rittinger, P., Biggs, A., and Peirson, D. 1987. Histochemistry of lignin and suberin deposition in boundary layers formed after wounding in various plant species and organs. Can. J. Bot. 65: 1886-1892.

Ro, D.-K., Arimura, G.-I., Lau, S.Y.W., Piers, E., and Bohlmann, J. 2005. Loblolly pine abietadienol/abietadienal oxidase PtAO (CYP720B1) is a multifunctional, multisubstrate cytochrome P450 monooxygenase. Proc. Natl. Acad. Sci. U. S. A. 102(22): 8060-8065. doi:10.1073/pnas.0500825102.

Rodríguez-García, A., López, R., Martín, J.A., Pinillos, F., and Gil, L. 2014. Resin yield in Pinus pinaster is related to tree dendrometry, stand density and tappinginduced systemic changes in xylem anatomy. For. Ecol. Manage. 313: 47-54. doi:10.1016/j.foreco.2013.10.038.

Rodríguez Martín, J.A., Nanos, N., Miranda, J.C., Carbonell, G., and Gil, L. 2013. Volcanic mercury in Pinus canariensis. Naturwissenschaften 100(8): 739-747. doi:10.1007/s00114-013-1070-1.

Rojo, E., León, J., and Sánchez-Serrano, J.J. 1999. Cross-talk between wound signalling pathways determines local versus systemic gene expression in Arabidopsis thaliana. Plant J. 20(2): 135-142. doi:10.1046/j.1365313x.1999.00570.x.

Romero, C., and Bolker, B.M. 2008. Effects of stem anatomical and structural traits on responses to stem damage: an experimental study in the Bolivian Amazon. Can. J. For. Res. 38(3): 611-618. doi:10.1139/X07-205. 
Chano, $V$-Transcriptomics of the response to wounding

Sachs, T., and Cohen, D. 1982. Circular vessels and the control of vascular differentiation in plants. Differentiation 21(1-3): 22-26. doi:10.1111/j.14320436.1982.tb01189.x.

Sánchez Alvarado, A., and Yamanaka, S. 2014. Rethinking differentiation: Stem cells, regeneration, and plasticity. Cell 157(1): 110-119. doi:10.1016/j.cell.2014.02.041.

Sandak, J., Sandak, A., Cantini, C., and Autino, A. 2015. Differences in wood properties of Picea abies L. Karst. in relation to site of provenance and population genetics. Holzforschung 69(4): 385-397. doi:10.1515/hf-2014-0061.

Sarojam, R., Sappl, P.G., Goldshmidt, A., Efroni, I., Floyd, S.K., Eshed, Y., and Bowman, J.L. 2010. Differentiating Arabidopsis shoots from leaves by combined YABBY activities. Plant Cell 22(7): 2113-2130. doi:10.1105/tpc.110.075853.

Savidge, R. 2001. Intrinsic regulation of cambial growth. J. Plant Growth Regul. 20(1): 52-77. doi:10.1007/s003440010002.

De Schepper, V., Steppe, K., Van Labeke, M.C., and Lemeur, R. 2010. Detailed analysis of double girdling effects on stem diameter variations and sap flow in young oak trees. Environ. Exp. Bot. 68(2): 149-156. doi:10.1016/j.envexpbot.2009.11.012.

Schmieder, R., and Edwards, R. 2011. Quality control and preprocessing of metagenomic datasets. Bioinformatics 27: 863-864. doi:10.1093/bioinformatics/btr026.

Schmitt, U., and Liese, W. 1993. Response of xylem parenchyma by suberization in some hardwoods after mechanical injury. Trees 8(1): 23-30. doi:10.1007/BF00240978.

Schmitt, U., and Liese, W. 1994. Wound tyloses in Robinia pseudoacacia L. IAWA J. 15(2): 157-160. doi:10.1163/22941932-90001357. 
Schneuwly, D.M., Stoffel, M., and Bollschweiler, M. 2009a. Formation and spread of callus tissue and tangential rows of resin ducts in Larix decidua and Picea abies following rockfall impacts. Tree Physiol. 29(2): 281-9. doi:10.1093/treephys/tpn026.

Schneuwly, D.M., Stoffel, M., Dorren, L.K.A., and Berger, F. 2009b. Threedimensional analysis of the anatomical growth response of European conifers to mechanical disturbance. Tree Physiol. 29(10): 1247-1257. doi:10.1093/treephys/tpp056.

Schröder, F., Lisso, J., Lange, P., and Müssig, C. 2009. The extracellular EXO protein mediates cell expansion in Arabidopsis leaves. BMC Plant Biol. 9: 20. doi:10.1186/1471-2229-9-20.

Schuetz, M., Smith, R., and Ellis, B. 2013. Xylem tissue specification, patterning, and differentiation mechanisms. J. Exp. Bot. 64: 11-31. doi:doi: 10.1093/jxb/ers287.

Schultz, E., and Haughn, G. 1991. LEAFY, a homeotic gene that regulates inflorescence development in Arabidopsis. Plant Cell 3(8): 771-781. doi:10.1105/tpc.3.8.771.

Schweingruber, F. 2007. Wood structure and environment. Edited byT.E. Timell and R. Wimmer. Springer Series in Wood Science, Heidelberg.

Schweingruber, F., Börner, A., and Schulze, D. 2006. Atlas of woody plants stems. Evolution, structure, and environmental modifications. In First. Edited byD. Czeschlik,. Springer, Heidelberg.

Seki, M., Narusaka, M., Abe, H., Kasuga, M., Yamaguchi-Shinozaki, K., Carninci, P., Hayashizaki, Y., and Shinozaki, K. 2001. Monitoring the expression pattern of 1300 Arabidopsis genes under drought and cold stresses by using a full-length cDNA microarray. Plant Cell 13(1): 61-72. doi:10.1105/tpc.13.1.61.

Sena, G., and Birnbaum, K.D. 2010. Built to rebuild: In search of organizing principles in plant regeneration. Curr. Opin. Genet. Dev. 20(4): 460-465. 
Chano, $V$-Transcriptomics of the response to wounding

doi:10.1016/j.gde.2010.04.011.

Sena, G., Wang, X., Liu, H.-Y., Hofhuis, H., and Birnbaum, K.D. 2009. Organ regeneration does not require a functional stem cell niche in plants. Nature 457(7233): 1150-3. doi:10.1038/nature07597.

Seo, P.J., Lee, A.K., Xiang, F., and Park, C.M. 2008. Molecular and functional profiling of Arabidopsis pathogenesis-related genes: Insights into their roles in salt response of seed germination. Plant Cell Physiol. 49(3): 334-344. doi:10.1093/pcp/pcn011.

Shannon, P., Markiel, A., Ozier, O., Baliga, N.S., Wang, J.T., Ramage, D., Amin, N., Schwikowski, B., and Ideker, T. 2003. Cytoscape: A software Environment for integrated models of biomolecular interaction networks. Genome Res. 13(11): 2498-2504. doi:10.1101/gr.1239303.

Shigo, A.L. 1984. Compartmentalization: A conceptual framework for understanding how trees grow and defend themselves. Annu. Rev. Phytopathol. 22: 189-214. doi:10.1146/annurev.py.22.090184.001201.

Shigo, A.L. 1989. A new tree biology: facts, photos, and philosophies on trees and their problems and proper care. In 2nd editio. Shigo \& Trees, Associates, Durham, New Hampshire.

Shigo, A.L., and Marx, H.G. 1977. Compartmentalization of Decay in Trees. Sci. Am. 252(4): 96-103. doi:10.1038/scientificamerican0485-96.

Shortle, W. 1979. Compartmentalization of Decay in red maple and hybrid poplar trees. Phytopathology 69: 410-413. doi:10.1094/Phyto-69-410.

Sieber, P., Gheyselinck, J., Gross-Hardt, R., Laux, T., Grossniklaus, U., and Schneitz, K. 2004. Pattern formation during early ovule development in Arabidopsis thaliana. Dev. Biol. 273(2): 321-334. doi:10.1016/j.ydbio.2004.05.037.

Singh, B., Nordgren, A., Lofvenius, M., Hogberg, M., Mellander, P., and Hogberg, P. 
2003. Tree root and soil heterotrophic respiration as revealed by girdling of boreal Scots pine forest: extending observations beyond the first year. Plant Cell Environ. 26: 1287-96. doi:doi: 10.1046/j.1365-3040.2003.01053.x.

Skoog, F., and Miller, C. 1957. Chemical regulation of growth and organ formation in plant tissues cultured in vitro. Symp Soc Exp Biol 54: 118-30.

Smith, D.E. 1980. Abnormal wood formation following fall and spring injuries in black walnut. Wood Sci. 12(4): 243-251.

Smyth, G.K. 2004. Linear models and empirical bayes methods for assessing differential expression in microarray experiments. Stat. Appl. Genet. Mol. Biol. 3(1): 1-25. doi:10.2202/1544-6115.1027.

Smyth, G.K., and Speed, T. 2003. Normalization of cDNA microarray data. Methods 31(4): 265-273. doi:S1046202303001555 [pii].

So, H.A., Choi, S.J., Chung, E., and Lee, J.H. 2015. Molecular characterization of stress-inducible PLATZ gene from soybean (Glycine max L.). Plant Omics 8(6): 479-484.

Spicer, R., and Holbrook, N.M. 2007. Parenchyma cell respiration and survival in secondary xylem: Does metabolic activity decline with cell age? Plant, Cell Environ. 30(8): 934-943. doi:10.1111/j.1365-3040.2007.01677.x.

Spoel, S.H., Koornneef, A., Claessens, S.M.C., Korzelius, J.P., Van Pelt, J.A., Mueller, M.J., Buchala, A.J., Métraux, J.-P., Brown, R., Kazan, K., Van Loon, L.C., Dong, X., and Pieterse, C.M.J. 2003. NPR1 modulates cross-talk between salicylateand jasmonate-dependent defense pathways through a novel function in the cytosol. Plant Cell 15(3): 760-70. doi:10.1105/tpc.009159.

Sprugel, D.G. 2002. When branch autonomy fails: Milton's Law of resource availability and allocation. Tree Physiol. 22(15-16): 1119-1124. doi:10.1093/treephys/22.15-16.1119. 
Chano, $V$-Transcriptomics of the response to wounding

Stanford, A., Bevan, M., and Northcote, D. 1989. Differential expression within a family of novel wound-induced genes in potato. Mol. Gen. Genet. 215(2): 200208. doi:10.1007/BF00339718.

Sterky, F., Regan, S., Karlsson, J., Hertzberg, M., Rohde, A., Holmberg, A., Amini, B., Bhalerao, R., Larsson, M., Villarroel, R., Van Montagu, M., Sandberg, G., Olsson, O., Teeri, T.T., Boerjan, W., Gustafsson, P., Uhlén, M., Sundberg, B., and Lundeberg, J. 1998. Gene discovery in the wood-forming tissues of poplar: analysis of 5,692 expressed sequence tags. Proc. Natl. Acad. Sci. U. S. A. 95(22): 13330-13335.

Stobbe, H. 2002. Developmental stages and fine structure of surface callus formed after debarking of living lime trees (Tilia sp.). Ann. Bot. 89(6): 773-782. doi:10.1093/aob/mcf137.

Stoffel, M. 2008. Dating past geomorphic processes with tangential rows of traumatic resin ducts. Dendrochronologia 26(1): 53-60. doi:doi: 10.1016/j.dendro.2007.06.002.

Stoffel, M., and Klinkmüller, M. 2013. 3D analysis of anatomical reactions in conifers after mechanical wounding: first qualitative insights from X-ray computed tomography. Trees 27(6): 1805-1811. doi:10.1007/s00468-013-09002.

Su, Z., Ma, X., Guo, H., Sukiran, N.L., Guo, B., Assmann, S.M., and Ma, H. 2013. Flower development under drought stress: Morphological and transcriptomic analyses reveal acute responses and long-term acclimation in $<$ I $>$ Arabidopsis</i > . Plant Cell 25(10): 3785-3807. doi:10.1105/tpc.113.115428.

Sugimoto, K., Gordon, S.P., and Meyerowitz, E.M. 2011. Regeneration in plants and animals: Dedifferentiation, transdifferentiation, or just differentiation? Trends Cell Biol. 21(4): 212-218. doi:10.1016/j.tcb.2010.12.004.

Sugimoto, K., Jiao, Y., and Meyerowitz, E.M. 2010. Arabidopsis regeneration from 
multiple tissues occurs via a root development pathway. Dev. Cell 18(3): 46371. Elsevier Ltd. doi:10.1016/j.devcel.2010.02.004.

Szemenyei, H., Hannon, M., and Long, J.A. 2008. TOPLESS mediates auxindependent transcriptional repression during Arabidopsis embryogenesis. Science. 319(5868): 1384-6. doi:10.1126/science.1151461.

Tam, J.P., Wang, S., Wong, K.H., and Tan, W.L. 2015. Antimicrobial peptides from plants. Pharmaceuticals 8(4): 711-757. doi:10.3390/ph8040711.

Tamagnone, L., Merida, A., Parr, A., Mackay, S., Culianez-Macia, F., Roberts, K., and Martin, C. 1998. The AmMYB308 and AmMYB330 transcription factors from antirrhinum regulate phenylpropanoid and lignin biosynthesis in transgenic tobacco. Plant Cell 10(2): 135-54. doi:10.1105/tpc.10.2.135.

Tanaka, W., Toriba, T., Ohmori, Y., Yoshida, A., Kawai, A., Mayama-Tsuchida, T., Ichikawa, H., Mitsuda, N., Ohme-Takagi, M., and Hirano, H.-Y. 2012. The YABBY gene TONGARI-BOUSHI1 is involved in lateral organ development and maintenance of meristem organization in the rice spikelet. Plant Cell 24(1): 80-95. doi:10.1105/tpc.111.094797.

Taylor, A., Gartner, B., and Morrell, J. 2002. Heartwood formation and natural durability: A review. Wood Fiber Sci. 34(4): 587-611.

Telewski, F. 2006. A unified hypothesis of mechanoperception in plants. Am. J. Bot. 93: 1466-76. doi:doi: 10.3732/ajb.93.10.1466.

Telewski, F., and Jaffe, M. 1986. Thigmomorphogenesis: the role of ethylene in the response of Pinus taeda and Abies fraseri to mechanical perturbation. Physiol. Plant. 66: 227-33. doi:doi: 10.1111/j.1399-3054.1986.tb02413.x.

Thornalley, P.J. 1998. Glutathione-dependent detoxification of a-oxoaldehydes by the glyoxalase system: involvement in disease mechanisms and antiproliferative activity of glyoxalase I inhibitors. Chem. Biol. Interact. 111112: 137-151. doi:10.1016/S0009-2797(97)00157-9. 
Chano, $V$-Transcriptomics of the response to wounding

Torelli, N., Krizaj, B., and Oven, P. 1994. Barrier zone (CODIT) and woundassociated wood in beech (Fagus sylvatica L.). Holzforschung 46(3): 49-51.

Traas, J., and Vernoux, T. 2002. The shoot apical meristem: the dynamics of a stable structure. Philos. Trans. R. Soc. London 357(1422): 737-47. doi:10.1098/rstb.2002.1091.

Trapp, S.C., and Croteau, R.B. 2001. Genomic organization of plant terpene synthases and molecular evolutionary implications. Genetics 158(2): 811-832.

Tredici, P. 2001. Sprouting in temperate trees: A morphological and ecological review. Bot. Rev. 67(2): 121-140. doi:10.1007/BF02858075.

Tzin, V., Hojo, Y., Strickler, S.R., Bartsch, L.J., Archer, C.M., Ahern, K.R., Zhou, S., Christensen, S.A., Galis, I., Mueller, L.A., and Jander, G. 2017. Rapid defense responses in maize leaves induced by Spodoptera exigua caterpillar feeding. J. Exp. Bot. 68(16): 4709-23. doi:10.1093/jxb/erx274.

Untergasser, A., Cutcutache, I., Koressaar, T., Ye, J., Faircloth, B.C., Remm, M., and Rozen, S.G. 2012. Primer3-new capabilities and interfaces. Nucleic Acids Res. 40(15): e115. doi:10.1093/nar/gks596.

Vale, R.D. 2000. AAA proteins: Lords of the ring. J. Cell Biol. 150(1): 13-19. doi:10.1083/jcb.150.1.F13.

Valério, L., De Meyer, M., Penel, C., and Dunand, C. 2004. Expression analysis of the Arabidopsis peroxidase multigenic family. Phytochemistry 65(10): 133142. doi:10.1016/j.phytochem.2004.04.017.

Vanholme, B., Grunewald, W., Bateman, A., Kohchi, T., and Gheysen, G. 2007. The tify family previously known as ZIM. Trends Plant Sci. 12(6): 239-244. doi:10.1016/j.tplants.2007.04.004.

Vanholme, R., Demedts, B., Morreel, K., Ralph, J., and Boerjan, W. 2010. Lignin Biosynthesis and Structure. Plant Physiol. 153(July): 895-905. 
doi:10.1104/pp.110.155119.

Varshney, R.K., Song, C., Saxena, R.K., Azam, S., Yu, S., Sharpe, A.G., Cannon, S., Baek, J., Rosen, B.D., Tar’an, B., Millan, T., Zhang, X., Ramsay, L.D., Iwata, A., Wang, Y., Nelson, W., Farmer, A.D., Gaur, P.M., Soderlund, C., Penmetsa, R. V, Xu, C., Bharti, A.K., He, W., Winter, P., Zhao, S., Hane, J.K., Carrasquilla-Garcia, N., Condie, J.A., Upadhyaya, H.D., Luo, M.C., Thudi, M., Gowda, C.L., Singh, N.P., Lichtenzveig, J., Gali, K.K., Rubio, J., Nadarajan, N., Dolezel, J., Bansal, K.C., Xu, X., Edwards, D., Zhang, G., Kahl, G., Gil, J., Singh, K.B., Datta, S.K., Jackson, S.A., Wang, J., and Cook, D.R. 2013. Draft genome sequence of chickpea (Cicer arietinum) provides a resource for trait improvement. Nat Biotechnol 31(3): 240-246. doi:10.1038/nbt.2491.

Verdú, M., and Climent, J. 2007. Evolutionary correlations of polycyclic shoot growth in Acer (Sapindaceae). Am. J. Bot. 94(8): 1316-1320. doi:10.3732/ajb.94.8.1316.

Verslues, P.E., and Juenger, T.E. 2011. Drought, metabolites, and Arabidopsis natural variation: A promising combination for understanding adaptation to water-limited environments. Curr. Opin. Plant Biol. 14(3): 240-245. doi:10.1016/j.pbi.2011.04.006.

Vesk, P.A., and Westoby, M. 2004. Sprouting ability across diverse disturbances and vegetation types worldwide. J. Ecol. 92(2): 310-320. doi:10.1111/j.00220477.2004.00871.x.

Vidhyasekaran, P. 2015. Salicylic acid signaling in plant innate immunity. In Plant Hormone Signaling Systems in Plant Innate Immunity. Springer, Dordrecht. pp. 27-122. doi:10.1007/978-94-017-9285-1_2.

Vieira, J. 2013. Cambial activity and wood formation of Maritime pine in a drought-prone environment: the effect of growth rate, size and climate. Universidade de Coimbra. Available from http://hdl.handle.net/10316/44374. 
Chano, $V$-Transcriptomics of the response to wounding

Wahlstrom, K.T., and Johansson, M. 1992. Structural responses in bark to mechanical wounding and armillaria-ostoyae infection in seedlings of Pinus sylvestris. Eur. J. For. Pathol. 22(2): 65-76. doi:10.1111/j.14390329.1992.tb01434.x.

Wan, X., Landhäusser, S.M., Lieffers, V.J., and Zwiazek, J.J. 2006. Signals controlling root suckering and adventitious shoot formation in aspen (Populus tremuloides). Tree Physiol. 26(5): 681-687.

Wang, J.E., Liu, K.K., Li, D.W., Zhang, Y.L., Zhao, Q., He, Y.M., and Gong, Z.H. 2013. A novel peroxidase CanPOD gene of pepper is involved in defense responses to Phytophtora capsici infection as well as abiotic stress tolerance. Int. J. Mol. Sci. 14(2): 3158-3177. doi:10.3390/ijms14023158.

Wang, Q., Ci, D., Li, T., Li, P., Song, Y., Chen, J., Quan, M., Zhou, D., and Zhang, D. 2016. The role of DNA methylation in xylogenesis in different tissues of Poplar. Front. Plant Sci. 7(1003): 1-12. doi:10.3389/fpls.2016.01003.

Ward, E., Uknes, S., Williams, S., Dincher, S., Wiederhold, D., Alexander, D., AhlGoy, P., Metraux, J., and Ryals, J. 1991. Coordinate gene activity in response to agents that induce systemic acquired resistance. Plant Cell 3(10): 1085-1094. doi:10.1105/tpc.3.10.1085.

Warnes, G.R., Bolker, B., Bonebakker, L., Gentleman, R., Liaw, W.H.A., Lumley, T., Maechler, M., Magnusson, A., Moeller, S., Schwartz, M., and Venables, B. 2015. gplots: Various R programming tools for plotting data. doi:10.1111/j.00223646.1997.00569.x.

Wegrzyn, J.L., Lee, J.M., Tearse, B.R., and Neale, D.B. 2008. TreeGenes: A forest tree genome database. Int. J. Plant Genomics 2008(412875): 1-7. doi:10.1155/2008/412875.

Weigel, D., Alvarez, J., Smyth, D.R., Yanofsky, M.F., and Meyerowitz, E.M. 1992. LEAFY controls floral meristem identity in Arabidopsis. Cell 69(5): 843-859. 
doi:10.1016/0092-8674(92)90295-N.

Wiedenhoeft, A.C., and Miller, R.B. 2002. Brief comments on the nomenclature of softwood axial resin canals and their associated cells. IAWA J. 23: 299-303.

Xu, J., Hofhuis, H., Heidstra, R., Sauer, M., Friml, J., and Scheres, B. 2006. A molecular framework for plant regeneration. Science. 311(5759): 385-388. doi:10.1126/science.1121790.

Xu, Z., Gongbuzhaxi, Wang, C., Xue, F., Zhang, H., and Ji, W. 2015. Wheat NAC transcription factor TaNAC29 is involved in response to salt stress. Plant Physiol. Biochem. 96: 356-363. doi:10.1016/j.plaphy.2015.08.013.

Yamada, T., Yokota, S., Hirayama, Y., Imaichi, R., Kato, M., and Gasser, C.S. 2011. Ancestral expression patterns and evolutionary diversification of YABBY genes in angiosperms. Plant J. 67(1): 26-36. doi:10.1111/j.1365313X.2011.04570.x.

Yamashita, S., Yoshida, M., Yamamoto, H., and Okuyama, T. 2008. Screening genes that change expression during compression wood formation in Chamaecyparis obtusa. Tree Physiol. 28(9): 1331-40.

Yang, T., Du, M., Guo, Y., and Liu, X. 2017. Two LEAFY homologs ILFY1 and ILFY2 control reproductive and vegetative developments in Isoetes L. Sci. Rep. 7(1): 225-235. doi:10.1038/s41598-017-00297-3.

Yuan, S., Wang, Y., and Dean, J.F.D. 2010. ACC oxidase genes expressed in the woodforming tissues of loblolly pine (Pinus taeda L.) include a pair of nearly identical paralogs (NIPs). Gene 453(1-2): 24-36. doi:10.1016/j.gene.2009.12.008.

Zajaczkowska, U. 2014a. Regeneration of Scots pine stem after wounding. IAWA J. 35: 270-80. doi:doi: 10.1163/22941932-00000065.

Zajaczkowska, U. 2014b. Overgrowth of Doublas fir (Pseudotsuga menziensii 
Chano, $V$-Transcriptomics of the response to wounding

Franco) stumps with regenerative tissue as an example of cell ordering and tissue reorganization. Planta 240: 1203-11. doi:doi: 10.1007/s00425-014-2142y.

Zedler, P.H., Gautier, C.R., and McMaster, G.S. 1983. Vegetation change in response to extreme events: the effect of a short interval between fires in California chaparral and coastal scrub. Ecology 64(4): 809-818. doi:10.2307/1937204.

Zhang, J., Elo, A., and Helariutta, Y. 2011a. Arabidopsis as a model for wood formation. Curr. Opin. Biotechnol. 22(2): 293-299. doi:10.1016/j.copbio.2010.11.008.

Zhang, J., Gao, G., Chen, J.J., Taylor, G., Cui, K.M., and He, X.Q. 2011b. Molecular features of secondary vascular tissue regeneration after bark girdling in Populus. New Phytol. 192(4): 869-884. doi:10.1111/j.1469-8137.2011.03855.x.

Zhang, Y., and Wang, L. 2005. The WRKY transcription factor superfamily: its origin in eukaryotes and expansion in plants. BMC Evol. Biol. 5: 1. doi:10.1186/1471-2148-5-1.

Zhong, R., Richardson, E.A., and Ye, Z.H. 2007. The MYB46 transcription factor is a direct target of SND1 and regulates secondary wall biosynthesis in Arabidopsis. Plant Cell 19(9): 2776-2792. doi:10.1105/tpc.107.053678.

Zhong, R., and Ye, Z.-H. 2007. Regulation of cell wall biosynthesis. Curr Opin Plant Biol 10(6): 564-572. doi:10.1016/j.pbi.2007.09.001.

Zhu, Y.Y., Machleder, E.M.E., Chenchik, A., Li, R., and Siebert, P.D. 2001. Reverse transcriptase template switching: A SMART approach for full-length cDNA library construction. Biotechniques 30(4): 892-897.

Zhulidov, P.A., Bogdanova, E.A., Shcheglov, A.S., Vagner, L.L., Khaspekov, G.L., Kozhemyako, V.B., Matz, M. V, Meleshkevitch, E., Moroz, L.L., Lukyanov, S.A., and Shagin, D.A. 2004. Simple cDNA normalization using kamchatka crab duplex-specific nuclease. Nucleic Acids Res. 32: e37. doi:10.1093/nar/gnh031. 
Zulak, K.G., and Bohlmann, J. 2010. Terpenoid biosynthesis and specialized vascular cells of conifer defense. J. Integr. Plant Biol. 52(1): 86-97. doi:10.1111/j.1744-7909.2010.00910.x. 

ANNEX 

For space reasons, some tables are not included in the printed version of this dissertation and can be found online.

Supplementary Data for Chapter 1. Transcriptomic analysis of juvenile wood formation during the growing season in Pinus canariensis.

\section{Supplementary Figures}
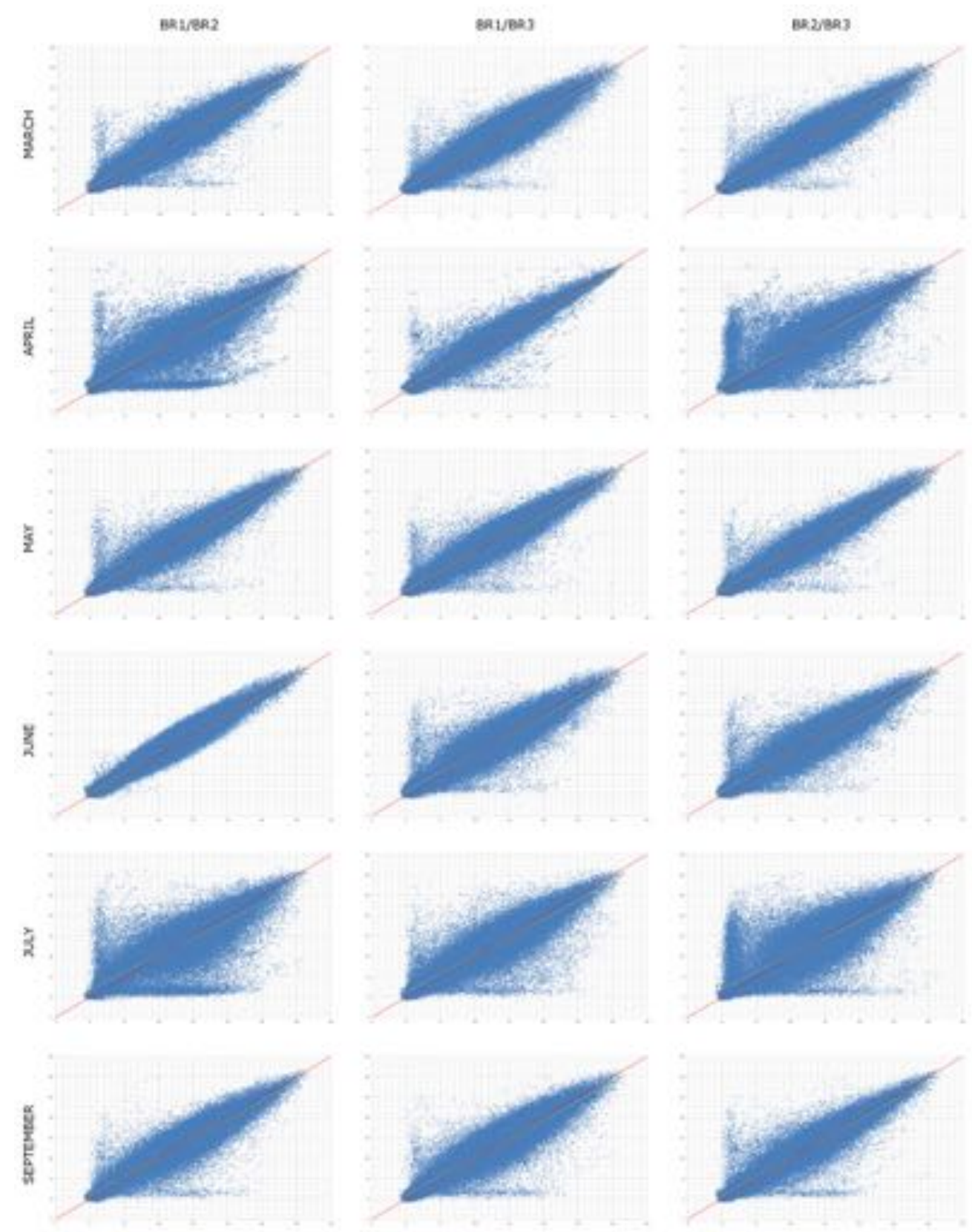

Figure S1: Pairwise correlation of microarray signals obtained for the three biological replicates (BR1, BR2 and BR3) for each sampling point. 


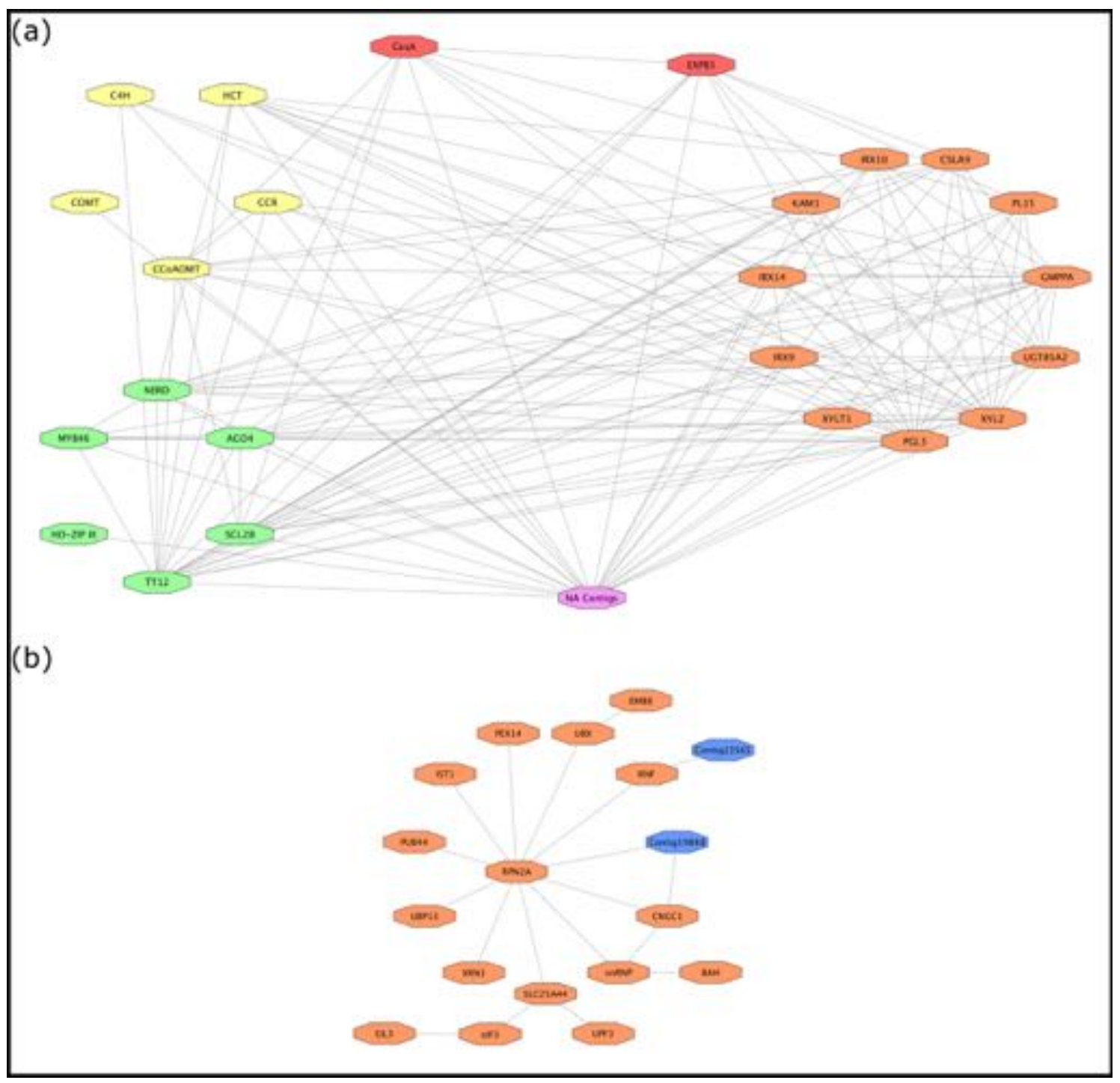

Figure S2: Two relevant co-expression networks. A) Coexpressed DEGs with a transcription peak in spring, during earlywood formation (cluster 1) and related to cell wall formation. Orange: CAZymes superfamily. Yellow: phenylpropanoid biosynthesis pathway. Red: a CesA-like, and a $\beta$-expansin. Green: transcription factors. Pink: 66 non-annotated contigs. B) Network of connected DEGs with maximum transcription in July during LW formation (cluster 4), mainly related to ubiquitination and protein recycling.

\section{Supplementary Tables}

Table S1: Probes included in the microarray and correspondence to contigs obtained after metaassembly of libraries (available online)

https://www.researchgate.net/publication/322910631_TableS1

Table S2: Complete annotation of the transcriptome for xylogenesis in $P$. canariensis (available online).

https://www.researchgate.net/publication/322910549_TableS2 
Table S3: Differentially expressed genes (DEG) during wood formation in P. canariensis (available online).

\section{https://www.researchgate.net/publication/322910459_TableS3}

Table S4: DEGs included in co-expression networks (Figure S2).

\begin{tabular}{|c|c|c|c|c|}
\hline Network & Contig ID & Symbol & BLASTx Description & Cluster \\
\hline a & Contig00446 & Contig00446 & ---NA--- & 1 \\
\hline a & Contig00492 & CSLA9 & glucomannan 4-beta-mannosyltransferase 9-like & 1 \\
\hline a & Contig01691 & IRX10 & probable beta- -xylosyltransferase irx10l-like & 1 \\
\hline a & Contig01735 & IRX14 & probable beta- -xylosyltransferase irx14-like & 1 \\
\hline a & Contig01861 & CCR & cinnamoyl- reductase 1 -like & 1 \\
\hline a & Contig02909 & GMPPA & mannose-1-phosphate guanyltransferase alpha-like & 1 \\
\hline a & Contig02954 & Contig02954 & ---NA--- & 1 \\
\hline a & Contig03195 & Contig03195 & ---NA--- & 1 \\
\hline a & Contig03377 & Contig03377 & ---NA--- & 1 \\
\hline a & Contig03588 & Contig03588 & ---NA--- & 1 \\
\hline a & Contig03715 & AGO4 & protein argonaute 4-like & 1 \\
\hline a & Contig05066 & PL15 & probable pectate lyase 15 -like & 1 \\
\hline a & Contig05567 & $\mathrm{C} 4 \mathrm{H}$ & trans-cinnamate 4-monooxygenase-like & 1 \\
\hline a & Contig06513 & HDZIP III & homeobox-leucine zipper protein athb-15-like & 1 \\
\hline a & Contig06522 & Contig06522 & ---NA--- & 1 \\
\hline a & Contig07594 & Contig07594 & ---NA--- & 1 \\
\hline a & Contig07732 & TT12 & protein transparent testa 12 -like & 1 \\
\hline a & Contig08025 & Contig08025 & ---NA--- & 1 \\
\hline a & Contig08356 & UGT85A2 & udp-glycosyltransferase 85a2-like & 1 \\
\hline a & Contig08604 & Contig08604 & ---NA--- & 1 \\
\hline a & Contig08779 & Contig08779 & ---NA--- & 1 \\
\hline a & Contig10110 & KAM1 & xyloglucan galactosyltransferase katamari1-like & 1 \\
\hline a & Contig10178 & XYL2 & beta-xylosidase alpha-l-arabinofuranosidase 2-like & 1 \\
\hline a & Contig10747 & Contig10747 & ---NA--- & 1 \\
\hline a & Contig10887 & Contig10887 & ---NA--- & 1 \\
\hline a & Contig11364 & Contig11364 & $---\mathrm{NA}---$ & 1 \\
\hline a & Contig11436 & PGL3 & probable polygalacturonase non-catalytic subunit jp650-like & 1 \\
\hline a & Contig12017 & Contig12017 & $---\mathrm{NA}---$ & 1 \\
\hline a & Contig12050 & MYB46 & transcription factor myb46-like & 1 \\
\hline a & Contig12072 & CSLA9 & glucomannan 4-beta-mannosyltransferase 9-like & 1 \\
\hline a & Contig12190 & CCOAOMT & caffeic acid 3-o-methyltransferase-like & 1 \\
\hline a & Contig12329 & TT12 & protein transparent testa 12-like & 1 \\
\hline a & Contig12414 & EXPB3 & expansin-b3-like & 1 \\
\hline a & Contig13067 & Contig13067 & ---NA--- & 1 \\
\hline a & Contig13135 & Contig13135 & ---NA--- & 1 \\
\hline a & Contig13218 & Contig13218 & ---NA--- & 1 \\
\hline a & Contig13246 & Contig13246 & ---NA--- & 1 \\
\hline a & Contig13528 & Contig13528 & ---NA--- & 1 \\
\hline a & Contig13565 & Contig13565 & ---NA--- & 1 \\
\hline a & Contig14178 & COMT & clavata3 esr-related 12 family protein & 1 \\
\hline a & Contig14527 & Contig14527 & ---NA--- & 1 \\
\hline a & Contig15337 & XYLT1 & xylosyltransferase 1-like & 1 \\
\hline a & Contig15476 & Contig15476 & ---NA--- & 1 \\
\hline a & Contig15489 & Contig15489 & ---NA--- & 1 \\
\hline a & Contig15496 & Contig15496 & ---NA--- & 1 \\
\hline a & Contig15639 & Contig15639 & ---NA--- & 1 \\
\hline $\mathrm{a}$ & Contig15886 & Contig15886 & ---NA--- & 1 \\
\hline a & Contig16112 & Contig16112 & ---NA--- & 1 \\
\hline $\mathrm{a}$ & Contig16200 & Contig16200 & --NA--- & 1 \\
\hline a & Contig16387 & Contig16387 & ---NA--- & 1 \\
\hline a & Contig16423 & Contig16423 & ---NA--- & 1 \\
\hline $\mathrm{a}$ & Contig16655 & Contig16655 & ---NA--- & 1 \\
\hline
\end{tabular}




\section{Chano, $V$-Transcriptomics of the response to wounding}

\begin{tabular}{|c|c|c|c|c|}
\hline $\mathrm{a}$ & Contig19257 & Contig19257 & ---NA--- & 1 \\
\hline $\mathrm{a}$ & Contig19504 & Contig19504 & ---NA--- & 1 \\
\hline $\mathrm{a}$ & Contig19725 & Contig19725 & ---NA--- & 1 \\
\hline a & Contig19975 & Contig19975 & ---NA--- & 1 \\
\hline $\mathrm{a}$ & Contig20423 & Contig20423 & $---\mathrm{NA}---$ & 1 \\
\hline $\mathrm{a}$ & Contig20935 & HCT & shikimate o-hydroxycinnamoyltransferase-like & 1 \\
\hline $\mathrm{a}$ & Contig21300 & Contig21300 & ---NA--- & 1 \\
\hline $\mathrm{a}$ & Contig22222 & Contig22222 & ---NA--- & 1 \\
\hline $\mathrm{a}$ & Contig22430 & Contig22430 & ---NA--- & 1 \\
\hline $\mathrm{a}$ & Contig22563 & Contig22563 & ---NA--- & 1 \\
\hline $\mathrm{a}$ & Contig22567 & Contig22567 & ---NA--- & 1 \\
\hline $\mathrm{a}$ & Contig22891 & Contig22891 & ---NA--- & 1 \\
\hline $\mathrm{a}$ & Contig22900 & Contig22900 & ---NA--- & 1 \\
\hline $\mathrm{a}$ & Contig22948 & Contig22948 & ---NA--- & 1 \\
\hline $\mathrm{a}$ & Contig23339 & Contig23339 & ---NA--- & 1 \\
\hline $\mathrm{a}$ & Contig23345 & Contig23345 & ---NA--- & 1 \\
\hline $\mathrm{a}$ & Contig23475 & Contig23475 & ---NA--- & 1 \\
\hline $\mathrm{a}$ & Contig23493 & Contig23493 & ---NA--- & 1 \\
\hline $\mathrm{a}$ & Contig23672 & CCOAOMT & caffeic acid 3-o-methyltransferase-like & 1 \\
\hline $\mathrm{a}$ & Contig23978 & Contig23978 & $---\mathrm{NA}---$ & 1 \\
\hline $\mathrm{a}$ & Contig24325 & Contig24325 & ---NA--- & 1 \\
\hline $\mathrm{a}$ & Contig24825 & Contig24825 & ---NA--- & 1 \\
\hline $\mathrm{a}$ & Contig24868 & Contig24868 & ---NA--- & 1 \\
\hline $\mathrm{a}$ & Contig24927 & Contig24927 & ---NA--- & 1 \\
\hline $\mathrm{a}$ & Contig25845 & Contig25845 & ---NA--- & 1 \\
\hline $\mathrm{a}$ & Contig28275 & Contig28275 & ---NA--- & 1 \\
\hline $\mathrm{a}$ & Contig28837 & Contig28837 & ---NA--- & 1 \\
\hline $\mathrm{a}$ & Contig30727 & Contig30727 & ---NA--- & 1 \\
\hline $\mathrm{a}$ & Contig33639 & Contig33639 & ---NA--- & 1 \\
\hline $\mathrm{a}$ & Contig34117 & Contig34117 & ---NA--- & 1 \\
\hline $\mathrm{a}$ & Contig34538 & Contig34538 & ---NA--- & 1 \\
\hline $\mathrm{a}$ & Contig36781 & Contig36781 & ---NA--- & 1 \\
\hline $\mathrm{a}$ & Contig38257 & Contig38257 & ---NA--- & 1 \\
\hline $\mathrm{a}$ & Contig38537 & Contig38537 & ---NA--- & 1 \\
\hline $\mathrm{a}$ & Contig40747 & Contig40747 & ---NA--- & 1 \\
\hline a & Contig41129 & Contig41129 & ---NA--- & 1 \\
\hline $\mathrm{a}$ & Contig43666 & Contig43666 & ---NA--- & 1 \\
\hline $\mathrm{a}$ & FLPpcontig04143 & CesA & cellulose synthase-like protein d3 & 1 \\
\hline $\mathrm{a}$ & FLPpisotig01642 & XYL2 & beta-xylosidase alpha-l-arabinofuranosidase 2-like & 1 \\
\hline $\mathrm{a}$ & FLPpisotig02169 & MYB46 & transcription factor myb46-like & 1 \\
\hline $\mathrm{a}$ & FLPpisotig02929 & NERD & zinc finger ccch domain-containing protein 14 & 1 \\
\hline $\mathrm{a}$ & Ppisotig03412 & XYL2 & beta-xylosidase alpha-l-arabinofuranosidase 2-like & 1 \\
\hline $\mathrm{a}$ & Ppnisotig07937 & IRX9 & probable beta- -xylosyltransferase irx9h & 1 \\
\hline $\mathrm{a}$ & Ppnisotig09885 & TT12 & protein transparent testa 12-like & 1 \\
\hline $\mathrm{a}$ & Ppnisotig10775 & SCARECROW & scarecrow-like protein 28 & 1 \\
\hline $\mathrm{b}$ & Contig00240 & UBX & ubx domain-containing family protein & 4 \\
\hline $\mathrm{b}$ & Contig01016 & UBP13 & ubiquitin carboxyl-terminal hydrolase 13-like & 4 \\
\hline $\mathrm{b}$ & Contig08577 & snRNP & u4 tri-snrnp-associated protein 1-like & 4 \\
\hline $\mathrm{b}$ & Contig14725 & RNF & ring finger protein b-like isoform $\mathrm{x} 2$ & 4 \\
\hline $\mathrm{b}$ & Contig15087 & PEX14 & peroxisomal membrane protein pex14-like & 4 \\
\hline $\mathrm{b}$ & Contig15225 & BAH & bromo-adjacent homology domain-containing family protein & 4 \\
\hline $\mathrm{b}$ & Contig15612 & EMB8 & embryogenesis-associated protein emb8-like & 4 \\
\hline $\mathrm{b}$ & Contig19783 & eIF3 & eukaryotic translation initiation factor 3 subunit d-like & 4 \\
\hline $\mathrm{b}$ & Contig19888 & Contig19888 & $---\mathrm{NA}---$ & 4 \\
\hline $\mathrm{b}$ & Contig20079 & UPF3 & regulator of nonsense transcripts upf3-like isoform x1 & 4 \\
\hline $\mathrm{b}$ & Contig23247 & IST1 & ist1 homolog & 4 \\
\hline $\mathrm{b}$ & Contig23565 & Contig23565 & ---NA--- & 4 \\
\hline $\mathrm{b}$ & Contig24403 & XRN3 & 5 -3 exoribonuclease 3-like & 4 \\
\hline $\mathrm{b}$ & Contig30300 & EIL3 & ethylene insensitive 3 -like 1 protein & 4 \\
\hline $\mathrm{b}$ & Contig31644 & PUB44 & u-box domain-containing protein 44-like & 4 \\
\hline $\mathrm{b}$ & Contig38452 & SLC25A44 & solute carrier family 25 member 44 -like & 4 \\
\hline
\end{tabular}


Annex

\begin{tabular}{l|l} 
b & Ppisotig18275
\end{tabular}

Ppnisotig10203
CNGC1

RPN2A cyclic nucleotide-gated ion channel 1-like

26 s proteasome non-atpase regulatory subunit 1 homolog a-like
4 
Chano, $V$-Transcriptomics of the response to wounding

Supplemetary Data for Chapter 3: Transcriptomic analysis of wound xylem formation in Pinus canariensis.

\section{Supplementary Figure}

Cluster Dendrogram of Samples

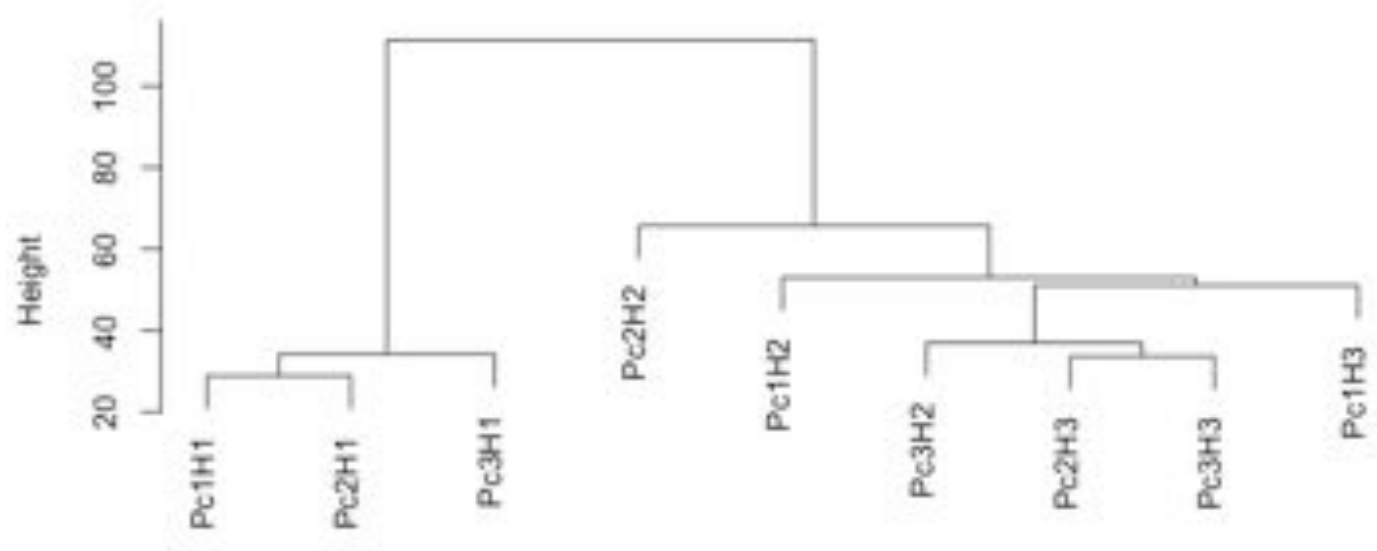

Samples

Figure S1: Hierarchical clustering of samples.

\section{Supplementary Table.}

Table S1: Wound-responsive differentially expressed genes. FC: fold change. FDR: adjusted p-value by False Discovery Rate. In bold, statistically significant values (available online).

https://www.researchgate.net/publication/321742889 Supplementary Material 1 
Supplemetary Data for Chapter 4: Differential expression analysis provides new insights of the resprouting process in Pinus canariensis.

\section{Supplementary Figures}

Cluster Dendrogram of Samples

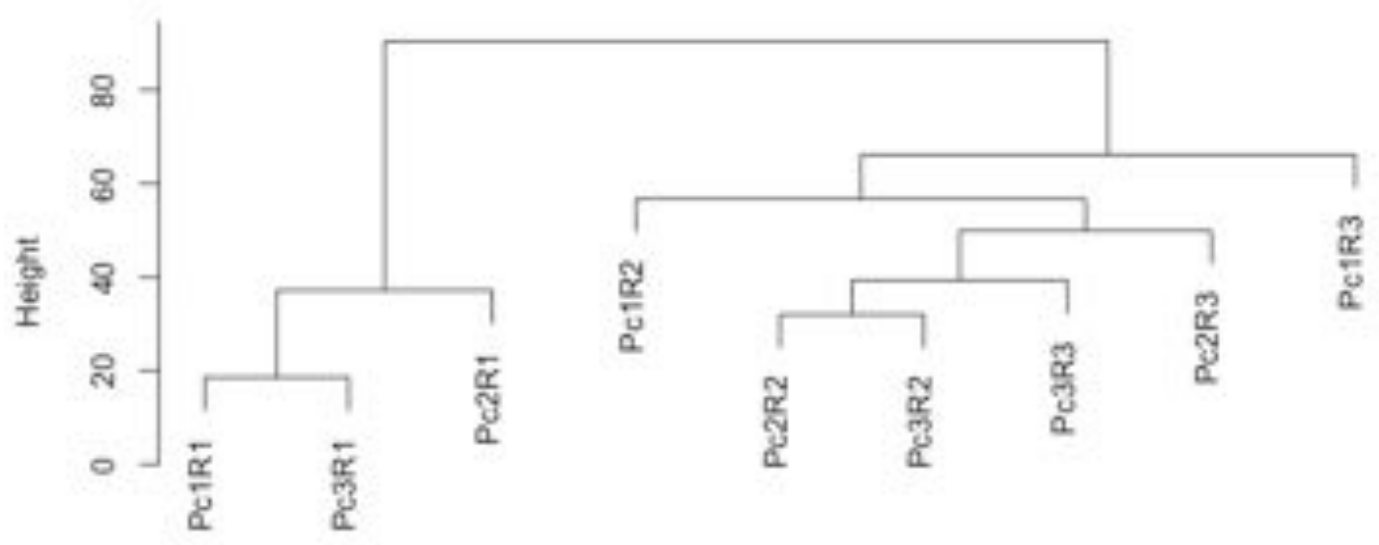

Samples

Figure S1: Hierarchical clustering of samples. 


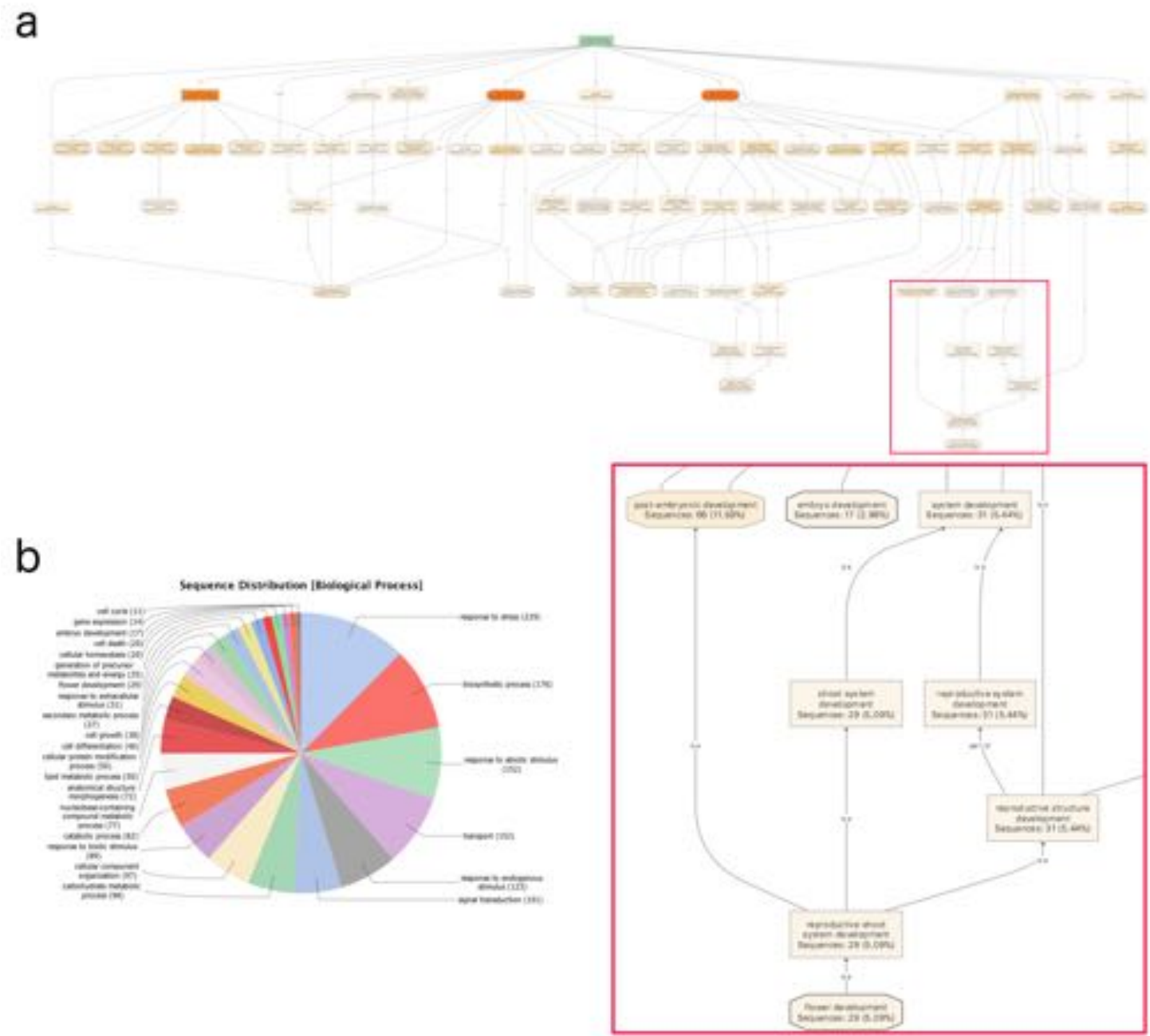

Figure S2: Distribution of GO terms associated to resprouting DEGs. A) Combined Graph of Biological Process GO terms. Those GOs related to lateral organogenesis, such as "shoot system development", are expanded (red square). B) Functional categorization of GO terms. Multilevel pie chart with the lowest node per branch.

\section{Supplementary Tables}

Table S1: Differentially expressed genes during resprouting. FC: fold change. FDR: adjusted p-value by False Discovery Rate. In bold, statistically significant values (available online).

https://www.researchgate.net/publication/322925892 Table S1

Table S2: Differentially expressed genes during seasonal apical growth in P. canariensis (available online).

https://www.researchgate.net/publication/322926039 TableS2 